\title{
New observations on the role of the A-V junction in tachycardias in man
}

Citation for published version (APA):

Brugada i Terradellas, P. (1982). New observations on the role of the A-V junction in tachycardias in man. [Doctoral Thesis, Maastricht University]. Rijksuniversiteit Limburg.

https://doi.org/10.26481/dis.19821104pb

Document status and date:

Published: 01/01/1982

DOI:

10.26481/dis.19821104pb

Document Version:

Publisher's PDF, also known as Version of record

\section{Please check the document version of this publication:}

- A submitted manuscript is the version of the article upon submission and before peer-review. There can be important differences between the submitted version and the official published version of record.

People interested in the research are advised to contact the author for the final version of the publication, or visit the DOI to the publisher's website.

- The final author version and the galley proof are versions of the publication after peer review.

- The final published version features the final layout of the paper including the volume, issue and page numbers.

Link to publication

\footnotetext{
General rights rights.

- You may freely distribute the URL identifying the publication in the public portal. please follow below link for the End User Agreement:

www.umlib.nl/taverne-license

Take down policy

If you believe that this document breaches copyright please contact us at:

repository@maastrichtuniversity.nl

providing details and we will investigate your claim.
}

Copyright and moral rights for the publications made accessible in the public portal are retained by the authors and/or other copyright owners and it is a condition of accessing publications that users recognise and abide by the legal requirements associated with these

- Users may download and print one copy of any publication from the public portal for the purpose of private study or research.

- You may not further distribute the material or use it for any profit-making activity or commercial gain

If the publication is distributed under the terms of Article $25 \mathrm{fa}$ of the Dutch Copyright Act, indicated by the "Taverne" license above, 


\section{New observations on the role of the $\mathrm{A}-\mathrm{V}$ junction in tachycardias in man}

\section{Proefschrift}

Ter verkrijging van de graad van doctor in de geneeskunde aan de Rijksuniversiteit Limburg te Maastricht, op gezag van de Rector Magnificus Prof.Dr. H.C. Hemker, volgens besluit van het College van Dekanen in het openbaar te verdedigen in de aula van de universiteit op donderdag, 4 november 1982 des namiddags te vier uur.

door

Pere Brugada i Terradellas geboren in Banyoles, Catalunya (Spanje), 11 augustus 1952. 
Promotor: Hein J.J. Wellens, M.D.

Referenten: Maurits Allessie, M.D., The Netherlands

Jerónimo Farré, M.D., Madrid, Spain

Mark E. Josephson, M.D., Philadelphia, U.S.A. 
A la Mercér a l'Isabel

A en Ramón i a la Pepita.

A Banyoles i a l'Estany.

Als desmais, al Drac, i a l'aigüa

de La Puda que tor ho cura.

Al pa amb tomate i pernil.

A un passeig per les Rambles

i a una Sardana una tarda d'estiu.

A una berenada a la munianya.

i a un descans vora del mar.

Al soroll de les onades,

i a les barques dels pescadors.

A la frescor sota un pien el despenyat,

ial sentiment del sol sobre el cos.

A Calalanya! 



\section{Contents}

Foreword

1. Introduction

2. The method of programmed electrical stimulation of the heart used in Maastricht. With emphasis on the approach in patients with supraventricular tachycardia.

3. Atrio-ventricular nodal tachycardia with and without discontinuous anterograde and retrograde atrio-ventricular nodal conduction curves: a reappraisal of the dual pathway concept.

4. Observations on spontaneous termination of atrio-ventricular nodal reentrant tachycardia.

5. Initiation of atrio-ventricular nodal re-entrant tachycardia in patients with discontinuous anterograde atrio-ventricular nodal conduction curves with and without documented supravent ricular tachycardia. Observations on the role of a discontinuous retrograde conduction curve.

6. Dual atrio-ventricular nodal pathways and atrial fibrillation.

7. Ventricular tachycardia with concealed retrograde conduction to two atrioventricular nodal pathways.

8. Incessant reciprocating atrio-ventricular tachycardia. Factors playing a role in the mechanisms of the arrhythmia.

9. Observations in patients showing $A-V$ junctional echoes with a shorter $\mathrm{P}-\mathrm{R}$ than $R$-P interval. Distinction between intranodal re-entry or re-entry using an accessory pathway with long conduction time.

10. Observations in patients showing a supraventricular tachycardia with a shorter $\mathbf{P}-\mathbb{R}$ than $\mathbb{R}$-P interval. Distinction between atrial tachycardia or tachycardia using an accessory pathway with long conduction time. 



\section{Foreword}

During the fall of 1979 my family and I arrived in Maastricht. At that time Prof. H.J.J. Wellens gave me the opportunity to work as a granted Fellow in his laboratory of clinical electrophysiology. The problem was that I had no grant!

Survival would have been difficult without the support of this beautiful, tiny little girl Meree to whom I am married. She agreed to stop her work as a Rheumatologist in our lovely Catalan country and abandloned any idea about a quiet, easy and comfortable position in the medical field in Barcelona.

Mercé is a genius, She started on the road of scientific investigation very early in life. As a child she questioned and replied to everybody. She even questioned her mother, when she told her the fairytale of Cinderella.

As you will remember Cinderella was a poor orphan girl abused by her stepmother and stepsisters. She worked all day in the ashes. She would have loved to go to the fancy ball which the Prince offered in the Palace to choose his wife. But this was prevented by the stepmother and stepsisters. Cinderella's fairy godmother, however, provided her with the necessary dress and carriage to get her to the Palace. She wore fancy cristal slippers. The condition was that at midnight the magic would stop and everything would be back in its original form. While dancing in the garden of the Palace the clock struck twelve, and Cinderella ran out of the Prince's arms. The magic was broken and everything regained its ashy look, except for the crystal shoe that Cinderella lost during hem desperate escape. The Prince tried to find Cinderella, searching all over the kingdom.

Lovely, but.... at the end of the story Mercé will always ask the same question: "Why did the crystal shoe not turn back into a rough hemp sandal at midnight?" That is the principle of scientific investigation! The identification of the unusual and unexplained, the small detail that escapes the keen look of all but one!

I do not know what would have happened to us without Hein Wellens. I did not know that he by accepting me in Maastricht committed himself to the responsibility of taking care of my entirc family. It did not take too long to realize this. He taught me electrophysiology. But I also found him to be an excellent teacher of clinical cardiology, the art of presenting in public but also ..... English and Dutch! The best thing that I continuously learn from him, however, is to have an open and interested mind for all details, such as the crystal shoe of Cinderella. I realize that it was a tremendous privilege that Hein Wellens gave me the opportunity to stay in Maastricht.

To all dreamers that listen to stories and ask why the shoe of Cinderella did not turn back into an rough hemp sandal at midnight I would like to offer this piece of work which I did in Maastricht in the past years inspired and guided by Hein Wellens. Drs Maurits Allessie, Mark Josephson and Jerónimo Farre not only showed me how to perform scientific work but also kindly consented to review and discuss this thesis. Miss Moniek Vermeulen expertly typed the manuscript.

I expect that this thesis will be the first step on my road of research. I do not know yet why the shoe of Cinderella did not turn back into a rough hemp sandal, but hopefully we will find out! 



\section{Introduction}

Programmed electrical stimulation of the heart introduced in 1967 into clinical cardiology proved to be a useful technique for identification of the mechanism, the site of origin and the pathways involved in arrhythmias. It also showed to be valuable in the selection of appropriate therapy and improved our diagnostic ability using the 12-lead electrocardiogram.

The purpose of this thesis is to concentrate on findings obtained during programmed electrical stimulation in patients suffering from supraventricular tachycardia.

In chapter 2 the method of programmed electrical stimulation of the heart is described, and the ways to diagnose pathways used during the tachycardia are outlined.

The complexity of intra A-V nodal tachycardia is illustrated in chapters 3 to 5 . Chapter 3 discusses modes of initiation of A-V nodal tachycardia. In chapter 4 unusual modes of termination of that arrhythmia are presented. It illustrates the interaction between different re-entrant circuits in the human heart, and also gives evidence for the presence of several A-V nodal pathways in the human $A-V$ node. Chapter 5 describes the importance of the relation between the electrophysiological properties of the different $A-V$ nodal pathways for initiation of $A-V$ nodal tachycardia. Knowledge about the properties of these pathways is helpful to identify patients able to sustain AV nodal tachycardia. Chapter 6 describes the determinants of the ventricular response during atrial fibrillation in patients with dual A-V nodal pathways. It shows that the presence of dual A-V nodal pathways does not result in a different pattern of atrio-ventricular conduction when compared to the ventricular response during atrial fibrillation in patients without dual $A-V$ nodal pathway curves. Chapter 7 illustrates how the presence of longitudinal dissociation in the A. $V$ node can result in complex electrocardiographic patterns during ventricular tachycardia. The syndrome of incessant supraventricular tachycardia is discussed in chapters 8 to 10 . The incessant tachycardias occurring in the setting of the Wolff-Parkinson-White syndrome or in the presence of a concealed "fast" accessory A-V pathway are not considered. The factors playing a role in the mechanisms of atrio-ventricular re-entrant incessant tachycardia are discussed in chapter 8 . The distinction by means of programmed electrical stimulation of the heart between intranodal reentry of the uncommon variety and re-entry using a slowly conducting accessory $A-V$ pathway is given in chapter 9 , and between atrial tachycardia and slowly conducting accessory A-V pathway in chapter 10. The thesis ends with a summary in the English. Dutch. Spanish and Catalan language. 



\section{The method of programmed electrical stimulation of the heart} used in Maastricht.

\section{With emphasis on the approach in patients with supraventricular tachycardia}

The method of programmed electrical stimulation of the heart (PES) presently used in Maastricht is an extension of the one introduced in 1967 by Durrer et al. (1). As described by Wellens $(2,3)$ programmed stimulation of the heart has shown to be effective in studying the mechanisms, pathways and sites of origin of tachycardias. The importance of this type of investigation for treatment of patients with tachycardia has been extensively discussed by Wellens $(2,3)$. In recent years our group made some changes in the stimulation protocol which increase the amount of information which can be obtained during the study. In this chapter we would like to review value and limitations of our present modes of stimulation with special emphasis on the study of mechanisms of supraventricular arrhythmias.

\section{General}

Patients are studied in the postabsortive non-sedated state using local anaesthesia with $2 \%$ Lidocaine. Children below five years of age are studied under general anaesthesia which is maintained as light as possible once the catheters have been introduced. Unless the antiarthythmic effects of drugs are being evaluated, patients are studied without medication.

In the absence of any contraindication full heparinization ( $100 \mathrm{IU} / \mathrm{kg}$ body weight) is used during the procedure. Electrode catheters are used to record intracavitary electrograms and to pace the heart at different locations. Catheters are passed through the femoral veins to the right atrium, right ventricle and to the tricuspid valve area to record activation of the bundle of His.

Catheterization of the left atrium via a patent foramen ovale or of the coronary sinus is also done by way of the femoral approach. Catheterization of the coronary sinus is attempted even when a patent foramen ovale is present (fig. 1). Using the femoral route we are presently able to catheterize the coronary sinus in $95 \%$ of our patients. If during catheterization from the femoral vein the coronary vein cannot be entered the left cephalic vein is used. In this way the coronary sinus can be catheterized in $98 \%$ of patients where this is considered indicated. When a patent foramen ovale is crossed, direct recordings from the left atrium are made in addition to those from the coronary sinus. This results in the use of a total number of four to five venous catheters during PES, with most patients having four catheters. The minimal number of catheters used is three: right atrium, right ventricle and His bundle. Six has been the maximal number of catheters that we have used in a single patient: one or two quadripolar catheters in the right atrium, one or two bipolar or one bipolar and one quadripolar in the His bundle area, one quadripolar in the laft atrium, one quadripolar in the coronary sinus, one quadripolar in the right ventricle, and one quadripolar in the left ventricle through a foramen ovale. In addition, retrograde arterial catheterization of the left ventricle using a bi or preferably quadripolar catheter is used when indicated (fig. 1). Catheters are moved to other locations during the procedure when required.

During the study 12-lead electrocardiograms are obtained during sinus rhythm and tachycardia. Leads I, II, III, VI and V6 are recorded continuously simultaneous with 6 bipolar recordings from the different intracardiac positions described. It is allso possible to record 6 surface leads with 5 endocavitary bipolar electrograms (fig. 2). A switch-box allows immediate changes in the electrodes used for stimulation or recording and the recorded surface leads.

A sixteen channel Siemens-Elema Mingograph is used for real-time continuous recording and display and two 8 channel osciloscopes for real-time monitoring (one at the paticnt's side and the other at the recording table). The remaining five channels are used for the coding system shown at the boltom of figure 2 , to display $20 \mathrm{~ms}$ interval time-marks, to indicate the stimulus artifact, and 

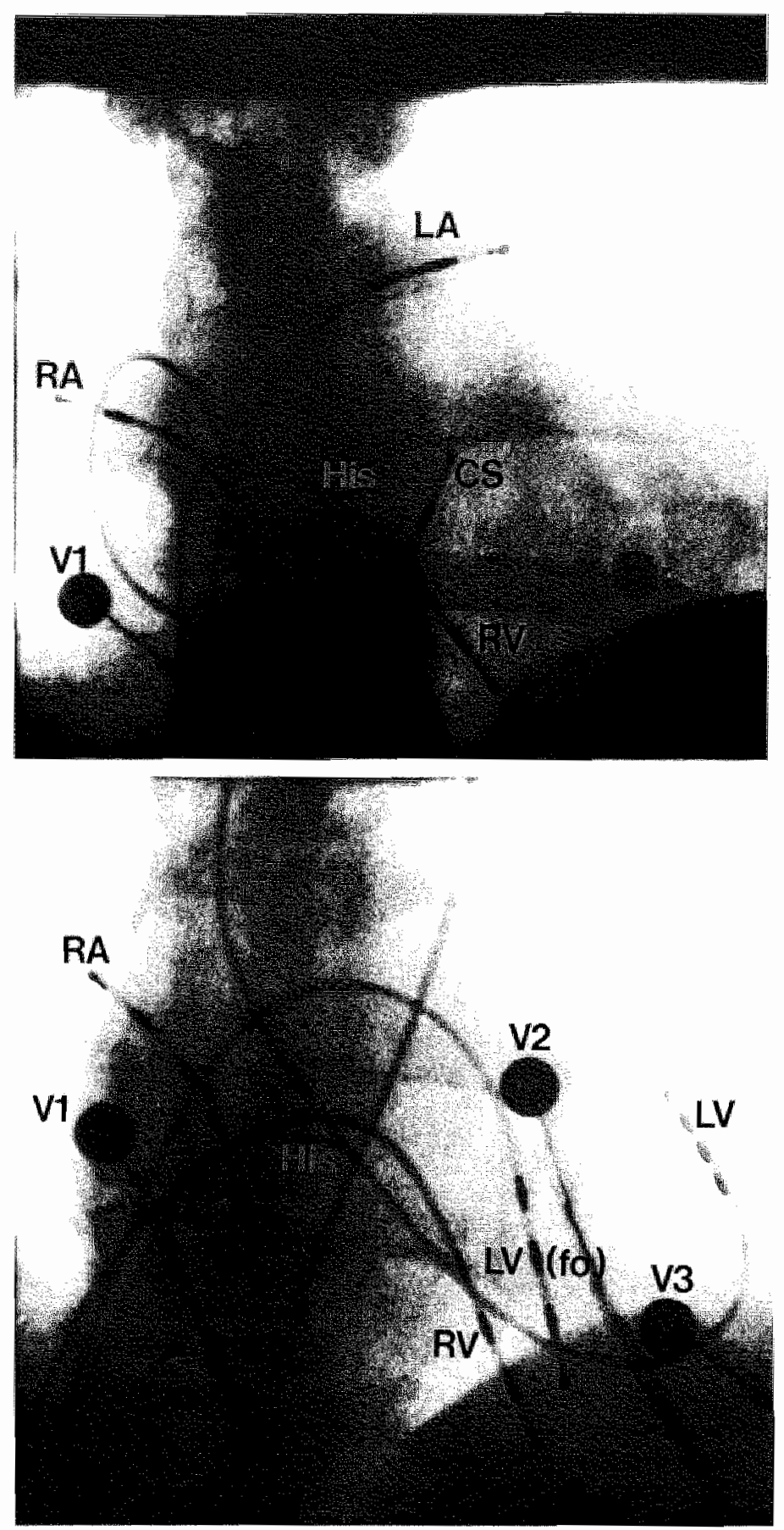

\section{Figure 1}

Catheter positions during study of supraventricular (top figure) and ventricular (bot tom figure) tachycardia. Catheters are locuted in the right atrum (RA), left atrium (LA) coronary sinus (CS). His bundle area (His). right ventricular apex (RV) and left ventricle via a foramen ovale (LVfo) and retrogradely wia the femoral artery (LV). VIt to V3: surface clectrodes of ieads V1 $6 \mathrm{~V}$. 

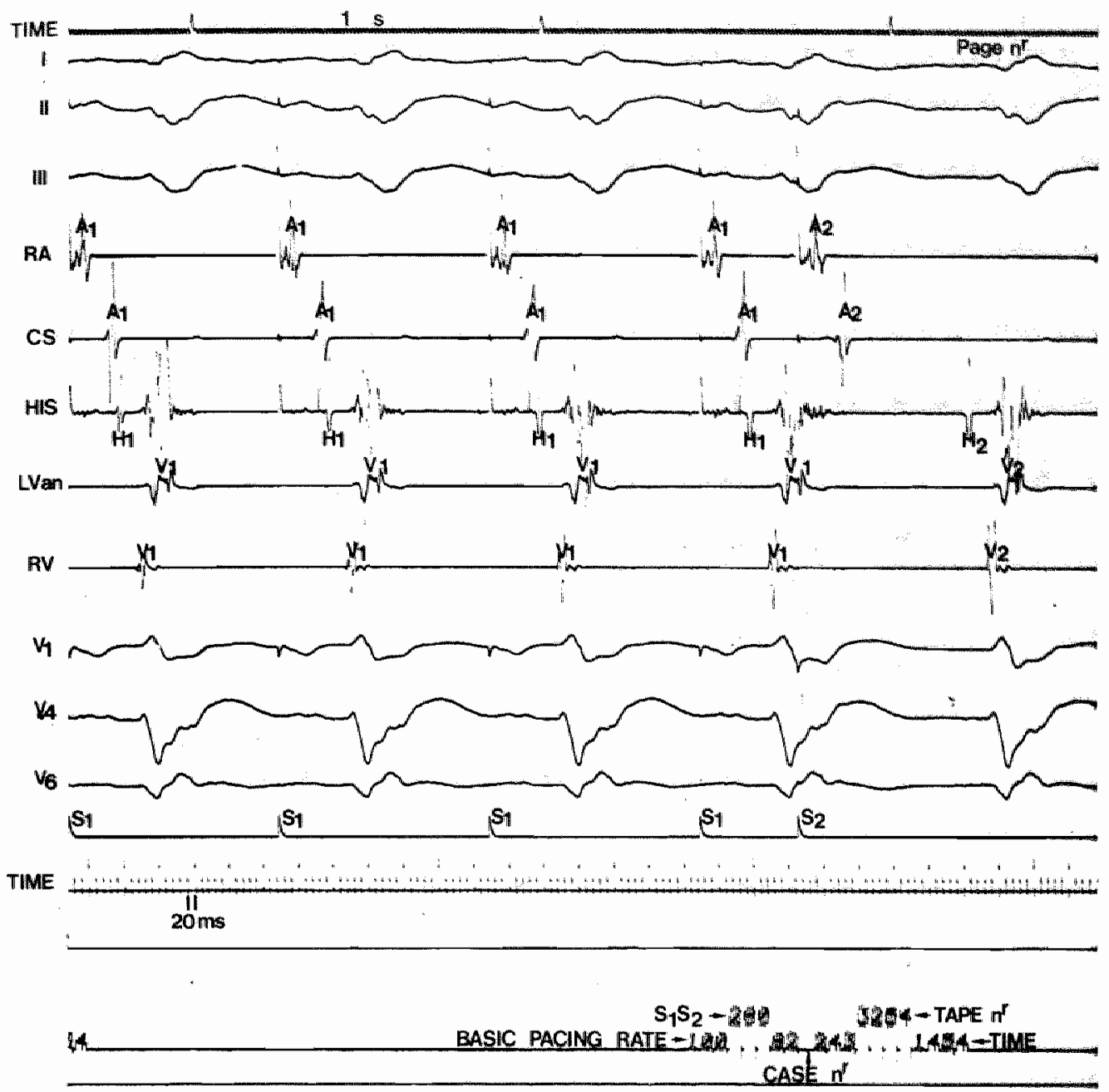

Figure 2

A tracing as registened by a 16 channel recorder is showh. 6 Surfitce leads are recorded simultaneoustly with bipolar electrograms from the right athum (RA), coronary sinus (CS). His bundla, right wentricle (RV) and left wentricte (LV). A one second time mark (mechanical) occurs in the top part of the tracing. Also the stimulus stifact, a $20 \mathrm{~ms}$ time-mark and data on pacing program, time and patient number are dimplayed.

the recording of arterial pressure. An atdditional one second mechanical time-mark is displayed in the top line of the registration. Intracardiac electrograms are preamplified using Janssen ISI 0387 preamplifiers directly connected to the catheters, and then amplified and filtered by HewlettPackard 8811A amplufiers. All data arc continuously stored on tape (14 channel, Ampex PR2200). Patterns of $\mathrm{A}-\mathrm{V}$ and $\mathrm{V}-\mathrm{A}$ conduction and duration of refractory periods are determined using the extrastimulus technique during sinus rhythm, paced supraventricular and paced ventricular rhythms and tachycardia(s). Several (at least three) basic cycle lengths of pacing are used during atrial and ventricular stimulation. When needed a maximum of 4 extrastimuli are delivered during a spontaneous or a paced rhythm. Progressive incremental pacing is dhone from atrium and ventricle. We rarely perform pacing of the ventricles at rates faster than $300 \mathrm{beats} / \mathrm{min}$, but we do not have a rate limit during atrial stimulation particularly when we try to induce atrial flutter or fibrillation. Several atrial sites (minimally right atrium and one site in the coronary sinus or left atrium) are paced. Pacing alt different right or left ventricular sites is only used when insufficient 
information is obtained during right ventricular apex stimulation or because of particular research protocols. Stimuli are given at twice diastolic threshold and have a $2 \mathrm{~ms}$ duration. except when the effect of changes in current or duration of the stimulus is studied.

All equipment is grounded and leakage current measured at regular intervals. Informed consent is obtained from each patient. The procedure is explained to the patient in the presence of the catheterizer, the electrophysiologist and the in-hospital attending physician.

\section{Catheters used:}

For pacing and recording from atrium, coronary sinus and ventricle bipolar ( 4 or $5 \mathrm{~F}$ ) or quadripolar (6F) electrodes are used Quadripolar catheters allow pacing and reconding from the same catheter. We do not use tripolar catheters to record electrograms from the His bundle area. They are helpful and probably necessary during special procedures like electrical ablation of the A-V node-His bundle, as recently described by Gallagher et al. (4). We have obtained stable good quality bipolar electrograms of the His bundle using a regular bipolar $1 \mathrm{~cm}$ interelectrode distance 4F catheter in most patients in whom it was attempted. This usually requires some rotation of the cattheter to obtain a good contact of the tip against the His bundle.

A quadripolar right ventricular catheter allows pacing and recording from the ventricie. Ventricular signals are of value to study timing and pattern of wentricular activation during sinus rhythm, pacing or tachycardia, and invariably used in patients with ventricular atrhythmias. Mapping of endocardial activation is performed at our laboratory using a bi or quadripolar catheter and fluoroscopic control including angulated views (fig. 3). Gallagher et al have designed a specially modified Brockenbourgh catheter to map the right atrium (5). We have no experience with this catheter.

We recently had the opportunity to evaluate the quadripolar catheter designed by Mark $\mathrm{E}$. Josephson (USCI). This catheter is a $6 \mathrm{~F}$ quadripolar electrode catheter with an interelectrode distance of half a centimeter. The distal electrode is arbitrarily named $\mathbb{1}$ and the most proximal 4. The catheter is suitable for recording of uni or bipolar electrograms it any combination and for pacing. Because of the small interelectrode distance we have found this catheter particularly useful in two situations: recording of a proximal and distal (electrodes 3,4 and electrodes 1,2) bipolar electrograms of the His bundle, and recording of two one centimeter distance bipolar electrograms (electrodes 1,3 and electrodes 2,4 ) of the His bundle or at any other location in the heart.

Figure 4 shows the good quallty of the recordings obtained with this catheter and how unusual forms of conduction disturbances within the His bundle can easily be identified. The two wery close bipolar recordings are helpful in mapping procedures. Mapping is facilitated by the special connector and elongator of the catheter which avoids the limitations of a too short catheter. This atso allows manipulation without losing torque control.

Using full heparinization the incidence of clinical venous thrombosis is low following PES. We have observed 3 cases in a consecutive series of 500 patients. Subclinical thrombosis seems to be high following any catheterization procedure, however. Heparin-coated catheters might be of help to reduce this incidence. They are not yet available for electrophysiologic investigations however.

\section{The pulse generator}

We are presently using a Janssen stimulator (Janssen Pharmaceutica, Belgium). The modular basis of this stimulator allows enlargement of the unit to any desired combination of stimuli and sensing during a driven rhythm or a spontaneous rhythm.

Apart from modes of stimulation universally applied during programmed stimulation of the heart $(2,3)$, this stimulator allows some special modes of stimulation like: 


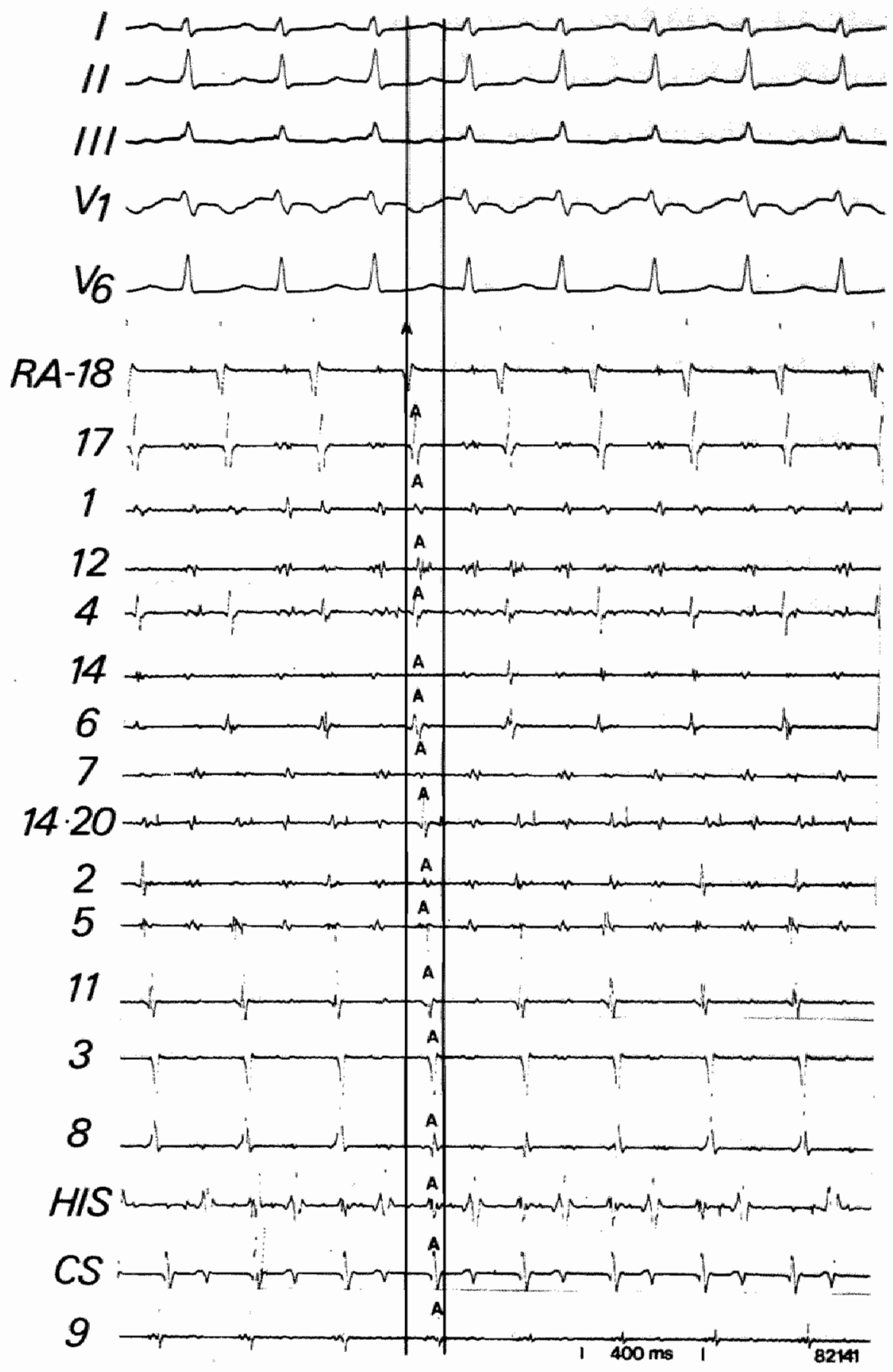

Figure 3

Example of atrial mapping during right atrial tachycardia using Josephson"s catheter. 5 Surface leads afc shown simultaneously with bipolar endocavitary electrograms of the right and left atrium at different locations, His bundle and coronary sinus (CS). Note that site 18 (low anterior right atrium) is the carlicst site of endocardial atrial activation. 


\section{Josephson's catheter}

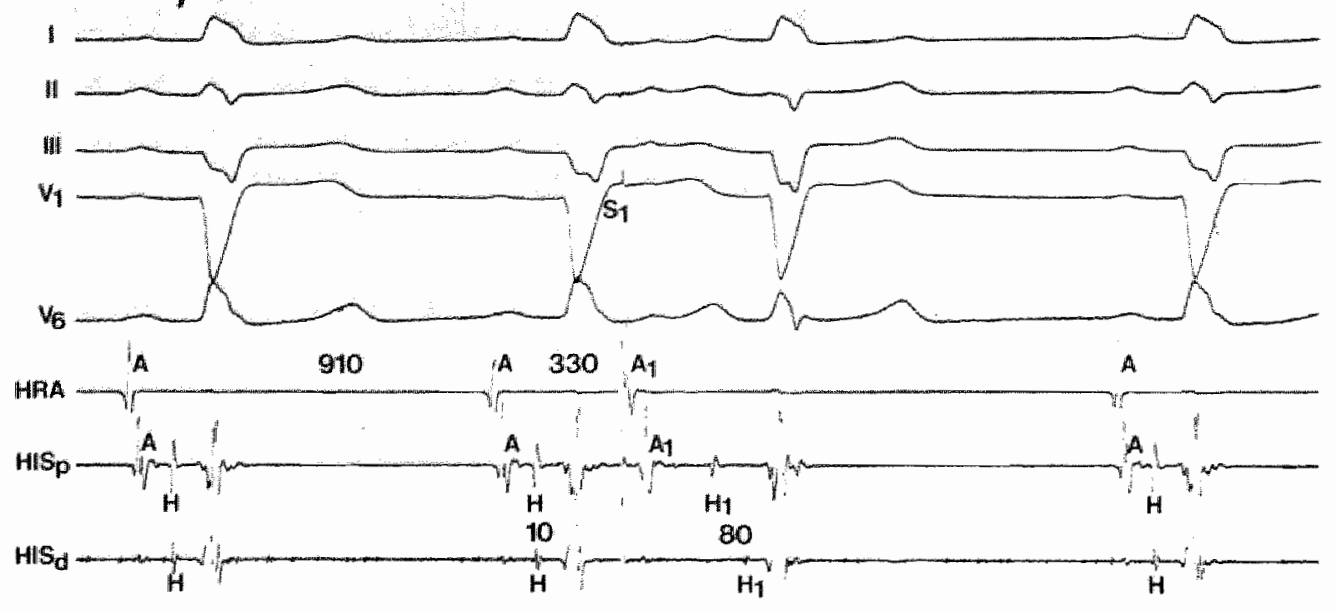

Fighe 4

Use of Josephson's catheter to record two clase bipolar, $0.5 \mathrm{~cm}$ interelectrode distance, electrograms of the His bundte in a paticnt with intran Hissian block. 5 Surface leads are recorded shmultaneously with a bipolar clectrogratm of the bigh RA. and a proximat and distal His bundle bipolar electrogram. During sinus rhyt hm Ha. Hp.Hd intarval measures $10 \mathrm{~ms}$, and prolongs $1080 \mathrm{~ms}$ aften an atrial premature given after $330 \mathrm{~ms}$ (A 1 ).

1. Pacing simultancously at the supraventricular and ventricular level with the sane basic rhythm followed by 1 to 4 stimuli at the desired (usually premature) interval. These premature beats can be given at one or both levels at any desired premature beat interval combination. An example of this mode of pacing is shown in fig. 5 . We found it useful in studying the pattern of $\mathrm{V}$-A conduction in patients with poor retrograde conduction during the basic driven rhythm. It is also helptul in the study of the mode of infiation of ventricular arrlythmas during ventricular stimulation in patients without $V$ - $A$ conduction during ventricular pacing by avoiding the occurrence of ventricular captures from sinus rhythm (fig, 6). It ako allows analysis of the mode of initiation of $A-V$ junctional tachycardia in patients having tachycardia initiated by any ventricular paced beat which is retrogradcly conducted to the atria.

2. A continued paced rhythm in the atrium after a pre-set $\mathrm{V}$ - $\mathrm{A}$ interval. This mode of stimulation simulates a re-centrant tachycardia with a fixed $V$ - A interval, as in the Wolf-Parkinson-White syndrome. Premature stimuli are delivered at the atriall or ventricular level during this simutated tachycardia and their effects studied. This mode of stimulation has been of interest to understand some mechanisms of re-centrant tachycardias like alternation of the achycatdiacyele due to alternation in anterograde A-V nodat conduction time (6-7).

3. Detivery of a train of stimuli at a pre-set rate during spontaneous rhythm with a pre-set coupling interval of the first paced beat. One of the most important drawbacks of the majority of commercially avilablo stmulators is their inability to deliver the first paced beat of a train of stimuli at a choseable interval. Figures 7 and 8 show how depending upon the coupling interval of the first paced beat $S 3$ is refractory or a $1-10-1$ or a 2 -to- 1 capture of the ventricle occurs. The ability to set the interval of the first paced beat allows study of the effects of pacing under reproducible conditions.

4. Pacing of one cardiac chamber at a tixed or variable rate during an exactly determined number of stimuli. Most stimulators will pace the heart tor eight beats tollowed by a certain number of extrastimuli (usually wo or thec). When accurate effects of a long tran of paced beats are being studied these stimulators will pace the heart al a fixed or variable rate unt the stimulation is switched off. The number of stimuli delivered will vary from stimulation to stimulation. We can select an exact number of stimuli with pacing rates that can be varied in steps of 1 beat/min. This has been of interest to study some clectrophysiological mechanisms of re entrant tachycardias like cntrainment. 

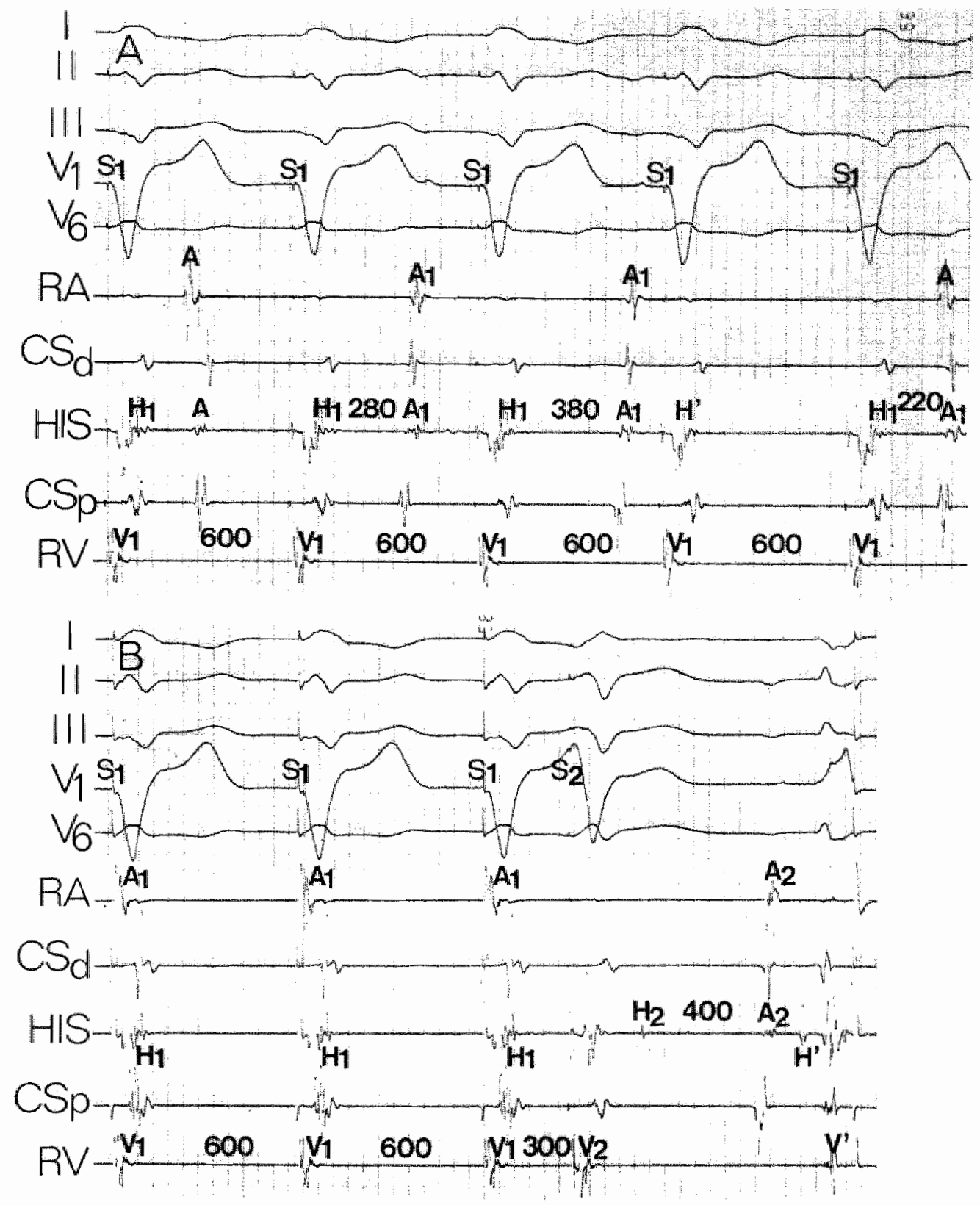

Pigures

Use of simultancous atrial and ventricular pacing to study the pattern of $\mathrm{V}$-A conduction. In the top pancl poor retrograde conduction is observed during ventricular patcing with a cycle fength of $600 \mathrm{~ms}$. An $\mathrm{H}-\mathrm{A}$ Wenckebach sequence is ohserved. but the relation between rettrograde conduction to the atrium and activation of the His bunde is hest studied by simultaneous $A$ and $V$ pacing, and by delivering a premature beat in the veratricle but not in the atrium. In this way it could be shown that conduction over the pathway used retrogradely was related to the retrograde inpent into the A-V node (S1-H2 and H1-H2 intervals) suggesting a location above the His bundic. This finding belped to exclude an accessory A.V pathway with long conduction times. 


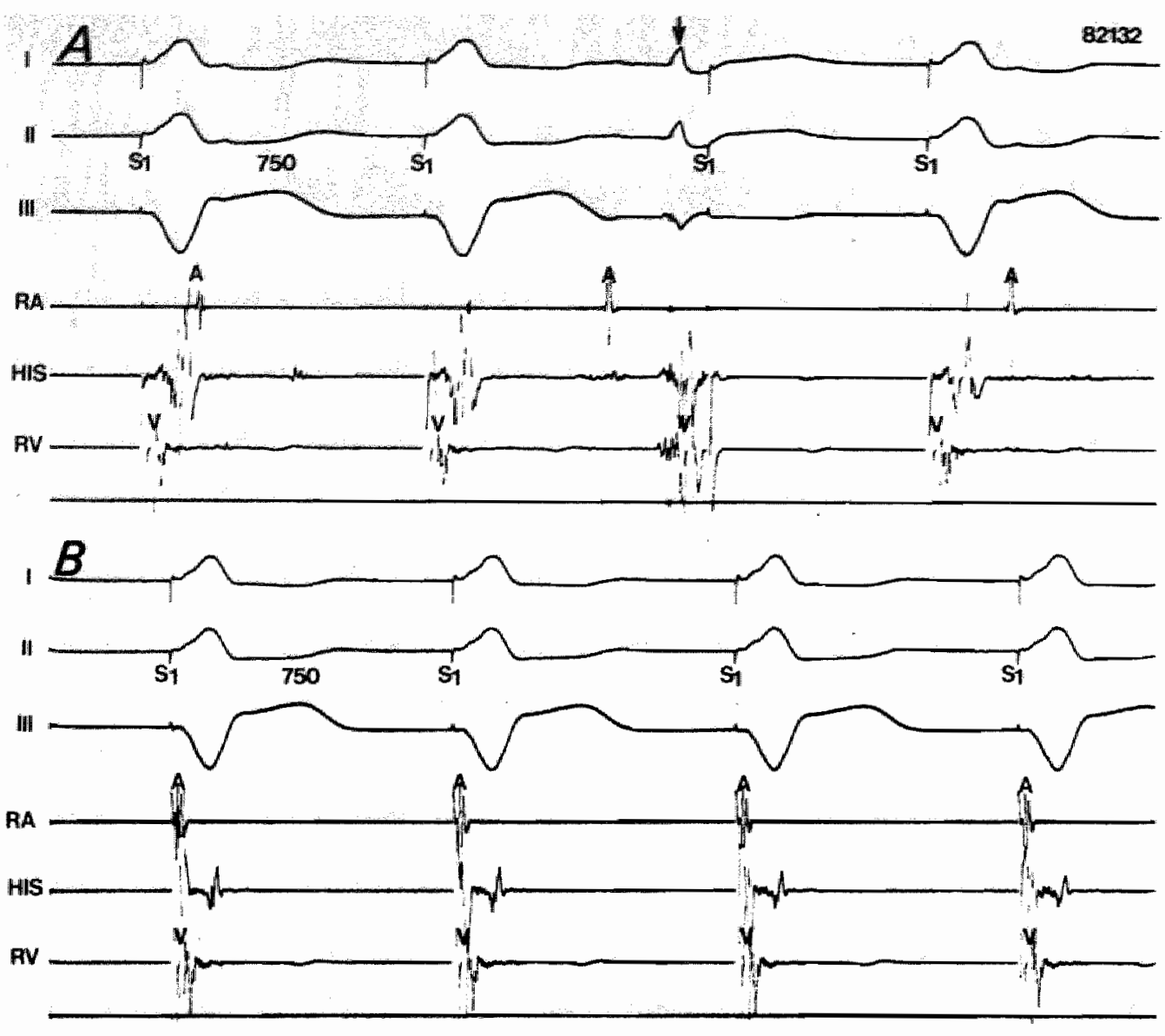

Figure 6

Use of simultaneous at rial and ventricular pacing to avoid ventricular captures by supraventricular impulses during ventricular pacing in patients with poor $V$-A conduction. In the top panel during pacing of the right ventricle with a basic cycle length of $600 \mathrm{~ms}$ captures occurned from conducted sinus impulses (arrow) and from reversed A-V nodal echoss. In the bottom panel simultaneous atrial and ventricular pacing prevents suppravenu ricular caphures of the ventricle. 5 Surface leads are shown simulaneously with two bipolar endocavilary ellectrograms. 
A

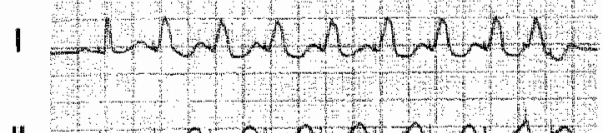

II

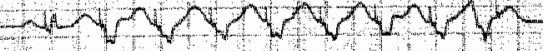

Ill $s_{1} s_{1} s_{1} s_{1 / s_{1}} s_{1} s_{2}$

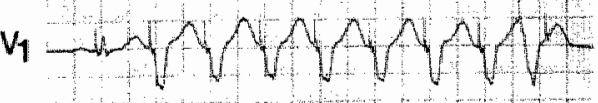

W4

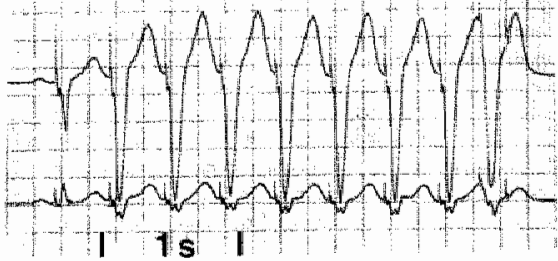

B

82)
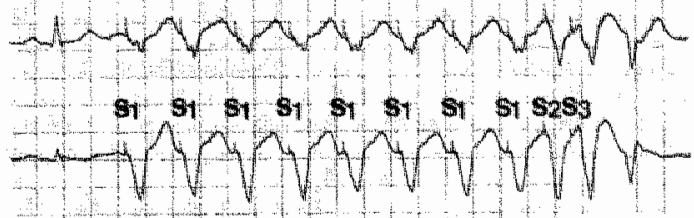

andMANANhr

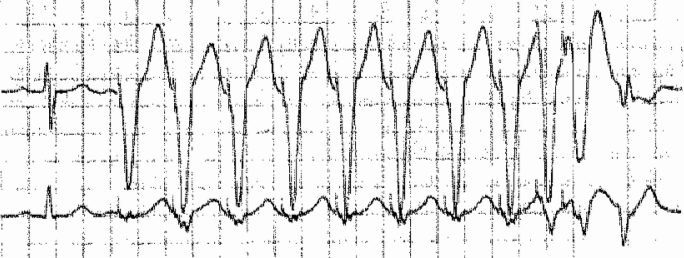

Figure 7

Importance of the coupling interval of the first beat of a train of paced stimuli. All paced stimuli actiwate the ventricle in panel $B$. In panel $A$ the first stimulus falls too early in the cycle resulting in ventricular activation by only 7 paced basic stimuli. Now $\$ 3$ given after the same interval as in panel B finds the ventricle refractory. 6 Surface leads are shown.
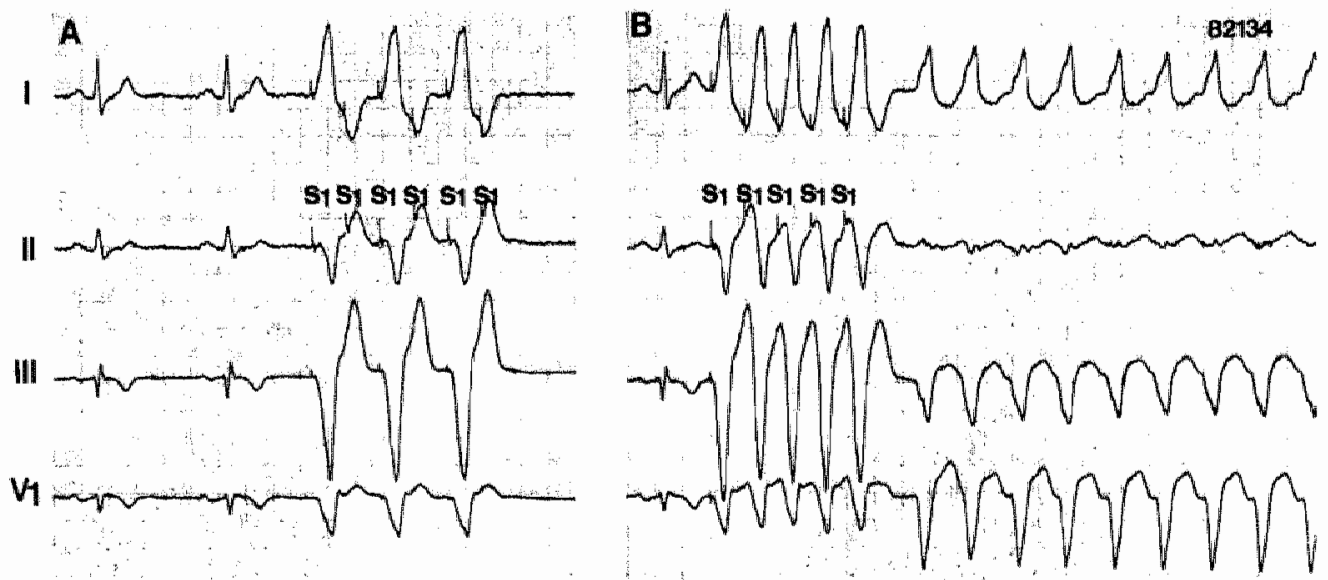

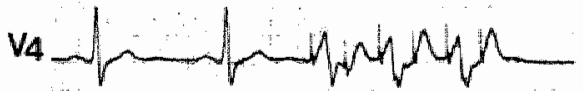
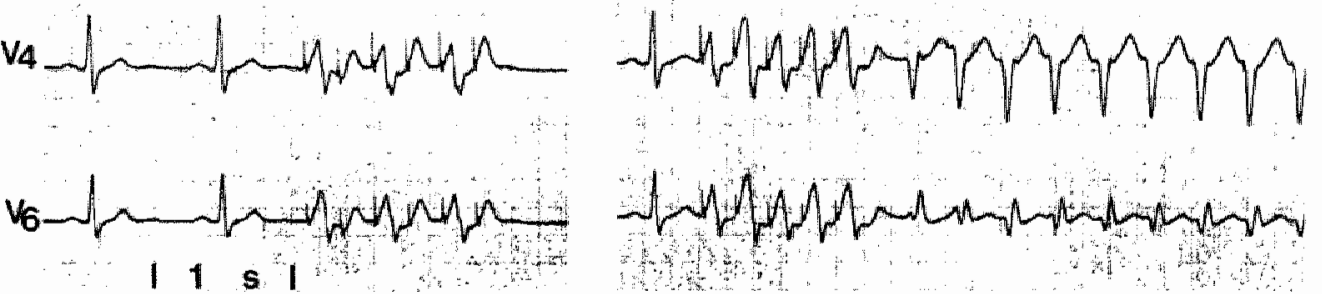

Figure 8

In panel A 6 beats delivered during sinus rhythm with a CL. of 240 ms result in 2-10-1 ventricular activation. In panel B initiation of a tachycardia using anterogradely a nodo-ventricular Mahaïm fiber occurs after 1-10-1 ventricular capture. Although the same pacing cycle length is used 1-10-1 wentricular activation occurs because the first paced beat falls earlier in the sinus cycle. 
5. Accurate selection of the amount of current delvered can only be accomplished when the selector of current intensily allows digital steps of at least $0.1 \mathrm{~mA}$. This is particularly true when effects of drugs on the excitability properties of cell membranes (strengthduration and strengthinterval curves) are being evaluated

\section{Future aims with the pulse generator}

We believe that some modifications of the stimulator are of value. Firstly, an increase in the number of outpurs. Like most stimulators ours has two outputs. Simultaneous pacing at several sites in the heart can be of interest to terminate arrhythmias. Simultaneous $A-V$ pacing terminates A-V junctional re-entrant tachycardia and prevents re-initiation. We have not been able so far to terminate atrial flutter by delivering a single atrial premature beat at a single or simultaneously at two atrial sites. Delivery of a single premature beat simultaneously at three or four atrial sites might however prove to be useful in terminating the arrhythmia. The same holds for ventricular tachycardia. In those cases in which a single or multiple ventricular premature beats are ineffective to terminate ventricular tachycardia simultaneous depolarization of the ventricles at two or more sites by a single premature beat might prove helpful in terminating the arrhythmia.

Secondly, changes in the mode of current given. Our stimulator gives the desired intensity of current with the selected strength and duration of the impulse (both $\mathrm{mA}$ and $\mathrm{ms}$ duration are selected). Selection of $\mathrm{mA}$ is superior to selection of $\mathrm{m} V$ (voltage difference between electrodes) because in the last situation the intensity of current given is unknown. Intensity varies in relation to the resistance from the catheter and the tissues receiving the current. The ability to select either voltage difference or current intensity allows measurements of tissue and catheter resistance and might be desirable. For example when thresholds of stimulation are being compared between normal and abnormal areas of the heart. Accurate measurement of membrane properties by catheter techniques is questionable. Factors that cannot be easily controlled, like changes in catheter position during diastole and systole also play a role in the amount of current required to depolarize the pacing site. Control of current intensity in sleps of $0.0 \mathrm{~mA}$ might be of interest. When given in the ventricles currents higher than $20 \mathrm{~mA}$ seem to be associated with an increased risk of ventricular fibrillation but they can be delivered to the atria without trouble and without discomfort to the patient if the catheter position is carefully checked. When the atrial refractory period approaches the cycle length of the tachycardia as in atrial flutter or reentrant tachycardia using an accessory pathway, atrial capture can only be obtained by delivering high intensity current. The possibility of delivering current intensities as high as $100 \mathrm{~mA}$ might be desirable in those situations. This can result in atrial capture when lower current intensities fail. Similarly, during pace-mapping for ventricular tachycardia current intensities of $35-50 \mathrm{~mA}$ are 50 metimes required to obtain capture in abnormal arcas within an ancurysm. The benefit of increased intensity current in initiating ventricular tachycardia has recently been demonstrated (8).

There is no doubt that stimulation protocols are becoming more and more agressive. Most paticnts with chronic recurrent ventricular tachycardia will require at least two extrastimuli during ventricular pacing or tachycardia to inttiate or terminate the arrhythmia (9). Any stimulator should be able to deliver four extrastimuli. This can be done with our present stimulator. When rescarch protocols are considered however, we would like to be able to vary the interval of each piced beat.

\section{Defibrillation:}

In our laboratory the incidence of defibrillation in patients with severe life-threatening ventricular arrhythmas has been $19 \%$ in a serics of 105 patients. In $75 \%$ of ventricular tachycardias-ventricular flutter leading to severe hemodynamic problems we are able to terminate the arrhythmia by pacing within 15 seconds. Obviously one would like to terminate all these arrhythmias and earlier. Therefore delivery of extrastimuli or overdrive pacing should be instantaneous when required. This means that a separate pacing module should be available with pre-set premature beat intervals or overdrive thythm. Part of our success rate in pacing control of severe ventricular arrhythmias is based upon the presence of a technician who only takes care of the stimulator while the physician is in exclusive control of the real-time recordings. Unfortunately the number of 
people participahing in a study is frequently less in most institutions. When defibrillation is required because of ventricular fibrillation the current given in the first shock is $200 \mathrm{w} / \mathrm{s}$. Two out of 20 patients did not respond to the first shock with this amount of current but reverted to sinus rhythm using the same energy at a second attempt.

Occasionally, usually following intravenous administration of an antrarthythmic drug patients develop a ventricular tachycardia which does not result in serious hemodynamic depression to make the patient lose consciousness, but cannot be terminated by pacing. In this situation cardioversion may be required to terminate the arhythmia. Our approach is to first sedate the patient with a rapid-acting short-lasting anacsthetic like etomidate. Of this drug 0.2 to $0.3 \mathrm{mg} / \mathrm{kgr}$ body weight is given by intravenous route and followed by a synchronized countershock of 10.20 w/s. The action of etomidate lasts $4-5 \mathrm{~min}$. The study can then be continued with the paticnt conscious and without the longer lasting effects of drugs like diazepam. When required, atrial fibrillation is converted to sinus rhythm using the same approach by delivering an intial shock of 25 to $100 \mathrm{w} / \mathrm{s}$.

\section{Acute intravenous testing of antiarrhythmic drugs:}

Administration of antiarrhythmic drugs in patients undergoing electrophysiological investigations allows study of the effects of these drugs on the mechanisms of the arrhythmia. The aim of administration of an antiarrhythmic drug in a patient with tachyeardias is to select the best therapy for that particular patient. The drug can be given by any route at the appropriate dose and the patient retested once the antiarrhythmic effect is supposed to be present. The acute intravenous dose of an antiarrhythmic is given the day of the first electrophysiological investigation. The effect of oral treatment is studied after the number of days required to obtain adequate loading with the antiarrhythmic.

During the acute study the drug is given intravenously during tachycardia, except when tachycardiat is poorly tolerated. When the arrhythmia is terminated by the intravenous drug, programmed stimulation using the same basic cycle lengths and stimulation sites as before drug administration is immediately repeated and continued for a period of at lcast $30-45 \mathrm{~min}$. When the intravenous injection does not terminate tachycardia a period of $5-10 \mathrm{~min}$ is allowed between the end of injection and reinitiation of programmed stimulation to terminate tachycardia. Thereafter the effect of the drug on echo and tachycardia-zones, rate of tachycardia, mode of termination and patterns of A-V and $\mathrm{V}-\mathrm{A}$ conduction and refractory periods are studied. Oral therapy is initiated simultancously with or four to six hours after the intravenous injection. This is continued until the patient is restudied. The electrocardiogram of the patient is continuously monitored during that time.

\section{Restudies during oral drug therapy:}

There are several ways to restudy patients during oral antiarthythmic trealment. When the effect of the given drug can be evaluated within three days of therapy we usually leave one or two intracardiac catheters in place to use them for stimulation and recording. However, this approach has some disadvantages. As previously outlined, the catheters are placed using the fomoral approach which results in immobilization of the patient during the days before restudy. Also when catheters are left in place, a continuous infusion of full dose heparine is used. We do not leive a catheter in place for restudy in patients showing signs of congestive failure, those who are overweight, have venous insufficiency or those with contraindications to heparine therapy. Patients in whom the restudy cannot be performed within three days will leave the catheterization laboratory without catheters. The only exception are patients with frequent severely symptomatic or life-threatening arrhythmias in whom the catheter might be of help to repeatedly terminate the arrhythmia while the full effect of the drug has not been reached. In these paticnts we sometimes place a new catheter by way of the left cephalic vein. Placement of a catheter using the arm has the advantage of easy mobilization of the patient. In these patients full heparinization by a continuous infusion pump is done by using an infusion holder on whects. If the catheter is placed in the right ventricle by way of the arm the restudy does not require readmission to the 
catheterization laboratory. After right ventricular stimulation has been performed withdrawal of the catheter under electrocardiographic or portable $\mathrm{X}$-ray control allows atral stimulation. The catheter used is a quadripolar electrode, which permits recording of a bipolar electrogram during pacing.

In general we prefer to insert new catheters on the day of restudy. The patient is then readmitted to the cathererization laboratory. This has the advantage of allowing recording of electrograms at the same location as during the initial study. It is more costly however and occupies the catheterisation laboratory. We have safely performed restudies at the patient's bed using a portable recording and stimulation unit with resuscitation requirements available. Patients have found this approach more comfortable. Patients with life-threatening arrbythmias are not discharged from hospital before control of the arrhythmia has been obtained. This might require testing of several antiarrhythmics, alone and in combitations.

\section{Special ways of stimulation to study patterns of conduction and mechanisms of tachycardias}

By using the method of programmed electrical stimulation of the heart one can study (1-3) sites of origin, pathways and mechanisms of most tachycardias. As will be demonstrated in chapters 9 and 10 the differential diagnosis of mechanism and pathways in patients with supraventricular tachycardia can be difficult, therefore the following special protocols have been developed:

\section{Special pacing protocols during superventricular tachycardia.}

\section{Incessant supraventricular tachycardia.}

We have studied eleven patients with the syndrome of incessant $A-V$ junctional supraventricullar tachycardia. In these patients participation of an accessory pathway in retrograde direction having a long conduction time and A-V nodal-like properties could be demonstrated by using some uncommon modes of stimulation during sinus rhythm, ventricular pacing or tachycardia.

There is a lot of controversy about the mechanism responsible for the different types of incessant supraventricular tachycardia. Incessant supraventricular tachycardia can either originate in the atrium or be based on a concealed accessory pathway having A-V nodal like properties and a long ventriculo-atrial conduction time (10-12). Theoretically a tachycardia showing a similar electrocardiogram can also be based upon an A-V nodal re-entry mechanism with anterograde conduction ower a fast $A-V$ nodal pathway and retrograde conduction over a slow $A-V$ nodal pathway (the so-called reversed A-V nodal tachycardia).

Incessant supraventricular tachycardia can only be considered to be the result of an intranodal reveried (fast-slow) re-entrant circuit when use of an accessory pathway has been excluded. The A-V nodall-like properties of the slowly conducting accessory pathway have been responsible for confusion. As will be shown, demonstration of the presence and use of an accessory pathway with long conduction times can sometimes be very difficult.

Demonstration of the use of an accessory pathway in supraventricular tachycardia is easily obtained when during tachycardia a single ventricular premature beat delivered at the time of refractoriness of the bundle of His is able to advance subsequent atrial activation with the same activation pattern as during tachyeardia (13). The ability to produce this phenomenon depends on several factors: first, the ventricular premature beat must be able to invade the re-entrant circuit. This will not only depend on the distance between the site of the ventricular premature beat and the location of the rewentrant circuit but also on the conduction velocity of the tissues between the site of stimulation and the re-entrant circuit. The ventriculowatrial conduction time of a right ventricular apicall extrasystole (a common site of stimulation during PES) is 30-50 ms longer when conducted over a left lateral accessory pathway as compared to the ventriculo-atrial conduction time of an extrasystole delivered at the same site with V-A conduction over a septally located accessory pathway (14). In the former situation the increase in the $\mathrm{V}$-A conduction time due to transeptal activation can prevent demonstration of pre-excitation of the atria at the time of refractoriness of the bundle of His. This is a not uncommonly observed phenomenon in patients 
using retrogradely a left-sided accessory pathway (14).

Secondly, advancement of subsequent atrial activation will not only depend upon location but also upon the properties of the retrograde pathway in the tachycardia circuit. In the common type of accessory pathway, which is one having fast conduction velocity, decrementall conduction properties are usually absent. Accessory pathways hawing long conduction times show decremental conduction (10-13,15-16). In these cases even when the re-entry circuit is invaded by a ventricular premature beat delivered during tachycardia an increase in the conduction time over the accessory pathway can prevent demonstration of advancement of atrial activation. In 5 out of our 11 patients having a septally located accessory pathway with a long conduction time a single ventricular premature beat given repeatedly at the time of refractoriness of the bundle of His did not result in advancement of subsequent atrial activation during tachycardia. This is a major challenge to the electrophysiologist performing the stimulation study, and special modles of pacing must be designed "in situ" to try to prove or exclude the use of an accessory pathway during tachycardia. Some of these methods are described here.

1. Delivery of a single late ventricular premature beat during sinus rhythm. A ventricular premature beat is delivered during sinus rhythm at the time of refractoriness of the bundle of His. As observed in one of our patients having an accessory pathway with long conduction time ventriculo-atrial conduction can occur following the ventricular premature beat and result in initiation of tachycardia (12). This mode of initiation of the arthythmia can best be cxplained by accepting the presence of an accessory pathway. Theoretically one might consider the presence of simultaneously occurring dissociation in two electrophysiologically different pathways within the His bundle and the A-V node. A distal connection within the His bundle should be present and the A-V nodal pathways must be able to conduct retrograclely. So far such a mechanism has not been demonstrated. Functionally, though not anatomically, this situation would be similar to an accessory pathway.

Demonstration of V-A conduction during sinus rhythm at the time of refractoriness of the bundle of His is not possible in patients having the common fastly conducting type of accessory pathway. The fast conduction velocity results in arrival of the impulse in the atrium at a time when this is still refractory.

2. Delivery of a single late ventricular premature beat during tachycardia. Sometimes a single ventricular premature beat delivered at the time of refractoriness of the bundle of His will not preexcite the atria, but result in termination of the arrhythmia when the accessory pathway has a long retrograde refractory period during tachycardia (11). Termination of tachycardia without $\mathrm{V}-\mathrm{A}$ conduction of a ventricular premature beat given when the His bundle is refractory excludes an atrial site of origin of the arthythmia, and proves that the ventricles are a necessary link in this supraventricular tachycardia. Such a finding proves that an aceessory A-V pathway is used in retrograde direction (figure 9).

3. Deliwery of single ventricular premature beats at different ventricular sites. When an accessory pathway located on the left side is used retrogradely during tachycardia a left wentricular premature beat will reach more easily the re-entry circuit than a right ventricular premature beat. The reverse is true in case of a right sided accessory pathway. Use of single ventricular premature beats at the appropriate ventricular site will demonstrate advancement of subsequent at rial activation at the time of His bundle refractoriness while they fail to do so when given at another ventricular site (fig. 10-11). In patients using retrogradely an accessory pathway located in the septum left ventricular pacing is probably of no benefit to demonstrate atrial pre-excitation during His bundle refractoriness when right ventricular apical premature beats failed to show this. In these cases, as described Coumel et al (17) stimulation high in the right ventricular septum can sometimes demonstrate the phenomenon because of the closer location to the reentry circuit.

\section{Delivery of single ventricular premature beats during intraventricular aberrant conduction.}

Though small, the risks of left ventricular stimulation are rarely justified in patients studied because of a supraventricular arrhythmia when they do not undergo simultaneous left heart catheterization because of coronary heart disease or other reasons. When left heart catheterization 


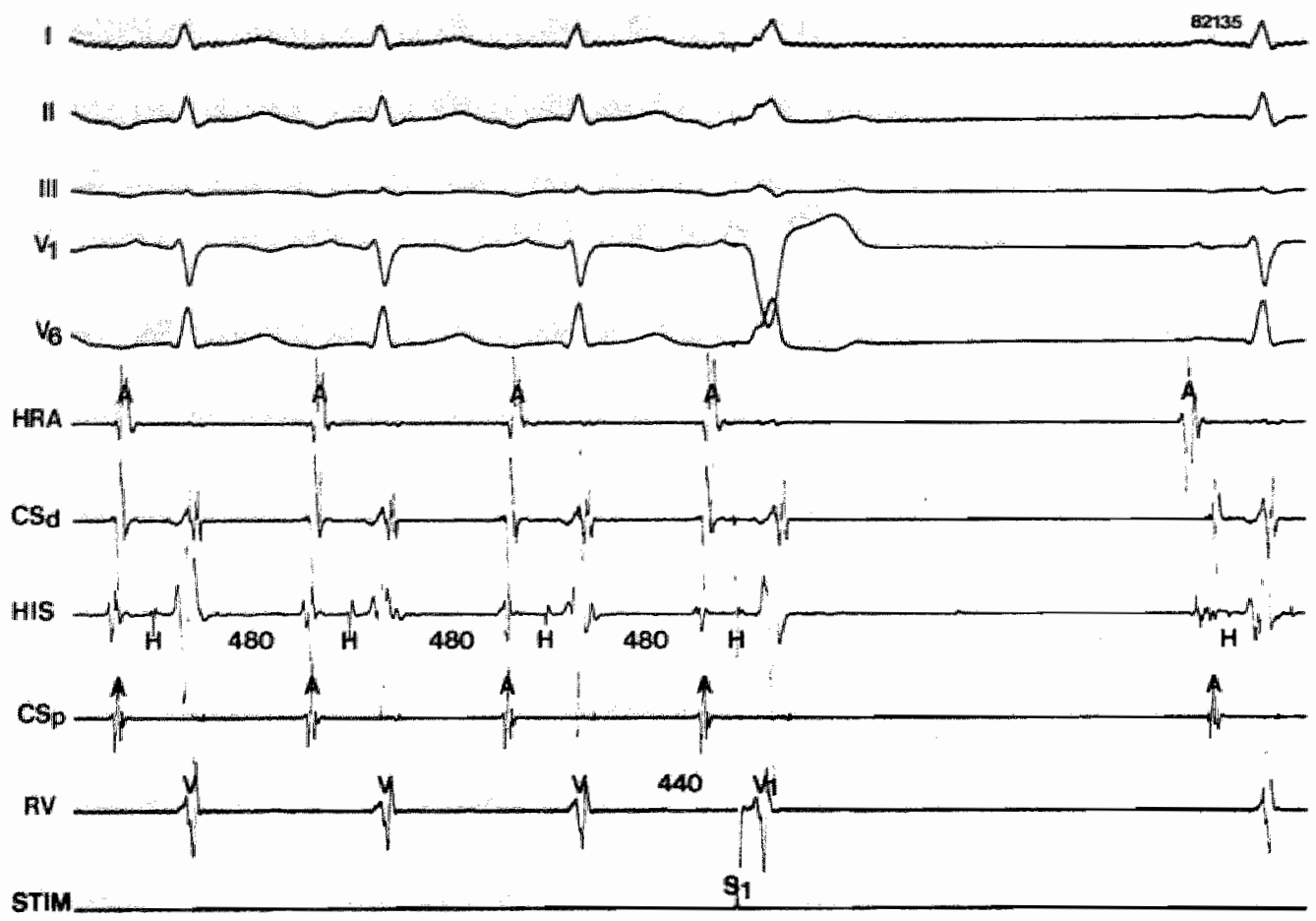

Figure 9

Termination of a supraventricular tachycardia having a $P$ ' $R$ interval shorter than $R$ - $P$ interval by a ventricular premature beat given in the right ventricular apex. "The ventricular premature beat occurs at the tione when the His bundle is refractory. Tachycardia is terminated without $\mathrm{V}$-A conduction of the ventricular premature beat. This mode of termination indicates that both atria and ventricles are incorporated in the tachycardia circuit and prowex that the accessory pathway has a long refrograde refractory period. 5 Surface leads were simultaneously recorded with five bipolar endocavitary electrograms.

is not performed, delivery of single ventricular premature beats during intraventricular aberrant conduction can be of help in demonstrating the presence of an accessory pathway. In the patient using retrogradely a left sided accessory pathway a single ventricular premature beat delivered in the right vent ricular apex may fail to advance subsequent atrial activation when the His bundle is refractory for reasons discussed already. During left bundle branch block however even a much later premature beat ean advance atrial activation when the His bundle is refractory. This is the result of the increase in the dimensions of the re-entrant circuit during left bundle branch block, the stimulation site (the right ventricular apex) being now closer to or even within the re-entry circuit. When a right-sided accessory pathway is used retrogradely single right ventricular premature beats usually result in clear advancement of subsequent atrial activation during tachyeardia at the time of refractoriness of the bundle of His. This may even lead to a so called "paradoxical" capture of the atria due to a shorter conduction time from the site of stimulation in the right ventricle to the atria than the ventriculo-atrial conduction time during tachycardia. Left bundle branch block does not modify the dimensions of the re-entry circuit in these cases and does not change the effects of right ventricular apical premature beats. "Paradoxical" captures by right ventricular apical premature beats are however most easily demonstrated when right bundle branch block develops and the cireuit enlarges. In patients using it truly septally located accessory pathway, intraventricular aberrant conduction does not result in easier or more difficult demonstration of atrial pre-excitation at the time of His bundle refractoriness.

\section{Use of two ventricular premature beats to demonstrate retrograde conduction over an accessory} pathway during supraventricular tachycardia. When a single ventricular premature beat fails to terminate tachycardia without $V$. A conduction at the time of refractoriness of the bundle of His or 


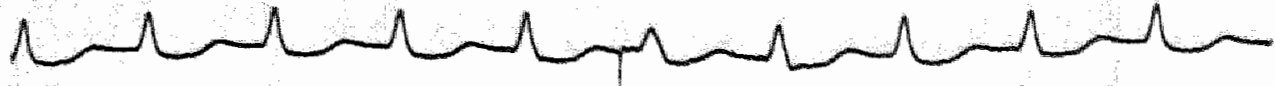

期
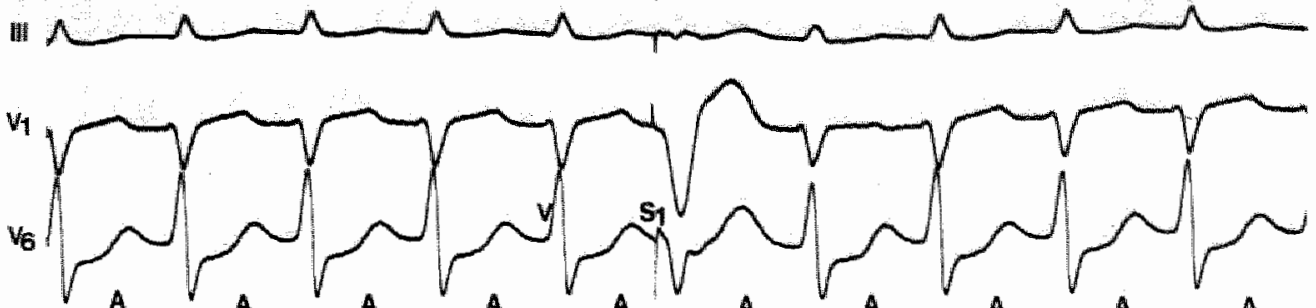

A

A

A

A
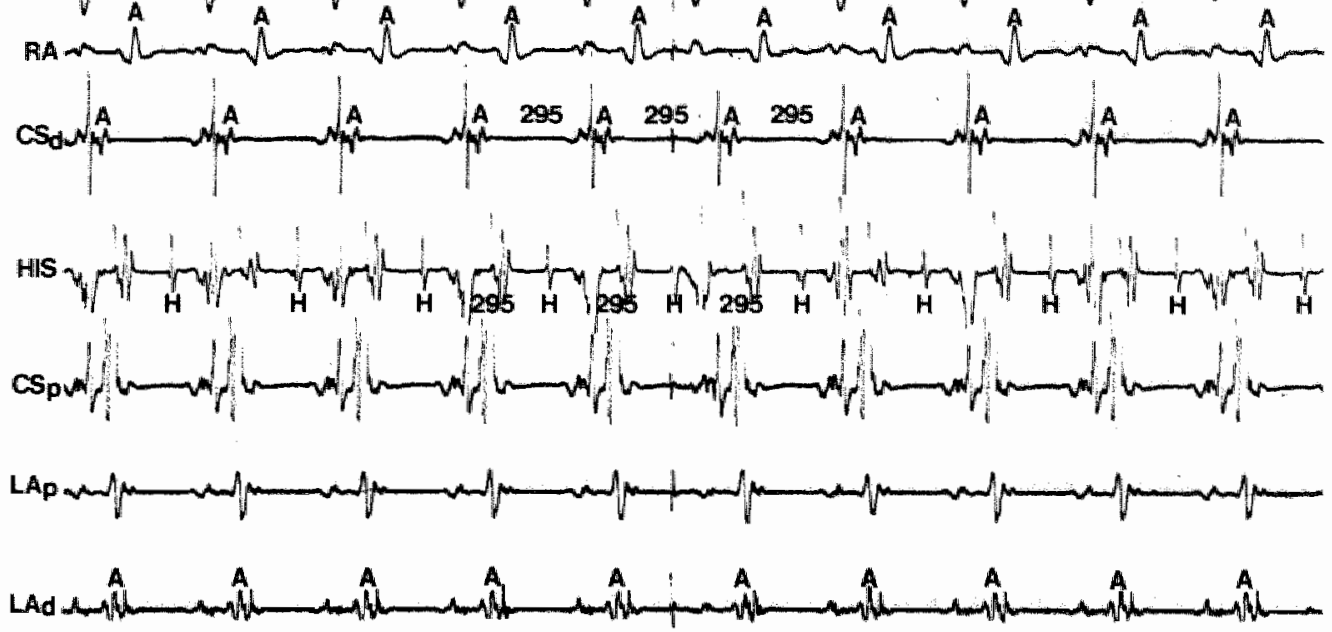

Figure 10

A ventricular premature beat is given during circusmovement tachycardia using retrogradely an accessory pathway located laterally in the left A-V groove at the time that the His bundle is refractory for conduction. This ventricular premature beat which is given in the apex of the right ventricle fails to adwance subsequent atrial activation.

to advance subsequent atrial actiwation, other modes of stimulation have to be applice to exclude or prove the use of a retrogradely conducting accessory pathway. Intraventricular aberrant conduction lengthens only minimally ( $\leqslant 25 \mathrm{~ms}$ ) the $V$-A conduction time during a tachycardia using a truly septally located accessory pathway (18). Therefore in these patients the delivery of : second ventricular premature beat during tachycardia can be of help to demonstrate that an accessory pathway is being used retrogradely. There are several ways of giving these two ventricular premature beats:

a) The first ventricular premature beat is given at the time of refractoriness of the His bundle but fails to advance subsequent atrial activation. Under these circumstances it is impossible to decide whether or not the ventricular premature beat has entered the re-entry circuit and failed to advance subsequent atrial activation because of transeptal activation time or because of decremental conduction properties in the $\mathrm{V}$-A link of the tachycardia circuit. Giving a second ventricular premature beat late in the cycle several possible observations can be made. The first and second ventricular premature beat are given when the His bundle is refractory for conduction during two consecutive cycles, and the interval between the two ventricular premature beats (S1-S2) is adjusted to exactly the tachycardia cycle length or a shorter cycle. Pre-excitation of the atria by the second ventricular premature beat can sometimes be demonstrated at the time of refractorincss of the bundle of His (fig. 12). This suggests that the first ventricular premature beat indeed invaded the re-entry circuit, but failed to pre-excite the atria becausc of the transeptal activation time or because of decremental conduction in the retrograde limb of the tachycardia circuit. When 


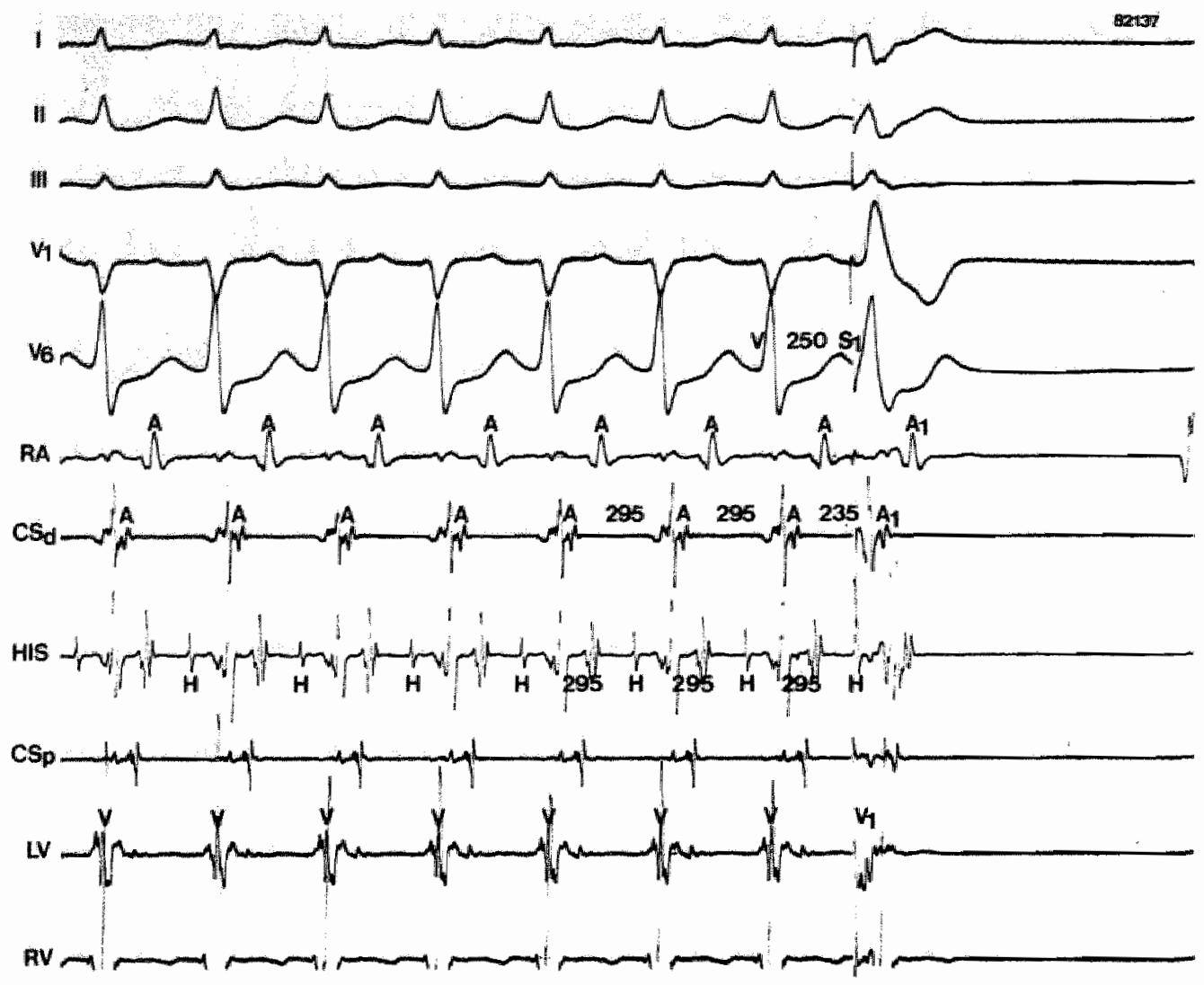

Figure 11

Same patient as in fig. 10. A left ventricular premature beat paradoxically advances subsequent atrial activation and terminates tachycardia. These observations are explained by the shorter distance between the re-cntry circuit and the stimulus delivered in the left ventricle. 6 Surface leads are shown simultaneously with six entocavitary bipolar electrograms.

the first premature beat did not capture the re-entry circuit atrial preaexcitation is not demonstrated by a second, third or fourth ventricular premature beat (fig. 13).

b) The first ventricular premature beat is given at the time of refractoriness of the His bundle and fails to advance subsequent atrial activation. When the second ventricular premature beat is given carly in the cycle before the expected anterograde His bundle depolarization this can be of help to demonstrate the presence of an accessory pathway. In figure 14 wo examples are given. In the top pane: the second ventricular premature beat advances subsequent atrial activation without modifying anterograde depolarization of the His bundle. In the bottom panel a $10 \mathrm{~ms}$ shortening of the second ventricular premature beat interval te rminates tachycardia without $V$-A conduction and without influencing the expected anterograde depolarization of the His bundle.

c) The first ventricular premature beat has falled to pre-excite the atria at the time of refractoriness of the bundie of His, but when given early in the cycle results in termination of tachycardia without retrograde conduction to the atria. In this situation it is not possible to decide whether the tachycardia is located intranodally or uses an accessory pathway retrogradely, although an atrial site of origin of tachycardia is excluded. Interesting observations can be made by giving a second ventricular premature beat. When the first ventricular premature beat is given after the correct interval to terminate tachycardia and the second is given very late after the first (at least twice the tachycardia cycle length), this second ventricular premature beat can reinitiate tachycardia following $\mathrm{V}$-A conduction. On increasing the prematurity of the second premature beat a zone of 

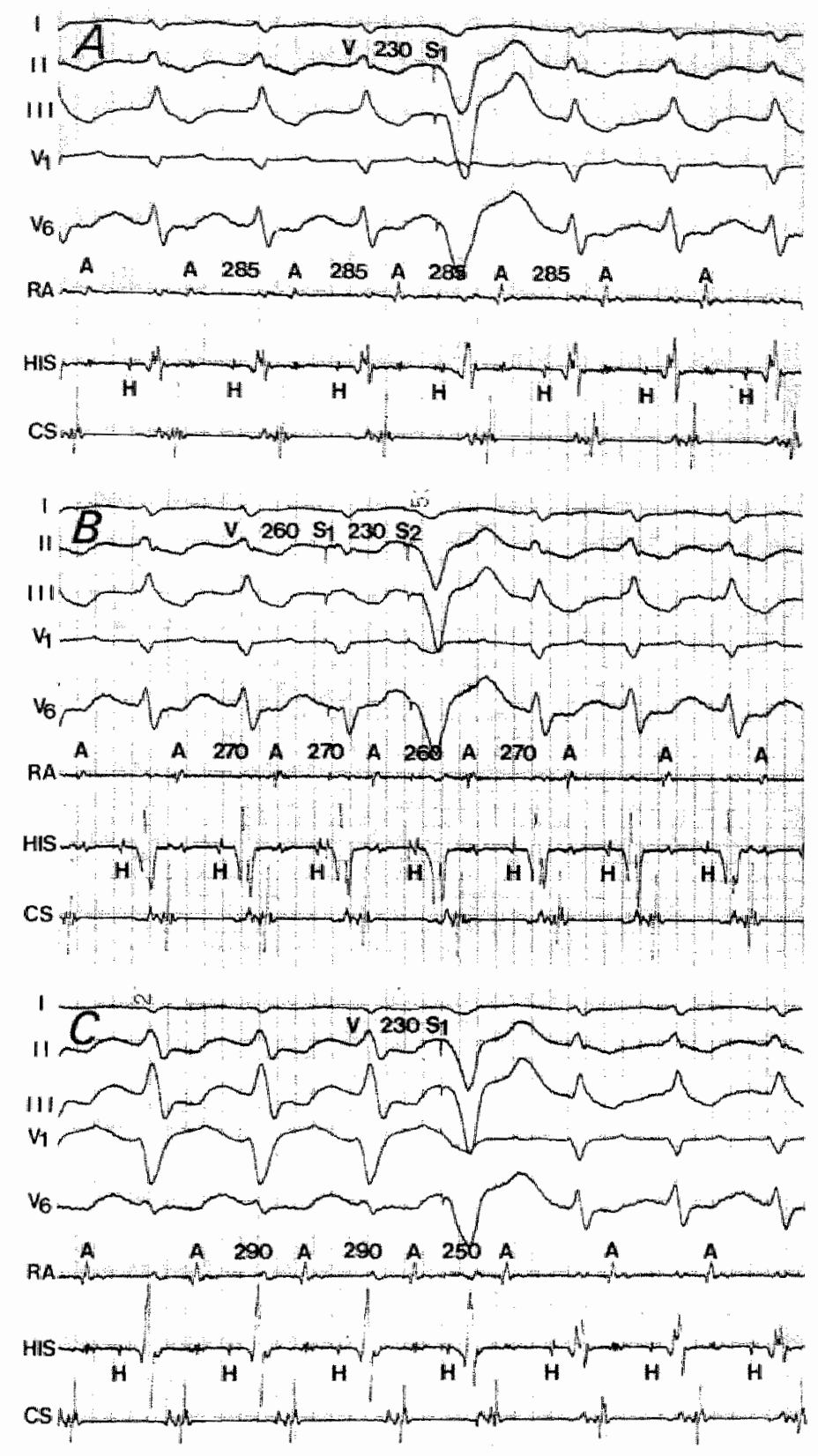

Figure 12

During circus movement tachycardia using retrogradely an accessory left-sided A-V pathway a right ventricular apical premature beat given after $230 \mathrm{~ms}$ (panel A) falls to advance subsequent atrial activation. The ventricalar premature beat is given just before the expected anterograde His bundle depolarization and does not affect the A-H interval. A premature beat given after the same interval advances subsequent atrid activation by $10 \mathrm{~ms}$ when it is preceded by another ventricular premature beat (panel $B$ ) and wher given during tachycardia with left bundle branch block aberrancy (pancl C). Five surface leads are simultancously recorded with 3 endocavitary bipolar electrograms. 


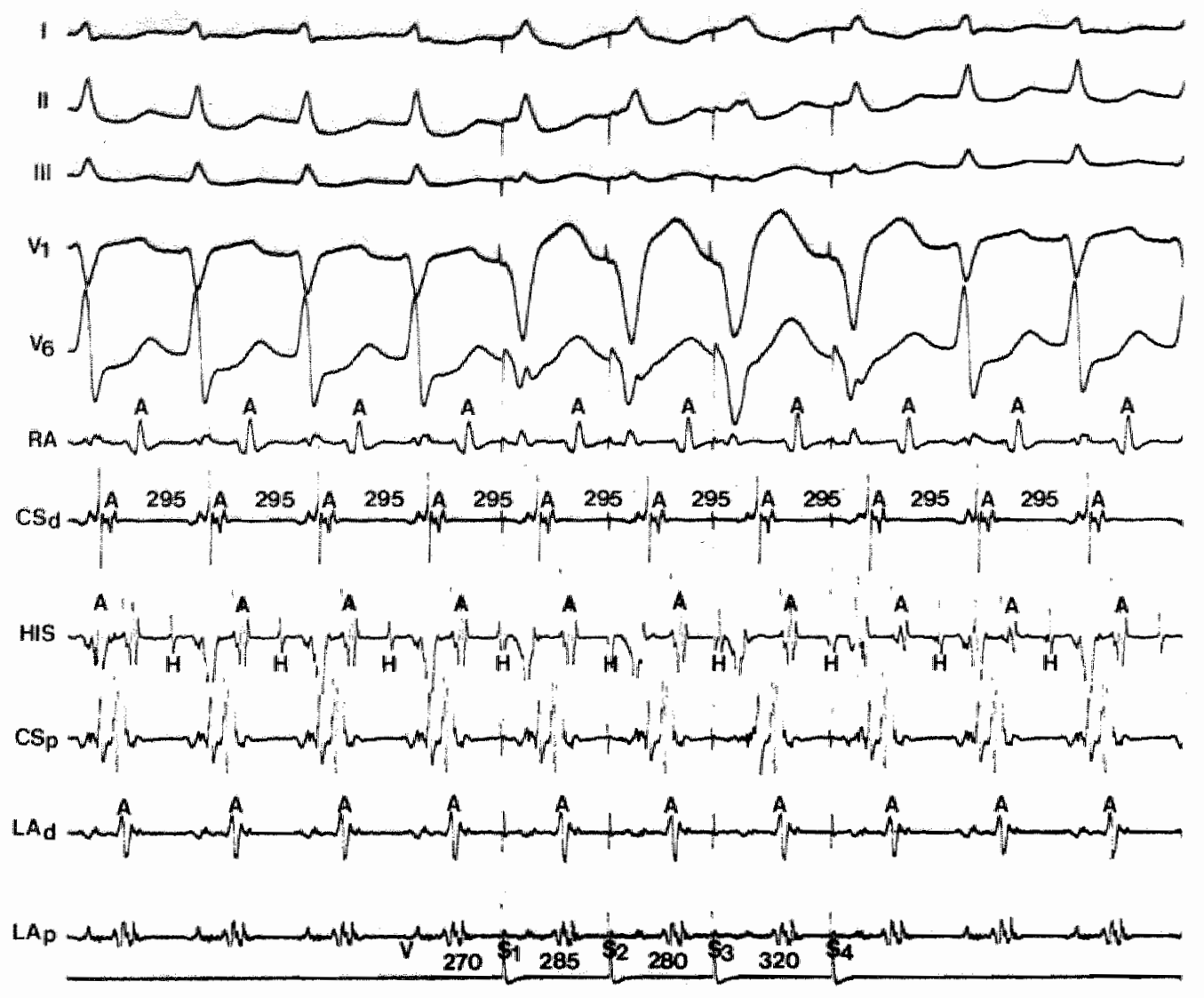

Figure 13

The first ventricular premature beat given during a tachycardia using a left-sided accessory A -V pathway faits to advance subsequent atrial activation when occurring at the time of refractorines of the bundle of His. A scond. hird and fonth ventricular premature beat also given when the His bunde is refractory during

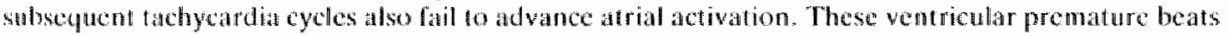
probably lated to aner the re-endry circuit. S Surbere leads are shown simultancously with six chdowaviary bipular electrograms.

initiation of tachycardia will be observed which terminates when the refractory period of the $\mathrm{V}-\mathrm{A}$ pathway is reached. With increasing prematurity of the second ventricular beat delay in retrograde conduction to the His bundle will be observed by measuring the interval between the first ventricular premature beat (S1) and retrograde depolarization of the His bundle following the second ventricular premature beat (H2). It can be shown that in spite of marked subnodal delay and very long $\mathrm{S} 1-\mathrm{H} 2$ intervals tachycardia is not reinitiated. Ewen with $\mathrm{S1}-\mathrm{H} 2$ intervals which are much longer than the shortest V1-V2 interval able to reinitiate tachycardia. This suggests that the pathway used retrogradely during reinitiation of tachycardia is dissociated from the A-V node-His bundle axis. However the demonstration of two zones of reinitiation of re-entry following the second ventricular premature beat, the first one as in the preceding situation, but the second zone after the ocenrrence of subnodal delay on reaching a critical $\mathrm{S} 1-\mathrm{H} 2$ interval suggests that the pathway used retrogradely at the time of reinitiation of tachycardia is connected to the A-V nodeHis bundle axis, tavoring an intranodal location of the tachycardia circuit (12).

d) The first ventricular premature beat fails to preexcite the atria when given at the time of refractoriness of the His bundle and to terminate tachycardia, but advances subsequent atrial activation when activation of the His bunde is no longer observed (hidden into the QRS 


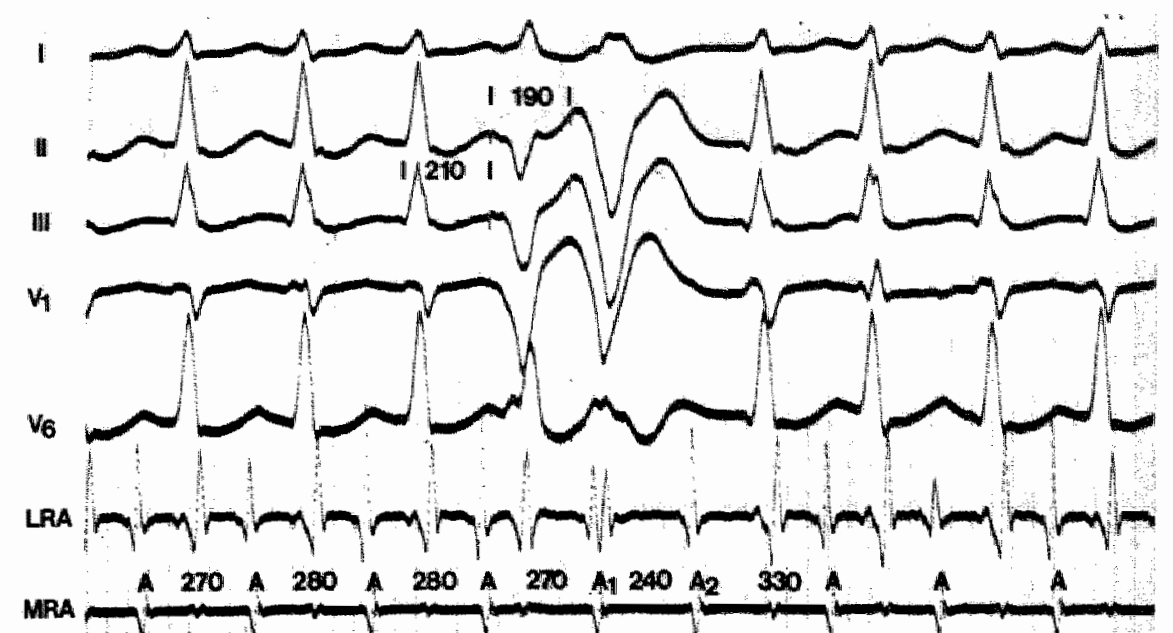

His

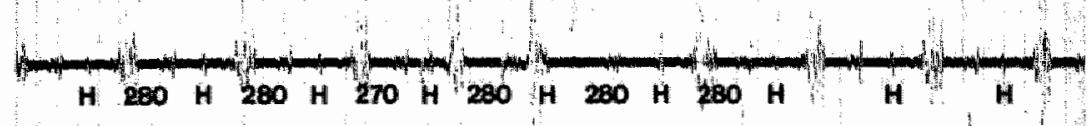

$\operatorname{cs}_{p} p_{\mathrm{f}}$
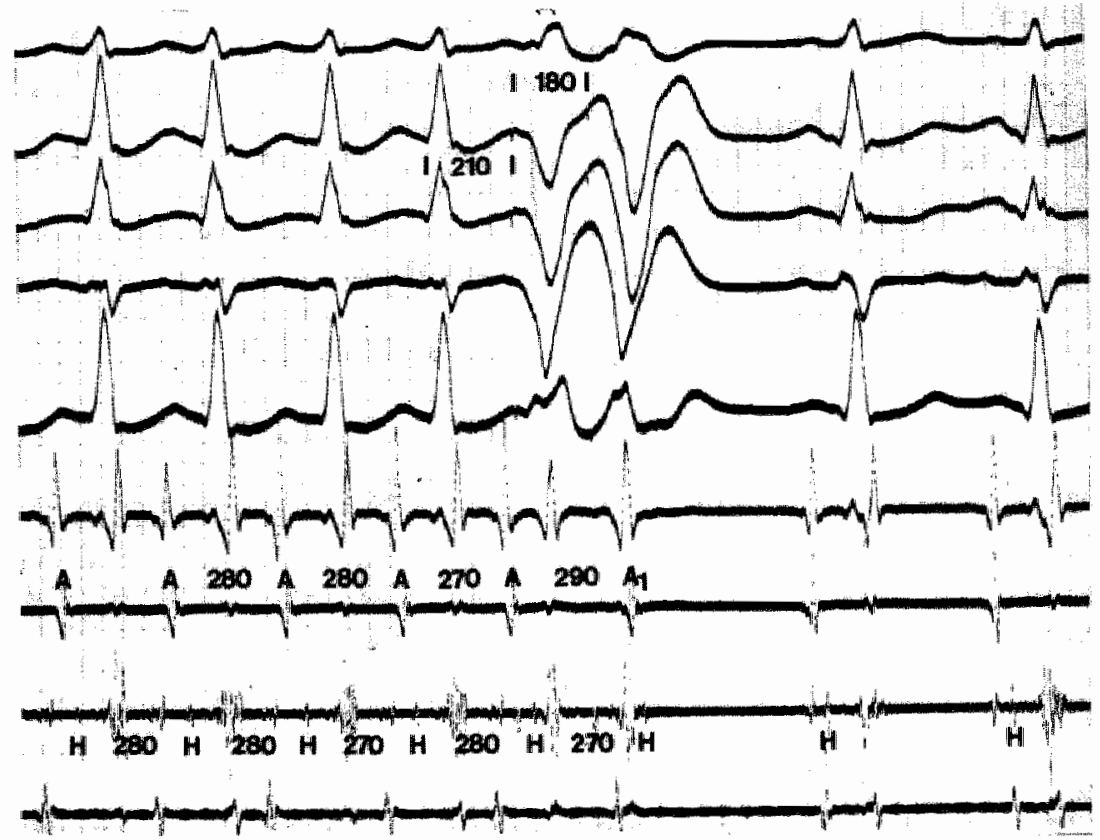

Figure 14

In panels $A$ ard $B$ the first ventreular premature beat given at the line of refractoriness of the bundle of His fails to advance subsequent atrial activation. In parel A second went ricular premature buat adwances atrial activation without modifying anterograde depolarization of the bundle of His. A 10 ms shortening of the second ventricular premature beat interval terminates tachyeardia. This occurs withoull $\mathrm{V}-\mathrm{A}$ oonduction and without modifying anterograde depolarization of the bundle of His (pancel B). These observalions indicate participation of an accessory A-V pathway as the retrograde arm of the tachycardia dircuit. 5 Surface leads simulaneously recorded with four bipolar endocavitary electrograms. 
complex). Under these circumstances, advancement of subsequent atrial activation can occur because of retrograde conduction over an accessory pathway or over an $\mathrm{A}-\mathrm{V}$ nodal retrograde pathway prematurely engaged after retrograde depolarization of the His bundle. A second ventricular premature beat can advance subsequent atrial activation when the first one is given carly in the cycle and the second one at the time of refractoriness of the bundle of His by the same principles previously discussed. When given earlier in the cycle it can be shown that the V-A conduction time of the first and second premature beat are the same and that no decremental conduction occurs. This finding is very suggestive for the use of an accessory pathway in ventriculo-atrial direction.

These special modes of stimulation during supraventricular tachycardia are not the only way to demonstrate use of an accessory pathway during tachycardia. There are other criteria useful to suggest that diagnosis like eccentric atrial activation during tachycardia when an atrial site of origin of the arrhythmia can be excluded, or an increase in V-A interval during tachycardia upon development of bundle branch block ipsilateral to the location of the accessory pathway. The: special modes of stimulation which we discussed are especially useful when $\mathrm{A}-\mathrm{V}$ nodal retrograde conduction simulates accessory pathway conduction $(12,19)$ or when accessory pathway conduction simulates retrograde A-V nodal conduction (as in septally located accessory pathways).

In the literature it can be repeatedly observed that an A-V nodal re-entrant tachycardia is diagnosed when no evidence for the use of an accessory pathway during tachycardia is found. An intranodal tachycardia is diagnosed when a ventricular premature beat does not pre-excite the at ria at the time of His bundle refractoriness, when the atrial activation sequence is not eccentric, when intraventricular aberrant conduction does not modify the $V-A$ interval during tachycardia. These arguments do not prove the presence of an accessory pathway, but they do not exclude its use during tachycardia either. Negative observations do not prove that the tachycardia is located intranodally. Positive arguments have to be presented to exclude use of an accessory pathway. Positive arguments also have to prove an intranodal or atrial location of the re-entry circuit. We want to stress that the presence of discontinuous A-V nodal conduction curves suggesting the presence of dual $A-V$ nodal pathways is not diagnostic of an intranodal location of the tachycardia circuit, even when tachycardia is initiated at the time of the shift in conduction from the fast to the slow A-V nodal pathway. Up to $10 \%$ of patients having an accessory pathway used retrogradely during tachycardia will demonstrate discontinuous $\mathrm{A}-\mathrm{V}$ nodal conduction curves during atrial stimulation (20). Similarly, the presence of an accessory pathway does not mean that it is used during supraventricular tachycardia. Examples of intranodal tachycardias in patients with accessory pathways have been reported $(21-23)$.

Positive arguments to exclude use of an accessory pathway during supraventricular tachycardia: There are some very useful findings which positively exclude use of an acessory A-V pathway during supraventricular tachycardia, and also some observations which positively prove an intratial location of the re-entry circuit:

a) Demonstration of $\mathrm{A}-\mathrm{V}$ block during tachycardia without termination of the arrhythmia: This phenomenon can sometimes be observed to occur spontaneously, positively excluding the use of an accessory A-V pathway during tachycardia. Single or multiple atrial or ventricular premature beats can result in A-V block of subsequent tachycardia P waves without terminating tachycardia (fig. 15). It can also be produced by vagal manoeuvres.

b) The occurrence during tachycardia of atrial activation which precedes or occurs simultaneously with ventricular activation (fig. 16). In this situation there is no true "V-A" conduction therefore an accessory A-V pathway as participating retrogradely in the tachycardia circuit is excluded (13).

\section{Positive arguments to suggest an intranodal location of the tachycardia circuit are:}

a) The demonstration that only the $A-V$ node is required to inifiate and perpetuate the arrhythmia. One has to show the simultaneous occurrence of $\mathrm{H}$-A and $\mathrm{H}-\mathrm{V}$ block during tachycardia without termination of the arrhythmia. Josephson et al. have suggested that by delivering atrial premature beats it can be shown that most of the atrial activation can be advanced without modifying the timing of activation of the His bundle (24). This phenomenon depends on the conduction 

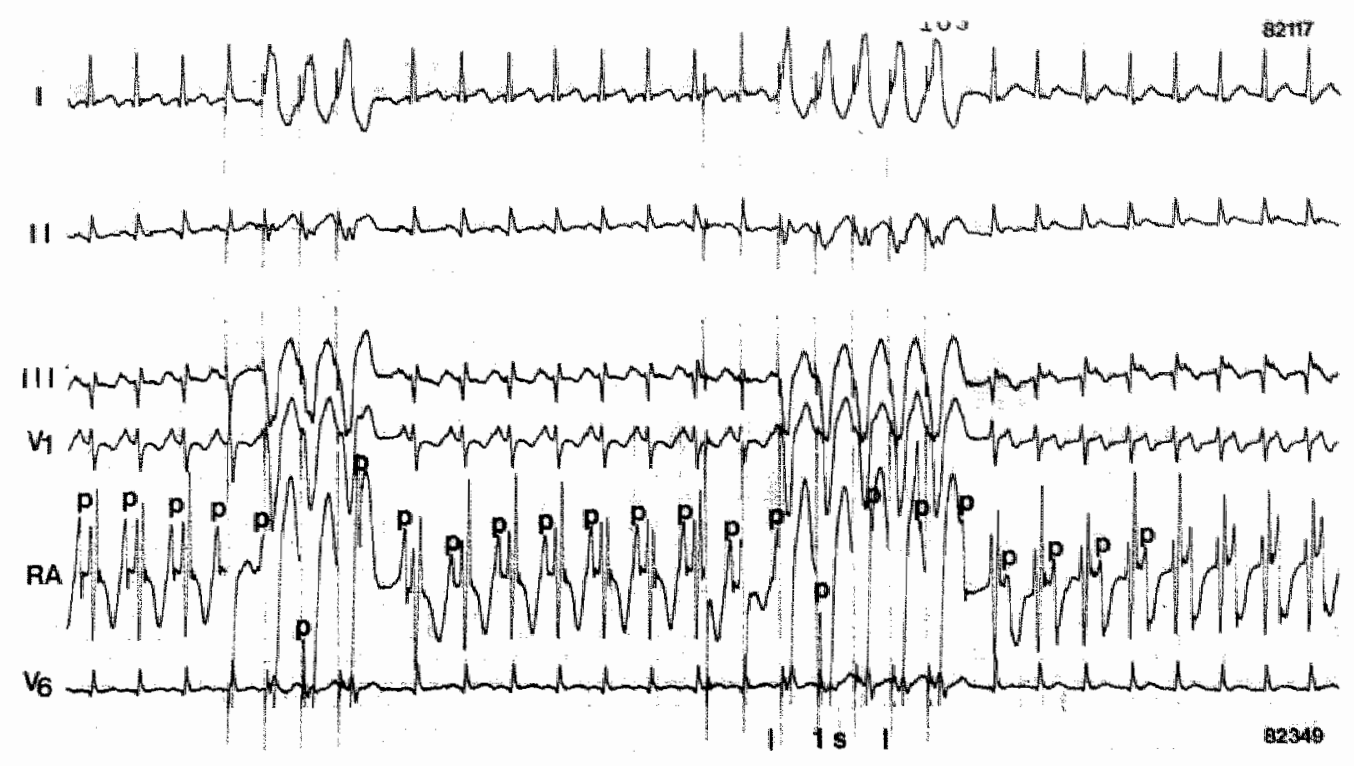

Figure 15

Demonstration of $\mathrm{A}-\mathrm{V}$ block during supraventricular tachycardia by vertricular pacing without termination of the arrhythmia. These observations exclude a tachycardia using an accessory A.V pathway. 5 surface leads and one right atrial lead are showm.

properties of the A-V node during tachycardia. The atrial premature beat can pre-excite the atrium completely, penetrate the re-entry circuit, but because of delay in conduction over the slow A-V nodal pathway result in activation of the His bundle on time, suggesting that the re-entry circuit has not been penetrated. We believe that this observation cannot be taken as a positive argument to exclude participation of the atria in the tachycardia circuit (figure 17).

b) Termination of a supraventricular tachycardia showing simultaneous activation of atria and ventricles (common type of A.V nodal tachycardia) or a $P^{\prime}-R$ shorter than the R-P" (uncommon or "reversed" form of A-V nodal tachycardia) by a ventricular premature beat which is not retrogradely conducted to the atrium after an accessory pathway has been excluded this mode of termination does exclude an atrial site of origin of tachycardia.

c) Initiation of the uncommon type of $A-V$ nodal tachycardia by a ventricular premature beat in relation to delay in retrograde conduction (shift from retrograde fast to retrograde slow $\mathrm{A}-\mathrm{V}$ nodal pathway) after an accessory pathway has been excluded by positive arguments (figure 18).

d) Demonstration of two zones of initiation of tachycardia of the uncommon variety during ventricular stimulation. The first zone is determined by the latest premature beat resulting in shift of conduction from the retrograde fast to the retrogsade slow pathway up to the ventricular premature beat interval which reaches the retrograde refractory period of the slow pathway. The second zone occurs after a "gap" in initiation of tachycardia, and begins when sufficient subnodal delay of retrograde conduction of the ventricular premature beat allows arrival of the impulse to the A-V nodal slow pathway late enough after its refractory period. This observation prowes that the slow pathway is located above the His bundle, and that there is no accessory A-V pathway with long conduction times (12).

We have observed only one case of long-lasting ( 60 beats) but non-sustained A-V nodal tachycardia of the reversed form. This arrhythmia was never documented clinically. Our patient demonstrated A- $V$ block during tachycardia, whthout termination of the arrhythmia, thus excluding use of a retrogradely conducting accessory pathway with long, conduction times. 

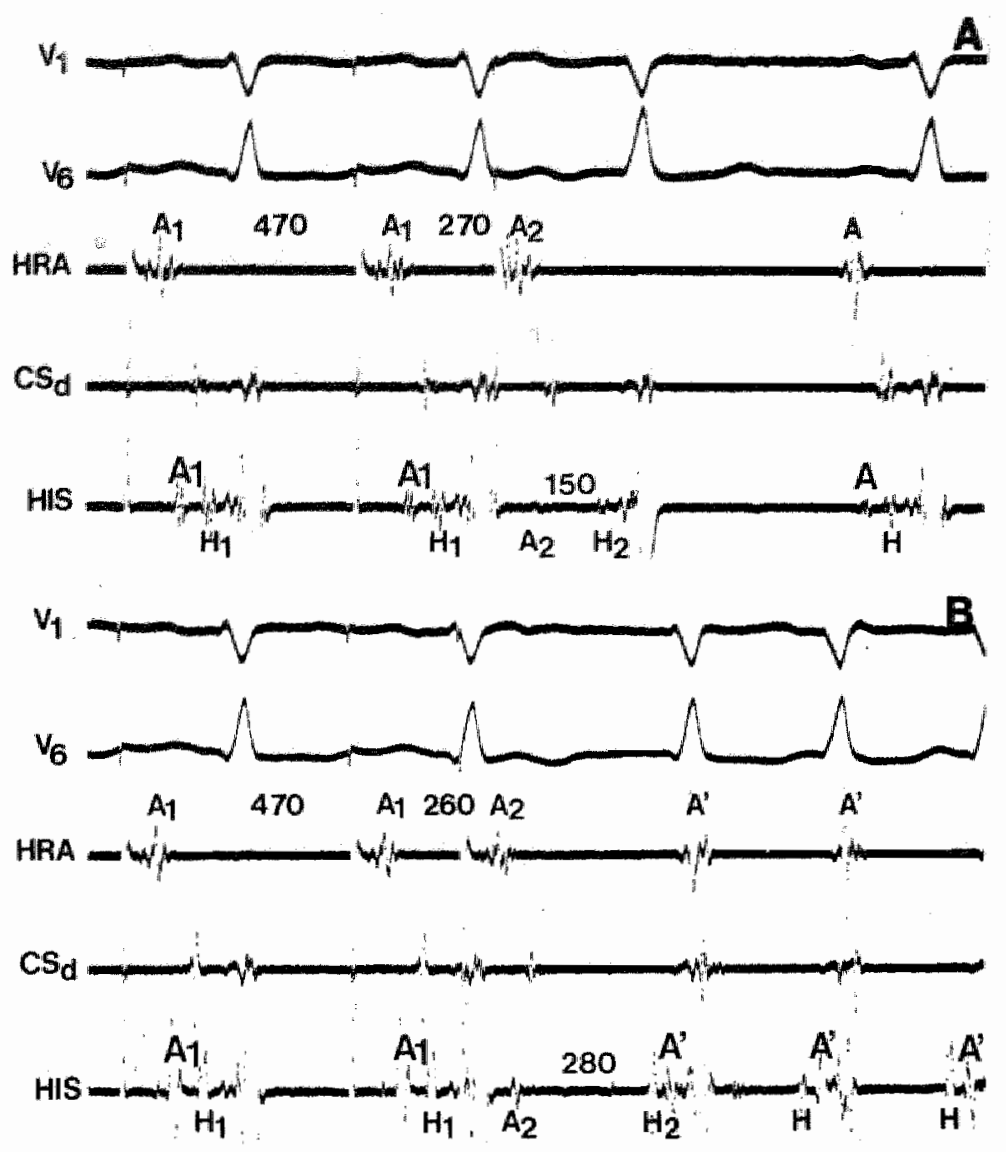

Figure 16

Initation of a suprawentricular tachycardia during atrial pacing by a critically timed atrial premature beat during atrial pacing. At the time of intiation and during supraventricular tachycardia atrial activation occurs simultancously with ventricular activation (panel B). This exeludes incorporation of an accessory $A-V$ pathway in the tachyeardia circuit.

Special pacing protocols used during a wide qrs complex tachycardia with 1-to-1 relation between atrial and ventricular activation.

Several diagnostic possibilities must be considered during a wide ORS complex tachycardia showing a 1-10-1 A-V relation.

a) Supraventricular tachycardia in a patient with a functional or a pre-existing bundle branch defeet,

b) Atrial tachycardia with anterograde conduction over an accessory A-V pathway,

c) Circusmovement tachycardia using anterogradely an accessory pathway and retrogradely the normal A-V pathway or a second accessory pathway, and

d) Ventricular tachycardia with 1-to-1 retrograde conduction to the atria.

In situation a) His bundle activation precedes and does not follow the QRS complex. This type of tachyeardia will therefore not be considered. When confronted with possibilities b) to d) our first approach is to give an atrial premature beat with a progressively shorter interval. Several possibilities can occur:

1. Ventricular capture by the atrial premature beat with a ORS complex showing a different morphology as compared to the tachycardia QRS complex, without termination of tachycardia, 


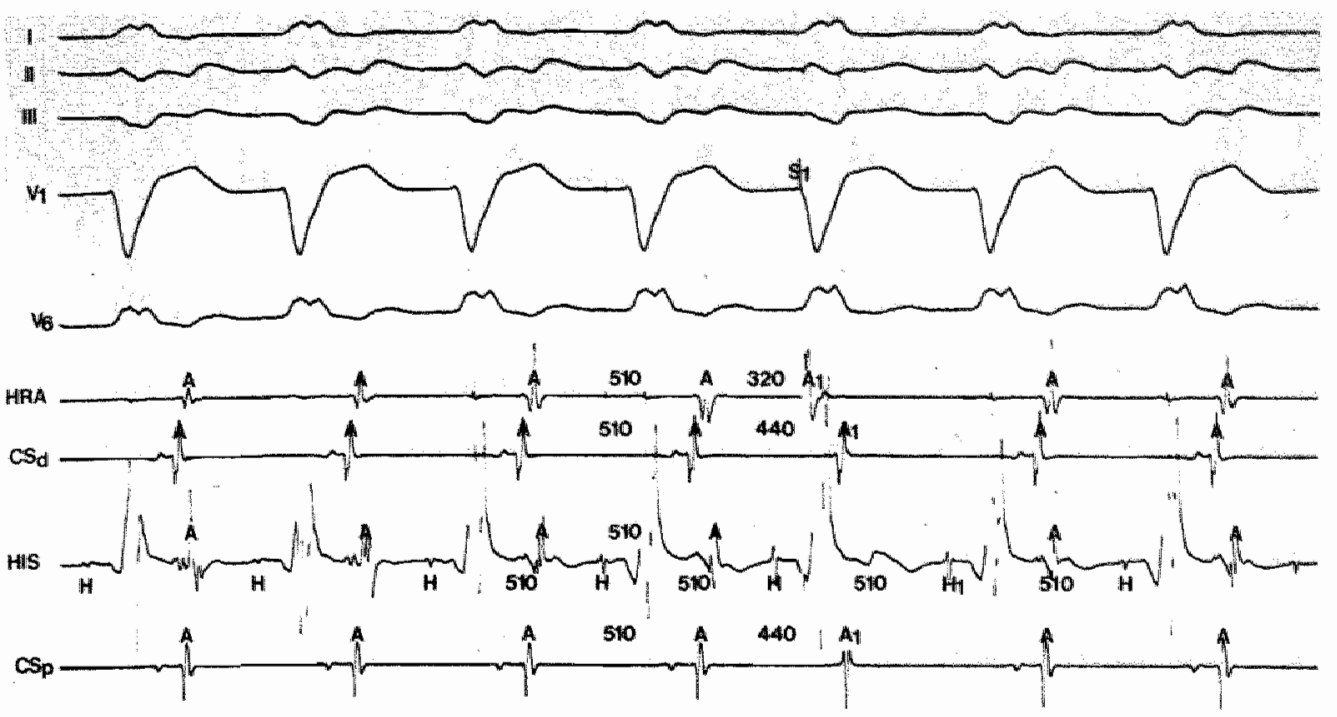

Figure 17

During a circusmovement tachycardia using retrogradely a left-sided accessory A-V pathway an atrial premature beat advances all atrial electrograms but does not modily the timing of subsequent anterograde activation of the His bundle. This observation cannot be used to exclude participation of the atria in the mechanisms of the arrhythmia. In lachycardias using an accessory A.V pathway, like the one shown in this figure, the atria are part of the re-entrant circuit.

followed by a fully compensatory pause at the ventricular level. This observation indicates that the pathway used anterogradely by the atrial premature beat is not used anterogradely during tachycardia. When a fully compensatory pause follows at the ventricular level anterograde use of an accessory $\mathrm{A}-\mathrm{V}$ pathway during tachycardia is excluded. The observation of a fully compensatory pause without atrial anctivation in between indicates not only a ventricular site of origin of tachycardia, but suggests as pointed out by Josephson et al. (25) a relatively small and protected circuit of ventricular tachycardia. Ventricular capture by supraventricular stimuli can sometimes only occur by giving several atrial premature beats or by pacing the atria at rates faster than the vachycardia rate.

2. Exact wentricular capture (the V-Ve interval being identical to the A-Ac interval) with the same ORS morphology as during tachycardia with advancement of the tachycardia cycle. This observation (fig. 19) is the best way to demonstrate the use of anterograde conduction over an accessory $A-V$ pathway during tachycardia. It indicates that the same pathway used to capture the ventricles by the atrial premature beat is used anterogradely during tachycardia. Exact advancement of the tachycardia cycle indicates absence of decremental conduction properties in the anterograde limb, and participation of the atria in the tachycardia circuit and of the ventricles, thus proving use of an accessory A-V pathway anterogradely.

3. Atrial premature beat does not result in ventricular capture but terminatles tachycardia. This observation excludes a ventricular site of origin of tachycardia, the only exception being bundle branch re-entry tachycardia (26). If a supraventricular site of origin of the arrhythmia has been excluded tachycardia is the result of re-entry in the bundle branch system. When the atrial premature beat terminates the wide QRS tachycardia without being conducted to the bundle of His a ventricular site of origin and bundle branch re-entrant tachycardia are excluded. This observation indicates participation of the atria in the mechanisms of the armythmia. When during tachycardia activation of the His bundle follows the QRS complex, an A.V nodall site of origin of tachycardia with anterograde use of a nodo-ventricular accessory pathway cannot be excluded by this observation allone. 

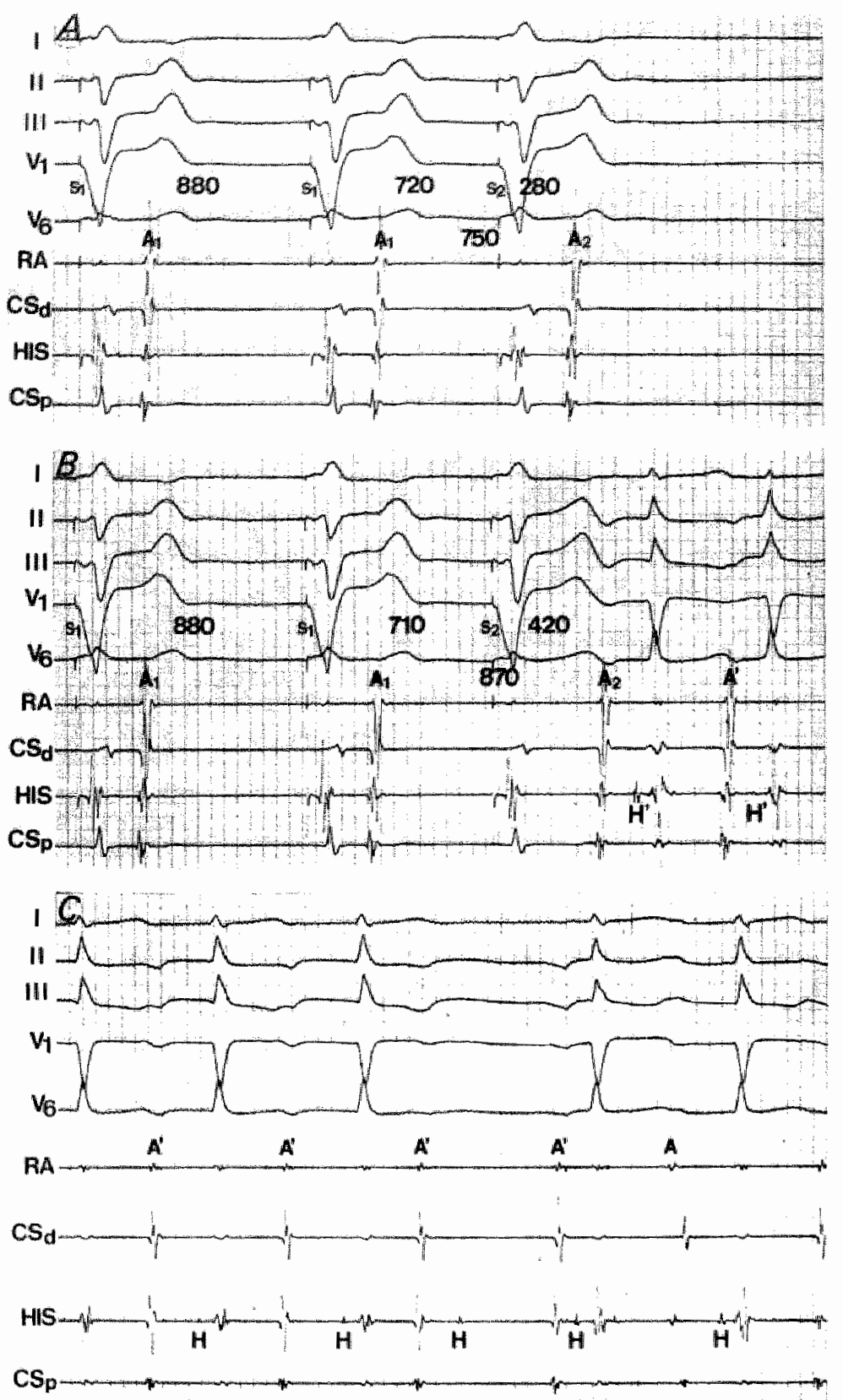

Figute 18

Initiation of a supraventricular tachycardia with a P.R shorter than R.P interval by a ventricular premature beat at the time of a change in conduction from a retrograde fast to a retrograde slow pathway. Following initiation $A-V$ block ocen's not resulting in termination of the arrhythmia. Thesc observations suggest an intra A.V nodal location of the re-entry circuit. 


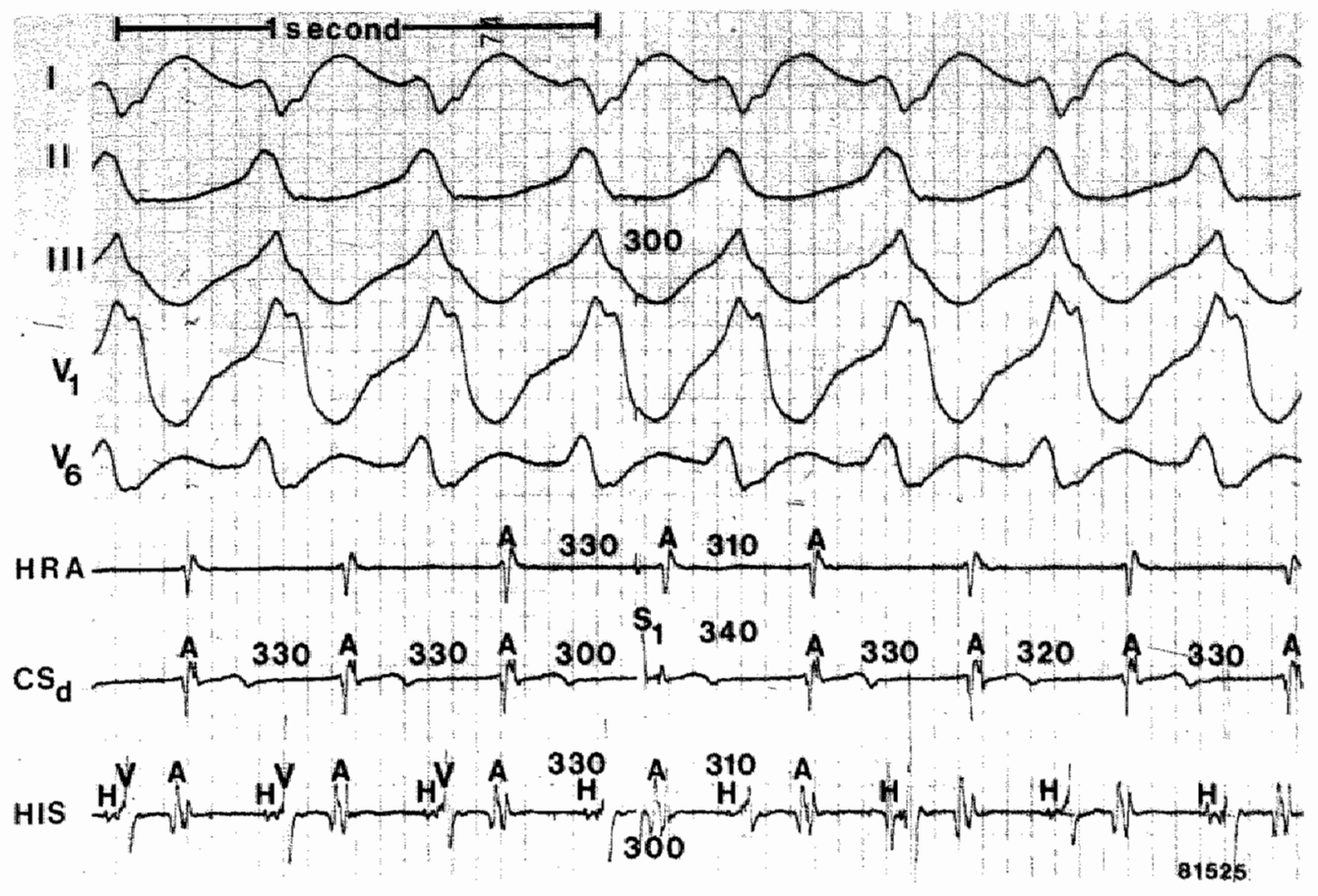

Figure 19

Ventricular capture by an atral premature beat showing the same ORS morphology as charing tachycardia. This capture has the ventricular level the sisme interwal as the coupling interval of the atrial premature beat. The capture is foltowed by shit in subsequent tachycardia cyetes to the left. This observation proves that: a. "The same pathway used to actiwate the ventricles during tachycardia is used during anterograde conduction of the atrial premature beat.

b. ihe atria and ventricles are incorporated in the tachyeardia circuit

c. no decremental conduction occurs in the anterograde pattwaly.

They prove the use during tachycardia of an anterogradely conducting accessory $A-V$ pathway.

4. The atrial premature beat does not result in ventricular capture or termination of tachycardia. but the subsequent tathycardia ORS complex shows delay on block in retrograde condection tos the atria without affectng the ventricular rate of the tachycardia. "This absurvation cxcludes participation of the atria in the mechanisms of lacloycardia.

5. The atrial premature beat fails to modify subsequent atrial and ventricular events. No conclusions can be made from this observation in regard to mechanism or pathway of tachyciadia

In patients with suspected or documented supraventricular tachycardia we start our stimulation study by pacing in the ventricle. We start by pacing in the atria in patients with suspected or documented ventricular tachycardia. The observation of $\mathrm{V}$ - $\mathrm{A}$ dissociation during ventricular pacing makcs a tachycardia based upon re-entry using an accessory A-V pathway or an intranodal tachycardia unlikely and suggests the likelhood of an atrial tachycardia. A long refractory period of the fast retrograde $A-V$ nodal pathway resulting in discontinuous retrograde $A-V$ nodal conduction curves makes initiation of $A-V$ nodal tachycardia of the comnon wariety unlikely during atrial stimulation. As pointed out elsewhere A.V nodal tachycardia may then be initiated after abbreviation of the fast pathway refractory period by atropinc.

Electrophysiologic studies are expensive (3). They may be dangerous in incxperienced hands. Adequate training resulting in understanding of the mechanisms of tachycardias and their expressions during a stimulation study is required before the start of a clinical clectrophysiologic 
program. Well performed electrophysiologic studies are of help in selecting the best therapy for a particular arrhythmia. Poor electrophysiological investigations, however, can result in wrong conclusions, the selection of inadequate therapy and risk for the patient.

\section{Results of programmed electrical stimulation of the heart}

Table I summarizes the results of programmed electrical stimulation of the heart in a series of 440 consecutive patients with supraventricular tachycardia. Only in 3 out of these 440 patients the cxact mechanism of the arrhythmia could not be uncowered. All three patients suffered from $A-V$ junctional supraventricular tachycardia, but the exact pathways could not be determined.

\section{Table I}

Incidence of different types of tachycardiat in 440 patients with electrocardiographically documented regular paroxysmal supraventricular tachycardia (SVT), studied by programmed electrical stimulation of the heart.

\begin{tabular}{lcc}
\hline Type of SVT & Number & Percentage \\
\hline Atrial tachycardia & 58 & 13.1 \\
Atrial flutter & 60 & 13.6 \\
Intranodal tachycardia & 107 & 24.3 \\
Circusmovement tachycardia & & \\
using a concealed accessory & 61 & 13.8 \\
pathway & 3 & 0.6 \\
Unknown mechanism & 151 & 34.3 \\
WPW syndrome & 440 & \\
\end{tabular}

\section{References}

1. Durfer D, Scliow 1., Schoilenburg RM, Wellens HJJ: The role of premature beats in the inatiation and termination of supraventricular tachycardia in the Wolf-Parkinson- White syndrome. Ciretation 1967. 36:64.4. $(12$

2. Wellens Hy. Electrical scimatation of the hear in the study and treatment of tachycardias. Leiden, Stenfert Kroese 1971 .

3. Wellens My: Valuc and limitations of programmed clectrical stimulation of the beant in the study and trowtment of tinchyeardias. Chiculation 1978; 57:845-52.

4. Gallagher JJ, Svenson KH, Kasell JK, et al: Catheter technique for closed chest ablation of the atriow ventriculat conduction system. N. Eng.J. Med. 1982;306:194-200,

5. Gallaghe JN, Pritchet ELC, Benditt DG et al: Now catheter techniques for anatysis of the sequence of rotrogracle atrial activation in man. Eur.J. Cardiol. 1977; 6:1-14.

6. Dassen WRM, Ross D1, Brogada P, Bär t:, Vanagt E, Wellens HJJ: A computer model for the study or cycle lengh alternation during tachyedrdia. Procedings of Computers in Cardiology, 1980; 179-82.

7. Ross DL, Dassen WRM, Vanagt E, Brugadia P, Bär FWHM, Wellens HJJ: Cycle length abternation in circus movement tachycardia using an atrio-ventricular accessory pathwa. Circulation 1982; 65:862-8.

8. Merer AB, Simpson R. Gettes LS, Foster JR: Strength-interval testing to entance ventricular tachycardia induction during clinical electrophysiology study. Am. J. Cardiol. 1982; 49:958 (Abstr.)

9. Vandepol CJ, Furshidi A, Spluman SR, Greenspan A M, Horowitz LN, Josephson ME: Incidence and clinical significance of induced ventricular tachycardia. Am. J Cardiol. 1980; 45:725-31. 
10. Farré J, Ross D, Wiener I, Bår F, Vanagt E, Wellens HIJ: Reciprocal tachycardias using accessory pathways whth long conduction limes. Am. J. Cardiol. 1979:44:1099-109.

11. Brugada $P$, Vanagt EJ, Bär F, Wellens HJJ: Incessant reciprocating atrio ventricular tachycardia. PACE $1980,3.670-7$.

12. Brugada P, Bar F, Vanagt E. J, Friedman PL. Wellens HJJ: Observations in patiends showing A-V junctional ochoes with a P-R shorter than R-Pinterval Am. J. Cardiol. 1981;64:611-22.

13. Wellens HJJ, Durrer D: The role of an accessory atrio-ventriculat pathway in reciprocal dachyeardia. Circulation $1975: 52: 58-72$

14. Weiss J, Brugada P, Roy D, Bär FWHM, Wellens HJJ: Localization of the accessory pathway in tha WPW syndrome from the ventriculo-atrial conduction time of right ventricular apical extrasystoles. ACE. in press.

15. Gallagher JI, Sealy WC: The permanent form of junctional reciprocating tachycardia: further elucidat bun of the underlying mechanism. Eur ICardiol. 8:413, 1978.

16. Denes P, Kehoe P, Rosen KM: Multiple re-entrant tachycardias due to retrograde conduetion of dual atrio ventricular bundles with atrioventricular nodal-like properties. Am J Cardiol, 1979, $44: 498$.

17. Coumel P, Attuel P, Mugica I: Junctional reciprocal tachycardia. The permanent form. In HE Kulbertus (ed): Re-entrant arrhythmias. MTP Press, Lancaster 1977, p. 170.

18. Kerr ChR, Gallagher IJ, German LD: Effect of bundle branch block on ventriculo-atrial intervals during reciprocating tachycardia in patients with accessory atriomentricular pathways. Am. J. Cardiol. 1982, 49,994 (Abstr).

19. Sung RJ, Waxman HL: Physiological shift of retrograde atrio-ventricular nodal owtput mimicking retrograde accessory pathway conduction. Circulation 1979;54-60: Supp II:II-191 (Abstr).

20. Wellens HJJ, Bär F, Farré J, Wiener I, Ross D, Gorgels AP, Vanagt E, Brugada P: Diagnóstico tu inciedencia de vias accesorias ocultas en pacientes con taquicardias paroxisticas de la Unión AV. Rev. Lat. Cardiol. 1980, $3: 60-71$.

21. Spurrell RAJ, Krikler D, Sowton E: Two or more intra A.V nodal pathways in association with cither a lames or Kent extranodal bypass in three patients with paroxysmal supraventricular tachycardha. $\mathrm{Br}_{\mathrm{r}} \mathrm{Heart} \mathrm{J}$. 1973 , 35:113-9.

22. Neuss M, Schlepper M: Unusual re-entry mechanisms in patients with the Wolff-Parkinson-White syndrome.

Br. Meart 1. 1974; $36: 880-6$

23. Mandel WJ, Laks MM, Obayashi K: Afrio-ventricular nodal re-entry in the Woltf-Parkinson-White syndrome. Chest 1975;68:321-6.

24. Josephson ME, Kastor JA: Paroxysmal supraventricular tachycardia. Is the atrium a necessary link? Circulation $1976 ; 54: 430-8$.

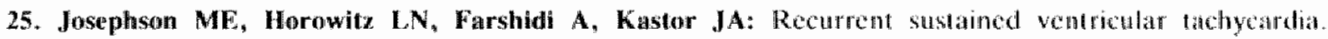
Circulation 1978; $57: 431-40$.

26. Wellens HJJ, Le KI, Durrer D: Further observations on ventricular dachycardia as studiced by electrical stimulation of the heart. Circulation 1974;49:647-53. 
3.

\title{
Atrioventricular nodal tachycardia with and without discontinuous anterograde and retrograde atrioventricular nodal conduction curves: a reappraisal of the dual pathway concept
}

\author{
P.Brugada, E.Vanagt, W.R. Dassen, A.P. Gorgels, F.W.H.M. Bär and H.J.J. Wellens.
}

Deparment of Cardiology, University of Limburg, Annadal Hospial, Manurich, The Nerherlands

KEY WORDS: A-V nodal tachycardia, dual pathways.

To illustrate the complexity of the electrophysiological behaviour of the human atrioventricular (A-V) node two patients suffering from $A$-V nodal wachycardia are described. During tachycardia an A-V nodal slow pathway was used for anterograde conduction. and an $A$-V nodal fast pathway for retrograde conduction. Patient I showed smooth A.V nodal conduction curves in both the amterograde and the retrograde direction. Tachycardia could only be initiated by ventricular premalure beats. No critical delay in wentriculo-atrial conduction time was required for initiation of tachycardia. Patient 2 showed smooth $A-V$ nodal conduction curves at the lowest rate of pacing during atriat and ventricular stimulation. The curves became discontinuous in both directions when the basic drivencycle length was decreased. Tachycardia could only be initiated by atrial premature beats. Ventricular premature beas induced non-sustained A-V nodal reentry that used an A-V nodal fast pathway for anterograde conduction, and an A-V nodal slow pathway for retrograde conduction. Accepting dual pathways in the anterograde and retrograde directions in the $A-V$ node, means that depending upon. their electrophysiological properties a large number of combinations of anterograde and retrograde. conduction are possible. When more than two A-V nodal pathways are present, the number of possible combinations will increase markedly. These considerations are of help in understanding electrophysiological findings in patients with A-V nodal achycardia. They are also useful to explain the importance of autonomic tone and she resuls of drug admimisration in these patients.

Most patients with atrioventricular (A-V) nodal reentrant tachycardia and their tachycardia circuit confined to the A.V node show discontinuous anterograde $\mathrm{A}-\mathrm{V}$ nodal conduction curves during. extrastimulus testing, suggesting the presence of dual $A-V$ nodal pathways ']. In retrograde direction, A-V nodal conduction curves are usually continuous. Only a few examples have been reported of patients with intra $A-V$ nodal reentrant tachycardia showing discontinuous anterograde and retrograde A-V nodal conduction curves, or discontinuous curves solely in the retrograde direction[2]. The initiation of a supraventricular

Received for publication 23 June 1980.

Requesis for reprimes to Hein I. 1. Wellens, Department of Cardiolagy. University of llimburg, Annadal Hospilal. Maastricht. The Netherlands. tachycardia by a single timed ventricular premature beat without apparent increase in the $\mathrm{V}-\mathrm{A}$ conduction time of the premature beat has been considered suggestive of a tachycardia either using an accessory pathway or located in the atrium[-s], The initiation of intra $A-V$ nodal reentrant tachycardia by an atrial premature beat in patients showing continuous anterograde A.V nodall conduction curves has been reported $[0-1]$, but the electrophysiological mechanisms involved have not been explained.

In this articlle, two patients are described in whom an $\mathrm{A}-\mathrm{V}$ nodal reentrant tachycardia utilizing an A.V nodal slow pathway for anterograde conduction, and an A-V nodal fast pathway for retrograde conduction was initiated during the stimulation study. Patient I showed continuous antero. grade and retrograde $\mathrm{A}-\mathrm{V}$ nodal conduction curves, 
and tachyoardia could onlly be iniliated with a sing vervicular premature beat. Paticnt 2 showed continuous anterograde and retrograde A-W conduction curves at the lowest rates of pacing, but the curves becume discontinuous in both directions on increasing the basic pacing rati. The examples wert hosen to illustrate the wide spectrum of electro. physiological behaviour of the A-W node during stimulation studies in pallents with $A-V$ nodal tachycardia.

\section{Patients and methods}

Patienl was a 63 year old male. Nine years prior to the sudy he suffered from an uncomplicated inferior myocardial infarction. Palpitation started four years before our investigation. Sponaneous apisodes of tachycardia were characterized by a narrow ORS complex. without identifable $P$ waves. Oral digoxin in a dose of $0.25 \mathrm{mg} / \mathrm{day}$ did not prewent the arthythmia.

Patient 2 was a 75 year old female. She complatined of palpitations for three years before our study. No lachycardia had been documented clectrocardiographically. Cardiovascular examination revealed no abnormalities. She was receiving no medication.

\section{Electrophysiological studies}

Following informed consent, an electrophysiological study was performed on both patients in the pesting. postabsortive, non-sedaled state. ln patient. 1. digoxin had been discontinued 48 h prior to the inverstgation. Using the femoral approach, cathcters were placed for both stimulation and rocond. ing of intracadiac electrograms, at the right ventricular apex, tricuspid valve ring and high Iateral right aldium. In patient 1, a fourth catheter was placed in the leth atrium va a patent foramen ovalo. Out methods of recording. stimulation and analysis of tracings have been previously described Alter recording of basic condection intervals durimg smus rhythm, the right atrum was paced in pationt I at basic cycte lengths of 665 and 600 ms, and in patient 2 at basic cycle lenghs of $600.545,500,460$ and $430 \mathrm{~ms}$. Refmetory periods were detemined using the extrastimulus technique. Ventriculomatrial $(V-A)$ conduction was studich during pacing of the right ventreular apex using the single test stimulus technique al the sume basic cycle langhs as during atrial stimulation. The eftect of timed atrial and ventricular premature beats was tested during tachycardia.

\section{Definitions}

Conventional definitions were used for refactory periods. An A-V nodal conduction curve was considered to be discontinuous it the $A-V$ nodal conduction time of a premature beat (atrial or vemiricular inereased by $50 \mathrm{~ms}$ or more on increasing the prematurity of the test pulse by 10 ms lal. Diagnosis of $A-V$ nodal tachycardia using anterograde slow and retrograde fast pathway conduction was based upon:

(1) Simultaneous activation of atria and ventricles during lachycardia $\left.{ }^{4}\right]$.

(2) Inability to advance atrial activation by ventricular premature beats given during tachycardia at the time of refractoriness of the bundle of His ${ }^{[40]}$. (3) A similar pattern of atrial activation during lachycardia and following $V$-A conduction during ventricular pacing.

\section{Results}

\section{PATIENT I}

His bundle recordings during sinus rhythm frate 75 beats min) revealed an $A-H$ interval of $80 \mathrm{~ms}$. and a prolonged H- $V$ interval of $65 \mathrm{~ms}$.

Single atrial test stimulation at a basic cycle length of 665 and 600 mus showed a continuous $A_{1} A_{2} / H_{1} H_{2}$ curve with an $A \cdot V$ nodal effective refractory pertod of 310 ms fing. 1). Neither echo beats nor tachyodia could be induced.

Ventricular stimulation at a basic cycle length of 665 mis revealed a continuous $V_{1} V, A_{1} A_{2}$ curwe up to a $\mathrm{V}_{1} \mathrm{~V}$, interval of $310 \mathrm{~ms}$. Veniricular premature beats given at shorter $V, V$ intervals showed an increase in $\mathrm{V}_{2} \mathrm{~A}$, intervals. As shown in Fig. 2 this increase in $V-A$ conduction lime was subnodally localed at very premature beat intervals, and it was assumed that the same site of detay accounted for the changes in $\mathrm{V}$-A conduction time of ventriculan premature beals given later in distole. Withou relation to the $V-A$ conduction lime of the ventricular test stimulus ( $\left.V_{2}\right)$, tachycardia could be initiated by premature beats given with $\mathrm{V}_{1} \mathrm{~V}_{2}$ intervals ranging from 460 to $250 \mathrm{~ms}$, bul only if the resulting $A_{1} A_{\text {, interval ranged from } 46010}$ $360 \mathrm{~ms}$. A premature beal given with a $V_{1} V_{2}$ interwal of $310 \mathrm{~ms}$ did not induce tachycardia when the $A_{1} A_{2}$ interval was 350 ms, but only when the $A_{1} A_{2}$ 
(a)
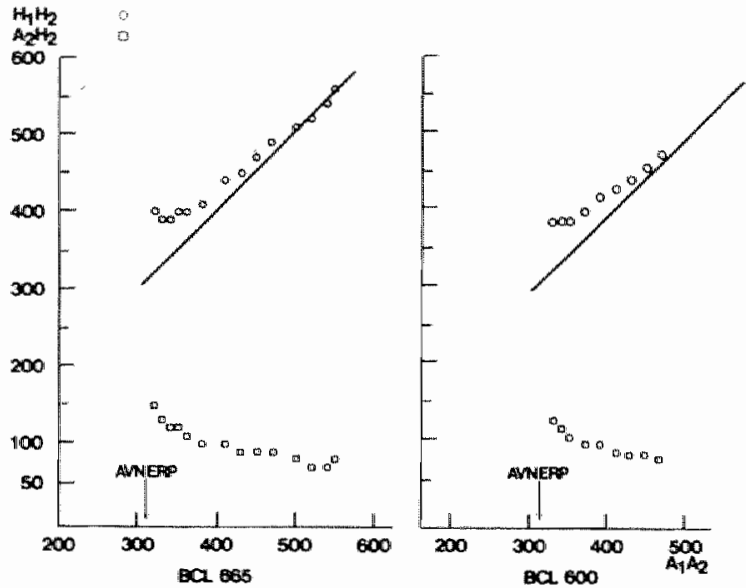

(b)
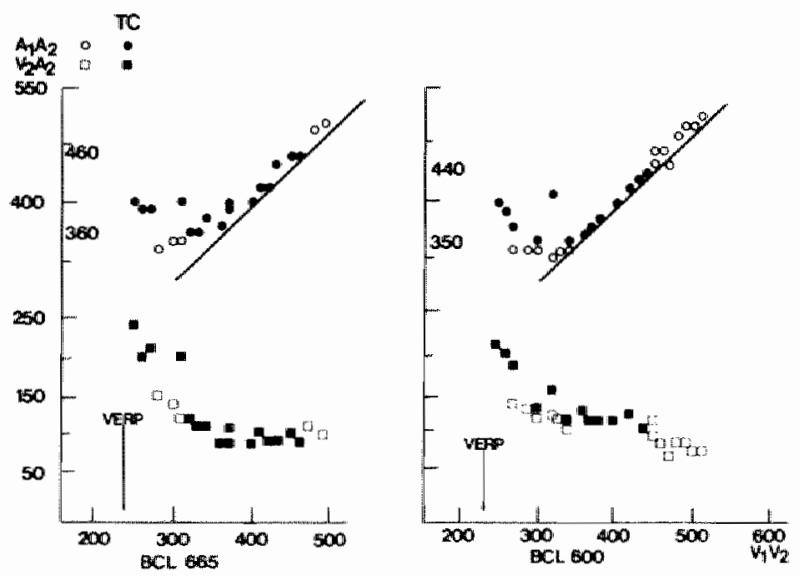

Fighre / Case 1. (a) Graphs showing the rolation between the $A_{1} A_{2}$ and the $H_{1} H_{2}$ and $A_{2} H_{2}$ interwals during atrial pacing with basic cycle langths off 665 and 600 ms. As shown the curves were continuous and no echo beats or tacthycardia were induced (b) The relation bet ween the $V_{1} V_{2}$ and the $A_{1} A_{2}$ and $V_{2} V_{2}$ intervals during ventricular pacing with basic cycle lengths of 665 and $600 \mathrm{~ms}$. Tachycardia (TC) was unitiated without relation to the ventriculo-atrial conduction time of $V_{2}$. Initiation of tachycardia was related to a critical range of $A_{1} A_{2}$ intervals. See text.

interval measured $400 \mathrm{~ms}$. Similar observations were made during ventricular extrastimulus testing at a basic cycle length of $600 \mathrm{~ms}$ (Fig. 1).

During tachycardia atria and ventricles were simultaneously activated (Fig. 2). Onset of atrial activation was forst recorded in the His bundle lead and preceded wentricular activation. Subsequent atrial activation occurred in the proximal left atrial (LAp), the distal left at rial (LAd), and the high right atrial (HRA) recording. The $R-R$ interval during tachycardia ranged from $4 \| 0$ to 480 ms. One single ventricular premature beat and one single HRA 

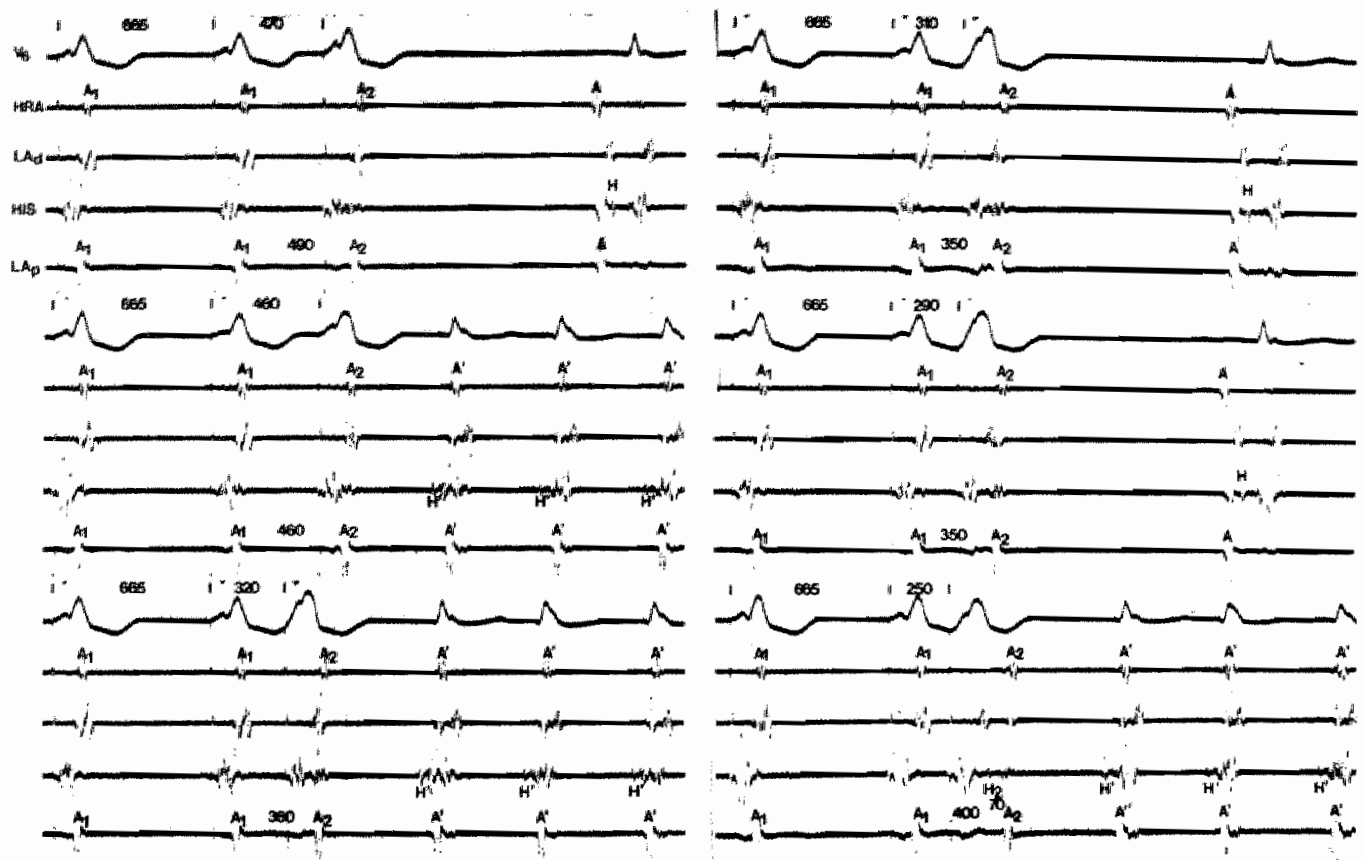

Figure 2 Case 1. Six different ventricular premature beat intervals are shown during pacing of the right wentricle with a basic cycle length of $665 \mathrm{~ms}$. Tachycardia is initiated withoult apparent relation to the ventriculoatrial conduction time of $V_{2}$, when the $A_{1} A_{2}$ interval ranges from 36010460 ms. Note that with very early premat ure beats a retrograde $H$ is potential is recorded preceding atrial activation. Lead $V_{n}$, a high right atrial (HRA) lead, a distal left atrial (LAd) lead, a His bundle lead, and a proximal left atrial (LAp) lead were recorded simultaneously.

premature beat could reproducibly terminate the tachycardia.

\section{PATIENT 2}

His bundle recordings during sinus thythm (rate 80 beats $/ \mathrm{min}$ ) revealed an A.H interval of $75 \mathrm{~ms}$, and an $\mathrm{H} \cdot \mathrm{V}$ interval of $40 \mathrm{~ms}$.

Single atrial test stimulation at basic cycle lengths of 600 and $545 \mathrm{~ms}$ showed continuous anterograde $A-V$ nodal conduction curves, with $A-V$ nodal conduction occurring up to the refractory period of the right atrium (Fig. 3). During pacing with basic cycle lengths of 500,460 and $430 \mathrm{~ms}$ however the $A-V$ nodal conduction curves became discontinuous, with an $A \cdot V$ nodal effective refractory period of the fast pathway of 280,290 and $300 \mathrm{~ms}$ respectively. A-V nodal conduction over the slow pathway occurred up to the refractory period of the right atrium. Tachycardia could only be initiated by a single atrial premature beat during pacing of the right atrium at a basic cycle length of $430 \mathrm{~ms}$ (Fig. 4 ).

Ventricular stimulation at a basic cycle length of $600 \mathrm{~ms}$ revealed a continuous retrograde conduction curve up to the refractory period of the right ventricle (Fig. 3). Decreasing the basic cycle length resulted in discontinuous retrograde conduction curves, with the induction of A.V nodal echo beats. As shown in the His bundle recordings, the discontinuity in the retrograde conduction curve was the resuit of retrograde $A-V$ nodal conduction over the slow pathway (Fig. 4). A.V nodal echo beats following a ventricular test stimulus used the $A-V$ nodal slow pathway for retrograde conduction and the A-V nodal fast pathway for anterograde conduction. No sustained tachycardia could be initiated.

During the tachycardia initiated by an atrial premature beat atria and ventricles were simultaneously activated (Fig. 4). The onsel of atrial activation was first recorded in the His bundle lead, 
(o)

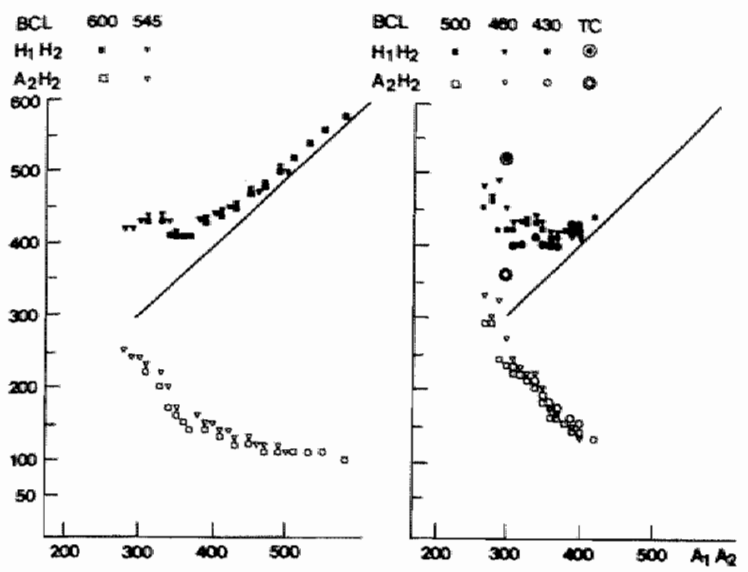

(b)
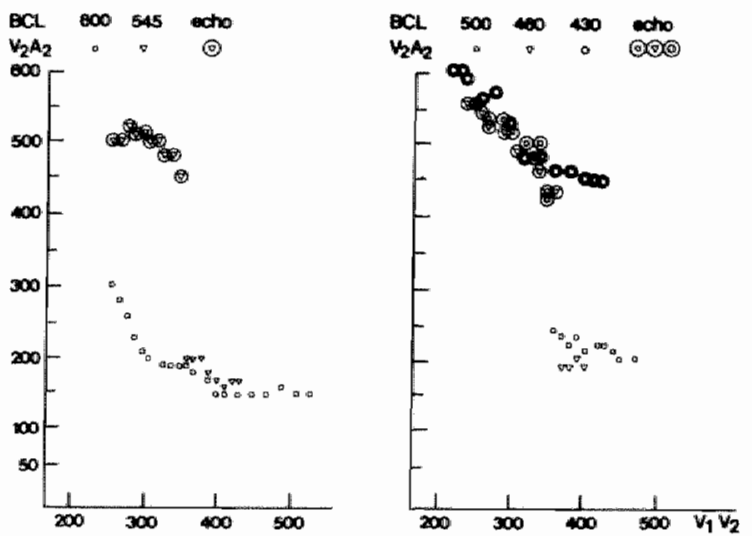

Figure 3 Case 2. (a) Graphs sthowing the relation between the $A_{9} A_{2}$ and the $\mathrm{H}_{1} \mathrm{H}_{2}$ and $\mathrm{A}_{2} \mathrm{H}_{2}$ intervals during atrial pacing with basic cycle lengths of $600,545,500,460$ and $430 \mathrm{~ms}$. The curves were continuous: at basic cycle lengths of 600 and $545 \mathrm{~ms}$, but became discontinuous at shorter basic cycle lengths. Tachycardia (TC) could only be initiated by an atrial premature beat given after $300 \mathrm{~ms}$ during pacing with a basic cycle length of 430 ms. (b) The relation between the $V_{1} V_{2}$ intervals during ventricular pacing at the same basic cycle lengths as during atrial stimulation. At a basic cycle length of 600 ms the curves were continuous. They became discontinuous on decreasing the basic cycle length, and were accompanied by initiation of echo beats. Note the increase in the width of the echo zone on decreasing the basic cycle length. The lower limit was determined by the refractory period of the right ventricle, and the upper limit by the retrograde refractory period of the fast pathway, which lengthened on decreasing the basic cycle length. 


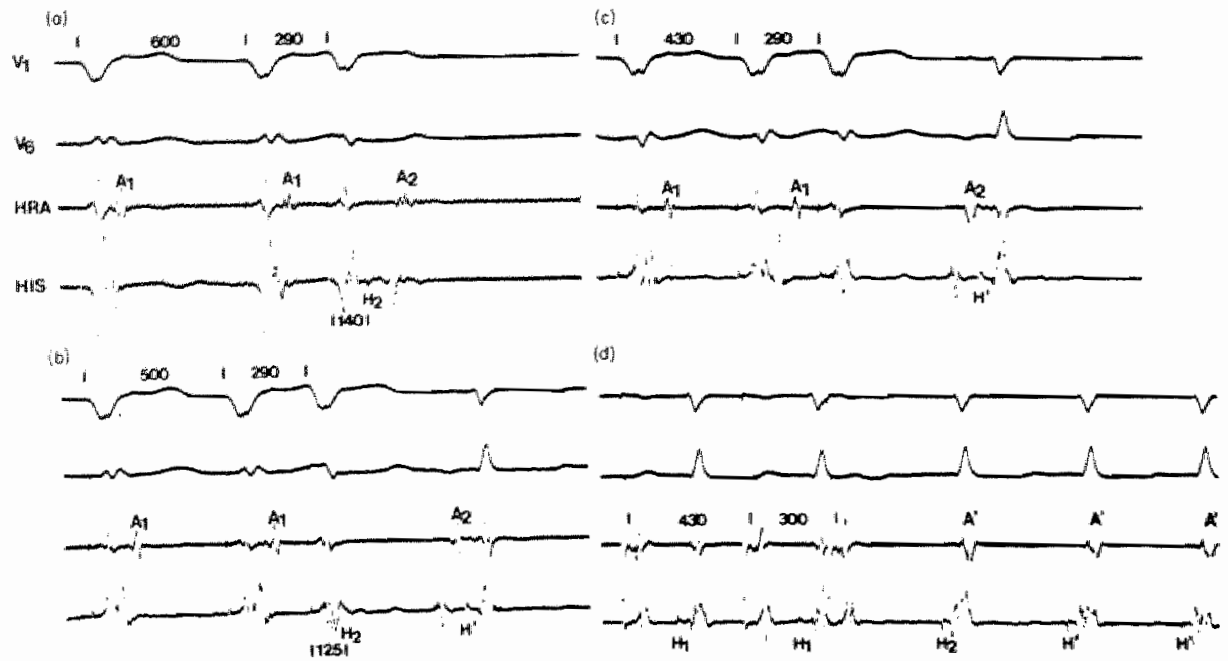

Figher 4 Case 2. (a), (b) and (c) Show a ventricular premathe beat given alter 290 ms during ventricular paycing with a basic cyele length of 600,500 and 430 mas respectively. Note that the $V_{2} F_{2}$ interval becomes shorter on decreasing the basic cycle length and is hidden into the QRS complex at a basic cycle length of 430 ms (c). In (a) $V_{z}$ is retrogradely condescted over the $A$. $V$ nodal fast pathway, and no echo beat is induced. In (b) and (c) $V_{2}$ is retrogradiely conducted over the slow pathway and an $A-V$ nodal wo ho beat appears showing anterograde conduction over the last pathway. (d) Shows the initiation of A-V nodal tachycardia by an atrial premature beat given after $300 \mathrm{~ms}$ during atral slimulation at a basic wste length of $430 \mathrm{~ms}$. During tachycardia there is anterograde conduction over the slow pathway and retrograde conduction over the fast pathway.

and preeded the onset of ventricular activation. The $\mathbf{R}-\mathrm{R}$ interval during tachycardia ranged from $37010410 \mathrm{~ms}$. Tachycardia could reproducibly be terminated by a single atrial or ventricular premature thest.

\section{Diseussion}

The intiation of a supraventricular tachycardia by a single ventricular premature beat in pationt 1 . without apparent increase in the $V$ - $A$ conduction timo has been considered suggestive that the tachycardia is cother using an accessory pathway or is located in the arruma 4 . In this patient the idemtiad seguence of atrat activation during ventricular pacing and tachyourdia, and the mability 60 preaxcite the atria when the $H$ is bunde was retractory, argues ingainst the presence of an accessory pallumay.

lin 1975 one of usli repored a case of supra. ventriculat tachyeardia intiated by a single venmeula premature beat. No critical increase in the $V$ A conduction lime of the ventricular premalure beat was required to initiate the tachycardia. When the $A_{1} A_{2}$, interval following $V_{1} V_{2}$ reached a certain value, lachycardia was initiated. The initiation of tachycardia without an increase in $V . A$ conduction time was considered suggestive of an intra-atrial location of the tachycardia circuit. A limit of $A_{1} A_{2}$ intervals below which no tachycardia could be induced was not present in that patient. Similarly our patient 1 showed a critical range of A, A, intervals for the initiation of tachycardia. Now also a lower limit was found of $\mathrm{A}_{1}$ intervals which were not followed by tachycardiat. The most likely explanation for our patient from 1975 and our present patient $I$ is an A-V nodal tachycardia in the presence of dua! A-V nodal pathways with the last pathway having the shortest ollective refactory period in both the anterograde and the retrograde difection. Under these circumstances, discontinuities in the anterograde and retrograde A-V nodal conduction curve will not be found during arrial and ventricular pacing. The presence of dual A-V nodal pathways can only indirectly be dic monstrated by inducing A-V nodal echoes or 
tachycardia during the stimulation study. If with continuous anterograde and retrograde A.V nodal conduction curves, the effective refractory period of the slow pathway in the anterograde direction is shorter than the retrograde effective refractory period, only critically limed and conducted ventricular premature beats will be able to induce A-V nodal echoes or tachycardia, as shown in Fig. 5. The relation between the refractory periods of the iwo A-V nodal pathways and the mode of anterograde and retrograde $A-V$ nodal conduction. explains the absence of dual pathway curves during anterograde and retrograde $A-V$ nodal conduction. and the intiation of tachycardia without change in the $V$-A conduction time:

In patient 2 decreasing the basic paced cycle length brought out discontinuities in the $\mathrm{A}-\mathrm{V}$ nodlal conduction curve that were not apparent at slower rates of pacing. Factors intluencing demonstration of dual A-V nodal pathways during atrial stimufation are the refactory period of the atrium and the properties of the $\mathrm{A}-\mathrm{V}$ node itselt. Both are known to be related to the basic cyele lengthlu- -4 t. In our patient 2, the effective refractory period of the fast pathway in the anterograde dircenion became longer on shortening the basio cycle length. Also during ventricular stimulation the $\mathrm{A}-\mathrm{V}$ nodal properties are expected to change with changes in basic cycle length. In patient 2 , the retrograde enective refractory period of the fast pathway lengthened on decreasing the basic cycle length. When the ventricle was paced at different rates the His bundle electrogram of the basic beats wats hidden in the QRS complex, so that plotting of the $v_{1} v_{2}$ and $\mathrm{H}_{1} \mathrm{H}_{2}$ interwals was not possible. However, als shown in Fig. 4. when the same $V_{1} V_{2}$ imterval was studied at different basie cycle longths, the $\mathrm{V}_{2} \mathrm{H}_{2}$ interval shortened on decreasing the cycle length of basic pacing. Figure 4 shows how depending upon the basic cycle length subnodal delay of $V$, can lead to failure to demonstrate discontimuous retrograde A-V nodal conduction curves. If illustrates that the

$\mathrm{A}_{2}$

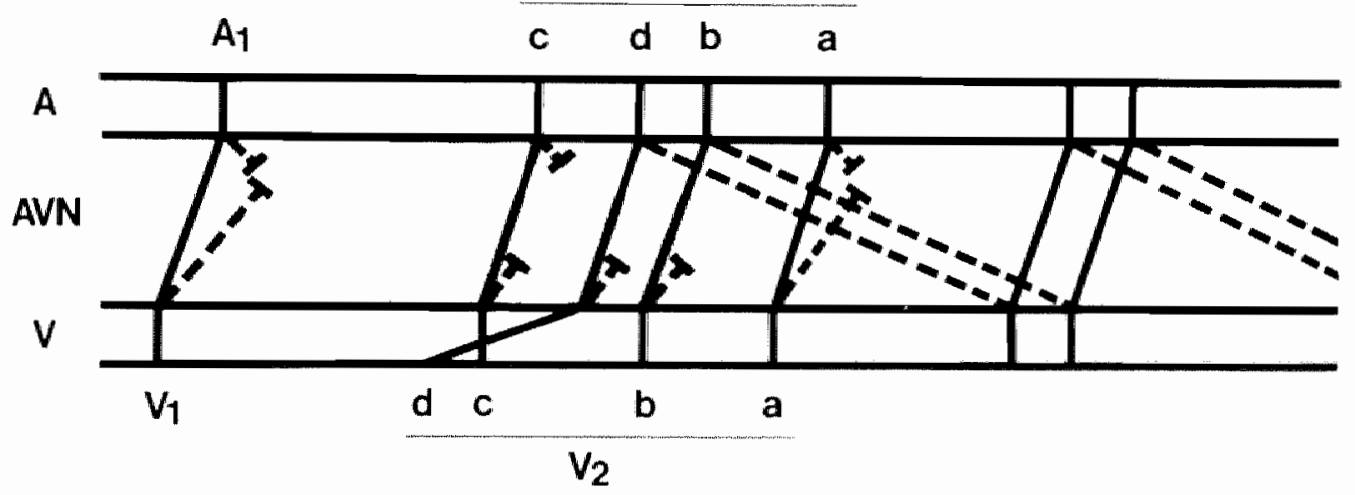

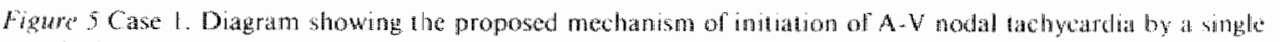
ventricular premature beal. $A$, atrum. AVN, atroventriculat node; V. ventricte: $V, A_{1}$. last basic driven

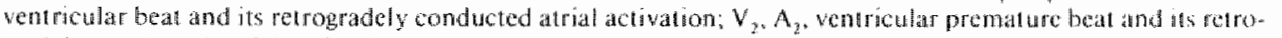
gradely conducted atrial activation. $a, b, c$ and $d$ are different degreas of prematurity of $W_{2}$. Top dashed anca = anterograde eflective refractory period of the slow pathwa. Botlom dashed area = retrograde affective refractory period of the slow pathway. During basic pacing. verntriculo-atral conduction occurs over the A-V rodal fast pathway (-). This mpulse reenters the A-V nodal slow pathway (ow- and collides with the impulse retrogradely conducted over the slow path way. A late $V_{2}$, a is retrogradely conducted smilar to the basic beat. and lachycardia is not initiaded. A more premature $V_{2}, b_{0}$ is retrogradely conducted to the atrial level over the fat pathway but blocked netrogradely in the slow pathway. Now the impulse rectitering the A.V nodal slow pathway is able to traverse the slow pathway and tachycardia is intiated. A more premature $V_{2}$, $c$, will be conducted lo the atrium over the fast pathway, and blocked retrogradely in the slow pathway. The recntering impulse, however. finds the slow pathway refractory in anterograde direction and no tachycardia will be initiated. A wery premat une $V_{2}, d$ is retrogradely conducted to the atrium with subnodal delaty. The later time of arrival at the distal $A$. W node will permit rhe same sequence of events as described for a premature beat given after interwal b. Note that the tachycardia uses the A.W nodal last pathway retrogradely and the A-V nodal slow pathway anterogradely. 
late arrival of the impulse at the distal A.V node will result in am inability to attain retrograde $\mathrm{H}_{1} \mathrm{H}_{2}$ intervals short enough to reach the refractory period of the retrograde fast pathway. It stresses the necessity to use ventricular pacing at high rates to expose dual retrograde A.V nodal pathways.

If one accepts the concept of the presence of $t$ wo different pathways in anterograde and retrograde directions, a large combination of possibilities can theoretically exist depending on the electrophysiological properties of these pathways. Table I shows that at least six combinations are possible showing discontinuous conduction curves in both anterograde and retrograde direction. There are at least six other possible combinations with continuous curves in both anterograde and retrograde direc. tion. This illustrates the complexity of the A-V node, which is further complicated by the possiblity that a certain combination of electrophysiological properties of the A-V nodal pathways may change into another depending upon autonomic tone, basic pacing rate, drugs, etc. The ability to demonstrate dual A-V nodal pathways seems also related to the stamina of the investigator! Using several basic cycle lengths and different atrial stimulation sites will increase the chance of showing the presence of dual pathways $[\mid s]$. As demonstrated in our patient 2. subnodal delay during ventricular pacing may

Table? Theorical approach to the possible combinarons of dwat at wedal pathwaks. The cambinations are made by changing the relation in duration of the effective wastacery periods of the wo pachwas in the amevograde and retrograde directions

\begin{tabular}{|c|c|c|c|}
\hline$A B C D+H$ & $B A C D+$ & $C A B D+4+$ & $D A B C$ \\
\hline$A B D C+\infty$ & $B A D C+$ & $\mathrm{CADB}+4$ & $\mathrm{DACB}+$ \\
\hline$A \subset B D+++$ & $A C A D+$ & $C B A D+$ & $D B A C+$ \\
\hline$\triangle C D B+4$ & $B C D A+$ & $C B D A+$ & $\mathrm{DBCA}+$ \\
\hline$A D C B++$ & $B D A C+$ & CDAB $+\cdots+4$ & $D C A B+4$ \\
\hline$A D B C++$ & $\mathrm{BDCA}+$ & $\mathrm{CDBA}+$ & $\mathrm{DCBA}+$ \\
\hline
\end{tabular}

* Discontinuous A.V nodal conduction curves in both anterograde and retrograde direction; +4 discontmous A- $V$ nodal conduction curves only anterogradely: + , discontinuows $A$. W nodal conduction curves only retrom gradely: +4 , continuous $A-V$ nodal conduction curves in both anterograde and reirograde direction. A. AnteroBrade effective refactory period of the fast pathway; $B$. anterograde effective refractory period of the sllow path. wa: $C$, retrograde eftective refractory period of the last pathway; $D$, retrograde effective refractory period of the slow pathway. In each column the duration of the four effective refractory periods are given. The duration lengthens going from lent to right. result in failure to prove the presence of two retrograde pathways. As shown, this subnodal delay can be avercome by increasing the basic pacing rate during ventricular stimulation. We have selected our two examples to show that in some patients with A-V nodal tachycardia (as in patient 1 ) dual A-W nodal pathways can only be demonstrated indirectly, while in otbers they are readily apparent both during atrial and ventricular pacing (patient 2). The concept that pathways with different electrophysiological properties are present in the $A \cdot V$ node is supported by obserwations from animal studies[10!. The animal studies suggest that acceptance of a two pathway concept might be an oversimplification. Availability of several A.V nodal pathways in anterograde and retrograde direction makes the theoretical number of possible combinations for reentry in the $A-V$ node almost. infinite. We believe that this complex situation may account for the differences in findings between different groups of investigators $11,2,6,8,13,4,4,-20 !$. It also helps in understanding the importance of changes in autonomic tone for initiation of A-V nodal tachycardia $1,2,4,21,2\}$, and it might explain some of the sometimes conflicting results following drug administration $[1,6,7,23-35]$.

\section{References}

11] Rosen KM, Denes P. Wu D. Dhingra RC. Electrophysiological diagnosis and manifestation of dual A. $V$ nodal pathways. In: Wellens HJ, Lie KI, Jense MJ, eds. The conduction system of the heart Leiden: HE Stenfert Kroese BV, 1976:453-66.

(2) Wu D. Denes P. Amai-y-Leon F. Wyndham CRC. Dhingra $\mathbb{R}$. Rosen KM. An unustal variely of atrioventricular nodal reentry due to retrograde dual atrioventricular todal pathways. Circulation 1977 . 56: $50-9$.

[3] Wellens HJJ. Unusual examples of supraventricular reentrant tachycardias. Circulation 1975: 51 : $997-1002$.

(4) Wellens HJJ, Durrer D. The role of an accessory alrioventricular pathway in texprocal tachycardia. Cinculation $1975 ; 52: 58-72$.

(5) Wellens HJJ Bär FW, Farre $J^{*}$ al Diagnosis and incidence of concealed accessory pathways in patients suffering from paroxysmal A-V junctional (anclyycardia. Rev Lat Cardiol 1980 (in press).

161 Wu D. Wyndham C. Amat-y-Leon $F$. Denes $P$. Dhinga $R$, Rosen KM. The effects of ouabain on induction of atrioventricular modal reentrant paroxysmal supraventrienfar tachycardia. Circulation $1975 ; 52: 201-7$

[7] Wellens HJJ Tan SL. Bär FWH, Düren DR, Lie KI. Dohmen HM. Effect of verapamil studied by programmed electrical stimularion of the heart in patients with paroxysmal reentrant supravestricular lachycardia. Br Heart $1977: 39: 1058-66$. 
18] Akhtar M, Damato AN, Ruskin $\mathbb{N}$, et al Anterograde and retrograde conduction characteristics in three pattems of paroxysmal atrioventricular junctional reentrant tachycardia. Am Heart J 1978; 95 $22-42$.

[9] Ross D. Farre J, Bär FWHM, ey al Comprehensive clinical electrophysiological studies in the investigation of documented or suspected tachycardias. Circulation $1980 ; 61: 1010-6$.

[10] Wu D. Denes P, Wyndham C, Amal-y-Leon F, Dhingra RC. Rosen KM. Demonstration of dual atrioventricular nodal pathways utilizing a ventricular extrastimulus in patients with atrioventricular nodal reentrant paroxysmal supraventricular tachy. cardia. Circulation 1975; 52: 789-98.

[11] Cagin NA, Kunstad D, Wolfush P, Levit B. The infuence of heart rate on the refractory period of the atrium and $A-V$ conducting system. Am Heart I $1973 ; 85: 358-66$.

[12] Denes P, Wu D, Dhingra $R$, Pietras RJ, Rosen KM. The effects of cycle length on cardiac refractory periods in man. Circulation, $1974 ; 49: 32-41$.

[113] Denes $P$, Wu D, Dhingra R, Amat-y-Leon $F$, Wyndham $C$, Rosen KM. Dual atriowentricular nodal pathways. A common electrophysiological response. Br Heart J 1975; 37: 1069 -76.

[14] Neuss H, Schlepper M, Spies HF, De Mey CH. Effects of heart rate and atropine on 'dual AV conduction'. Br Heart J 1975; 37: 1216-27.

[15] Ross D, Farre J, Wiener I, Bär $F$, Vanagt $\mathbb{E}$. Wellens H. Comparison of right $v$ coronary sinus stimulation in $A V$ nodal reentry. Circulation 1979;60:63.

[16] Janse M], van Capelle FIL, Anderson RH, Touboul $P$. Billette J. Electrophysiology and structure of the atrioventricular node of the isolated rabbil heart. ln:
Wellens HJJ, Lie KI, Janse MJ, eds. The conduction system of the Heart. Leiden: HE Stenfert Kroese BV. $1976: 296-315$

[17] Touboul P. Huerta F, Porte J, Delahaye JP. Reeiprocal rhythm in patients with normal electrocardio. gram: evidence for dual conduction pathways. Am Heart J 1976;91: 3-10.

[18] Denes P. Wu D, Amat-y-Leon $F$, Dhingra $R$. Wyndham CR, Rosen KM. The deteminants of atrioventricular nodal reentry with premature atrial stimulation in patients with dual A.V nodal pathways. Circulation $1977 ; 56: 253-9$.

[19] Pritchet ELC. Gallagher JJ, Wallace AG. Reentry within the atrioventricular node in man: a reassess. ment. Eur J Cardiol 1978: 6/6:437-47.

[20] Akhtar M. Paroxysmal atrioventricular nodal rentrant tachycardia. In: Narula OS. ed. Cardiac arthythmias. Baltmore: The Williams and Wilkins Co., 1979:294-317.

[21] Akhtar M., Danato AN, Batsford WP, er al Induction of atrioventriculag nodal reencrant tachycarda after atropine. Am J Cardiol 1975; 36: 286-93.

[22] Wu D, Demes $P$, Bauerveind $R_{\text {, Dhingra }} R$. Wyndham C, Rasen KM. Eflects of atropine on induction and maimenance of atrioventriculat nodal reentrant tachycardha. Circulation 1979; 59:779-88.

[23] Wu D, Denes P, Dhingra $R$, Khan A, Rosen KM. The effects of propanolol on induction of A-V nodal reentrant tachycardia. Circulation 1974:50:665-7.

[24] Wellens HJJ, Duren DR, Liem KL, Lie KI. Enect of digitalis in pacients with paroxysmal arrioventricular nodal achycandia. Circulation 1975:52:779-88.

[25] Wu D, Denes P. Bauernfeind $\mathbb{R}$. Amal 4 -Leon $F$, Rosen $K M$. Efrects of procainamide on A-V nodal reentrant paroxysmal tachycardia. Circulation 1978 , $57: 1171-9$. 


\title{
Observations on Spontaneous Termination of Atrioventricular
} Nodal Reentrant Tachycardia

\author{
Pedro Brugada, MD; David Ross, FRACP*; Frits W.H.M. Bär, MD; Willem R.M. Dassen, \\ PhD; Hein J.J. Wellens, MD, FACC.
}

Moastricht "The Netherlands.

From the Department of Cardiology, Univer sity of Limburg. Annadal Hospital, Maastricht. The Notharlands. Manuscript meceiwed: August 13 , 1980; rewised manuscript recelved Octobar 22 . 1980, accepted Ociober 24, 1980.

1" Over seas clinical fellow of the Nationall theart Foumdation of Ausiliatia, Mvelbourne, Australia.

Address for reprints: thein b. W. Wellens. hat Department of Candioliogy. Uniwersity of Limburg. Annadal Hospital, Masitrich, The Netherlands.
Unusual mechanisms of spontaneous termination of atrioventricular (A-V) nodal reentrant tachycardia were observed in two patients during programmed electrical stimulation of the heart. In both patients the mechanism of termination was based on the use of another reentrant pathway than the one used during tachycardia. This pathway was localed extranodally in one pattent and intiranodally in the other. The observations IIlustrate some of the complexilties of reentry in the human heart and how they can play a role in spontaneous vermination of $A \cdot V$ nodal tachycardia.

Observations in the animal heart ${ }^{12}$ and data from programmed electrical stimulation in the human heart ${ }^{3,4}$ support reentry as the nost common mechanism for atrioventricular (A-V) nodal tachycardia. Reentry re. quires the presence of two interconnected pathways having different electrophysiologic properties. Termination of reentry occurs when refractory tissue hal ts the circulating impulse somewhere in the reentrant pathways. In this study we report observations on sponteneous temi. nation of tachycardia in two patients with $A-V$ nodal tachycardia, em. phasizing how a third pathway that is connected to the reentry circuit can result in refractoriness in the reentry circuit and termination of the arrhythmia.

\section{Methods}

Patient 1 was a 20 year ofd man with $A$ V nodal tachycardio at a rate of $200 /$ min. Patient. 2 was a 70 year wid man with $A$. V modal tachycardia at an mat

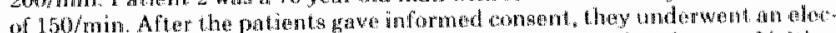

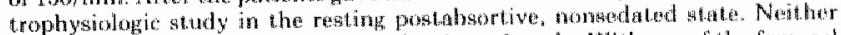
poient was receivin medication at the time of etudy. Wib ase of the fomotal approach, catheters were placed for buth stimulation and recording of intracardiac atectrograms in the apex of the right wentricks, the bundle of His region,

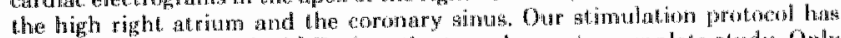

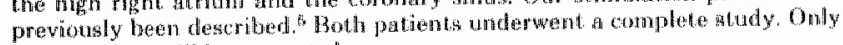
relevant data will be presented.

Criteria for the diagnosis of A-V nodul reontrant tachycarding? The di.

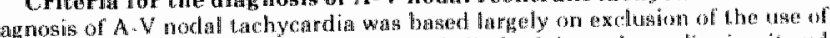

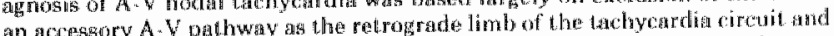

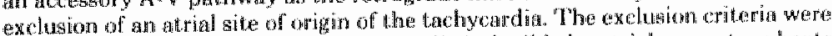
as follows: (1) Supraventricular tackycardia ind ucible by atrial premat re beats as follows: (1) Supraventricular tackycardia ind ucible by at riat premature beats

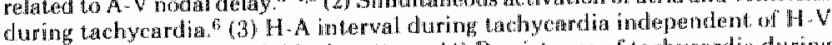

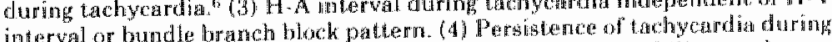
A.V block distal to the bundle of His area (Patient 1). (5) Inobility to adwance A. $V$ bock distal to the bunde of His area (Pation

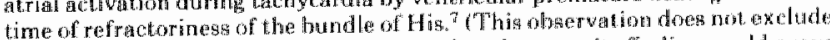

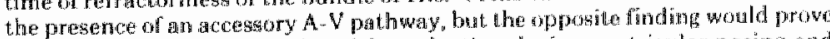
is presence.") (6) Ventriculoatrial conduction durbug ventrieular pacing and its presence. and subnodal delay of verntricular premefure beats." 77 similar atrial activation 


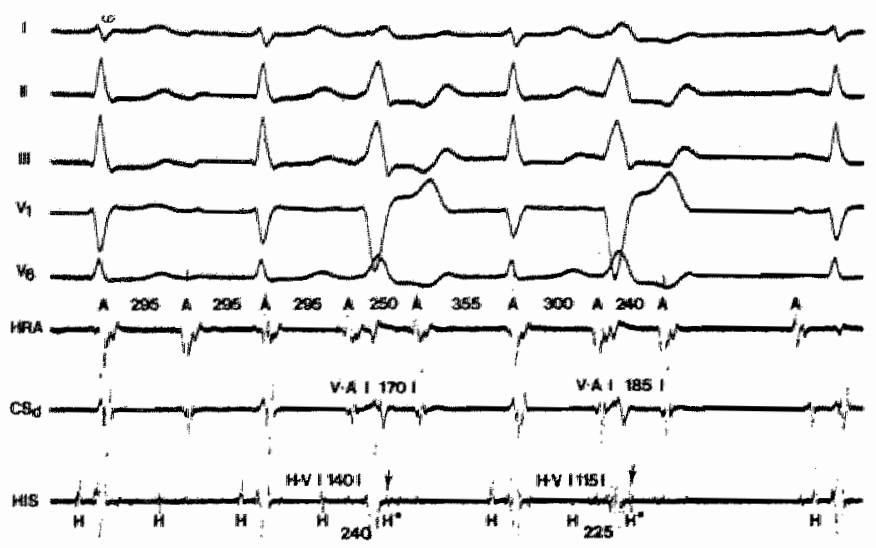

IFHGURE 1. Casia 1. Atriowantricular (A-Vh modal tachycardia siginally sthowing 2 : 1 block ofistal to

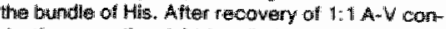

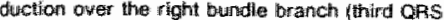
complex. with a left bundle branch block config wation) subsequent atral atcitwation is advancedi. When this patien in repeated ifith OfS complex) tachycardla is ferminated Indicalled are the tactsycardiug cycle liength in ms, the H-W interwat prexceding the wichemed ORS romplexes and the $V$-A interwal Hollowing these witumed CRS complexes as measured in the distal coronary sinus (CSd) Head for clarty Arrown point to possible retragrade His bundle potenitials labeled H" . Sele text and Figure 2 for explanation. Leads I. ili, ill, $V_{3 i}$ and $V_{6}$ ware sinultaneously recorded with a high right atrial (HAA), a distal cononary silnus and a Hils bundle electrogram. pattern during tachycardia and after retrograde conduction during ventricular pacing, saggesting that in both circumstances the same pathway usased for retrograrte conduc. thion.

Contentional definitions tovere used for refractory periods. "The A.V nodal conduction curve was considered discontintots if increasing the prematurity of the test pulse fatrial or vestricular) by 10 ms realted in a sudden increase in A.V nodal condaction time by 50 ms or more. This sudden unexpected increase in $\mathrm{A}-\mathrm{V}$ nodst teonduction time of a premature beat. suggests a shift in conduction from a fast to a slow A.V nod al pathway. $4,-8,7$

\section{Results}

Patient 1: Termination of A-V nodal tachycardia by bundle branch reentry: A.V nodal tachycardia with a cycle length of $245 \mathrm{~m}$ originally showed $2: 1$ block distal to the bund le of $H$ is (Fig. 1 ). During recovery of $1: 1 \mathrm{~A}-\mathrm{V}$ condaction the first QRS complex shows a prolonged H.V interval (140 mag) and a complete left bundle branch block configuration. "This QRS complex followed by atrial activation with the

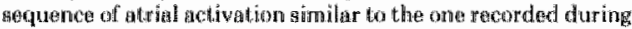

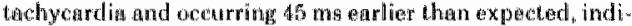
cating that the atrinl complex in not the regult of regular impalse formation during tachycardia. The fifth QRS complex during tachycardia agoin shows a left bundle branch block patterm, but with an $\mathrm{H}$. V interwal of $115 \mathrm{~ms}$. This QRS con. plex is followed by atrial activation occurring earlier than expected. After this atrinel complex the tachycardiaterminates.

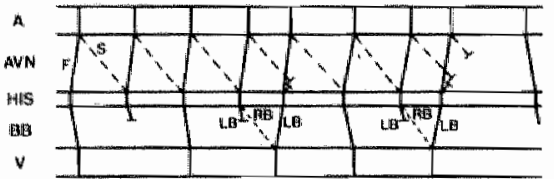

Ficuat 2. Case 1. Diekgam showing the proposed mechanism of terminalion of tachycardita in Figure 1. $A=$ atrium: $A$ VN $=$ atrilovent

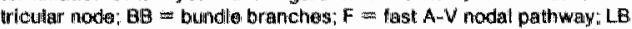
$=$ left bundle branch; $A B=$ ight bundle branch: $S$ slow $A-V$ rodid patthuna: $V=$ wentricio. Sem toxt.
The $\mathrm{H}$-A interwal stays the same in spite of changing $\mathrm{H}-\mathrm{V}$ interwals during the aberrant complexes, or in spite of block of conduction to the ventricles at as site distal to the bundle of His. We postulate (Fig. 2) that during left bundle branch block the impulse traveling to the ventricles ower the right bundle branch is able to invade in retrograde fashion the left bund he branch and reenters the A-V node. Retrograde condtiction over the last $A$. $V$ nodal pathway allows premature aetivation of the atritum.

In Figures 1 and 3 possible retrograde His bunde potent ids following the aberrant QRS complexes are identified. considered that they should precede the atrial echo by $80 \mathrm{~ms}$ or more (the H.A interval during tachycardia). An inverse relation is observed between the H.V interval and the V.H interval after the aberrant QRS complexes, the $W$-H interval measures $100 \mathrm{~ms}$ after an $\mathrm{H}-V$ interval of $140 \mathrm{~ms}$, and $110 \mathrm{~ms}$ after an $H-V$ interval of 115 ms). ${ }^{T}$ the $V$-A interval following the aberrant complexes (as measured from the ventriculogram in the distal coronary sinus lead to the onset of atrial activation in the same lead) changes in the absence of changes in the bund le branch block pattern. "This observation suggests that a free wall bypags tract is not the pathway used for retrograde conduction. Tachyoardia is terminated depending on the retrograde and anterograde input in the A.W nesdal pathways as reffected by the $\mathrm{H}$. H and $\mathrm{A}$. A intervals. After the first abarrant QRS complex the H.H interval meas ures 240 ms (Fig. $1)$ and the A interval $250 \mathrm{~ms}$. This results in sorre degree of concealed penetration of the impulse in the slow A. V nodal pathway (Fig. 2) and collision with the anterograde front within this pathway, whereas retrograde conduction to the atria takes place over the fast A.V nodal pathway. The atrial complex is conducted in anterograde manner with a transient increase in the slow pathway conduction time. However, after the second aberrant QRS complex both the H-H interval (225 ms) and the A.A interval (240 ms) are shorter (Fig. 1). "This shortening results in a major degree of concealed penetration of the impulse in the slow pathway that, in combination with a shorter A-A interval, results in block of impulse conduction in the slow pathway and termination of tachycardia (Fig. I. and 2).

Occasionally right bundle branch block was observed during the change from $2: I$ to $1: 1 \mathrm{~A}-\mathrm{V}$ conduction. "This also resulted in the echo phenomenon (Fig. 3). Howewer, because of the retrograde and anterfograde input in the $A-V$ nodal pathways 
(H H interval $240 \mathrm{~ms}$ and $A-A$ interval $260 \mathrm{~ms}$ after the aberrant QRS complex) a fully compensatory pause followed and tachycardia continued. In this patient atrial premature beats delivered during atrial pacing at a basic cycle length of $600 \mathrm{~ms}$ dlid not result in aberrant conduction to the ventricles, the shortest attainable $\mathrm{H}_{1}-\mathrm{H}_{2}$ interval measuring $330 \mathrm{~ms}$.

Patient 2. Termination of A-V nodal tachycardia by a sudden change in another anterograde A-V modial pathway: An A-V nodal tachycardia with anterograde conduction. over a "slow" pathway and retrograde conduction over a "fast" pathway (Fig. 4) was terminated spontaneously by a cycle that (1) was $115 \mathrm{~ms}$ shorter than the cycless seen during tachycardia, and (2) was not followect by retrograde conduction to the atria. This mode of spontaneous termination was repeatedly ob. served and probably can be explained by the A. V modal con. duction curves shown in Figure 5. During single test stimulation of the right atrium at a basic cycle length of $500 \mathrm{~ms}$, several discontinuities in the $\mathrm{A}_{2}-\mathrm{H}_{2}$ curve are seen. This was also during stimulation with a basic cycle length of $460 \mathrm{~ms}$. These findings support the presence of either more than one "Elow" pathway or delay in a final common patibway. "The former hypothesis is supported by the fixed Ho totrial echo interval at the time of initiation of tachycardia irrespective of the preceding A-H interval. If a final comumon pathswy were responsible for delay in conduction to the His bundle and the "gumps" in the conduction curve, a changing relation between His bundle activation and atrial echo would have been ob. served.

We postulate that in this patient tachycardia terminates spontaneously because of conduction over a "slow" pathway that is not slow enough to werconse retrograde refractoriness of the "fast" retrograde pathway (Fig. 6). Aithough the anterograde and retrograde refractory periods of the fast path. way need not be equal, the anterograde refractory period of the fast pathway measured $290 \mathrm{~ms}$ and the $\mathrm{H} \cdot \mathrm{H}$ interval ter. minating tachycardia measured $280 \mathrm{~ms}$ (a lesser value). After inutiation of tachycardia (Fig. 6), we postulate a decreasing concealment in the third pathway that is finally relievect, of lowing anterograde conduction over this pathway, the impulse colliding in the slow pathway with the anterograde front and blocking in the fast pathway hecanse it is entering at a time when the patthway is stitll refractory.

\section{Discussion}

A third pathway with bundile branch reentry: In these two patient the findings stromgly suggest that reentry into the tachycardia circuit over at third pathway was responsible for termination of the arrhythmia. This third pathway was not involved in the reentrant pach. ways kuring initimation and perpetantion of tachycardia. Atrial echo beats based on reentry over the bundle branches have been demonstraled to accur. ${ }^{10-12} \mathrm{As}$ in those studies, the atrial echoes in our Patient. 1 required the presence of block in one of the bundle branches and sufficient delay in conduction over the other bundle branch to complete a reentrant cycle. The time of ar rival of the impulse in the A. V nodal pathways (in both an. terograde and retrograde directions as reflected by the $\mathrm{H}-\mathrm{H}$ and $\mathrm{A}-\mathrm{A}$ interwals following the aberrant complex) was crucial for temination of the reentrant movernent. It seems unlikely that the widened QRS complexes represented ventricular extrasystoles occurring late in diastole. Ventricular premature beats were not observed to occur spontaneously throughout the investigation and, as shown, advancement of subsequent atrial activation was observed during both left and right bundle

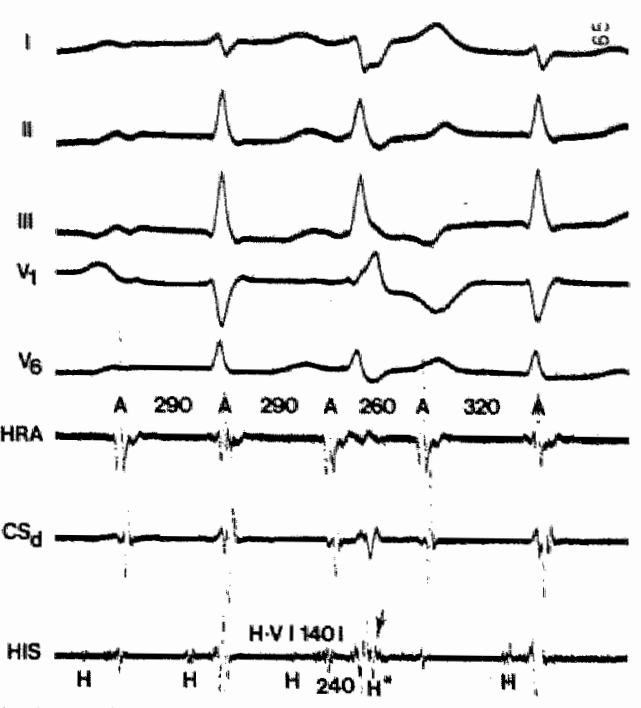

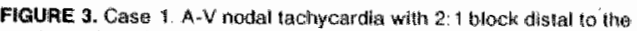
bundle of His showing tecovary of conduction over the left bundile branch (socond ORS complex, with a rling bunde branch bilock con

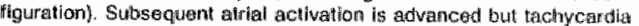
continuts. Same leads and labuling as in Flgum 1 . See text:

branch block-shaped QRS complexes. The range of H-V intervals preceding these widened QRS complexes is in keeping with previous clinical observations ${ }^{10}$ and the results of experimental studies.

An inverse relation between $H-V$ and $V-M$ intervals during the widened QRS complexes was demonstrated in our Patient 1, supporting the concept of bundle branch reentry. ${ }^{10}$ In this patient we could exclude the presence of an extranodal accessory pathway. Depolarization of the bundle of His occurred wice during H.H incervals of 240 to 225 me (Fig. 1 and 3 ). Fuperi. mental studies bave shown that retrograde depolnt izotion of the His bundle con ocur as som as $160 \mathrm{~ms}$ after its anterogrede depolarization. The observation of bundle branch blow whth show conduedion ower the contralateral branch with ad wancement of subsequent atrial acivation makes bundle brandh reentry the most. Wausible explanation for termination of tachycardia in this patient. Unfortumately, bundle branch block and atmial echoes were not observed during atriall promature beats dellivered dining pacing of the rigtht atrum at a basic cycle length of $600 \mathrm{~ms}$. "Their absence might have occurred because the $\mathrm{H}$ H interval of $300 \mathrm{mg}$ during tachycardia could result in concealment in the bundle branch system, allowing development of bundle branch block patterns, whereas such concealed conduction presurably did not occur during atrial pacing a a basic: cycle length of $600 \mathrm{~ms}$.

Anterograde intranodal conduction over third A-V nodal pathway: In Patient 2 a sudden shortening in the cycle length of reentry was followed by termina- 
tion of tacthycardia "The degree of shortenirg is too gredt to be acounted for by a sudden change in automomic tone. The most atractive hypothesise to explain this phenomenon is anteragrade intranodal conduction over a different. A-V nodal pathway with sow cothduction time. The finding of several discontinedities in the $A-V$ nodal conduction curve might support this theory. It is of interest thot the $A-H$ interval after the forst break in the A.V nodal conduction curve ss similar to the A-H interwal before termination of tachycardia, measturing 230 and $215 \mathrm{~ms}$, respectively (Fig. 4 and 5 ). We cannot exclude the possibility that $\mathrm{His}$ bundle extrasystole was responsible for termination of tachycardia and the apparent shortening of the $A$. $H$ interval. Also we do not know the validity of comparing the A-H interval terminating tachycatdia with the $\mathrm{H}$ interval after the

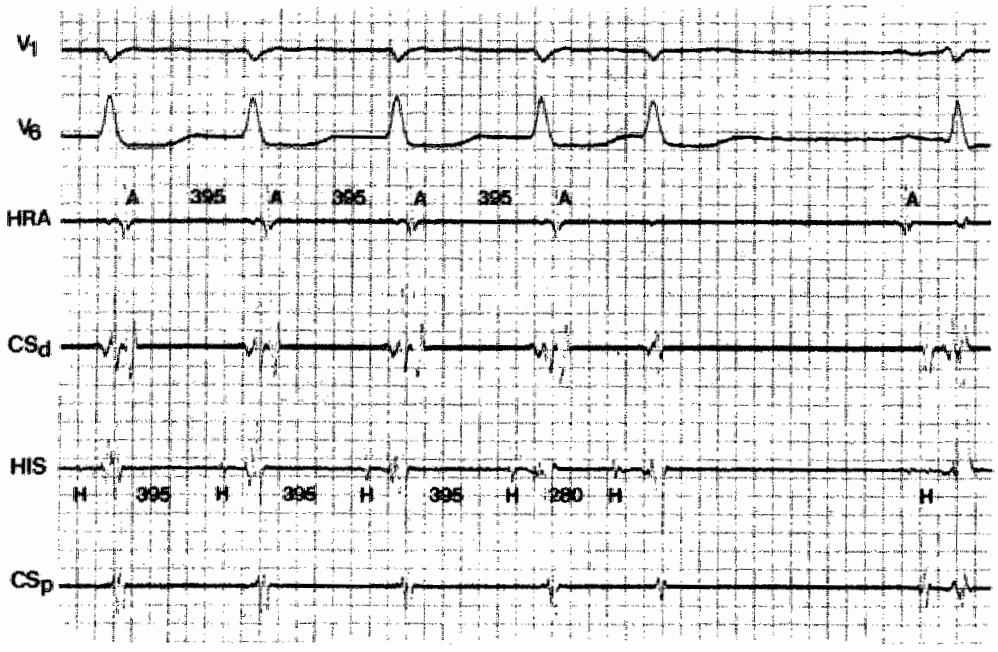

FilGuRE 4. Case 2. A.W modal tachycardial with a cycle length of $395 \mathrm{~ms}$. Tackycardlia terminates: after suddien shortening in the H/m interwal by $115 \mathrm{~ms}$, corrosponding to 115 ms shortening in the A.H in terwal. This reperatedly observed phenomemon was not precedied by any changes in time ralations during the tachycardia. Leads $W_{y}$ and $W_{s}$ were simultanecusily recorded whith four endocavitary electrograms. CSp = Praximal coronary sirnus olectrogram.
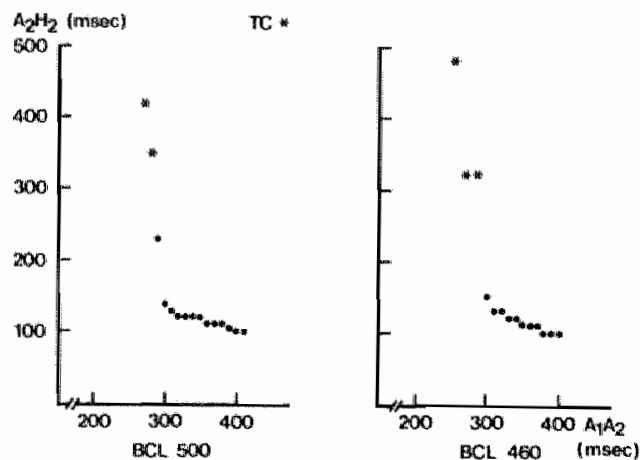

FIOUAE 5. Gase 2, Relation between the A,-A intervals (abscissa)

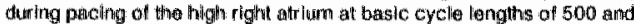
460 ms. Three disconthumities in the A.V modal conduction curve ware observed during atriat pacing whth a basic oycle length of $500 \mathrm{~ms}$ (left) and two wher the basic cycle length of pacing was decreased to 460 ms (filght). TO $=$ atrial priamature beats lnitiating tachycardia.

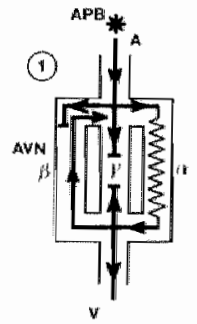

(2)

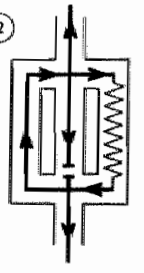

(3)

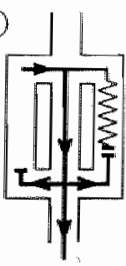

FHQUFE 6. Case 2. Diagriam illustrating the proposed mechathism of

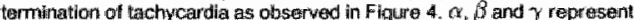

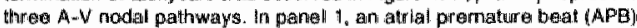
is blockedi lon pathways $\beta$ and $\gamma$ and inhtilites tachycardia after anterograde conductom oven pathway of (the slowest conducting path way) and retrograde conduction over pathway $\beta$ (the lastest pathway). Pathway $\gamma$ is maintainect refractory bocaus of conceated anterograde and retrograde peneitrat lon of impulses thering tachycarcila. Im panel 2. decreasing concealled penetraiticn in patthway $\gamma$ in the retrograde diroction is postulated. In panel 3 , aftir recowery of conduction in the anterograde direction in pathway $\gamma$ the impulse is conductad to the ventricles with a shorter than expected A-H haterwal. The impulse bilocks in pathway $\beta$ because of relractoriness of this pathway, and collides in pathwey of with the anterograde impulse, resulting in termination of lachycardla. Albbreviatlons as in Figure 2. 
first breat in the A-V nodal conduction curve of the lleft graph from Figure 5 when cycle lengths are different. However, we bellieve that the reproducibility of our observations, the several discontinuities in the $\mathrm{A}-\mathrm{V}$ nodal conduction curve and the mode of termination of tachycardia suggest the availability of several $A$-V nodal pathways. The availability of seweral A nodal path. ways has already been advanced from animal studies. ${ }^{2}$ In Patient 2 a similar A.V nodal conduction thme was observed not to initiate or tho terminate tachycardia, thus suggesting the use of a third $A . V$ nodal pathway that was not slow enough to overome refractoriness of the retrograde A.V nodal pathway used during tachycardia.

Implications: In these two patients, sudden unexpected conduction ower another reentrant pathway accounted for termination of the arrhythmia. Why these pathways were suddenly able to conduct is difficult to explain. Although, the factors leading to the new teantrant pathway terminating tachycardia conld be recognized in Patient 1, they temain unclear in Patient 2 One can speculate that differences in degree of conm cealed penetration of the inpulse in potential reentrant circuits or changes in refractoriness and conduction velocity during tachyourdia might have played a role. However, our present methods of investigation in the intact human heart ane not tefined enough to uncover most of these complex mechanisms.

\section{Acknowledgment}

We gratefuly acknowledge the many helpful suggestions made by Mark Fo Josephon, MD d aring the preparation of the manuscript.

\section{References}

1. Moe GIK, Mendez C. The physiclogical basis of reciprocal thythm, Prog Cardionasc Dis 1966:8:46:1-82.

2. Janse MJ, van Capulle FJL, Anderson RH, Touboul $\mathbf{P}_{\text {, Bllette, }}$ J. Electrophysiology and structure of the artioventricular mode of

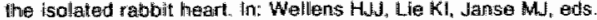
The Conduction System of the Heart. Philadelphia: Lea \& Febigar. $1976: 296-315$.

3. Goldreyer BN, Damato AN. The essentlal role of atriowentricular conduction delay in the intiation of paroxysmal supraventricular tachycardia. Dirculation $1977_{10} 43: 679 m 87$.

4. Rosen KM, Meht A, Mither RA. Demorstration of dual atrioventricular rodal pathways in man. Am J Cardiol 1974;33:291-4

5. Ross $D_{1}$. Fairr J, Bàr FWHM, ell al. Comprehensive electrophysialagical studies in the investigation of documented or suspected tachycardias. Circulation 1980;61:10110-4.

6. Wellens $H . H J$, Durrer D. The rolle of an accessory altioventricullar pathway in reciprocal tachycardia. Cliculation $1975,52,58-71$

7. Wu D, Denes P, Wyndham C, Amat-y Leon F, Dhingyra RC, Fiosen
KM. Demonstration of disal atriowentricular nodal pathways uthlizhou a wentricular extrastimulus in putients with atriowentricular nodgat reantrant paroxysfat supraventricalas tachycardia. Circulatlon $1975 ; 5: 2: 789-98$

8. Akhlar M, Damalo AN, Bolstort WP, Ruskin JW, Ogunkelu JE, A comparative analysis of anlegrade and retrograde conducton patterns in man, Circulation 1975:52:768-78.

9. Brugada $P$, Vanagt EJ, Bär FWHAl, Wallens HJJ. Incessunt ret ciprocating atr ioweintrilcular vachycarclia. Pace 1980;3:670 7.

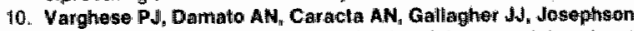
ME, Lau SH. Intravervitcutar conduction delay as a determinant of atrlal ocho beats. Circulation 1974:49:805-10.

11. Castellanos A, Embi A, Aranda J, Beleler B. Retrograde his bundle deflectiom in bundle branch rementry. Br Hearl J! $1976,38: 30$ i-3.

12. Moe GK, Mondez C. Han J. Alborrant A-W Impulsa propagation in the dog heart: a study af functional bundle branch block. Circ Res $1965 ; 16: 261-86$ 


\title{
Initiation of atrio-ventricular nodal re-entrant tachycardia in
} patients with discontinuous anterograde atrio-ventricular nodal conduction curves with and without documented

\author{
supraventricular tachycardia. Observations on the role of a \\ discontinuous retrograde conduction curve.
}

Pedro Brugada, M.D.; Bill Heddle, M.B., B.S.; Frits W.H.M. Bär, M.D.; and Hein J.J. Wellens, M.D.

From the Deparmemt of Cardiology, University of Limburg. Annadal Hospital, Maasiricht, The Netherlands.

\section{Summary}

To evaluate factors playing a role in initation of atrioventricular (A-V) nodal re-entrant tachycardia utilizing anterogradely a slow and retrogradely a fast conducting A-V nodal pathway, thirty-eight patients having no accessory pathways and showing discontinuous anterograde $A-V$ nodal conduction curves during atrial stimulation were studied. Twenty-two patients (group A) underwent an electrophysiologic investigation because of recurrent paroxysmal supraventricular tachycardia that had been electrocardiographically documented before the study. Sixteen patients (group B) underwent the study because of a history of palpitations (15 patients) or recurrent ventricular tachycardia ( 1 patient). In none of them a supraventricular tachycardia had been ever electrocardiographically documented before the investigation.

Twenty-one of the twenty-two patients of group A demonstrated continuous retrograde conduction curves during ventricular stimulation. In twenty tachycardia was initiated by either a single atrial premature beat ( 18 patients) or two atrial premature beats ( 2 patients). The remaining two patients received atropine and tachycardia could then be initiated by a single atrial premature beat.

Fifteen of the sixteen patients of group $\mathrm{B}$ had discontinuous retrograde conduction curves during ventricular stimulation, with a long refractory period of their retrograde fast pathway. Tachycardia was initiated by multiple atrial premature beats in one patient. Thirteen out of the remaining fifteen patients receiwed atropine. Thereafter tachycardia could be initiated in three patients by a single atrial premature beat, by two atrial premature beats in one patient, and by incremental atrial pacing in another one. In the remaining eight patients tachycardia could not be initiated.

This study demonstrates that in patients having discontinuous anterograde A-V nodal conduction curves and clinical documentation of supraventricular tachycardia, the refractory period of their retrograde fast pathway is short, and tachycardia can easily be initiated during atrial stimulation. Only a few patients require administration of atropine to facilitate initiation of the arrhythmia. Patients without documentation of supraventricular tachycardia have a long refractory period of their retrograde fast pathway, and tachycardia is not likely to be initiated during atrial stimulation. Administration of atropine however can in some of these patients result in shortening of the refractory period of the retrograde fast pathway and initiation of tachycardia. Our observations indicate that the pattern of ventriculo-atrial conduction found during ventricular stimulation is a marker for ease of initiation of $A-V$ nodal tachycardia in patients with discontinuous anterograde A-V nodal conduction curves. 


\section{Introduction}

Experimental and clinical studies indicate that longitudinal dissociation of the atrio-ventricular $(A-W)$ node leading to functionally different pathways plays a role in supraventricular tachycardia in man (1-8). In several patients with supraventricular tachycardia whom the presence of an accessory pathway is excluded during the electrophysiological investigation a re-entry circuit confined to the A-V node can be demonstrated (9). These patients usually show discontinuous anterograde $\mathrm{A}-\mathrm{V}$ nodal conduction curves during atrial stimulation suggesting the presence of dual A-V nodal pathways. Initiation of tachycardia is related to a shift in anterograde conduction from a fast to a slowly conducting $A-V$ nodal pathway. Some studies have shown however absence of initiation of tachycardia in the presence of a discontinuous anterograde conduction curve (1012). In these studies the possible role of a long refractory period of the retrograde fast pathway preventing initiation of tachycardia was not systematically studied. Also how a drug that induces changes in the properties of the A-V nodal pathways may facilitate initiation of tachycardia was not analysed.

In the present study the results of programmed electrical stimulation of the heart are reported in 38 patients showing discontinuous anterograde A-V nodal conduction curves during atrial stimulation in the absence of accessory atrio-ventricular pathways. Twenty-two patients had electrocardiographic documentation of supraventricular tachycardia before the investigation and sixteen patients not. The results of this study emphasize the role of the refractory period of the retrograde fast pathway in initiation of $A-V$ nodal tachycardial cluring atrial stimulation. They also show why the administration of atropine can result in initiation of tachycardia.

\section{Patients and methods}

Consecutive patients were included in the present study when they met the following criteria:

a. A complete electrophysiologic study using a previously described protocol of stimulation, recording and analysis of tracings (13). During the study leads $\mathbb{I}, \mathbb{I 1}, \mathrm{III}, \mathrm{V} 1$ and V6 were simultaneously recorded with bipolar endocavitary clectrograms from the right atrium, His bundle area, coronary sinus or left atrium.

b. Demonstration of discontinuous anterograde $\mathrm{A}-\mathrm{V}$ nodal conduction curves during single test stimulation of the atria at at least two of three different basic cycle lengths of pacing. Discontinuous anterograde conduction curves of the $\mathrm{A}-\mathrm{V}$ node were diagnosed when a $50 \mathrm{~ms}$ or more increase in the A-V nodal conduction time occurred on increasing the prematurity of the atrial premature beat by $10 \mathrm{~ms}$ (4), and by the method described by Rosen et al (1).

c. Presence of ventriculo-atrial conduction during ventricular pacing.

d. No evidence of accessory atrio-ventricular pathways.

The extrastimulus technique was used during atrial and ventricular stimulation to determine the patterns and refractory periods of $A-V$ and $V$ - A conduction. Anterograde A-V nodal conduction was studied by plotting the atrial premature beat intervals (A1-A2) against their $A-V$ nodal conduction time (the $\mathrm{A} 2-\mathrm{H} 2$ interval and the $\mathrm{H} 1-\mathrm{H} 2$ interval). The same cycle lengths used during atrial stimulation were used during ventricular stimulation. Retrograde conduction curves were analysed by plotting the ventricular premature intervals (V1-V2) against their ventriculo-atrial conduction time (V2-A2 and A1-A2 interval). Care was taken to identify when possible retrograde His bundle potentials both during basic paced ventricular beats and following ventricular premature beats. When both could be identified the retrograde $\mathrm{H} 1-\mathrm{H} 2$ intervals were taken as the premature beat interval of the retrograde input into the A-V node. An approximation of the retrograde imput into the $A-V$ node was obtained by measuring the $S 1-H 2$ interval when 
retrograde actrvation of the His bundle was only obserwed following the ventricular premature beat (V2) (14). This interval results in an overestimation of the interval of the retrograde input into the A-V node. In all patients in whom a discontinuous retrograde conduction curve was diagnosed during ventricular stimulation the initiation of $A-V$ nodal echoes using retrogradely a slow and anterogradely a fast pathway was required to support the A-V nodial site of the discontinuity in the retrograde conduction curve, including those in whom retrograde His bundle potentials were readily identified both during ventricular pacing and following the ventricular premature beat.

An accessory atrio-ventricular pathway was excluded, and the diagnosis of the A-V node as site of origin of tachycardia was made by using previously reported criteria $(4,15)$.

Informed consent was obtained from each patient. All medication was stopped at least 72 hours before the study.

\section{Results}

\section{a. Clinical data.}

Thirty-eight out of 350 consecutive patients studied by programmed electrical stimulation of the heart in our laboratory fulfilled the criteria for inclusion in the study. Their clinical data are given in table I. In twenty-two patients a paroxysmal recurrent supraventricular tachycardia had been electrocardiographically documented before the investigation (group A). On analyzing the relation between $P$ waves and $Q R S$ complexes during tachycardia $(16,17)$ the documented arrhythmia was considered to be $\mathrm{A}-\mathrm{V}$ nodal in origin in these 22 patients. Of the remaining 16 patients one was studied because of an electrocardiographically documented recurrent ventricular tachycardia on the basis of chronic coronary artery disease, but he never had an electrocardiogram showing a supraventricular arrhythmia. The remaining 15 patients were studied because of a history of recurrent palpitations. In all of them multiple electrocardiograms had failed to document a supraventricular tachycardia. In each patient a least one out of hospital 24 hours electrocardiographic recording had been made. Additional monitoring of variable duration (6-48 hours) was performed in hospital in all these sixteen patients (group B). Although supraventricular and ventricular premature beats were registered, in none of them a supraventricular tachycardia was documented. The history of complaints, ranged from 0.3 to 39 years in patients of group A and from 1 to 30 years in patients of group B. Excluding the patient of group B with ventricular tachycardia the mean duration of symptoms was longer in patients of group $A(16.3 \pm 12.7$ years) than in patients of group B $(9.6 \pm 8.4$ years $)$. These results were statistically significant $(p<0.05)$ (Student's $t$ test). There was a wide variation in frequency of complaints and in duration of episodes both inter and intraindividually, and these data were not analysed.

\section{b. Electrophysiological studies (table II):}

During single test stimulation of the atriad during atrial pacing all 38 patients demonstrated the presence of discontinuous anterograde A-V nodal conduction curves at at least two different basic cycle lengths of pacing. In patients of group $A$ the anterograde refractory period of the fast $A-V$ nodal pathway ranged from 240 to $500 \mathrm{~ms}$, and in group B from 250 to $560 \mathrm{~ms}$. These results werc not significantly different. Also the cycle lenghts of pacing used in each group were not significantly different. In most patients, both in group $A$ and B, the anterograde refractory period of the slow pathway could not be exactly determined, because conduction over this pathway was present up to the refractory period of the atrium. Statistical analysis of these walues was not performed.

During single test stimulation of the ventricle during ventricular pacing twenty-one patients of group A demonstrated (fig. 1) a continuous retrograde conduction curve with conduction to the atrium over a fast $A-V$ nodal pathway. In most instances ventriculo-atrial conduction occurred up to the refractory period of the right ventricle. "There was onc paticnt (patient 22 ) in whom a 
"rible 1

Clinical data of thirty-eight patients studied

\begin{tabular}{|c|c|c|c|c|}
\hline Patient & Age(yr)/sex & $\begin{array}{l}\text { Indication } \\
\text { forstudy }\end{array}$ & $\begin{array}{c}\text { ECG documentation } \\
\text { of } S V T\end{array}$ & Heart Disease \\
\hline
\end{tabular}

\section{Group A:}

$\begin{array}{rll}1 & 57 \mathrm{~F} & \text { Paroxysmal SVT } \\ 2 & 54 \mathrm{~F} & \text { Paroxysmal SVT } \\ 3 & 65 \mathrm{~F} & \text { Paroxysmal SVT } \\ 4 & 46 \mathrm{M} & \text { Paroxysmal SVT } \\ 5 & 50 \mathrm{M} & \text { Paroxysmal SVT } \\ 6 & 23 \mathrm{M} & \text { Paroxysmal SVT } \\ 7 & 35 \mathrm{M} & \text { Paroxysmal SVT } \\ 8 & 30 \mathrm{~F} & \text { Paroxysmal SVT } \\ 9 & 30 \mathrm{~F} & \text { Paroxysmal SVT } \\ 10 & 52 \mathrm{~F} & \text { Paroxysmal SVT } \\ 11 & 71 \mathrm{~F} & \text { Paroxysmal SVT } \\ 12 & 43 \mathrm{M} & \text { Paroxysmal SVT } \\ 13 & 62 \mathrm{M} & \text { Paroxysmal SVT } \\ 14 & 49 \mathrm{~F} & \text { Paroxysmal SVT } \\ 15 & 28 \mathrm{~F} & \text { Paroxysmal SVT } \\ 16 & 78 \mathrm{~F} & \text { Paroxysmal SVT } \\ 17 & 24 \mathrm{M} & \text { Paroxysmal SVT } \\ 18 & 80 \mathrm{~F} & \text { Paroxysmal SVT } \\ 19 & 24 \mathrm{~F} & \text { Paroxysmal SVT } \\ 20 & 49 \mathrm{~F} & \text { Paroxysmal SVT } \\ 21 & 44 \mathrm{~F} & \text { Paroxysmal SVT } \\ 22 & 21 \mathrm{M} & \text { Paroxysmal SVT }\end{array}$

$\begin{array}{lc}+ & - \\ + & - \\ + & - \\ + & - \\ + & - \\ + & - \\ + & - \\ + & - \\ + & - \\ + & - \\ + & - \\ + & - \\ + & \text { CAD } \\ + & - \\ + & \text { CAD } \\ + & - \\ + & - \\ + & \text { RHD } \\ + & -\end{array}$

Group B:

$\begin{array}{lllll}23 & 15 \mathrm{M} & \text { Palpitations } & - & - \\ 24 & 55 \mathrm{~F} & \text { Palpitations } & - & - \\ 25 & 40 \mathrm{M} & \text { Palpitations } & - & - \\ 26 & 30 \mathrm{M} & \text { Palpitations } & - & - \\ 27 & 45 \mathrm{M} & \text { Palpitations } & - & - \\ 28 & 25 \mathrm{~F} & \text { Palpitations } & - & - \\ 29 & 38 \mathrm{M} & \text { Palpitations } & - & - \\ 30 & 23 \mathrm{M} & \text { Palpitations } & - & - \\ 31 & 60 \mathrm{M} & \text { Palpitations } & - & - \\ 32 & 55 \mathrm{~F} & \text { Palpitations } & - & \mathrm{CAD} \\ 33 & 43 \mathrm{M} & \text { Palpitations } & - & - \\ 34 & 52 \mathrm{M} & \text { Recurrent VT } & - & - \\ 35 & 29 \mathrm{M} & \text { Palpitations } & - & - \\ 36 & 36 \mathrm{~F} & \text { Palpitations } & - & - \\ 37 & 53 \mathrm{M} & \text { Palpitations } & \text { Palpitations } & \end{array}$

Abbreviations: SVT: Supraventricular Tachycardia; VT: Ventricular Tachycardia; F: Female; M: Male; CAD: Coronary Artery Disease; RHD: Rheumatic Heart Disease. CCM: Congestive cardionyopathy; yr: years; $-\cdots$ : absent, 4 ; present. 

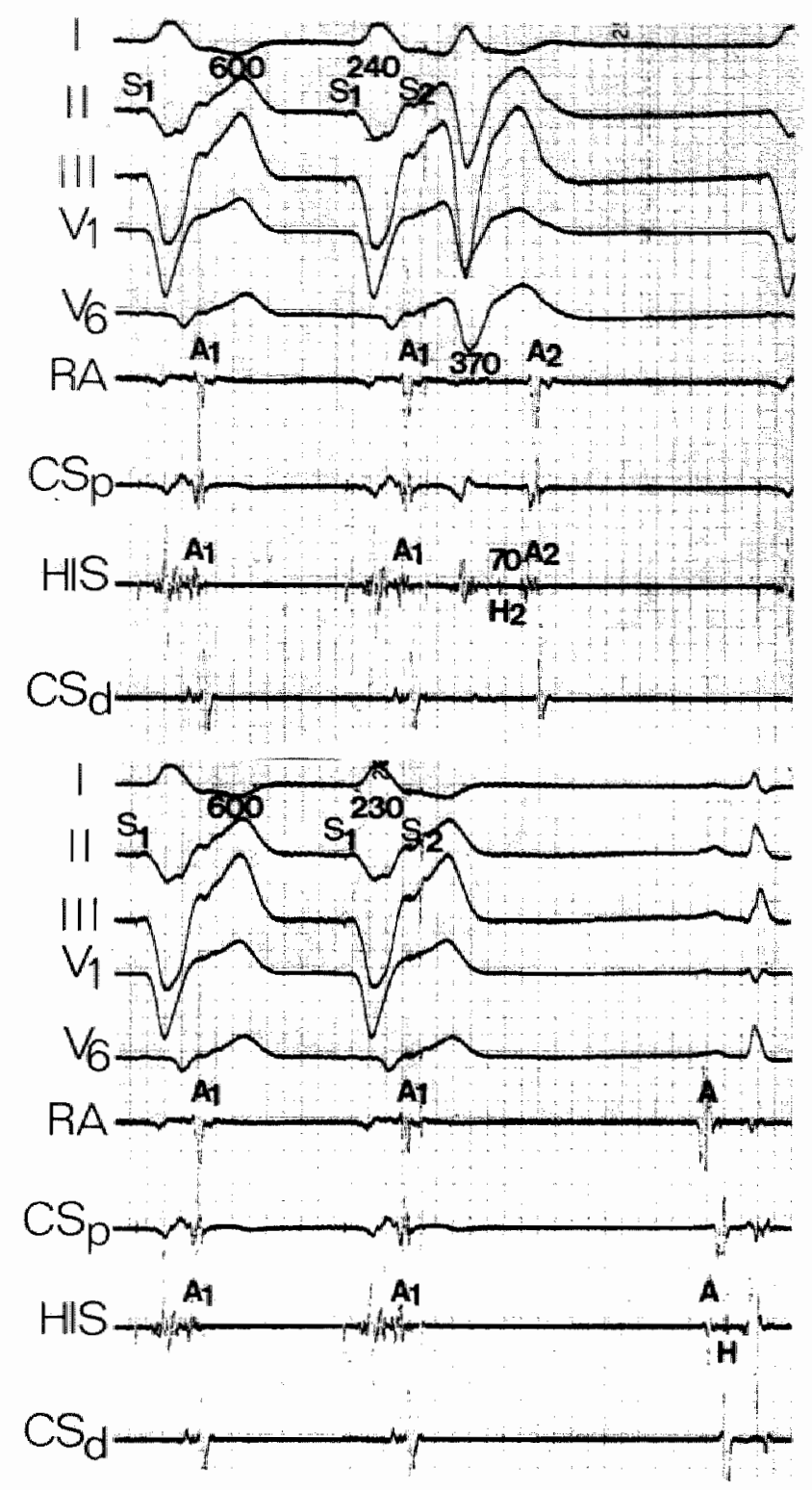

Figure 1

Patient 12. Representative example of findings in group A patients during ventricular stimulation studies. During ventricular pacing with a basic cycle length of $600 \mathrm{~ms}$ ventriculowatrial conduction over a retrograde fast A-V nodal pathway is present up to the refractory period of the ventricle. The top panel shows a ventricular premature beat given after $240 \mathrm{~ms}$ which is retrogradely conducted to the atria with a normal retrograde atrial aciivation sequence and preceded by a retrograde His bundle depolarization. The $H_{2} \mathrm{~A}_{2}$ interval measures $70 \mathrm{~ms}$, indicating conduction over a retrograde fast pathway. In the bottom panel a prenature ventricular stimulus given $10 \mathrm{~ms}$ earlier reaches the refractory period of the ventriclic. Five surface leads are shown simultaneously with four endocavitary electrograms of the right atrium (RA), the proximal (p) and distal (d) coronary sinus (CS) and the His bundle (His). 


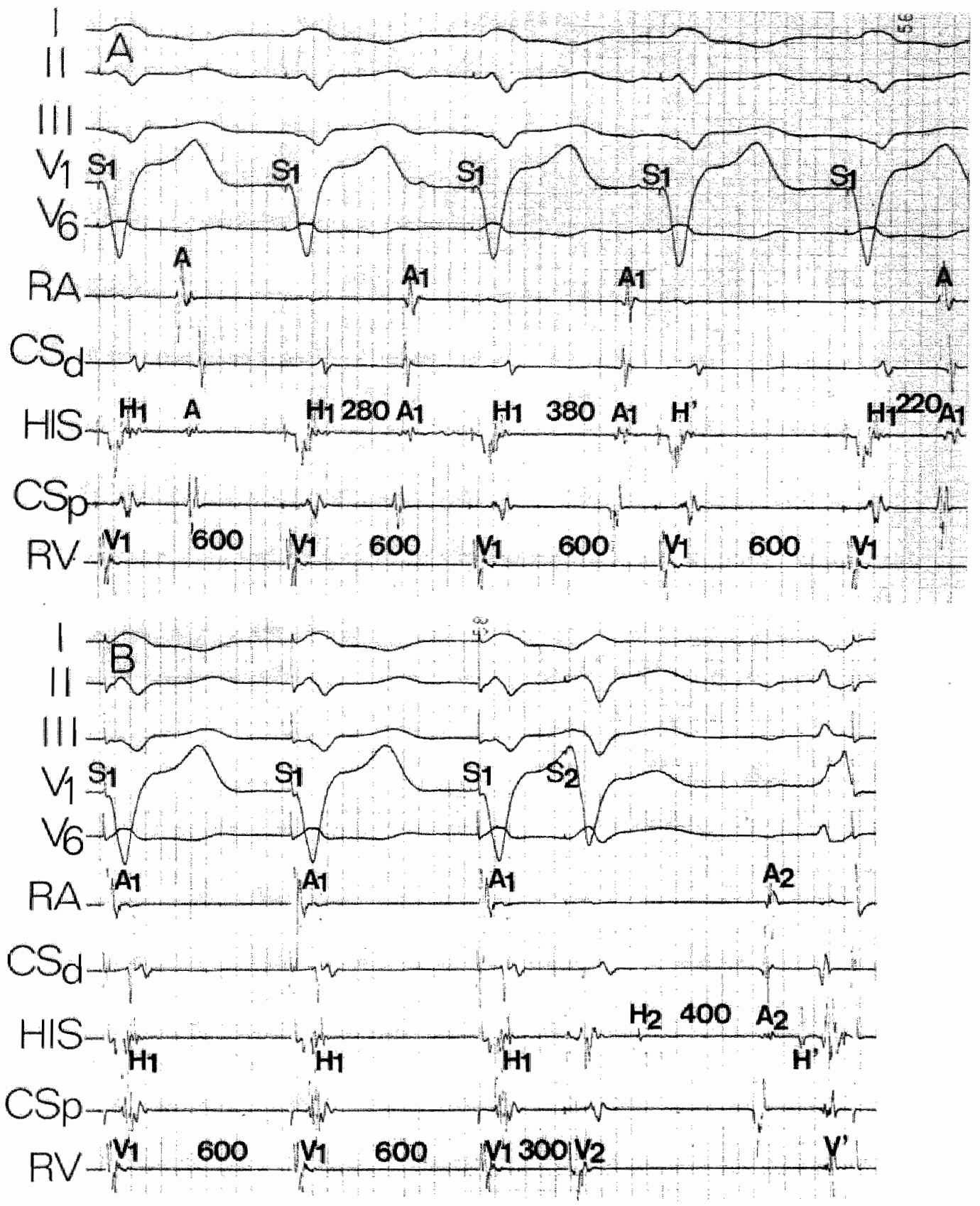

Figure 2

Patient 30. Typical example of findings in group B patients during ventricular stimulation before administration of atropine. In panch A pacing of the right ventricular apex with a basic cycle length of 600 ms results in retrograde condection to the atria over a slow A.V nodal pathway. (Note the retrograde His bundle potential at the end of the ventricular electrogram in the His bundle lead (HI)). A Wenckebach sequence of conduction wer the sllow pathway, with protongation of the SIAI interval is observed after the second paced ventricular complex. The lirst at rial complex shown is of simus node origin. These findings indicate a long retrograde refractory period of the fast pathway. In panel $B$ the right al rium and the right ventricle are paced simultancously with the same hasic cycte lenglh. A premature beat is given in the wentricle but not in the atrium. This allows retrograde conduction of the ventricular premature beat to the atria with marked subnodall delay over a slow 
A-V nodal pathway. An A-V nodal acho using anterogradely atast A. V nodal pathway is observed. During retrograde conduction to the atriat over the slow pathway the typical sequence of atriat activation is obserwed $(18,19)$, with atrial activation recorded first in the proximal cononary sinus leat.

Five surface leads are shown recorded simultameously with s endocaviary bipolar electrograms $(R V=$ right ventricular lead).

discontinuity in the retrograde conduction curve was present. In him the A-V node as the only retrograde pathway could be demonstrated by the initiation of the "reversed" form of A-V nodal choes (fast-stow) after the occurrence of the discontinuity in the retrograde conduction curve. In these twenty-one patients the retrograde refractory period of the fast pathway varied individually from less than $190 \mathrm{~ms}$ to $360 \mathrm{~ms}$. In the remaining patient of group $\mathrm{A}$ having discontinuous retrograde conduction curves the retrograde fast pathway refractory period measured $\geqslant 750 \mathrm{~ms}$.

During single test stimulation of the ventricle during ventricular pacing a discontinuous retrograde conduction curve in the $A-V$ mode followed by initiation of "reversed" A-V nodal echoes was demonstrated in 14 patients of group B. This occurred at the same cycle lengths as the ones used during atrial stimulation (fig. 2). Patient 25 had discontinuous retrograde conduction curves with initiation of "reversed" A-V nodal echoes only at one basic cycle length of pacing, and patient 37 demonstrated continuous retrograde conduction curves at all basic cycle lenghts tested.

In all patients the "reversed" form of rementry in the A-V node terminated spontaneously after 1 to 3 cycles, except for one patient in whom once a maximum of six cycles was observed. Using previously reported criteria (18) we excluded the presence of an accessory pathway with a long conduction time in all patients showing discontinuous retrograde conduction curves.

Initiation of the common type of re-entry in the A-V node (using anterogradely a slow and retrogradely a fast $\mathrm{A}-\mathrm{V}$ nodal pathway) was possible in the majority of patients of group $\mathrm{A}$ by giving a single atrial premature beat during atrial stimulation (table II, fig. 3). Two patients (patient 5 and patient 13) required two atrial premature beats. In two patients (patients 10 and 22) single or multiple atrial premature beats, and incremental atrial pacing failed to initiate re-entry in the $A-V$ node in the basal condition. In all patients of group $A$ in whom the retrograde refractory period of the fast pathway could be measured during wentricular stimulation, the A-H interval over the slow pathway at the time of initiation of re-entry in the A-V node during atrial stimulation was similar to or longer than the retrograde refractory period of the fast pathway (table II). In all patients of group $A$ where re-entry in the A-V node could be initiated during atrial stimulation a sustained intra-A-V nodlal tachycardia followed (fig. 1 and 3 ).

In paticnts of group B a sustained A-V nodal tachycardia using anterogradely at slow and retrogradely a fast pathway was initiated in the basal state during atrial stimulation in one patient (patient 28 ) by delivering three consecutive atrial premature beats during atrial stimulation. In 4 patients (patients 25,26,28 and 37) only a single atrial echo of $\mathrm{A}-\mathrm{V}$ nodial origin was initiated by a single atrial premature beat during atrial stimulation. This echo was usually followed by anterograde conduction to the ventricles. Thereafter re-entry in the A-V node terminated. Except for patient 28 , multiple atrial premature beats and incremental atrial pacing did not result in initiation of sustained A.V nodal tachycardia in the basal condition. The maximall duration of the A-H intervals over the slow pathway during atrial stimulation in the patients of group B showing no A-V nodal re-entry was similar to those in patients from group $A$ and $B$ in whom re-entry in the A-V node could be initiated. However, as shown in table $I I$, in patients in whom re-entry in the A-V node could not be initiated during atrial stimulation, the values of the maximal A-H intervals over the slow pathway were usually far below the value of the retrograde refractory period of the fast pathway when measured during ventricular stimulation (fig. 2 and fig. 4). This finding suggests that conduction over the slow pathway was not slow enough to overcome refractoriness of the retrograde pathway.

\section{c. Administration of atropine:}

In two patients of group A, and in thirteen patients of group B $1 \mathrm{mg}$ of atropine was given intravenously. In the two patients of group A (table III) a sustained A-V nodal tachycardia using 

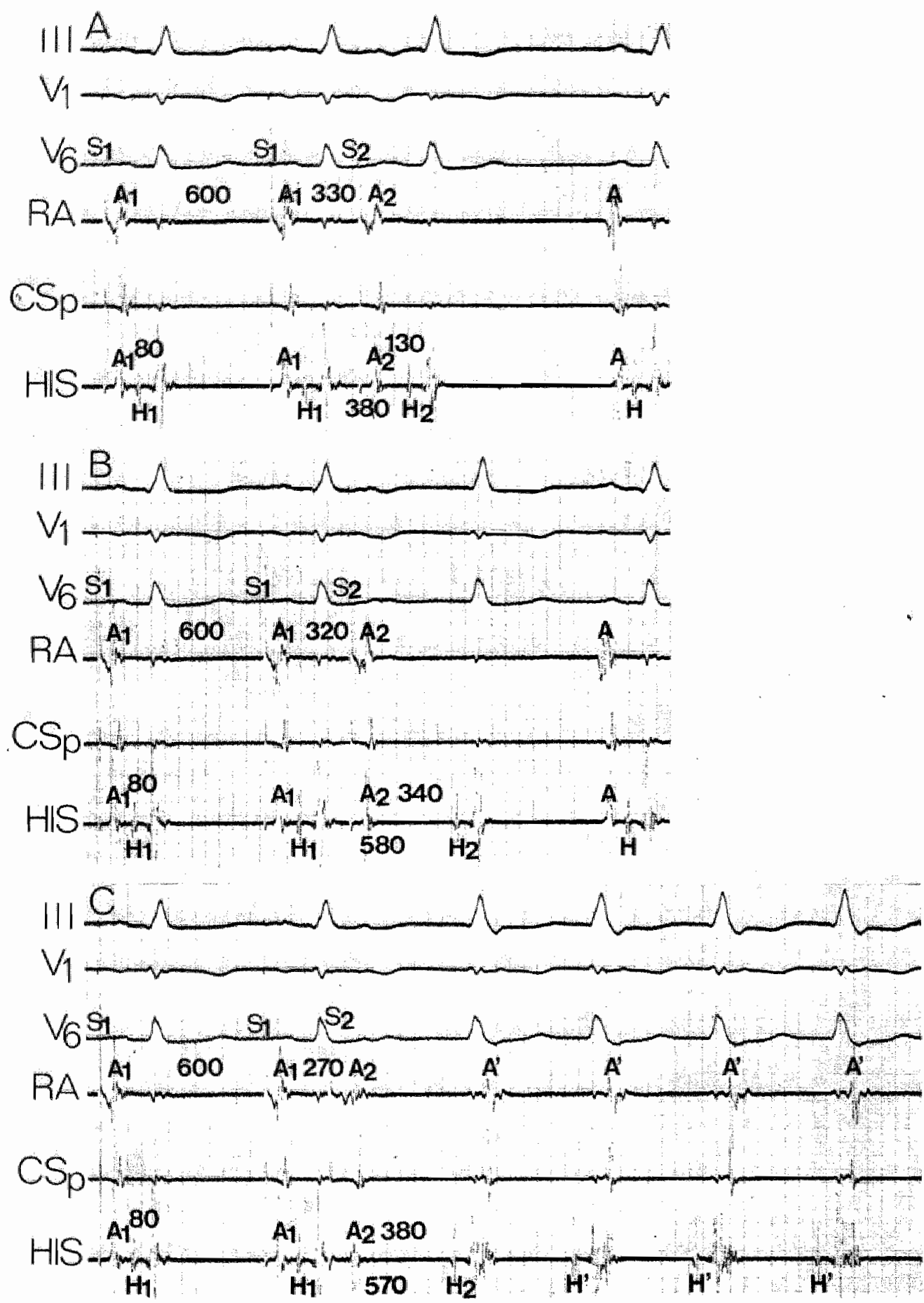

Figure 3

Same paticnt as in figure 1. During pacing of the right atrium with a basic cycle length of $600 \mathrm{~ms}$ an atrial premature beat given after $330 \mathrm{~ms}$ is conducted to the ventricles with an $\mathrm{A} 2 \mathrm{H} 2$ interwal of $30 \mathrm{~ms}$ and an $\mathrm{H} 1 \mathrm{H} 2$ interval of $380 \mathrm{~ms}$ (panel A). Shortening of the arrial premature beat interwal by $10 \mathrm{~ms}$ (panel B) results in marked prolongation of both the $\mathrm{A} 2 \mathrm{H} 2(340 \mathrm{~ms})$ and $\mathrm{H} 1 \mathrm{H} 2(580 \mathrm{~ms})$ interval. No echo follows, howewer. In 
panel $C$ further shortening of the atrial premature beat interval 10270 ms results in initiation of $A-V$ nodal tachycardia when a critical conduction time ower the slow $A-V$ nodal pathwayt is reached $(\mathrm{A} 2 \mathrm{H} 2=380$ ms). Three surface leads are shown simultaneously with three endocaviliary electrograms.

\section{Table III}

\section{Summary of electrophysiologic data on thirty-eight patients studied, during basal condition}

\begin{tabular}{|c|c|c|c|c|c|c|}
\hline$P t$ & $B C L$ & $E R P f a$ & $E R P s a$ & ERPfr & $\begin{array}{l}\text { shortest } A-H \text { over } \\
\text { Sa at time of echoes') }\end{array}$ & $\begin{array}{l}\text { Mode of initiation } \\
\text { of tachycardia }\end{array}$ \\
\hline
\end{tabular}

\begin{tabular}{|c|c|c|c|c|c|}
\hline \multicolumn{6}{|c|}{ Group A } \\
\hline \multirow[t]{2}{*}{1} & 600 & 350 & $<$ AFRP & $\leqslant 250$ & 445 \\
\hline & 500 & 360 & $<$ AFRP & 320 & 450 \\
\hline \multirow[t]{2}{*}{2} & 600 & 300 & $<$ AFRP & $\leqslant 220$ & 320 \\
\hline & 500 & 320 & $<\mathrm{AFRP}$ & $\leqslant 210$ & 330 \\
\hline \multirow[t]{2}{*}{3} & 600 & 430 & 340 & $\leqslant 270$ & 260 \\
\hline & 500 & 450 & 340 & $\leqslant 260$ & 230 \\
\hline \multirow[t]{2}{*}{4} & 600 & 250 & $<$ AFRP & $\leqslant 220$ & 300 \\
\hline & 500 & 260 & $<$ AFRP & $\leqslant 210$ & 290 \\
\hline \multirow[t]{2}{*}{5} & 600 & 260 & $<$ AFRP & $\leqslant 240$ & 200 \\
\hline & 500 & 250 & $<$ AFRP & $\leqslant 230$ & 200 \\
\hline \multirow[t]{2}{*}{6} & 600 & 290 & $<\mathrm{AFRP}$ & $\leqslant 230$ & 200 \\
\hline & 500 & 310 & $<\mathrm{AFRP}$ & $\leqslant 230$ & 200 \\
\hline \multirow[t]{2}{*}{7} & 600 & 340 & $<\mathrm{AFRP}$ & 250 & 269 \\
\hline & 500 & 360 & $<$ AFRP & $\leqslant 240$ & 290 \\
\hline \multirow[t]{2}{*}{8} & 460 & 260 & $<$ AFRP & $\leqslant 190$ & 220 \\
\hline & 400 & 240 & $<$ AFRP & $\leqslant 190$ & 230 \\
\hline \multirow[t]{2}{*}{9} & 600 & 270 & 220 & $\leqslant 250$ & 400 \\
\hline & 500 & 300 & $<$ AFRP & 240 & 290 \\
\hline \multirow[t]{2}{*}{10} & 600 & 310 & $<$ AFRP & 250 & - \\
\hline & 500 & 280 & $<\mathrm{AFRP}$ & $\leqslant 220$ & - \\
\hline \multirow[t]{2}{*}{11} & 600 & 500 & $<$ AFRP & $\leqslant 260$ & 200 \\
\hline & 500 & 470 & $<$ AFRP & $\leqslant 230$ & 270 \\
\hline \multirow[t]{2}{*}{12} & 600 & 320 & $<$ AFRP & $\leqslant 320$ & 380 \\
\hline & 500 & 360 & 300 & $\leqslant 330$ & 360 \\
\hline \multirow[t]{2}{*}{13} & 550 & 280 & 240 & $\leqslant 210$ & 260 \\
\hline & 500 & 270 & 260 & $\leqslant 200$ & 260 \\
\hline \multirow[t]{2}{*}{14} & 600 & 390 & 200 & $\leqslant 270$ & 250 \\
\hline & 500 & 390 & $<\mathrm{AFRP}$ & $\leqslant 260$ & 250 \\
\hline \multirow[t]{2}{*}{15} & 600 & 350 & $<\mathrm{AFRP}$ & 300 & 350 \\
\hline & 500 & 340 & $<$ AFRP & 250 & 300 \\
\hline \multirow[t]{2}{*}{16} & 600 & 380 & 330 & $\leqslant 250$ & 250 \\
\hline & 500 & 430 & 350 & $\leqslant 240$ & 400 \\
\hline \multirow[t]{2}{*}{17} & 750 & 340 & 320 & $\leqslant 240$ & 410 \\
\hline & 600 & 420 & 340 & $\leqslant 220$ & 350 \\
\hline \multirow[t]{2}{*}{18} & 680 & 280 & $<$ AFRP & $\leqslant 220$ & 360 \\
\hline & 600 & 290 & $>$ AFRP & $\leqslant 210$ & 290 \\
\hline \multirow[t]{2}{*}{19} & 600 & 320 & 280 & $\leqslant 220$ & - \\
\hline & 500 & 290 & 240 & 360 & 390 \\
\hline \multirow[t]{2}{*}{20} & 500 & 310 & $<$ AFRP & $\leqslant 210$ & 250 \\
\hline & 450 & 320 & 270 & $\leqslant 200$ & 270 \\
\hline \multirow[t]{2}{*}{21} & 600 & 290 & $<$ AFRP & $\leqslant 230$ & 300 \\
\hline & 500 & 340 & $<\mathrm{AFRP}$ & $\leqslant 210$ & 320 \\
\hline \multirow[t]{2}{*}{22} & 750 & 320 & $<$ AFRP & $\geqslant 750$ & - \\
\hline & 600 & 350 & $<$ AFRP & $\geqslant 600$ & - \\
\hline
\end{tabular}

1. $\mathrm{APB}$

$1 \mathrm{APB}$

$1 \mathrm{APB}$

$1 \mathrm{APB}$

2 APB's

$1 \mathrm{APB}$

1. APB

$\mathbb{A P B}$

$1 \mathrm{APB}$

$1 \mathrm{APB}$

$1 \mathrm{APB}$

2. APB's

$1 \mathrm{APB}$

$\triangle \mathrm{APB}$

$1 \mathrm{APB}$

$1 \mathrm{APB}$

$1 \mathrm{APB}$

$1 \mathrm{APB}$

$1 \mathrm{APB}$

$1 \mathrm{APB}$ 


\begin{tabular}{|c|c|c|c|c|c|c|c|}
\hline$P_{i}$ & $B C L$ & ERPfa & ERPSa & ERPfr & $\begin{array}{c}\text { longest } \\
\text { possible } \\
\text { A-Hover Sa }\end{array}$ & $\begin{array}{c}\text { echoes") } \\
\text { initiation }\end{array}$ & $\begin{array}{c}\text { Mode of } \\
\text { of tachycardia }\end{array}$ \\
\hline \multirow[t]{2}{*}{23} & 680 & 250 & $<\mathrm{AFRP}$ & 500 & 220 & - & - \\
\hline & 600 & 270 & $<$ AFRP & 500 & 280 & - & \\
\hline \multirow[t]{2}{*}{24} & 680 & 310 & $<$ AFRP & 630 & 340 & - & - \\
\hline & 600 & 290 & $<A F R P$ & $>600$ & 320 & - & \\
\hline \multirow[t]{2}{*}{25} & 600 & 320 & $<$ AFRP & $\leqslant 250$ & 530 & - & - \\
\hline & 500 & 360 & 300 & 370 & 500 & + & \\
\hline \multirow[t]{2}{*}{26} & 750 & 370 & 290 & 410 & 260 & - & - \\
\hline & 600 & 430 & 280 & 290 & 270 & + & \\
\hline \multirow[t]{2}{*}{27} & 600 & 400 & $<\mathrm{AFRP}$ & 340 & 330 & - & - \\
\hline & 500 & 420 & $<\mathrm{AFRP}$ & 390 & 310 & - & \\
\hline \multirow[t]{2}{*}{28} & 750 & 320 & $<$ AFRP & 350 & 310 & - & $M A P B$ \\
\hline & 600 & 350 & $<\mathrm{AFRP}$ & 300 & 320 & + & \\
\hline \multirow[t]{2}{*}{29} & 600 & 430 & $<$ AFRP & 370 & 320 & - & - \\
\hline & 500 & 420 & $<310$ & 340 & 330 & - & \\
\hline \multirow[t]{2}{*}{30} & 600 & 430 & $<$ AFRP & $>600$ & 440 & - & - \\
\hline & 500 & 400 & $<$ AFRP & $>500$ & 410 & - & \\
\hline \multirow[t]{2}{*}{31} & 600 & 300 & $<\mathrm{AFRP}$ & 350 & 300 & - & - \\
\hline & $500)$ & 280 & $<\mathrm{AFRP}$ & 360 & 310 & - & \\
\hline \multirow[t]{2}{*}{32} & 600 & 410 & $<A F R P$ & 350 & 290 & - & - \\
\hline & 450 & 420 & $<$ AFRP & 360 & 290 & - & \\
\hline \multirow[t]{2}{*}{33} & 600 & 300 & $<\mathrm{AFRP}$ & 380 & 380 & - & - \\
\hline & 500 & 310 & 270 & 410 & 400 & - & \\
\hline \multirow[t]{2}{*}{34} & 680 & 560 & 320 & $\geqslant 680$ & 330 & - & - \\
\hline & 600 & 560 & 280 & $\geqslant 600$ & 470 & - & \\
\hline \multirow[t]{2}{*}{35} & 600 & 460 & 340 & 550 & 380 & - & - \\
\hline & 500 & 450 & 330 & $\geqslant 500$ & 400 & - & \\
\hline \multirow[t]{2}{*}{36} & 600 & 310 & $<A F R P$ & 460 & 300 & - & - \\
\hline & 430 & 250 & $<\mathrm{AFRP}$ & 260 & 260 & - & \\
\hline \multirow[t]{2}{*}{37} & 600 & 280 & $<$ AFRP & $\leqslant 220$ & 240 & + & - \\
\hline & 500 & 290 & $<$ AFRP & $\leqslant 220$ & 290 & + & \\
\hline \multirow[t]{2}{*}{38} & 900 & 350 & $<\mathrm{AFRP}$ & 580 & 300 & - & - \\
\hline & 750 & 370 & $\angle A F R P$ & 440 & 300 & - & \\
\hline
\end{tabular}

Abbreviations: ERP: Effective Refractory Period; fa: anterograde fast $A-V$ nodal pathway; sa: anterograde slow A-V nodal pathway; fr: retrograde fast A-V nodal pathway; AFRP: Functional Refractory Period of the Atrium; APB: Alrial Prenature Beat;" '): A.V nodal echoes slow-fast; MAPB: Multiple Atrial Premature Beals. -: not initiated; : : initiated. 

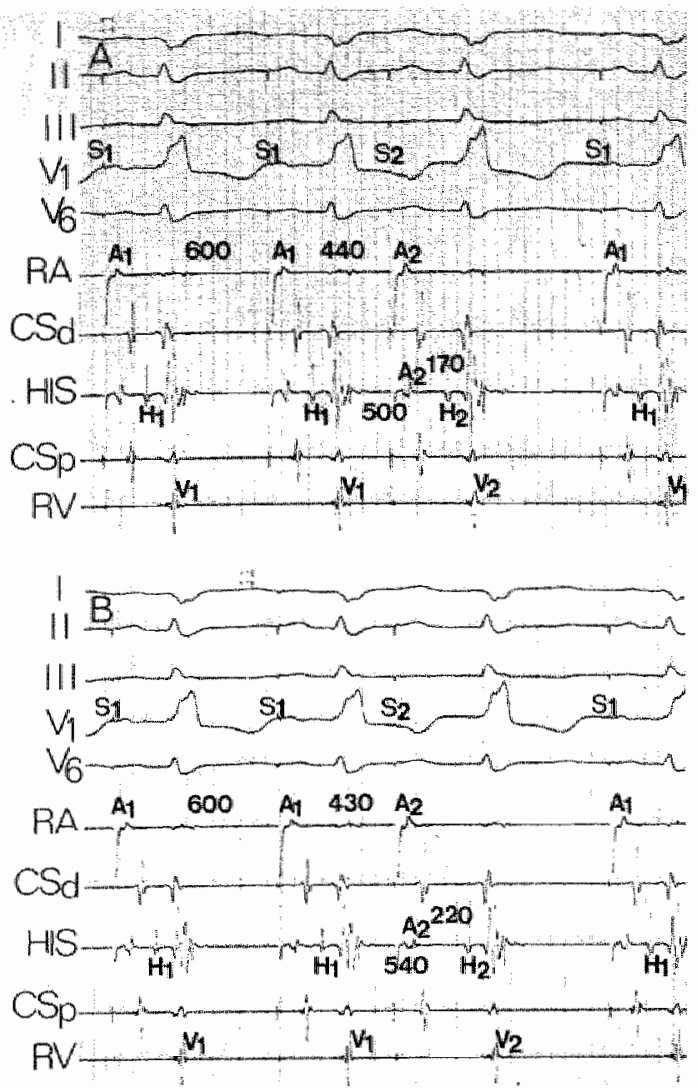

Figure 4

Same patient as in figure 2. During pacing of the right atrium with a basic cycle length of $600 \mathrm{~ms}$ an atrial premature beat given after $440 \mathrm{~ms}$ is conducted to the ventricles with an $\mathrm{A} 2 \mathrm{H} 2$ interval of $170 \mathrm{~ms}$ and a $\mathrm{H} / \mathrm{H} 2$ interval of $500 \mathrm{~ms}$ (panel A). Shortening of the atriall premature beat interval by $10 \mathrm{~ms} 10430 \mathrm{~ms}$ (pancl B) results in an increase of the A2H2 interval by $50 \mathrm{~ms} 10220 \mathrm{~ms}$, the $1111 \mathrm{H} 2$ intervall now measuring $540 \mathrm{~ms}$. In panet $C$ the atrial prenature beat interval has been shortened to $260 \mathrm{~ms}$, the $\mathrm{A} 2 \mathrm{H} 2 \mathrm{interval}$ measuring $440 \mathrm{~ms}$ and the HIH2 interval $590 \mathrm{~ms}$. In spite of this very long A2112 interval, no A.V nixdill echo follows,

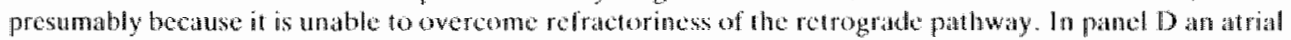
premature stmulus given after $240 \mathrm{~m}$ reaches the ref ractory period of the right at ritum. Throe surface leads are shown simula aneously with 5 endocaviary bipolar clectrograms.

anterogradely a slow and retrogradely a fast pathway could then be initiated by a single atrial premature beat given during atriall stimulation. In both patients the A-V nodal conduction curves were still discontinuous in the anterograde direction. In patient 22 the retrograde conduction curves which were discontinuous before atropine administration became continuous following administration of the drug. The A-H intervals over the slow pathway at the time of initiation of tachycardia were not longer after atropine as compared to the A-H intervals over the slow pathway before atropine. These data indicate that atropine facilitated initiation of A-V nodal tachycardia by shortening of the retrograde refractory period of the fast pathway.

In 5 patients of group B initiation of a sustained A-V nodal tachycardia became possible after administration of atropine (table III, fig. 5-6). In three patients following a single atrial premature beat during atrial stimulation, in 1 patient after two consecutive atrial premature beats and in the remaining patient during incremental atrial pacing. In these 5 patients, similar to the two patients of group $\mathrm{A}$ in whom tachycardia could be initiated after atropine, the A-H intervals over the slow pathway at the time of initiation of tachycardia did not become longer after atropine (fig. 5-6). 
Effects of atropine on the A-V nodal conduction curves and on initiation of A-V nodlal tachycardia using anterogradely a slow and retrogradely a fast pathway

\begin{tabular}{cccc} 
Patient & $\begin{array}{c}\text { Anterograde A-V nodal } \\
\text { conduction curves }\end{array}$ & $\begin{array}{c}\text { Retrograde A-V nodal } \\
\text { conduction curves }\end{array}$ & $\begin{array}{c}\text { Mode ofinitiation } \\
\text { of fachycardia }\end{array}$ \\
\hline Group A & discontinuous & & \\
10 & discontinuous & continuous \\
22 & continuous & $1 \mathrm{APB}$ \\
Group B & continuous & APB \\
23 & continuous & continuous & \\
24 & discontinuous & absent V-A conduction & - \\
25 & discontinuous & continuous & IAP \\
26 & discontinuous & continuous & -7 \\
27 & discontinuous & continuous & $2 \mathrm{APB}$ s \\
29 & continuous & continuous & $1 \mathrm{APB}$ \\
30 & discontinuous & continuous & - \\
31 & continuous & continuous & APB \\
33 & discontinuous & ? & - \\
35 & discontinuous & continuous & - \\
36 & continuous & continuous & APB \\
37 & continuous & continuous & - \\
38 & &
\end{tabular}

Abbreviations: Same as table II. ?: Unknown; -.: not initiated; ") Maximal A-H interval over slow pathway strortened from $400 \mathrm{~ms}$ to $200 \mathrm{~ms}$ after atropine; 1 AP: Incremental Atrial Pacing.

In these patients initiation of tachycardia was facilitated by shortening of the retrograde refractory period of the retrograde fast pathway. In all 5 patients the discontinuity in the retrograde conduction curve had dissappeared while the characteristic discontinuous anterograde $\mathrm{A}-\mathrm{V}$ nodal conduction curve was maintained. All 5 patients had initiation of the "common" form of A-V nodal tachycardia (slow-fast) after atropine. In the remaining eight patients any attempt to initiate an A-V nodal tachycardia failed. In none of them we were able to initiate re-entry in the A-V node of the "common" or "reversed" variety. Analysis of anterograde and retrograde conduction curves of the A-V node in these 8 patients showed a continuous retrograde conduction curve both in the anterograde and retrograde direction in 5 patients (fig. 7-8), with inability to shift conduction from the fast to the slow $A-V$ nodal pathway during atrial or ventricular stimulation. This was due to a shortening of the anterograde and retrograde fast pathway reftactory period after administration of atropine. In patient 24 the conduction curves were discontinuous in anterograde direction, but $\mathrm{V}$-A dissociation was observed during ventricular pacing using a basic cycle length of $375 \mathrm{~ms}$. In patient 26 the conduction curves were discontinuous in anterograde direction but the A-H intervals obtained over the slow pathway during atrial stimulation shortened from a maximal basal value of $400 \mathrm{~ms}$ to a maximal value of $200 \mathrm{~ms}$ following atropine. In patient 35 the anterograde conduction curves were discontinuous but the exact mechanism of failure to initiate tachycardia remained unknow because ventricular stinulation could not be performed following atropine.

\section{Discussion}

Although we frequently cannot assess the correct intervals of retrograde input into the A-V node during ventricular stimulation, our results are of interest because they suggest that: 


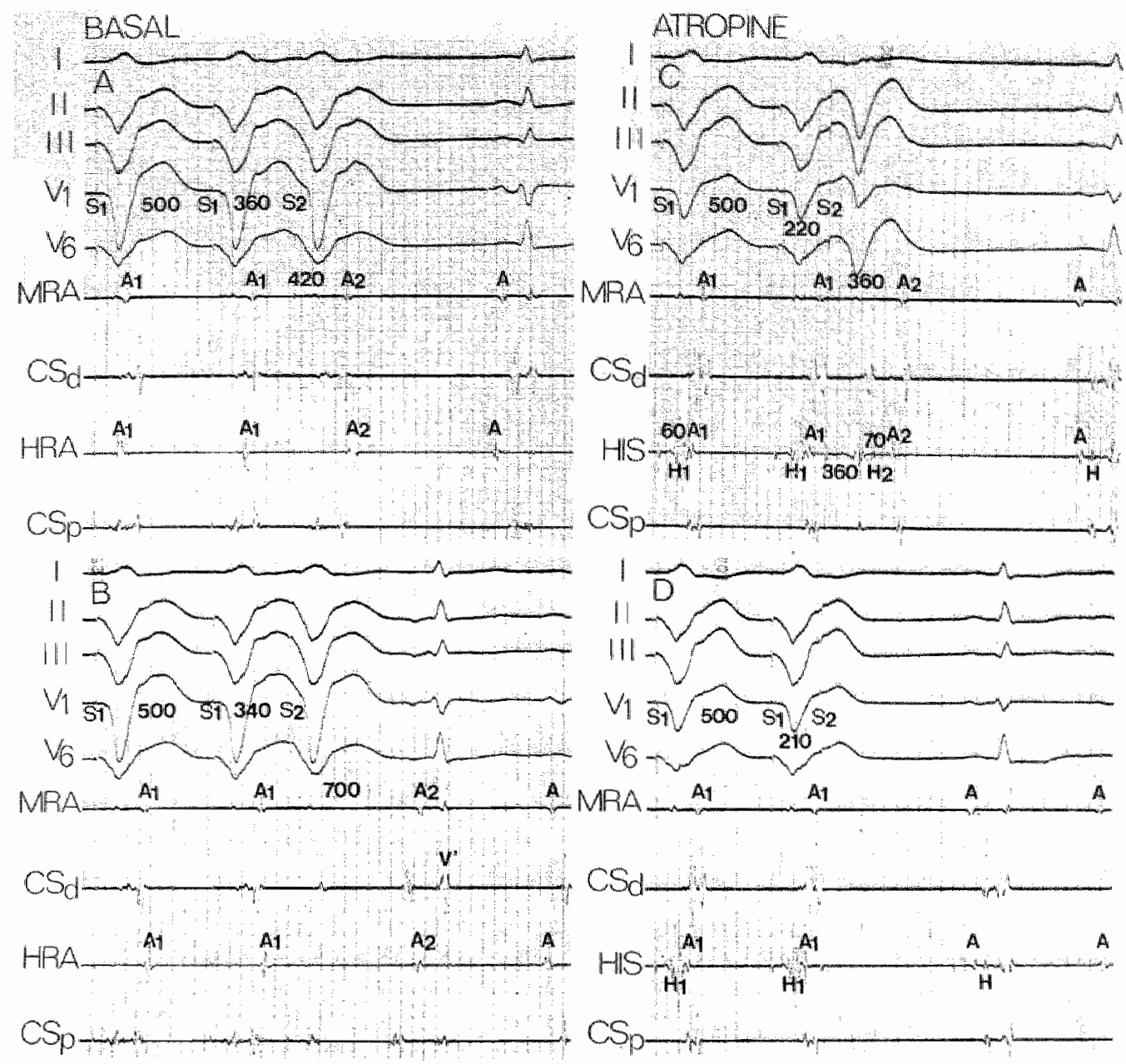

Figure 5

A representative example of findings duritig ventricular stimulation of group B pintients in whom tachyeardia could be initiated after administration of atropine. Patient 29 . Before atropine a discontinuity in the retrograde conduction curve was present when during pacing with a basic cycle length of $500 \mathrm{~ms}$ a ventricular premature beat was given after $340 \mathrm{~ms}$. This was followed by the initiation of a single "reversed" A-V nodal echo (panels $A$ and $B$ ). Atropine resulted in shortening of the retrograde refractory period of the fastl pathway, retrograde conduction over this pathway being now present up to the refractory period of the right ventricle. In contrast (panels $C$ and D) to panels $A$ and $B$ where His bundle elcetrograms were not recorded. following altopine admirnistration in panels $C$ and $D$ the retrograde His bundle potential precedes the ventriculogram during basic paced beats and follows the ventricular premature beat in panel $C$. The retrograde H1H2 interval shown in pane $\mathrm{C}$ measures $360 \mathrm{~ms}$ indicating that the refractory period of the retrograde pathway must have shortened to at least $360 \mathrm{msec}$ after atropine administration. MRA $=$ mid right atrium.

a. the presence of a discontinuous retrograde conduction curve during ventricular stimulation, suggesting a long refractory period of the retrograde fast A V nodal pathway, hampers initiation of $A-V$ nodal tachycardia in patients having discontinuous anterograde $A-V$ nodat conduction curves;

b. in patients without documented tachycardia initiation of a sustained tachycardia in the A-V node after atropine is mainly the result of shortening of the refractory period of the retrogradie fast. pathway; 

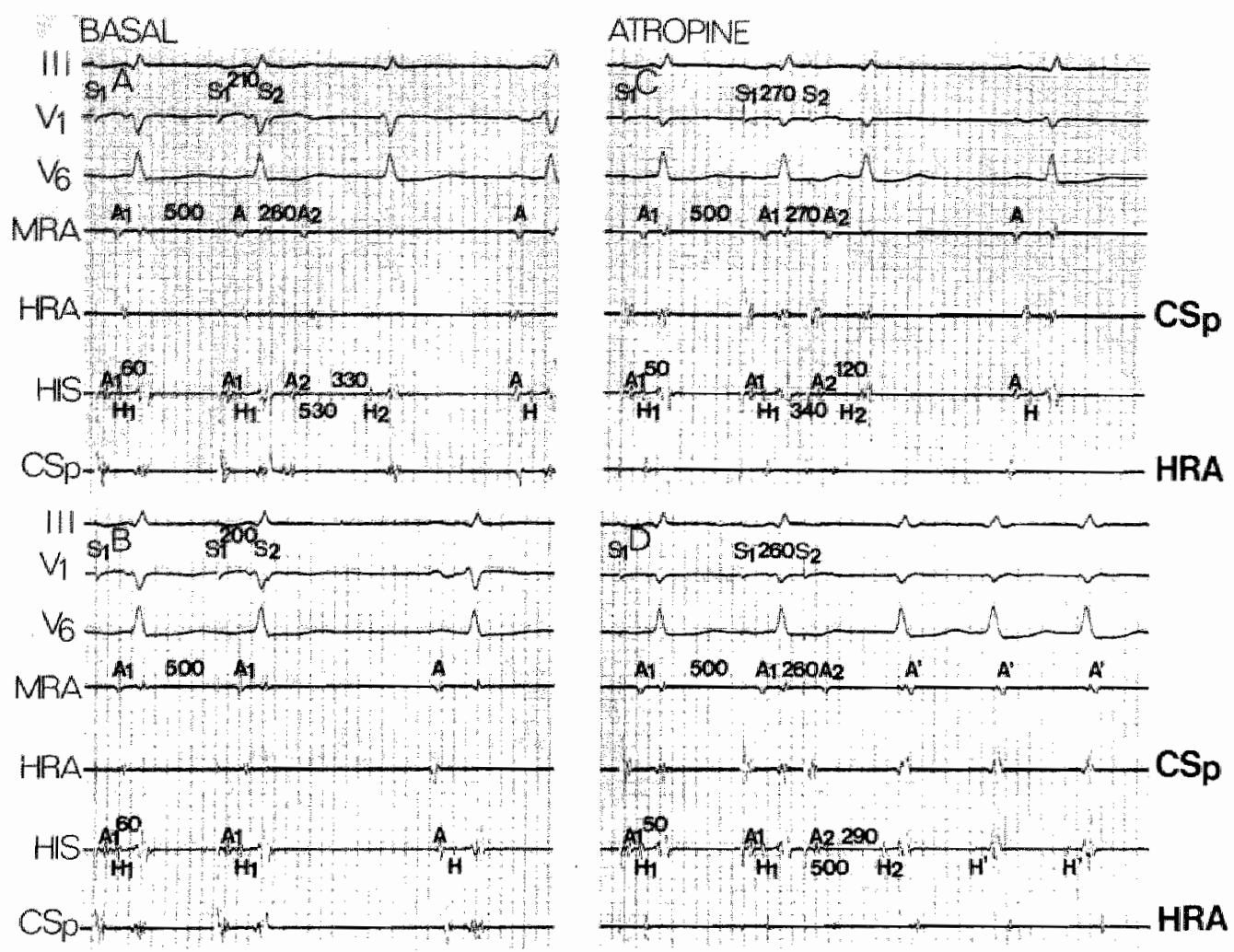

Figure6

Same patient as in figure 5 . Atrial stimulation before (panels A and B) and after (panels C and D) atropine. Before atropine pacing in the coronary sinus with a basic cycle length of $500 \mathrm{~ms}$ demonstrated a discontinuity in the anterograde $A-V$ nodal conduction curve when an atrial premature beat was given after $420 \mathrm{~ms}$. The longest possible A2H2 interval of $330 \mathrm{~ms}$ was obtained after an A1 A2 interval in the coronary sinus of $260 \mathrm{~ms}$ (panel A). This A2H2 interval was not followed by initiation of A.V nodal echoes of the "common" type (slowfast). In panet B on further shortening of the premature stimulus interval from 210 to $200 \mathrm{~ms}$ the reffactory period of the coronary simus was reached. After atropine the refractory period of the anterograde A.V nodal fast pathway shortened $10260 \mathrm{~ms}$. In panel $\mathrm{C}$ an atrial premature beat given after $270 \mathrm{~ms}$ is conducted to the ventricles with an A2H2 interval of 120 ms and a H1H2 interval of $340 \mathrm{~ms}$. In panel D 10 mis shortening of the atrial prematture beat interval $10260 \mathrm{~ms}$ results in demonstration of a discontinuity in the anterograde conduction curve and in initiation of tachycardia. That shortening of the retrogradle refractory period of the fast pattrway by atropine as shown in fig. 5 during ventricular stimulation was responsible for intiation of tachycardia is supported by observing that in pancl D inititiation of tachycardia occurs with an A2H2 interval of $290 \mathrm{~ms}$. Which is $40 \mathrm{~ms}$ shorter than the A2H2 interval in panel A when no echoes were initiated. Note that in panels $C$ and $D$ the electrograms from the HRA and CSp are reversed as compared to panels A en B.

e. patients with electrocardiographic documentation of sustained supraventricular tachycardia have a shorter tetrograde refractory period of their fast pathway, as compared to those with anterograde dual A-V nodal pathways but no documentation of supraventricular tachycardia.

This study confirms previous observations by other authors $(10-12)$ that the presence of a discontinuous A.V nodal conduction curve, either anterograde, or retrograde, is by no means a marker of the clinical occurrence of $A-V$ nodal tachycardia. By manipulating the autonomic tone in paticnts with dual A-V nodal pathways but no documented tachycardia, thereby changing their A-V nodal properties, a sustained A-V nodal tachycardia can be initiated in some of these patients. The clinical significance of this finding is not clear at the present time. 

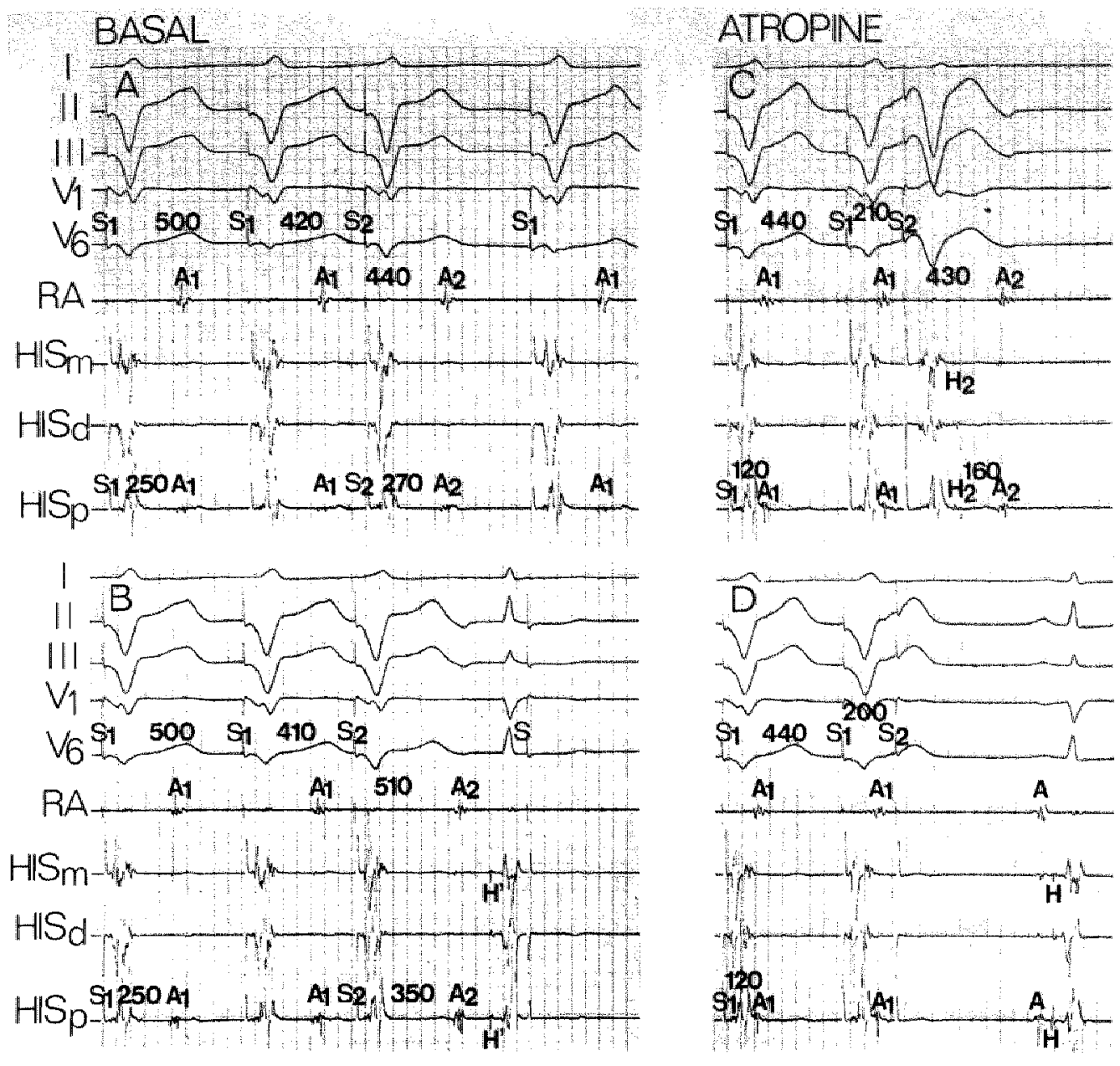

Figure 7

Patien 33. A representative ex mple of patients of group $B$ in whom no tachyeardia could be initiated afler atropine. Before atropine (pands $\mathrm{A}$ and $\mathrm{B}$ ) during pacing of the right ventricular apex with a basic cycle length of $500 \mathrm{~ms}$ a ventricular premature beat given after 420 ms was condacticd retrogradely to lhe atria wath an $\$ 2 A 2$ interval of $270 \mathrm{~ms}$ and an $\mathrm{A} / \mathrm{A} 2$ incerval of $440 \mathrm{~ms}$ (panel A). A premature beat givem in lhe ventricle 10 ms earlie (panel $B$ ) results in a marked increase in the retrograde conduction time ( $\$ 2 \mathrm{A2}$ ) $10.350 \mathrm{~ms}$ and a corresponding A 1 A2 interval of $510 \mathrm{~ms}$. A "reversed" (fast-slow) A-V nodal echo follows. This indicates that the refractory period of the fast pathway is approximately $410 \mathrm{~ms}$ (no retrograde His is observed during basic paced beats or following the vent ricular premature beat). After atropine (panels $C$ and $D$ ) pacing at lhe right ventricle with a shorter basic cycle length (440 ms) than in panels $A$ and $B$ shows retrograde conduction to the atria with a shorter $S 1 \mathrm{~A} I$ interval $(250 \mathrm{~ms}$ in panels $A$ and $B$ and $120 \mathrm{~ms}$ in pands $C$ and $D)$. A ventricular premature beat given after $210 \mathrm{~ms}$ is still retrogradely conducted to the atria over the fast $A$-V nodal pathway. the $12 \mathrm{~A} 2$ interval measuring $160 \mathrm{~ms}$ ( $p$ and $C$ ). On futher shortenimg of the interval of the ventricular premature teste pulse $10200 \mathrm{~ms}$ is reached the refractory period of the ventricte. Atropine therefore resulted in shortening of tetrograde conduction time during basic pacing and in shortening of the refractory period of the retrograde pathway with disappearance of $\mathrm{A}-\mathrm{V}$ nodal echoes during ventricular stimulation. 5 surface leads were simultaneously recorded with one endocavitary bipolar electrogram from the RA and threc electrograms from the distal (d). mid (m) and proximal (p) His bundle arefit. 

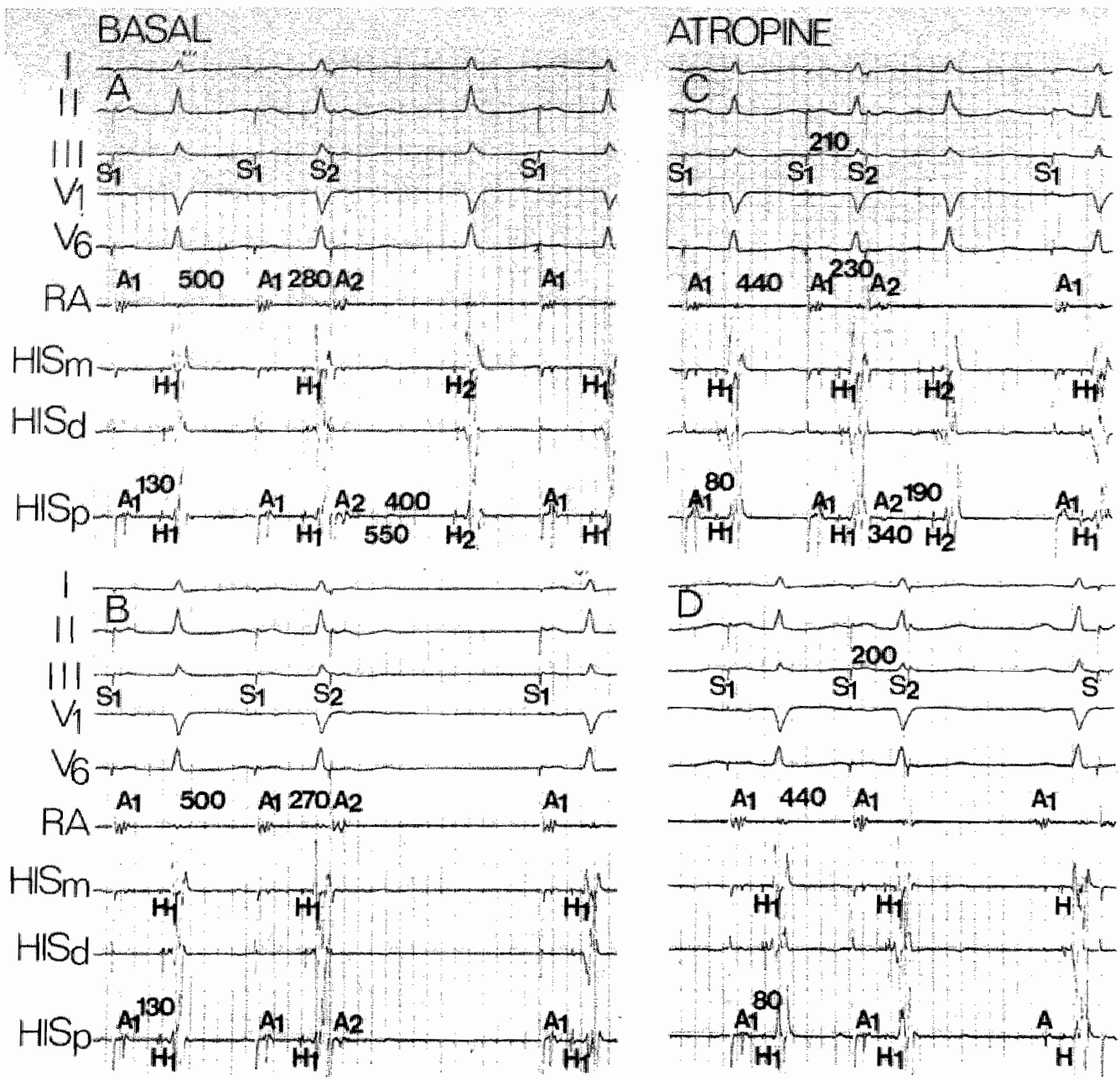

Figurats

Samo patient as fig. 7. Atral stimulation studies before and afier atropine. Before atropine (panels $\mathrm{A}$ and $\mathrm{B}$ ) a discontinuty in the conduction curve was present when dering pacing the right atrum with a basic cycle length of 500 ms an atrial premature beat was given after $310 \mathrm{~ms}$. Further shortening of the atrial premature beat interwat $10280 \mathrm{~ms}$ resulted in sn A2 212 interval of $400 \mathrm{~ms}$, the longest observed during atrial stimulation (panel A). It was not followed by initiation of te-entry in the A-V node most likely because the anterograde conduction time in the slow pathway was not long enough to overcome refractoriness of the retrograde fast pathway (which as shown in fig. 7 panel B measured $410 \mathrm{~ms}$ ). On further shortening of the interval of the at rial test pulse $10270 \mathrm{~ms}$ (panel B) the refractory period ot the slow A-V nodal pathway was reached. After at ropine the anterograde conduction curves of the $A \cdot V$ node became continuous. Pacing of the right atrium at a basic cycle length of $440 \mathrm{~ms}$ resulted in anterograde conduction to the ventricles with an $\mathrm{A} 1 \mathrm{H} \mathrm{I}$ interval of 80 ms $60 \mathrm{~ms}$ shorter than in panel $A$ and $B$ dong pacing with a cycle length of $50 \mathrm{~ms}$. An atrial prenature beat given after $230 \mathrm{~ms}$ is conducted to the ventrieles with an $\mathrm{A} 2 \mathrm{H} 2$ interval of $190 \mathrm{~ms}$ and a $\mathrm{H} 1 \mathrm{H} 2$ interval of 340 ms. On further shortening of the test stimulus interval by 10 ms the refractory period of the right atrium was reached. After altropine no re-entry in the A-V node could be initiated after atropine both during ventricular (fig. 7) and altral stimalation. Three surface leads are shown simultancously with four endocavitary bipolar clectrograms. 
The determinants of initiation of $A=V$ nodai tachycardia in patients having electrocardiographic documentation of the arrhythmia have been studied by several authors (1-8). They all stressed the importance of the classical conditions required to initiate and sustain a re-entrant loop:

a. presence of two electrophysiologically different pathways,

b. uniclirectional block,

c. conduction which is slow enough to overcome refractoriness of the formerly blocked pathway and

d. ability of both pathways to sustain sequential conduction.

Different electrophysiological methods have been used to assess the properties of the $A-V$ nodal pathways, a major problem being the assessment of the retrograde properties of the fast pathway. In the present study we have used an approximation of the retrograde properties of the A.V node by measuring the $\mathrm{V} 1-\mathrm{V} 2, \mathrm{H} 1-\mathrm{H} 2$ or the $\mathrm{S} 1-\mathrm{H} 2$ interval during ventricular stimulation. In this way we have studied the refractoriness of the retrograde fast pathway. We realize that this method is not accurate but the only way to obtain in patients of group $B$ an idea of the refractory period of the retrograde fast pathway. In all of them the initiation of "reversed" A-V nodal echoes at the time of the discontinuity in the retrograde conduction curve proved the $A-V$ node to be the site of origin of the discontinuity in the conduction curve. In patients with documented supraventricular tachycardia (group A) we could show the presence of a continuous retrograde conduction curve, in most of them suggesting a short retrograde refractory period of the fast pathway. This was in contrast with the results obtained in patients of group B having no documentation of

supraventricular tachycardia. In most of them we could demonstrate the presence of a discontinuous retrograde conduction curve suggesting a rather long refractory period of the retrograde fast pathway. By obtaining an approximate value of the refractory period of the retrograde fast pathway we were able to show in patients of group A that the A-H intervals over the slow pathway were sufficiently prolonged to overcome retrograde refractoriness of the fast pathway. In contrast, in patients of group B, even when the A-H intervals over the slow anterograde A-V nodial pathway were similar to those of group A patients, they were not long enough to overcomc refractoriness of the retrograde fast $A-V$ nodal pathway. These findings indicate that one can rapidly get information about the likelihood of initiation of $A-V$ nodal tachycardia at the start of the study by looking for the presence or absence of a discontinuity in the retrograde conduction curves during single test stimulation of the ventricle. Our data demonstrate that a long refractory period of the retrograde fast pathway hampers ease of initiation of tachycardia.

The majority of the patients receiving at ropine showed marked shortening in the refractory period of the retrograde fast pathway during ventricular stimulation. Initiation of tachycardia was facilitated by atropine-induced shortening of the refractory period of the retrograde fast pathway. This mechanism of facilitation of intiation of A-V nodal tachycardia has been described by other authors however in patients with electrocardiographic documentation of the arthythmia (20-22). Our study extends these observations to patients without documentation of supraventricular tachyable

In 5 of the patients of group B (table II) we were able to initiate a sustained A-V nodall tachycardia after atropine administration. The mechanism by which initiation of tachycardia was facilitated was the same as in patients hawing documented recurrent paroxysmal $A \cdot V$ nodal tachycardia. In eight patients of group B, however, the conditions required to initiate and maintain re-entry in the A-V node were not induced by atropine, and tachycardia could not be initiated. Six out of 7 patients (in one patient ventricular stimulation was not performed after atropine) showed shortening of the refractory period of the retrograde fast pathway. Two mechanisms prevented initiation of reentry in the A-V node following atropine in these patients:

In five the anterograde conduction curve became continuous after atropine because of shortening in the anterograde refractory period of the fast pathway. In the remaining patient showing anterograde discontinuous curves following atropine marked shortening of the A-H interval over the slow pathway during atrial stimulation, probably prevented retrograde activation of the fast pathway and initiation of reentry. One patient showed no $\mathrm{V}-\mathrm{A}$ conduction following atropinc. 
The exact level of $\mathrm{V}$-A block after atropine could not be determined in this patient. These observations indicate that in paticnts without elcctrocardiographic documentation of $\mathrm{A}-\mathrm{V}$ nodal tachycardia in whom the arrhythmia can be initiated following administration of atropine the mechanism of facilitution of initiation of the arrhtymia was shortening of the retrograde refractory period of the fast pathway. Although initiation of tachycardia occurred in some patients of group B, atropine-induced changes in the anterograde conduction curves, leading to continuous anterograde $A$-V nodal conduction prevented initiation of tachycardia in the majority of them.

Analysis of the results of programmed clectrical stimulation in the two groups of patients studied show that initiation of $A-V$ nodal tachycardia by this technique is casier in patients with electrocardiographic documentation of the arrhythmia (group A) as compared to patients with duall $A-V$ nodal pathways but without documented tachycardia. These data are in agreement with previous experiences by other authors (9). In most of our patients with documented supraventricular tachycardia we could initiate the arrhythmia in the basal state by a single atrial premature beat during atrial pacing. In these patients the conditions for rexentry in the A-V node were already present in the basal state except for unidirectional block which was created by the premature impulse. In patients without documented tachycardia, however a long retrograde refractory period of the fast pathway prevented initiation and/or perpetuation of re-entry of the common type in the $A-V$ node. A minority of patients of group $A$ required atropine to initiate the arrhythmia, in contrast to a majority of group $B$ patients. The presence of a discontimuous conduction curve in the $A-V$ node, even when retrograde, has been considered a possible marker of A-V nodal tachycardia in patients without documented arrhyhtmias suffering from palpitations (23). This is not the opinion of all authors (11-12). It has been shown that in arrhythmia-free children discontinuous $A-V$ nodal conduction curves during atrial stimulation are far from rare a (11-12). We have shown that in patients with a discontinuous retrograde conduction curve initiation of a sustained "roversed" (fast-slow) intra-A-V nodal tachycardia is unlikely (18). All our patients having a sustained A-V junctional tachycardia with a P-R interval shorter than the R$P$ interval in the presence of discontinuty in the curves of ventriculo-atrial conduction suffered from a tachycardia with a slowly conducting accessory A-V pathway with decremental conduction propertics incorporated in the tachycardia circuit.

We conclude that electrophysiologic studies of the A-V node in most patients clinically suffering from A-V nodal tachycardia of the common (slow-fast) type reveal discontinuous anterograde conduction curves and continuous retrograde conduction curves. In patients with dual A-V nodal pathways but no dlocumented tachycardia manipulation of the autonomic system will facilitate induction of A-V nodal tachycardia when this results in abbreviation of the duration of the refractory period of the retrograde fast pathway to values below the conduction time of the anterograde slow A.V nodal pathway. "The clinical significance of this arrhythmia is presently unknown.

\section{References}

1. Rosem KM, Mehta A, Miller RA: Demonstration of dual atrioventricular nodal pathways in man. Am J Cardiol 33:291., 1974.

2. Wu D, Denes P, Wyndham $C$. Amat-y-Leon F, Dhingra RC, Rosen KM: Demonstration of dual A-V nodal pathways entilizing a ventricular extrastimulus in patients with atrioventricular nodal re entrant paroxysmal supraventricular tachycardia. Circulation $52: 789.1975$.

3. Rosen KM, Denes $P, W u D$, Dhingra RC, Electrophysiological diagnosis and manifestations of dual $A-V^{\prime}$ nodal pathways. In: The conduction systern of the heart, edited by Wellens HJJ, Lie KI. Janse MJ. Leiden: Stenlert-Kroese BV; $1976 ; 453 m 66$.

4. Wellens MJJ. Durrer D: The role of an accessory atrioventricular pathway in reciprocal tachycardia. Circulation 51:997. 1975. 
5. Touboul P, Huerta F, Porte J, Delahaye JP. Reciprocal rhythm in patients with woitual dectrocardiogram: exidence for dual conduction pathways. Am Heart J $91: 3,1976$.

6. Denes P. Wu D, Amat-Y-Leon $\mathbb{F}$, Dhangra RC, Wyndham CR, Resen KM: The determinats of atrioventricular

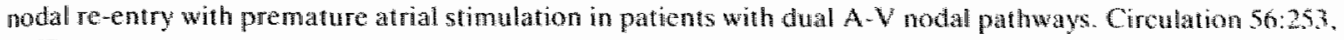
1977.

7. Pritchett ELC, Gallagher JJ, Wallace AG: Re-entry within the arrovemtricular node in nan: an rossesement. Eur J Cardiol 6/6:437, 1978

8. Ahtar M: Paroxysmal atroventricular nodal re-cntrant tachycardia. In: Cardac arthythmiss. edited by Nartla OS. Baltimore: The Willams and Wilkins CO.. 1979:294-317.

9. Wellens HJJ: Value and limitations of programmed electrical stimulation of the heart in the study and treatment of achycatias. Circulation $57: 845.1977$.

10. Denes P. Wu D, Dhingra $R$, Amat-y-Leon $F$, Wyndham C, Rosen KM: Dual atrio-ventricular nodal pathways. A common electrophysiological response. Br. Heart J 37: 1069, 1975.

1. Thapar MK, Gillete $\mathbb{P C}$. Dual atrioventricular nodal pat hways: A common electrophysiolgic response in children. Circulation 60:1369, 1979.

12. Casta A, Wolf GS, Mehta AV, Tamer D, Garcia OK, Pickoff A, Ferrer PI., Sung RJ, Gelband H: Dual atrioventricular nodal pathways: A benign finding in arrhybumia-free chuldren wh heart disease. Am I Cardiol 46:1013. 1980.

13. Ross D, Farré J, Bär FWHM, Dassen WRM, Wiener I, Wellens HIJ: Comprehcensive clinical electrophysiological studies in the irvestigation of documented or stspected tachycardias. Circulation 61 : I010. 1980 .

14. Josephson ME, Seides SF: Clinical cardiac electrophysiology. Philadelphia: Lea \& Febiger, 1979; $23-59$.

15. Brugada P, Ross D, Bär WHM, Vanagt FJ, Dassen WRM, Wellens HJJ: Obsenvations on spontaneous lermination of atrioventricular nodal re-entrant tachycandia. Am J Cardiol 47:703, 1981.

16. Akhtar M, Damato AN, Ruskin JN, Batsford WP, Reddy CP, Ticzon AR, Dhatt MS, Gomes JAC, Calon AH: Anterograde and retrograde conduction characteristics in three patterns of paroxysmal atrioventricular junctional re-entrant tachycardia. Am Heart J 95:22, 1978.

17. Farré $\mathbf{J}$, Wellens HJJ. The walue of the electrocardiogram in diagnosing the mechanism and site of origin of supraventricular tachycardia. In: What's new in electrocardiography, edited by Wellens HJI and Kulbertus HE. The Hague: Martinus Nijhoff Publishers, 1981; 131-71.

18. Brugada P, Bär FWHM, Varagt E.J, Friedman PI., Wellens H.J.: Obserwations in patients showing A-V junctional echoes with a shorter P-R than R.P interval. An J Candiol 48:611.1981.

19. Sung RJ, Waxman HL: Physiological shift of retrograde attriowentricular todat autput mimicking retrograde accessory pathway conduction Circulation 59.60): (5uppl. I1) 11. 191. 1979.

20. Neuss H, Schlepper M, Spies HF "De Mey CH. Effects of heart rate and atropine on "dual AV conduction". Br Heart J $37: 1216,1975$.

21. Akhtar M, Damato AN, Batsford WP, Caracta AR, Ruskin JN, Weisfogel GM, Iau SH: Inuluction of atroventricular nodal re-entwant tachycarda after atropine. Am J Cardiol $36: 286,1975$.

22. Wu D, Denes $\mathbf{P}$, Bauerinfelnd $\mathbb{R}$, Dhingra $R$, Wyndham $\mathbf{C}$, Rosen KM: Effects of atropine on ind uction and mantenance of atrioventricular nodall re-cntrant tachycurdia. Circulation 59:779. 1979.

23. Strasberg $\mathrm{E}$, Swiryn S, Bauernfeind $R$, Palileo $\mathbb{E}$, Scagliotti D, Flise Dufry C, Rosen KM: Retrogradic dual atrioventricular nodal pathways. Am J Cardiol 48:639, 1981. 


\title{
Dual atrio-ventricular nodal pathways and atrial fibrillation
}

\author{
Pedro Brugada, M.D.; Denis Roy, M.D.; Jim Weiss, M.D.; Willem R.M. Dassen. Ph.D.; Frits
} W.H.M. Bär, M.D.; and Hein J.J. Wellens, M.D.

From the Deparment of Cardiology, University of Limburg, Annadal Hospital. Moastricht, The Nerthertands.

\section{Summary}

The determinants of the ventricular rate during atrial fibrillation were studied in a group of eleven patients demonstrating dual $A-V$ nodal pathways during atrial stimulation. The shortest $R-R$ interval and the mean ventricular cycle length during at least 1 min of pacing induced atrial fibrillation were compared a) to the effective and functional refractory period of the fast pathway, b) to the effective refractory period of the slow pathway determined during atrial stimulation, at two or more different basic cycle lengths of pacing and c) to the shortest cycle length during atrial stimulation followed by 1-to-1 A-V conduction. A group of 8 patients not demonstrating dual $\mathrm{A}-\mathrm{V}$ nodal pathway-curves during atrial stimulation was used as control.

In both groups the shortest $\mathbb{R} \cdot \mathrm{R}$ interval during atrial fibrillation was best predicted by the shortest cycle length followed by 1-to-1 A-V conduction during atrial stimulation. The mean ventricular cycle length during atrial fibrillation was not accurately predicted by any of the variables studied. The similar results in patients with and without dual $\mathrm{A}-\mathrm{V}$ nodal pathways suggest that retrograde concealed conduction in the fast pathway does not play a role in determining the ventricular response during atrial fibrillation in patients with dual A-V nodal pathways.

\section{Introduction}

The electrophysiological properties of the normal A-V node protect the wentricle against supraventricular rhythms with excessively fast rates (1-2). The decremental conduction properties of the A-V node and its rather long refractory period at rest result in ventricular rates that rarely exced 180 beats/min in the normal individual (2). Concealed conduction in the A-V node is known to play an important role in the ventricular response during atrial fibrillation (1). The technique of programmed electrical stimulation of the heart has been of help to demonstrate longitudinal dissociation of the A-V node into different electrophysiological pathways (3). "The determinants of the ventricular rate during atrial fibrillation in the presence of dual A-V nodal pathways are not known. In patients with dual A-V nodal pathways retrograde concealed conduction from one to another pathway might result in a different pattern of A-V conduction during atrial fibrillation than in patients not having dual $A-V$ nodal pathways. We therefore compared a group of eleven patients with dual $A-V$ nodal pathways and a control group of eight patients without dual A-V nodal pathways. In both groups of patients a similar pacing protocol was used during atrial stimulation to assess the properties and patterns of $A$-V conduction. The results of this study are reported here.

\section{Patients and methods:}

Patients were included in this study when the following criteria were fulfilled:

a. Sinus rhythm at the time of study.

b. A complete electrophysiologicat investigation using our previously described protocol of stimulation, recording, and analysis of tracings (4).

c. No accessory pathways. 
d. A duration of atrial refractoriness not preventing determination of the exact values for the refractory periods of the A-V nodal pathway(s). e. At least one episode of pacing induced atrial fibrillation lasting at least 1 minute.

f. No antiarrhythmic medication

Patients having discontinuous $A-V$ nodal conduction curves but having a refractory period of the slow A.V nodal pathway which was less than the refractory period of the atrium were not included in this study. This markedly limited the number of patients considered for inclusion.

Nineteen patients out of a series of 370 consecutive paticnts studied by programmed electrical stimulation of the heart were included. Following informed consent they were studied because of a variety of reasons (table 1$)$. There were 15 males and 4 females. Aged ranged from 15 to 70 years. Eleven patients (group A) demonstrated the presence of dual A-V nodal pathway and eight paticnts (group B) not. Catheters were introduced in the femoral veins under fluoroscopic control and placed at the right atrium, right ventricular apex, His bundle area and in the coronary sinus in all but one patient (patient 7) of group A and in three patients of group B (patients 13-15). Simultaneous recordings were made of the surface leads I, II, III, V1 and V6 and bipolar endocavitary electrograms in the right atrium (RA), proximal and distal coronary sinus (CSp, CSd) when available, and His bundle. Atrial stimulation was performed using at least two different basic cycle lengths of pacing. Five patients in group $A$ and 2 patients in group $B$ had three and 2 patients in group $A$ and $I$ in group $B$ four cycle lengths tested. The extrastimulus technique was used to determine patterns of A-V conduction and reftactory periods. The prematurity of the test pulse was increased by $10 \mathrm{~ms}$ steps. Incremental atrial pacing was performed starting with a rate just above the spontaneous simus rate and every $10-15$ seconds increased in steps of 10 beats/min. This was done without interrupting pacing, to the pacing rate where the 1-to-1 A-V relation was lost, and usually thereafter continued until 2-to-1 A-V conduction developed. The Wenckebach point indicated in our patients failure of the anterograde fast $A-V$ nodal pathway.

The presence of dual A-V nodal pathways was diagnosed when a discontinuous A-V nodal conduction curve was present. A discontinuity in the anterograde (A1A2/H1H2;A1A2/A2H2) A$V$ nodal conduction curve was defined as a reproduceable increase by $40 \mathrm{~ms}$ or more in the A-V nodal conduction time of a premature beat when its prematurity was increased by $10 \mathrm{~ms}(5)$, and by the curve fitting method described by Rosen et al (3).

All patients in group A, and none in group B demonstrated the atypical form of Wenckebach sequence described by Rosen et al. (3) during incremental atrial pacing. These patients showed sudden increases in A-H interval at the Wenckebach point, a finding consistent with the presence of dual A-V nodal pathways. The effective refractory period (ERP) of the fast (f) A-V nodal pathway was defined as the longest A 1-A2 interval not conducted over this pathway. The ERP of the slow (s) A.V nodal pathway was defined as the longest A1-A2 interval not conducted over this pathway. The functional refractory period (ERP) of the fast A-V nodal pathway was defined as the shortest $\mathrm{H} 1 \mathrm{H2}$ interval resulting from any $\mathrm{A} 1 \mathrm{~A} 2$ anterogradely conducted over the fast pathway. Wo have previously shown that the atrial stimulation site modifies the A-H intervals but not refractoriness of the A-V node in patients with dual A-V nodal pathways (6). However, in view of the observations by Batsford et al. (7) who found significant differences in A-V nodal properties depending on the atrial stimulation site in patients without dual $A-V$ nodal pathways, only results of right atrial stimulation were used. After studies were performed during sinus rixythm atrial fibrillation was induced in these patients by high rate (300-500 beats/min) atrial stimulation. The shortest $R-R$ interval during atrial fibrillation and the mean ventricular cycle length were assessed by measuring them over a continuous 1 min period of atrial fibrillation. Measurements were made at a paper speed of $100 \mathrm{~mm} / \mathrm{s}$

The ERPf, ERPs, FRPI and shortest cycle length followed by 1-to-1 A-V conduction were compared to the shortest $\mathrm{R}-\mathrm{R}$ interval and mean ventricular cycle length during atrial fibrillation, looking for the best fit with the line of identity. 


\section{Results}

A summary of the electrophysiologic studies is given in table I.

Table I

Summary of clinical and electrophysiollogical data of patients studied

\begin{tabular}{|c|c|c|c|c|c|c|c|c|c|}
\hline$P f$ & Age/sex & $\begin{array}{l}\text { clinical } \\
\text { diagnosis }\end{array}$ & $B C L$ & ERPf & $E R P_{s}$ & FRPf & $\begin{array}{c}\text { ShCL } \\
1-10-1\end{array}$ & $\begin{array}{c}S h R R \\
A f b\end{array}$ & $\begin{array}{c}M V C L \\
A f i b\end{array}$ \\
\hline
\end{tabular}

Group A

\begin{tabular}{|c|c|c|c|c|c|c|c|c|c|}
\hline 1 & $22 \mathrm{M}$ & SVT/AOS & $\begin{array}{l}750 \\
600\end{array}$ & $\begin{array}{l}300 \\
310\end{array}$ & $\begin{array}{l}230 \\
330\end{array}$ & $\begin{array}{l}450 \\
430\end{array}$ & 400 & 400 & 600 \\
\hline 2 & $15 \mathrm{M}$ & SVT & $\begin{array}{l}600 \\
500\end{array}$ & $\begin{array}{l}290 \\
290\end{array}$ & $\begin{array}{l}280 \\
280\end{array}$ & $\begin{array}{l}430 \\
430\end{array}$ & 370 & 360 & 468 \\
\hline 3 & $52 \mathrm{~F}$ & SVT & $\begin{array}{l}680 \\
500\end{array}$ & $\begin{array}{l}360 \\
360\end{array}$ & $\begin{array}{l}220 \\
250\end{array}$ & $\begin{array}{l}440 \\
440\end{array}$ & 300 & 290 & 375 \\
\hline 4 & $49 \mathrm{~F}$ & SVT & $\begin{array}{l}500 \\
450\end{array}$ & $\begin{array}{l}280 \\
330\end{array}$ & $\begin{array}{l}250 \\
270\end{array}$ & $\begin{array}{l}380 \\
400\end{array}$ & 300 & 280 & 384 \\
\hline 5 & $62 \mathrm{M}$ & SVT & $\begin{array}{l}600 \\
550\end{array}$ & $\begin{array}{l}280 \\
270\end{array}$ & $\begin{array}{l}230 \\
260\end{array}$ & $\begin{array}{l}390 \\
370\end{array}$ & 333 & 310 & 441 \\
\hline 6 & $40 \mathrm{M}$ & SVT & $\begin{array}{l}600 \\
500\end{array}$ & $\begin{array}{l}370 \\
370\end{array}$ & $\begin{array}{l}270 \\
270\end{array}$ & $\begin{array}{l}470 \\
500\end{array}$ & 400 & 380 & 500 \\
\hline 7 & $53 \mathrm{M}$ & $\begin{array}{l}\text { LBBB/ } \\
\text { Asympt }\end{array}$ & $\begin{array}{l}850 \\
600\end{array}$ & $\begin{array}{l}410 \\
400\end{array}$ & $\begin{array}{l}350 \\
340\end{array}$ & $\begin{array}{l}500 \\
500\end{array}$ & 450 & 490 & 714 \\
\hline 8 & $69 \mathrm{M}$ & SVT & $\begin{array}{l}600 \\
500\end{array}$ & $\begin{array}{l}370 \\
370\end{array}$ & $\begin{array}{l}300 \\
320\end{array}$ & $\begin{array}{l}450 \\
450\end{array}$ & 400 & 380 & 600 \\
\hline 9 & $45 \mathrm{M}$ & Palp. & $\begin{array}{l}600 \\
500\end{array}$ & $\begin{array}{l}440 \\
400\end{array}$ & $\begin{array}{l}230 \\
260\end{array}$ & $\begin{array}{l}500 \\
430\end{array}$ & 353 & 300 & 340 \\
\hline 10 & $19 \mathrm{M}$ & $S V \mathbb{T}$ & $\begin{array}{l}600 \\
550\end{array}$ & $\begin{array}{l}290 \\
290\end{array}$ & $\begin{array}{l}280 \\
280\end{array}$ & $\begin{array}{l}590 \\
590\end{array}$ & 300 & 310 & 500 \\
\hline 11 & $70 \mathrm{M}$ & SVT & $\begin{array}{l}600 \\
500\end{array}$ & $\begin{array}{l}290 \\
270\end{array}$ & $\begin{array}{l}270 \\
250\end{array}$ & $\begin{array}{l}350 \\
330\end{array}$ & 333 & 320 & 435 \\
\hline
\end{tabular}

In patients of group A the ERPf ranged from 270 to $440 \mathrm{~ms}$, the ERPs from 220 to $350 \mathrm{~ms}$, and the FRPf from 330 to $590 \mathrm{~ms}$. In patients of group B the ERP of the A-V node ranged from 220 to 450 $\mathrm{ms}$, and the FRP of the A-V node from 310 to $550 \mathrm{~ms}$. The shortest cycle length during atrial stimulation followed by 1-to-1 A-V conduction ranged from 300 to $450 \mathrm{~ms}$ in patients of group A, and from 300 to 500 in group B.

Using the unpaired student"s T-test group $A$ and $B$ did not differ significantly in any measured parameter.

Shortest R-R interval during atrial fibrillation ranged from 280 to $490 \mathrm{~ms}$ in patients of group A. Those values were not accurately predicted from the data on ERPf, FRPf and ERPs (fig. 1). The shortest R-R interval during atrial fibrillation was best predicted from the shortest cycle length during atrial pacing followed by 1-to- $1 \mathrm{~A}-\mathrm{V}$ conduction (fig. 1).

Similar results were obtained in patients of group B, where the shortest cycle length with 1-to $1 \mathrm{~A}$ - 


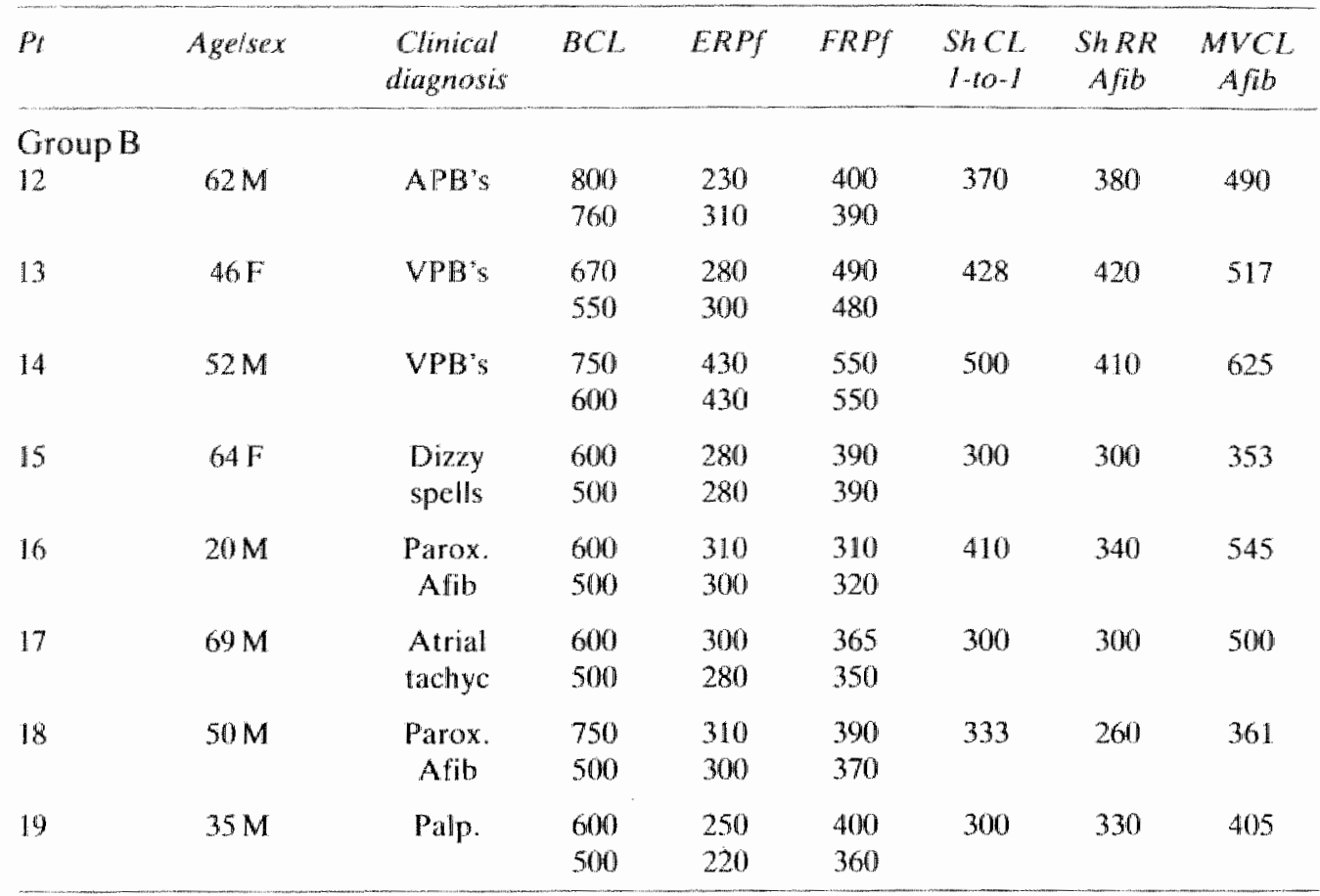

Age in years. Albreviations: SVT: suprawentricular tachycardia. AOs: aortic stenosis. LBBB/asympt: asymptomatic patient with teft bundle branch block. Palp: palpitations. APB's: atrial premature beats. VPB"s: ventricular premature beats. BCl: basic cycle length of pacing. ERPf: Effective refractory period of the fanst A.V nodal pathway, ERPs. flfective refractory period of the slow A-V nodal pathway. FRPE: Functional refractory period of the fast $A-V$ nodal pathway. Sh CL 1-to-1 AV conduction during atrial stimulation at inceasing rates. Sh RR Afib: Shortest RR interval during atriallibrillation. MVCL Afib: Mean ventricular cycle length during atrial fibrillation. All values in milliseconds.

$V$ conduction during atrial pacing best predicted the shortest $R$ - $R$ observed during atral fibrillation. But this was not predicted accurately by any other of the variables studied (ERPf, FRPf, ERPs) (Fig. 1).

Mean ventricular cycle length during atrial fibrillation ranged from $34040714 \mathrm{~ms}$ in patients of group $A$, and from 353 to $625 \mathrm{~ms}$ in patients of group B. In both groups the ERPf. FRPf, ERPS and shortest cycle lengtl with 1-to-I A-V conduction did not accurately predict the mean ventricular cycle length during atrial fibrillation (Fig. 2).

\section{Distribution of R-R intervals.}

Most of our patients had short-lasting ( 1 to $3 \mathrm{~min}$.) atrial fibrillation and analysis of the distribution of R-R intervals was hampered because of the short observation period. In four patients, however, more than 500 cycles during atrial fibrillation were available. Two patients were in group $A$ and two patients in group B. R-R intervals in these four patients followed a unimodal distribution curve during atrial fibrillation (Fig. 3). None of these 4 patients showed a bimodal distribution curve which may be observed in the presence of two A-V pathways. The ventricular response was irregular in all patients of group $A$ and group $B$. The mean difference between shortest $R-R$ interval and mean ventricular cycle length during atrial fibrillation was $137.9 \mathrm{~ms}$ in patients of group $A$ and $117.3 \mathrm{~ms}$ in patients of group $B$. These results were not significantly different, 


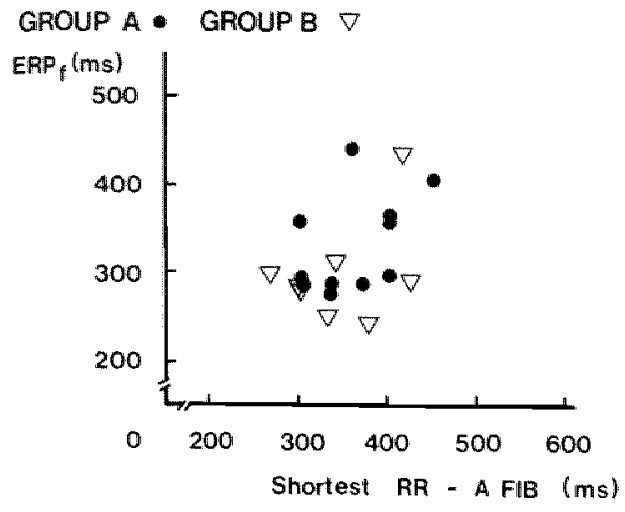

GROUP-A • GROUP B $\nabla$

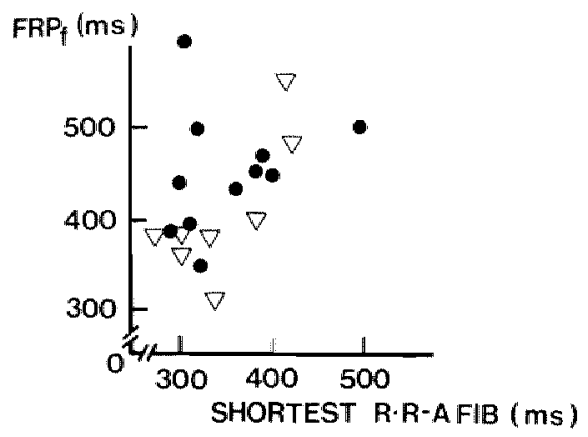

GROUPA *

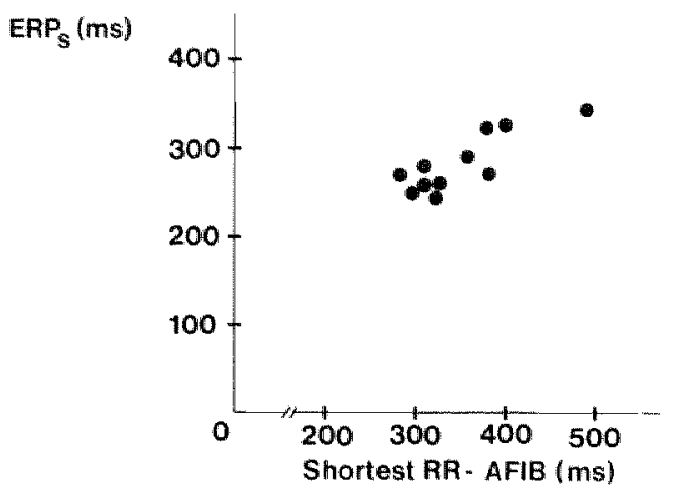

GROUP - A • GROUP B

Shortest CL $1-1$ (ms)

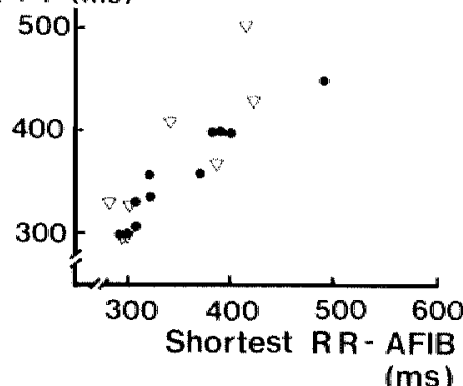

Figure 1

Relationships between the shortest $R-R$ interval during atrial fibrillation and the ERPf, ERPs, FRPf and shortest cycle length (CL) followed by 1-to-1 AV conduction during atrial pacing.

The shortest CL followed by $1-10-1$ AV conduction was the best predictor of the shortest $R-R$ interval during atrial fibrillation in both groups. Only the longest cycle length of pacing tested during right atrial stimulation is depicted in this figure and figure 2. Results were similar when the shortest cycle length of pacing used or combinations of the shortest and the longest were studied.

\section{Discussion}

The results of this study indicate that the determinants of the ventricular rate during atrial fibrillation (shortest $R-R$ interval and mean ventricular cycle length) are not affected by the presence or absence of dual A-V nodal pathways as demonstrated by atrial stimulation.

Some limitations of this study are obvious. First, we cannot exclude that patients of group $B$ also had longitudinal dissociation of the $A-V$ node. When the anterograde fast pathway has a refractory period which is shorter than the refractory period of the slow anterograde pathway discontinuities in the A-V nodal conduction curve will not be present, and a diagnosis of dual A-V nodal pathways cannot be made. Patients of group $A$ and $B$ underwent a similar stimulation protocol and the $A-V$ nodal conduction curves behaved differently during stimulation. The ventricular response during atrial fibrillation was however similar. Only the shortest cycle length

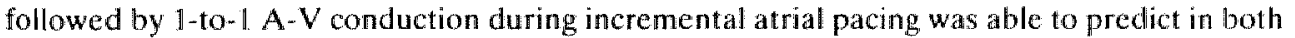
groups the shortest $R-R$ interval during atrial fibrillation. None of the variables studied could predict the mean ventricular cycle length during atrial fibrillation in any group. Second, the possibility exists that the similarity in ventricular response during atrial fibrillation in both groups 


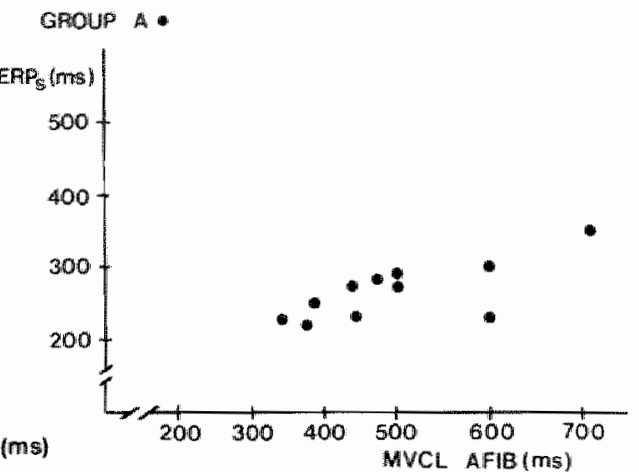

GROUP-A * GROUP B

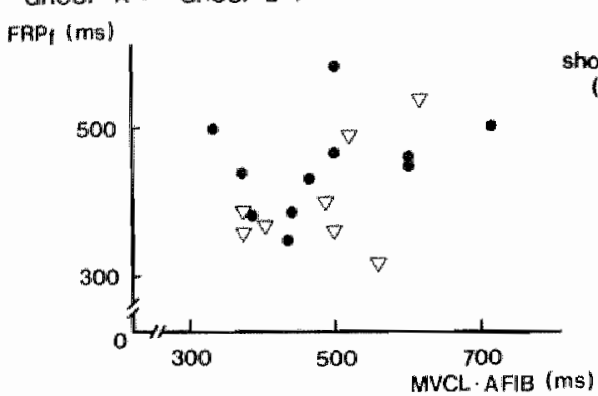

GROUP A - GROUP B $\square$

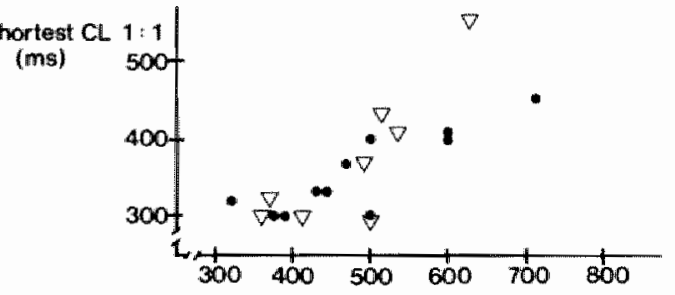

MVCL AFIB (ms)

Figure 2

Relationships between the mean wentrictar cycle length (MVCL) during atrial fibrillation and the ERPE. ERPS, FRPf and shortest CL with 1 -to-1 AV conduction during atrial pacing.

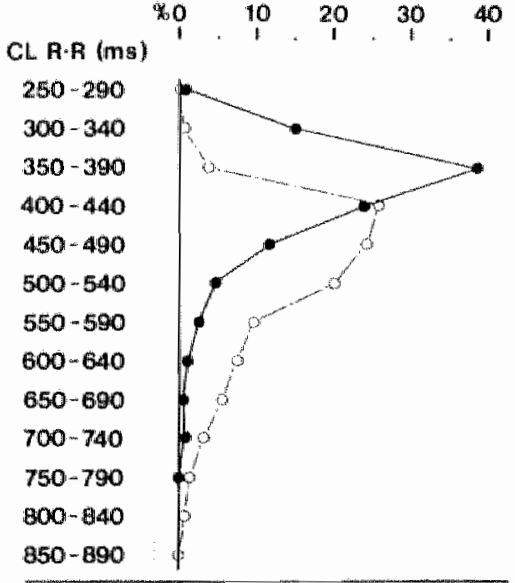

Figure 3

Distribution of $R-R$ intervals duning atrial fibrillation in two patients in whom 600 ventricular cycles were measured. Distribution of R-R intervals was unimodal in the patient of group A (solid line - closed circles) and in the patient of group B (broken line - open circles). 
was the result of a similar behaviour of the distal common pathway (the His bundle) while the A$\checkmark$ nodal output might be different. His bundle recordings were available in all patients during atrial fibrillation. A-V block distal to the His bundle was never observed. Third, these were selected patients from a population demonstrating dual A-V nodal pathways, and it is difficult to generalize the conclusions reached here to the whole population of patients showing dual A-V nodal pathways.

Concealed conduction in the $\mathrm{A}-\mathrm{V}$ junction is known to play a role in the ventricular response during atrial fibrillation (1). Impulses penetrating the $A-V$ node not being anterogradely conducted ate able to delay or block conduction of subsequent impulses. It has also been shown that concealed re-entry in the $A V$ node occurs during atrial pacing (8-11). The question arises therefore whether in the presence of dual $A=V$ nodal pathways additional concealed retrograde conduction in the fast $\mathrm{A}-\mathrm{V}$ nodal pathway can play a role in the behaviour of $\mathrm{A}-\mathrm{V}$ conduction during atrial fibrillation. The similar results obtained in this limited number of observations in patients of group A and group B suggests however, that in patients with dual A-V nodal pathways concealed retrograde conduction into the fast A-V nodal pathway does not play a role in the shortest $R-R$ interval and mean ventricular cycle length during atrial fibrillation.

The studies of Meijler et al. (12) are pertinent to our observations. Investigations performed by these authors in rat and dog hearts, and during clectrophysiological investigations in patients, showed small differences in A-V nodal menory (time required to accommodate A-V nodal conduction to changes in atrial rate) when compared to the differences in size of the A-V nodes of these species. Human A-V nodal memory was found to be relatively short compared to the average $R-R$ intervals during atrial fibrillation. They concluded that the ventricular irregularity during atrial fibrillation is caused primarily by the random excitatory process of the atria. The role of the A-V node in the ventricular response is limited to scaling down the atrial impulses, at resuli of the interplay between refractoriness and concealed conduction. A-V nodal memory was too short to affect conduction of subsequent impulses. Our data, with similar results in patients of group $A$ and $B$ would suggest that $A$-V nodal memory plays no role in the ventricular response in patients with duall A-V nodal pathways. Unfortunately we did not specifically study $A \cdot V$ nodal memory in our patients.

In conchusion, the ventricular response during atrial fibrillation in patients with dual A-V nodal pathways does not seem to differ from the ventricular response during atrial fibrillation in patients not demonstrating dual A-V nodal pathways during atrial stimulation studies. 


\section{References}

1. Langendorf R, Pick A, Katz $L N$ : Ventricular response in atrial fibrillation. Role of concealed conduction in the A-V junction. Circulation 32:69, 1965

2. Godtredsen J: Atrial fibritlation. Eliology, course and prognosis. A follow-up study of 1212 cases. Uniwersity of Copenthagen press. 1974, p. 107-9.

3. Rosen KM, Denes P, Wu D, Dhingra RC: Electrophysiological diagnosis and manifestations of dual A-V nodal pathways. In: The conduction system of the heart. Edited by Wellens H.J.J. Lie KI, Janse MJ. HE Stenfert Kroese BV. Leiden 1976, p. 453-66.

4. Ross DL, Farret J, Bär FWHM, Vanagt EJ, Dassen WRM, Wiener I, Wellens HJJ: Comprehensiwc cilectrophysiological studies in the investigation of documented or suspected tachycardias: times, stafi, problems and costs involved. Circulation 61:1010, 1980

5. Wellens HJJ, Durrer D: The role of an accessory atriowentricular pathway in reciprocal tachycardia. Circulation $52: 58,1974$

6. Ross DI, Brugada P, Bär FWHM, Vanagt EJ, Wiener I, Farré, Wellens HIJ: Comparison of right and left atrial stimulation in demonstration of dual atriowentricular nodal patbways and induction of intranodal reentry. Circulation 64:1051, 1981

7. Batsford WP, Akhtar $M$, Caracta AR dosephson ME, Seides SF, Damato AN: Effect of atrial stimulation site on the electrophysiological propertics of the atrio-ventricular node in man. Circulation $50: 283,1974$

8. Damato AM, Varghese PJ, Lau SH, Gallagher JJ, Bobb GA: Manifest and concealed re-entry. A mechanism of $\mathrm{AV}$ nodal Wenckebach phenomenon. Cire. Res. 30:283, 1972.

9. Gallagher JJ, Damato AN, Varghese PJ, Lau SH: Manifest and concealed re-entry. A mechanism of AW nodal Wenckebach in man. Circulation 47: 752, 1973.

10. Simson MB, Spear JF, Moore EW: Electrophysiologic studies in atrio-ventricular nodal Wenckebach cycles. Am. J. Cardiol. 41:244, 1978.

11. Littmann L, Svenson RH: Concealed re-entry: A mechanism of atrioventricular nodal alternating Wenckebach periodicity. Circulation 65: 1269, 1982.

12. Meijler FL, Heethaar RM, Harms FMA, Robles de Medina BO, Prystowsky EN, Zipes DP, Fisch C: Comparative altrowentricular conduction and its consequences for atrial fibrillation in man. In: Atrial Fibrillation. Edited by Kulbertus HE, Olsson SB, Schlepper M. A Lindgren and Söner AB. Mölndal, Sweden 11982, p. 72-80. 


\title{
Ventricular Tachycardia with Concealed Retrograde Conduction to Two Atrio-ventricular Nodal Pathways
}

\author{
Pedro Brugada, Erik W. Andries, and Hein J.J. Wellens. \\ Frow the Deparments of Cardiology, Lniversity of Limburg, Annadal Hospinal, Matastich, The Netherlands, \\ and O.L. Wrouw Hospial, Aalst, Belgiam.
}

In patients with ventricular tachycardia, analysis of the relation between atrial and ventricular activations during arrhythmia demonstrates some form of ventriculo-atrial [V-A] conduction in approximately $50 \%$ of the cases. ${ }^{1}$ In $5 \%$ of the patients with ventricular tachycardia, V-A conduction is a concealed phenomenon, only recogmized by its effects on conduction of subsequent cardiac impulses. Concealed conduction usually results in delay of conduction or block of subsequent impulses. This can be transient or persistent." When two A-V nodal pathways are present, concealed retrograde conduction during ventricular lachycardia can lead to very complex electrocardiographic patterns. An example is reported here.

\section{Discussion of the Electrocardiogram}

The electrocardiogram shown in Figure 1 was recorded the sixth day after an acute infero-lateral wall myocardial infarction in a 60-year-old male. That day the patient developed frequent short rums of ventricular tachycardia. He was not receiving antiarrhythmic or cardiotonic drugs at the lime of electrocardiogram recording. A central venous catheter having a unipolar electrode permitted the recording of a unipolar right atrial electrogram during the arhythmia. In the electrocardiogram two types of QRS complexes can be identified. One type has a width of

\footnotetext{
Adtress for reprints: Hein J.J. Wellens, M.D. Department of Cardiology, Universily of limburg. Annadal Hospilal, Maastrich, The Netherlands.

Received August 11. 1981; acrepted Angust 18, 1984.
}

0.08 sec. These QRS complexes are in the right part of the Figure preceded by $P$ waves of sinus origin. A second type of QRS complex having a width of 0.16 sec and a left bundle branch block morphology in lead $V_{1}$ and $Q S$ in lead II is also observed. These wide QRS complexes occur both in runs of three-to-four beals and as iso" lated premature beats. Measurement of the P-P interval starting in the right part of the Figure and going back to the left part of the tracing reveals a sinus tachycardia at the atrial level. There is dissociation between the wide QRS complexes and atrial activity. This suggests a ventricular origin of the wide QRS complexes. Following termination of a short run of ventricular tachycardia two different patterns of A$V$ conduction of the sinus impulses are observed. After the first run of ventricular tachycardia lasting three beats, the next sinus $P$ wave is conducted with a very long P-R interval $(0.44$ sec). "The time interval between the last tachycardia beat and the next $P$ wave measures 0.36 sec. This pattern of conduction with a very long P-R interval persists until a new episode of venIricular tachycardia develops. After four beats the ventricular tachycardia terminales. The $P$ wave following the last beat of this run of veniricular tachycardia is not conducted to the veniricles. The next sinus impulse is conducted to the ventricle with a $P-R$ interval of 0.16 sec. The inlerwal between the las tachycardia beal and the blocked $P$ wave measures 0.24 sec. "The sinus $P$ wave following the last episode of ventricular tachycardia (right part of the Figure) is conducted anterogradely to the ventricles with a P-R interval of $0.16 \mathrm{sec}$. The interval between 


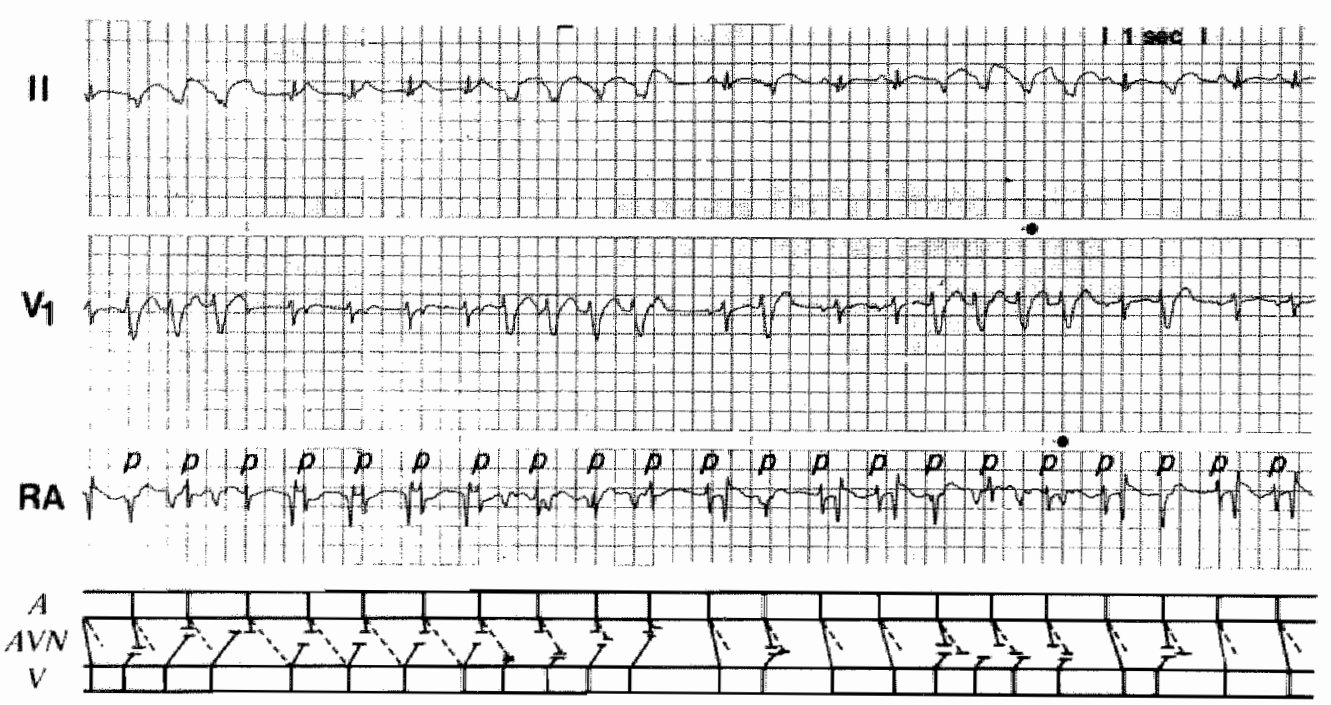

Figure 1. Leads $I I$ and $V_{1}$ are simultoneausly recorded with a unipolar electrogram of the right atrium at a paper speed of $25 \mathrm{~mm} / \mathrm{sec}$. The broken line in the ladder diagrom represents conduction over a slow A-V nodal pathway, the solid line conduction over a fasit $A-W$ nodal pothwoy. $A=$ atrium, $A V N=$ atrioventricular node. $V=$ ventricle. In the retrograde direction the line indicates retrograde concealed penetrotion of the A-V nodal pothways. See texi.

the last tachycardia beat and this $\mathrm{P}$ wave measures 0.44 sec.

The most likely explanation for the differences in P-R interval during anterograde $A-V$ conduction is given in the ladder diagram (Fig. 1]. It is postulated that the patient has two pathways for anterograde conduction in the A-V node: a fast conducting pathway with a long refractory period, and a slow pathway with a short refractory period. "The last beat of the first run of ventricular tachycardia results in concealed retrograde penetration of the A-V node. The nexl sinus p wave, occurring $0.36 \mathrm{sec}$ after the last tachycardia beal, finds the fast A-V nodal pathway refractory for conduction, but can be conducted over the slow A.V nodal pathway. Sustained slow pathway conduction with a P.R intarval of $0.44 \mathrm{sec}$ develops. The sustained nature of this slow pathway conduction leading to a long P.R interval can be explained by two mechanisms: a. persistence of the effect of concealed conduction during tachycardia in the fast pathway prolonging its refractory period to a value longer than the sinus cycle length, and $b$. concealed re-entry in the A-V node due to retrograde penetration into the fast pathway of the impulse which is conducted anterogradely over the slow pathway. The last explanation is considered to be the most likely one and is shown in the diagram. The second episode of ventricular lachycardia observed in the Figure is followed by a $\mathbf{P}$ wave which is not conducted to the ventricle. Following the third run of ventricular tachycardia the next $P$ wave occurs late enough to find the fast A-V nodal pathway recovered to conduct the impulse. This and subsequent $P$ waves are then conducted with a normal P-R interval.

As beautifully discussed by Pick and Langendorf," concealed conduction and concealed re- 
entry are not uncommon mechanisms for arrhythmias in the A-V junction. To our knowledge, concealed re-entry leading to persistent $P$. $\mathrm{R}$ prolongation is a rare phenomenon, however. In our patient no His bundle electrogram was recorded. This could have facilitated the location of the area of concealed re-entry. Concealed conduction and concealed re-entry in the A-V node is a more likely explanation for the phe-

\section{References}

1. Wellens, H.J.J., Bar, F.W.H.M., and Lie, K.I.: The value of the electrocardiogram in the differential diagnosis of a tachycardia with a wide QRS complex. Am. J. Med., 64:27, 1978.

2. Langendorf, R.: Concealed A-V conduction: The effect of blocked impulses on the formation and conduction of subsequent impulses. Am. Heart J.. $35: 542,1948$.

3. Rosen, K.M., Denes, P., Wu, D., et al..; Electrophysiological diagnosis and manifestation of dual nomena observed than concealed rementry located subnodally, considering the higl: prevalence of dual A-V nodal pathways in man. ${ }^{\text {n. }}$

The patient was treated with intravenous procainamide followed by oral doses of the same drug. Ventricular tachycardia did not recur during continuous electrocardiographic monitoring for ten days. A-V nodal tachycardia wias never observed.
A-V nodal pathways. In, H.J.J. Wollens, K.I. Lie. and M.]. Ianse. (Eds.): The Conduction System of the Heart. HE Slenfort Kroese BV, Leiden, 1976, p. $453-66$.

4. Pick. A., and Langendorf, R.: Interpretation of Complex Arrhythmias. Philadelphia, Lea and Febiger, 1979, p. 471.533.

5. Denes, $P_{\text {.. }}$ Wu . D., Dhingra, $R_{\text {, }}$ at al.: Dual atrioventricular nodal pathways. A common electro. physiological response. Br. Heart J. 37:1069, 1975. 


\title{
Incessant Reciprocating Atrioventricular Tachycardia Factors Playing a Role in the Mechanism of the Arrhythmia
}

\author{
Pedro Brugada, Eddy J. Vanagt, Frits W.H.M. Bär, and Hein J.J. Wellens
}

From the Deparment of Cardiology, University of Limburg. Anmadal Hosputal, Maastricht, The Netherlands.

\begin{abstract}
BRUGADA, P., ET AL.: Incessant reciprocating atrioventricular tachycardia. Factors playing a role in the mechanism of the arrhythmia. The case of a patient suffering from incessant supraventricular tachycardia is presented. The electrophysiological study showed the presence of an accessory atrioventricular $(A-V)$ bundle with nodal-like properties and long conduction times. This structure was used as the retrograde arm of the tachycardia circuit. Tachycardia was intermittent at rest, but had a sustained character during slight exercise. Administration of atropine and isoproterenol failed to sustain the arrhythmia and spontaneous initiation during sinus rhythm was no longer observed. During handgrip exercise a sustained tachycardia developed immediately. During ventricular stimulation a dual atrial response to a single paced ventricular premature beat was repeatedly observed, proving the availability of two separate A-V pathways for retrograde conduction. The case illustrates the labile nature of this type of accessory pathway, and suggests that autonomic changes can play an important role in the initiation, maintenance, termination, or even spontaneous cure of tachycardia in patients with this anomaly. (PACE, Vol. 3. November-December, 1980)
\end{abstract}

programmed electrical stimulation, incessant supraventricular tachycardia, autonomic tone, accessory pathway, dual atrial response, single ventricular premature beat

Recently, evidence has been published for the existence of accessory atrioventricular (A-V) pathways having conduction times longer than those over the normal A-V nodal-His-Purkinje axis ${ }^{\text {i-s }}$ In patients with this anomaly, supraventricular tachycardias presented with a so-called "permanent" or "incessant" character." Usually in these patients the accessory pathway is used

Submitled 4/22/80; revsed 6/16/80; accepted $6 / 20 / 80$.

Addressifor reprints: Hein 1.I. Wellens. M.D., Department of Cardiology, University of Limburg. Annadal Hospital, Masitriche. The Netherlands. as the retrograde limb of the tachycardia circuit. Characteristically, these patients show a supraventricular tachycardia with negative $P$ waves in II, III. AVF, and the precordial leads and a PR interval which is shorter than the RP interval.' It has been pointed out that the accessory patly. way in these patients might be composect of nodal tissue, as suggested ${ }^{3-5}$ by the behavior of this struclure during incremental pacing and following the administration of drugs, which is similar to the response shown by normal A-V nodal tissue. The anomaly is known to be congenital, but little is known about the mechanisms leading to initiation, maintenance, termination. 
or even spontaneous cures of the episodes of tachycardia in these cases.

We had the opportunity to study one patient with an incessant supraventricular tachycardia with some unusual features. The case illustrates the importance of autonomic changes on the genesis, maintenance, and termination of tachy. cardia in pattents having this type of accessory pathway. A dual atrial response to a single paced ventricular premature beat, supporting the existence of two separate A-V pathways, was repeatedly observed.

\section{Patient and Methods}

The patient was a 50 -year-old male who had noticed palpitations starting 11 years prior to this investigation. The electrocardiogram during lachycardia, having a rate of $120-160 \mathrm{beats} / \mathrm{min}$. showed a negative $\mathbb{P}$ wave in leads I, II, III, and in the precordial leads $V_{1}$ to $V_{6}$, followed $140 \mathrm{~ms}$ later by a normal QRS complex. The tachycardia, which was intermittent in rest, became incessant during slight exercise, such as elevating the legs (Fig. 1). Cardiovascular examination revealed no abnormalities other than tachycardia.

\section{Electrophysiological Study}

Following informed consent an electrophysiological study was performed in the resting, postabsarptive, nonsedated state. Using the femoral approach, catheters were placed at the right ventricular apex, tricuspid valve ring, and high lateral right atrium. A fourth quadripolar electrode catheter was placed in the coronary sinus. Our methods of recording, stimulation and analysis of tracings have been previously described." After recording of basic conduction intervals during sinus rhythm, the right ventricular apex was paced at basic cycle lengths of 690 and $520 \mathrm{~ms}$. Ventriculo-atrial (V-A) conduction and retrograde refractory periods were determined using the extrastimulus technique. Atrial test stimuli during sinus rhythm and atrial pacing immediately resulted in a brief period of tachycardia (2 10.3 beats) making it impossible to study the role of atrial premature beats in the initiation of tachycardia. Following these obser-

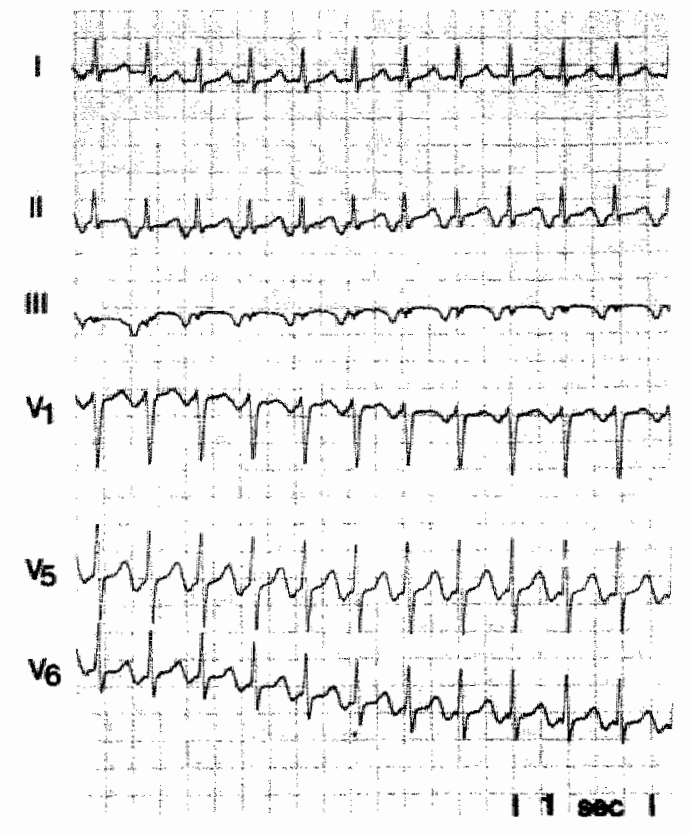

Figure 1. 6-lead electrocardiogram showing a supraventricular tachycardio with o rote of 160 beats $/ \mathrm{min}$. Note the negative $\mathrm{P}$ wave preceding the QRS complex with a PR interval shorter than the RP interval, which is characteristic of ann incessant $A-V$ tachycardia.'

vations, $0.5 \mathrm{mg}$ of atropine was administered intravenously and a single atrial test stimulation during sinus rhythm was performed from the coronary sinus. Forty-five minutes later, isoproterenol was given by continuous infusion intravenously in a dose of $1.5 \mu \mathrm{g} / \mathrm{min}$, and the venm tricular stimulation study, at a basic cycle length of $520 \mathrm{~ms}$, was repeated. This was followed by single atrial test stimulation from the coronary sinus during sinus rhythm. One hour after atropine administration, and $10 \mathrm{~min}$ after discontinuation of isoproterenol, handgrip exercise was performed. During tachycardia the ef fect of timed ventricular premature beats was tested. 


\section{Results}

\section{Resting State}

His bundle recordings during sinus rhythm (cycle length $800 \mathrm{~ms}$ ) revealed an A-H interval of $90 \mathrm{~ms}$ and an H-W interval of $40 \mathrm{~ms}$. The QRS complex showed no pre-excitation, and was normal and narrow. Single beats or short runs of tachycardia were observed to occur spontaneously during sinus rhythm and during atrial pacing. Their initiation could not be related to a shortening or lengthening of the sinus cycle length. During tachycardia (cycle length $500-540$ $\mathrm{ms})$ the A-H interval ranged from 90 to $120 \mathrm{~ms}$. Atrial activetion was first recorded in the proximal coronary sinus (CSp) lead, and was closely thereafter followed by activation in the His bun-

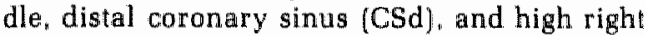
atrial (HRA) lead. Tachycardia was mever sustained; it terminated spontaneously without a definite pattern of shortening on lengthening of its cycle length, A-H or V-A intervals. Tachycar. dia always terminated by a QRS complex not followed by a $P$ wave.

During ventricular stimulation with a basic cycle length of $690 \mathrm{~ms}$ the following observations were made: the basic ventricular beats were retrogradely conducted to the atria, and the onset of atrial activation was recorded first in the His bundle lead, followed by atrial activation in the CSp. HRA, and CSd leads. A ventricular premature beat given with a $V_{1} V_{2}$ intervall of $440 \mathrm{~ms}$ was retrogradely conducted to the atria with the same atrial activation sequence as the basic paced ventricular beats, and a $20 \mathrm{~ms}$ increase in retrograde conduction time. This was not followed by initiation of tachycardia (Fig. 2, panel 1). A decrease of the premature beat interval by $10 \mathrm{~ms}$ showed retrograde conduction to the atrium with the same activation sequence as during basic ventricular pacing. However, following atrial activation, a second $P$ wave was recorded showing an atrial activation pattern in the endocavitary leads similar to the atrial activation sequence during tachycardia. This was followed by initiation of tachycardia (Fig. 2, pan. el 2 and Fig. 5]. A further decrease in the $V_{11} V_{2}$ interval revealed that the first atrial activation I showing the same sequence as during basic pac-

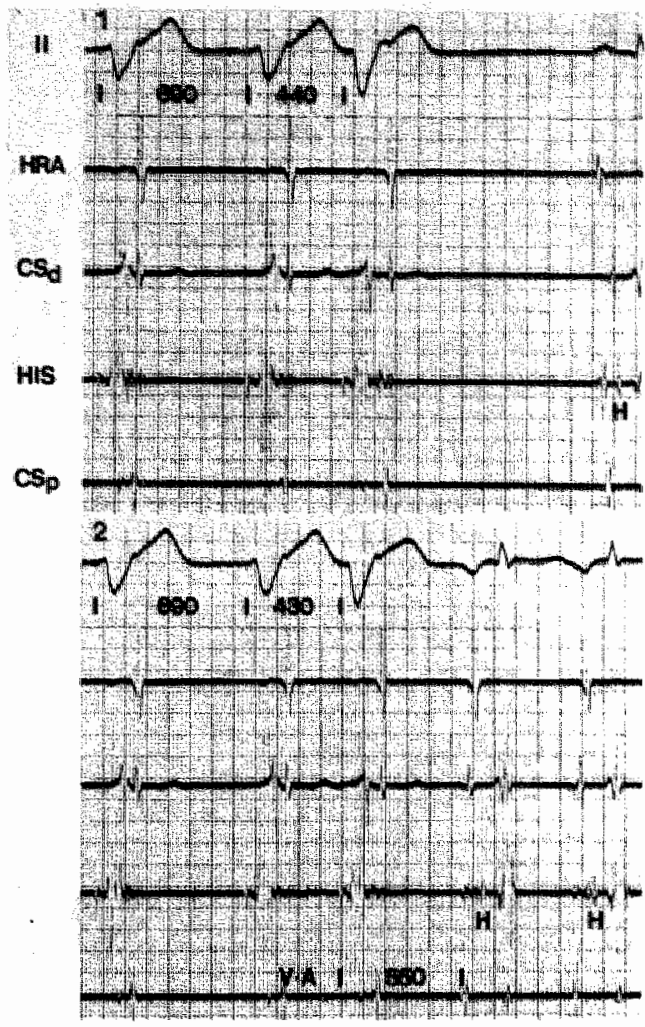

Figure 2 Ventricular stimulation study before drug odministration. Lead II was simulameausly recorded with four bipolar endocavitary electrograms from the high right atrium (HAAl, distal coronary sinus f $\mathrm{CS}$ l. His bundle, and proximal coronary sinus (CSp). Indicated are the basic pocing cycle length and the premature beat intervals in milliseconds betwean bars. $V-A=$ ventriculo-atrial conduction time of the premiture beat in milluseconds. See text.

ing) was not mecessary for initiation of techycardia (Fig. 3). A shortening of the coupling inter' val of the test pulse showed subnodal delay in retrograde conduction of $\mathrm{V}_{2}$ again followed by retrograde conduction to the atria with the lype of atrial activation sequence similar to basic 

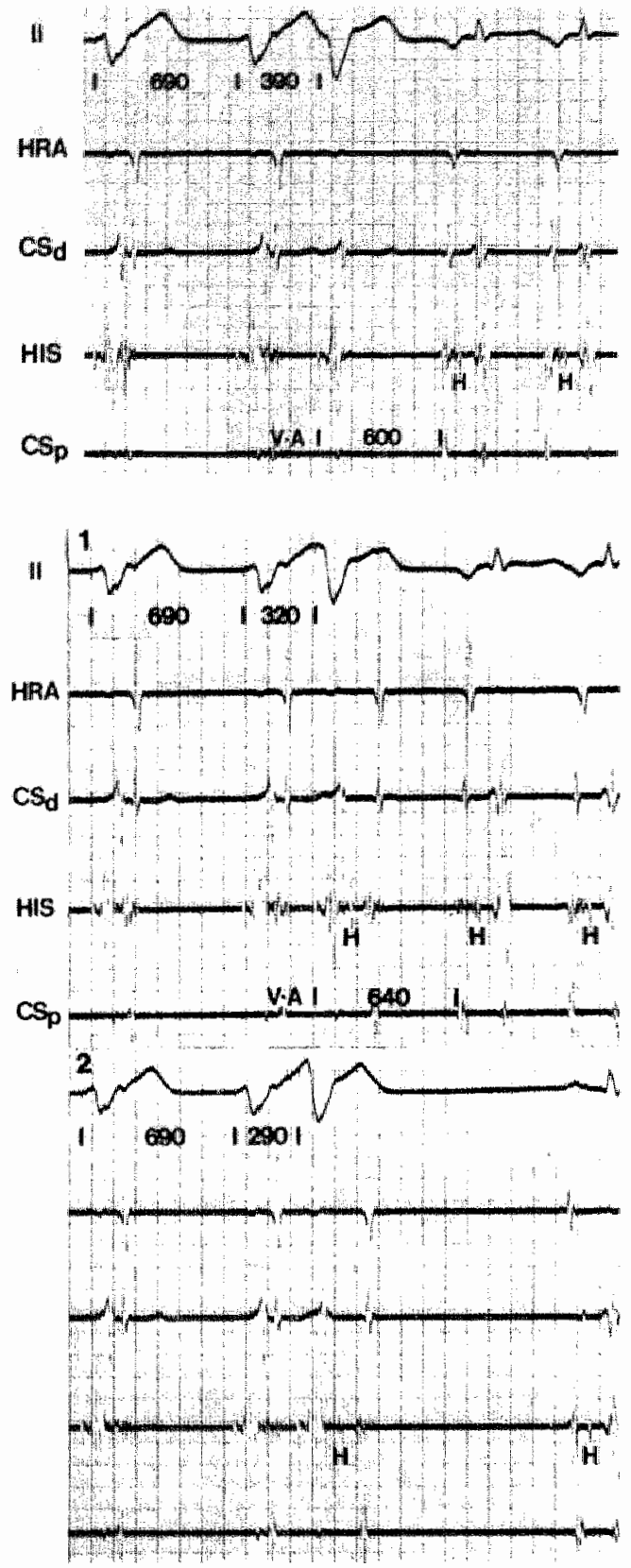

Figure 4. See legend for Figure 2. paced ventricular beats; however, the second $\mathrm{P}$ wave and initiation of tachycardia could still be observed (Fig. 4, panel 1). At $V_{1} V_{2}$ intervals from $290 \mathrm{~ms}$ to the refractiory period of the ventricle the first $\mathbb{P}$ wave appeared, but the second $P$ wave was no longer observed and tachycardia no lianger initiated (Fig. 4 panel 2).

During ventricular stimulation with a basic cy. cle length of $520 \mathrm{~ms}$ retrograde conduction to the atria with an atrial activation sequence similar to basic paced beats was seen up to the refractory period of the right ventricle. There was a gap in $V * A$ conduction of the first atrial response at $V_{1} V_{2}$ intervals from 380 to $360 \mathrm{~ms}$. This gap terminated after sufficient subnodal delay in retrograde conduction had occurred. During this gap in V-A conduction tachycardia was initiated.

During pacing with a basic cycle length of 690 ms and with a basic cycle length of $520 \mathrm{~ms}$, the $V$. A interwal as measured from the onsel of the QRS complex of $V_{2}$ to the onset of atrial activiam tion of the first tachycardia $P$ wave was abserved to increase on decreasing the $V_{1} V_{2}$ inlerval (Figs. 2-5).

\section{Atropine Administration}

Because of the unsustained nature of the tachycardia observed, atropine, $0.5 \mathrm{mg}$, was administered intravenous'y. The sinus cycle length shortened to $700 \mathrm{~ms}$, and this was accompanied by disappearance of the spontaneously occurring echo beats or short runs of tachycardia which were previously present. Single atrial test stimulation from the coronary sinus during sinus rhythm with $A_{1} A_{2}$ intervals of 490 to 350 ms initiated echo beats, but no sustained tachycardia (Fig. 6).

\section{Isoproterenol Administration}

Administration of isoproterenol by continuous infusion in a dose of $1.5 \mu \mathrm{g} / \mathrm{min}$ resulted in shortening of the sinus cycle length $10580 \mathrm{~ms}$. Spontaneous initiation of tachycardia was not observed during sinus rhythm.

Right ventricular stimulation at a basic cycle length of 520 ms showed intiation of tachycar- 


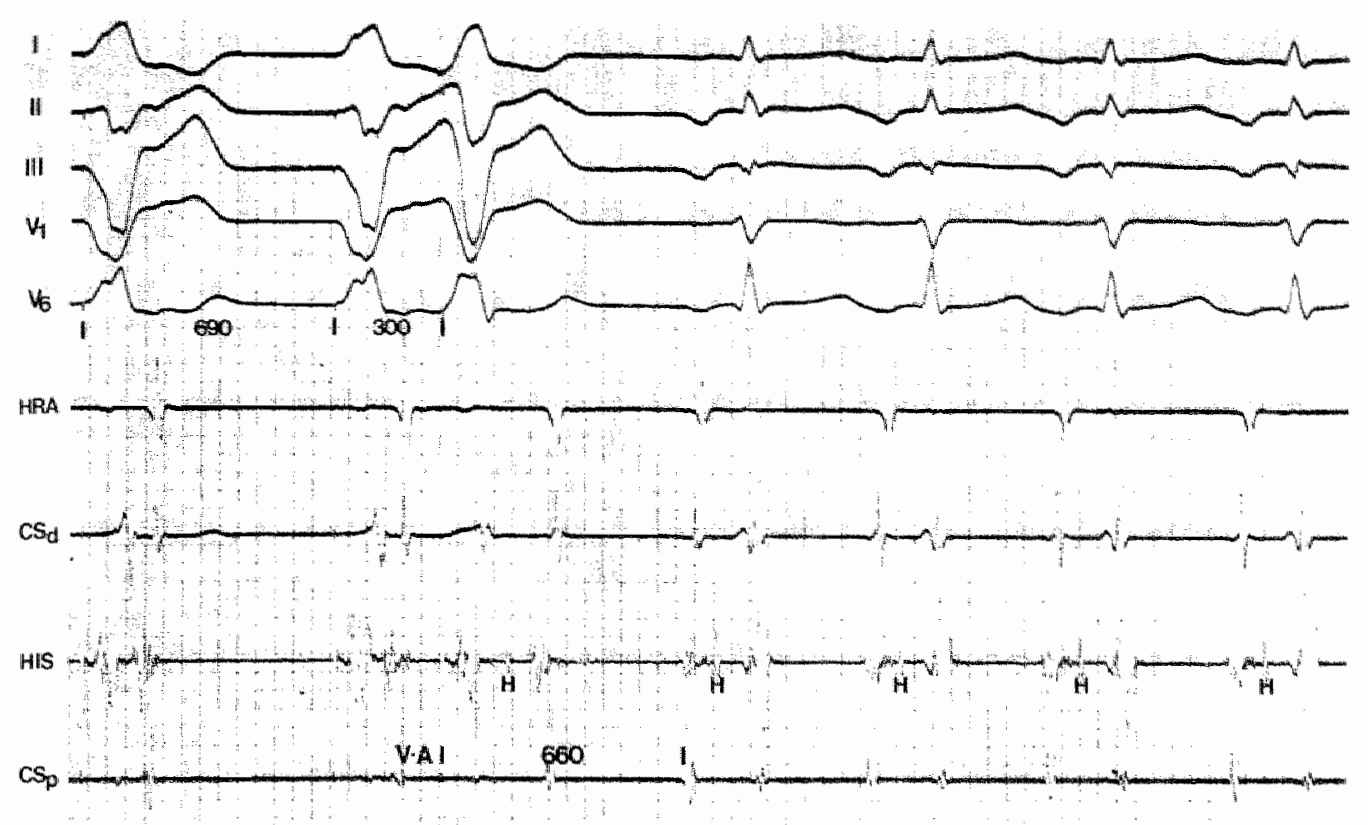

Figure 5. A ventricular premature beat given after 300 ms daring pacing of the right wantricular apex with a basic cycle length of $690 \mathrm{~ms}$. Leads $I_{2} I_{n} I I I_{1}, V_{1}$, and $V_{6}$ were simultaneously recorded with the same four endocavitary leads as in Figures 24 . The first retrogradely" conducted atrial activotion shows the same sequence of atrial octivation as during atrial activation following the paced beats of the basic rhythm, and is preceded by a retrograde His bundle electrogram. After this $P$ wave a second one, showing an atrial dotivation sequence similar to the one recorded during tachycardia, is seen. Same abbreviotions as in Figures 24.

dia only when a ventricular premature beat was given after 350 ms. As compared to similar $V_{1} V_{2}$ intervals during ventricular stimulation with the siame basic cycle length prior to drug adminis. tration, the $V$-A interval at the time of initiation of tachycardia shortened IV-A interval measured $640 \mathrm{~ms}$ after a $\mathrm{V}_{1} \mathrm{~V}_{2}$ interval of $360 \mathrm{~ms}$ prior to drug administration, and measured 550 ms after a $V_{1} V_{2}$ interval of $350 \mathrm{~ms}$ during isoproterenol administration). The $R-R$ interval during tachycardia shortened to $440 \mathrm{~ms}$ during isoproterenol administration with an $\mathrm{A}-\mathrm{H}$ interval of $80 \mathrm{~ms}$ and a $V$-A interval of $320 \mathrm{~ms}$ (as compared to an R-R interval of $520 \mathrm{~ms}$, an $\mathrm{A}-\mathrm{H}$ inter- val of $90 \mathrm{~ms}$, and $\mathrm{V}$ - A interval of $390 \mathrm{~ms}$ prior to drug administration) (Table $\mathbb{I}$ ).

Single arrial test stimulation from the coronary sinus during sinus rhythm initioted ocho beats with $A_{1} A_{2}$ intervals from 410 lo 360 ms. $A$ short run of tachycardia could only be initiated by an atrial premature beat given after $350 \mathrm{~ms}$.

\section{Spontaneous Termination of Tachycardia}

Under all conditions tachycardia terminated spontaneously by a QRS complex which was not followed by retrograde conduction to the atrum. 

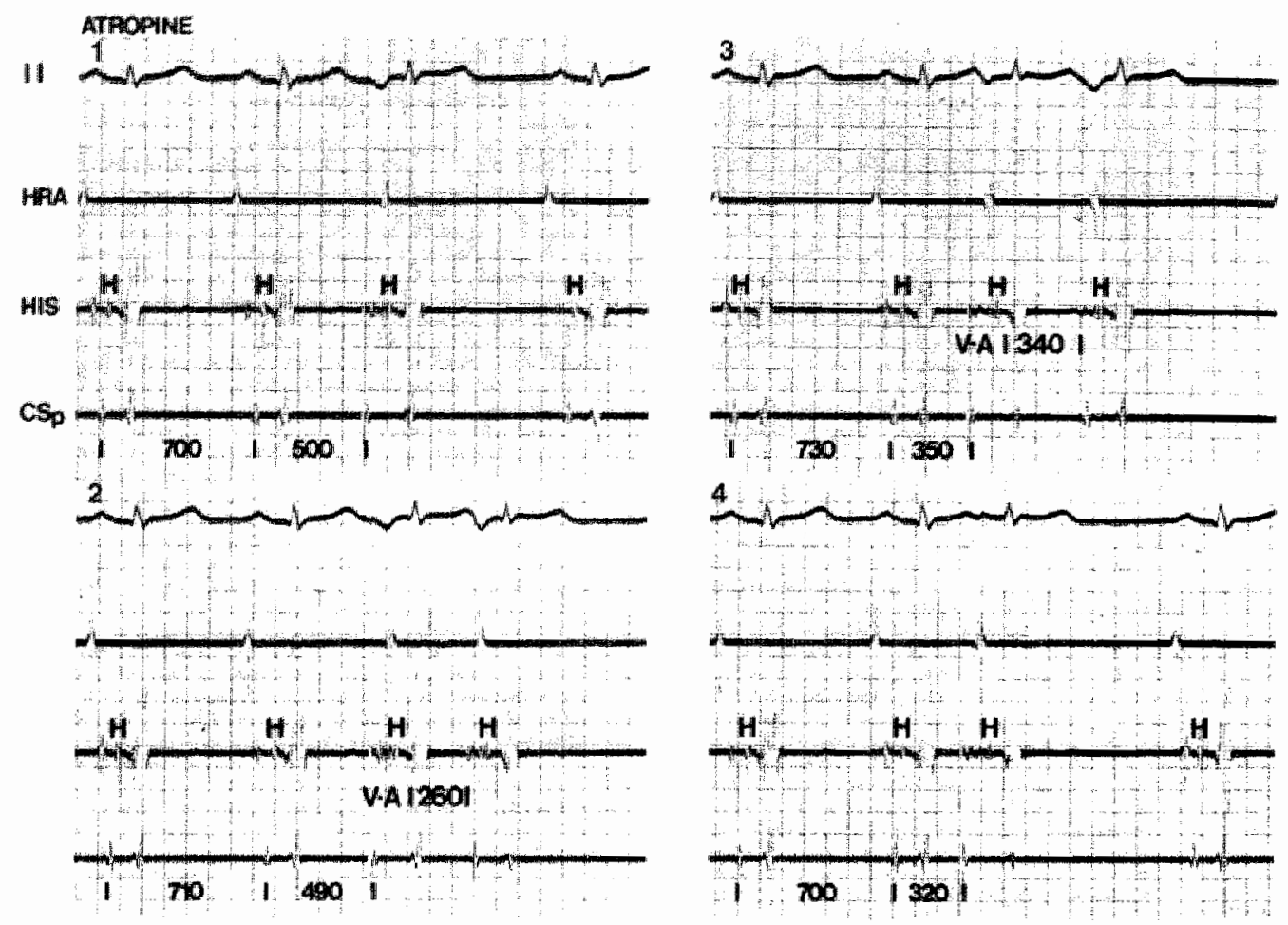

Figure 6. Four atrial premature bect intervals delivered from the coronary sinus during sinws ritythm after atropine administration. Lead II was simultaneously recorded with thee bipolar endocavitary electrograms. Nate initiation of single echos after atrial premature beats given after 490 lo $350 \mathrm{~ms}$, showing shorter $V$ - $A$ conduction times as compared to Figures 2-5. and terminating by a QHS complex not followed by next P wave. Same abbreviations as in Figures $2-5$.

\section{Handgrip Exercise}

One hour after atropine administration and 10 min after discontinuation of 1 saproterenol. handgrip exercise was performed. This was immediately followed by sustained tachycardia. Ventrisular premature beats given during tachycardia terminated the arrhythmia. These ventricular premature beats were never followed by a ratrograde $\mathrm{P}$ wave (Fig. 7). This finding indicates that the accessory pathway had a relalively long refractory period un ventriculo-atrial direction. The $R-R$ interval during tachycardia measured $440 \mathrm{~ms}$, with an A-H interval of $80 \mathrm{~ms}$ and a V-A interval of $320 \mathrm{~ms}$ (Table I).

\section{Discussion}

In our patient, two A- $V$ pathways were avail. able for retrograde conduction, the normal His$A-V$ nodal axis "and an A.V accessory pathway. During basic ventricular pacing ventriculo-atrial conduction occurred over the normal A-V pathway, as suggested by the atrial activation pattern of the first $P$ wave; the gap in retrograde 
Table I.

Time Intervals During Tachycardla Under Different Condltions

\begin{tabular}{lrcc} 
& Basal & $\begin{array}{c}\text { Iapro- } \\
\text { terenol }\end{array}$ & $\begin{array}{c}\text { Handgrip } \\
\text { Exercise }\end{array}$ \\
\hline R-R (ms) & 520 & 440 & 440 \\
A-H (ms) & 90 & 80 & 80 \\
V-A (ms) & 390 & 320 & 320 \\
\hline
\end{tabular}

conduction which was terminated after sufficient subnodal delay of $\mathrm{V}_{2}$ was obtained on increasing the prematurity of $V_{2}$." The $P$ wave initiating tachycardia showed the same atrial activation sequence as atrial activation during tachycardia. This sequence of atrial activation was the result of retrograde conduction to the atria over the accessory pathway, showing a different entrance point into the atria as compared to the A-V node [Figs. 2-5], Of importance for the determination of the ventricular end of the accessory pathway was the observation that subnodal delay of $V_{2}$ has no effect on the retrograde conduction time over the accessory pathway, excluding a ventricular origin of this structure in the bundle of His or the A-V node. The retrograde conduction time over the accessory pathway increased on decreasing the $V_{1} V_{2}$ interval, demonstrating that this structure had decremental conduction properties." A dual atrial response to a single ventricular premature beat was possible because of a very long retrograde conduction time over the accessory pathway [up to $660 \mathrm{~ms}$ in Fig. 5], resulting in arrival over the latter structure in the atrium after the end of the atrial refractory period which resulted from the first retrogradely conducted impulse. During basic ventricular pacing with a cycle length of $690 \mathrm{~ms}$ s the basic paced beals showed no retrograde conduction to the atria over the accessory pathway. This can be explained on the basis of conceated antegrade conduction in the accessory pathway of the atrial impulses resulting from retrograde conduction over the normal $A-V$ axis. Of importance to support this hypothesis is the previously reported observation that ante- grade conduction over such an accessory pathway is possible. ${ }^{\mathrm{B}}$

While our observations demonstrate ventriculo-atrial conduction over a slowly conducting accessory pathway, an atrial site of origin of the tachycardie must be excluded. This can be done by noting: 1) the similar sequence of atrial activation during tachycardia and during ventricular premature beats retrogradely conducted over the accessory pathway" and 2] the reproducible termination of tachycardia after ventricular premature beats not conducted retrogradely to the atria.

The previously reported shortening in $\mathrm{V}-\mathrm{A}$ conduction time over the accessory bundle following atropine administrations was also seen in this patient, again suggesting A-V nodal-like tissue as the functional make-up of the accessory pathway ${ }^{2-5}$ Interesting observations were made during isoproterenol administration and during handgrip exercise. Both maneuvers are known to increase sympathetic tone, but in a different manner. Isoproterenol administration produces beta-adrenergic stimulation, while handgrip exercise mainly results in alphe-adrenergic

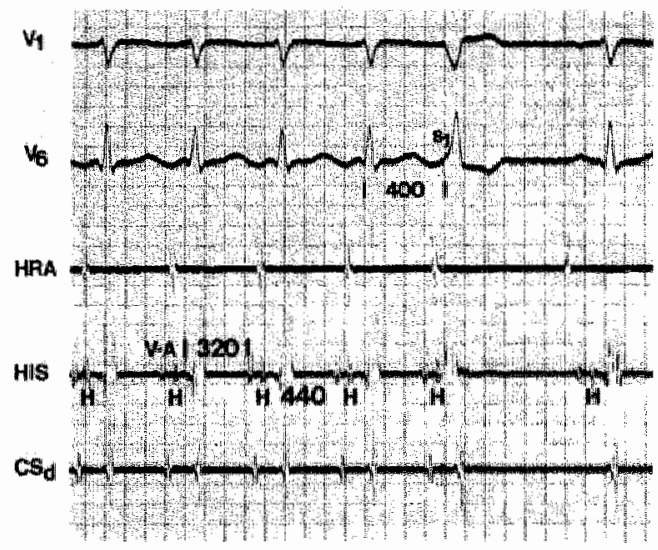

Figure 7. Tachycardia initioted during handgrip exercise. The H-H and $V-A$ intervols during tachycardia are indicated. A ventricular premature beat given aftar $400 \mathrm{~ms}$ terminates tachycardio. This ventricular premoture beat is not conducted to the atrium. Leads $V_{1}$ and $V_{6}$ and three endocavitary leads were recorded simultaneausly. 
3timulation." During isoproterenol administra. lion, spontaneous initiation of tachycardia during sinus rhythm was no longer observed and during single atrial test stimulation the echo zone was observed to narrow. As shown. the $R$. R. A-H, and $V-A$ intervals were simllar in tachycardia while isoproterenol was given and during handgrip exercise (Table 1). Handgrip exercise, however, readly initialed and sustained tachycardia. These facts suggest that the electrophysiological changes induced in the acces. sory bundle were different depending upon the type of sympathetic stimulation produced.

These lindings demonstrate that a delicate and labile balance in electrophysiological prop-

\section{References}

1. Coumel, P., Attuel, P., and Mugica, J.: Junctional reciprocal tachycardia. The permanent form. In H.E. Kulbertus (Ed.): Re-entrart Arrhythmias. Mechanisins and Treatment. MTP Press. Lancaster. England, 1977, p. 170.

2. Gallagher, J.J., and Sealy, W.C.: The permanent form of functional reciprocating tachycardia: further elucidation of the underlying mechanism. Eur. J. Cordiol., 8:413, 1978

3. Denes, P., Kehoe R. and Rosen, K.M.: Multiple reentrant tachycardias due to retrograde conduction of dual atrioventricular bundles with airioventricular nodal-Jike properties. Am. I. Cardiol., 44:162, 1979.

4. Epstein "M.L., Stone, F.M., and Benditt. D.G.: Incessant atrial tachycardia in childhood: association with rate-dependent conduction in an accessory atrioventricular palthway. Am. f. Cordiol. 44:498, 1970 .

5. Farrí. I., Rass, D. Wiener, 1., Bär. F.W.H.M. Vanagl, E.l. and Wellens, H.J.J. Reciprocal vachycardias using accessory pathways with long conduction times. Am. I. Cordiol., 44:1099, 1979.

A. Ross, D.. Farré. I. Bär, F.W.H.M. Vanagl, E.\}. Dassen, W.R.M., Whener, 1., and Wallens, H.J.J.: Comprehensive electrophysiological studies in erties of the lachycardia circuil was required to initlate and maintain tachycardia. This balance could easily be disrupted by changing autonomic tone. Our observations suggest that autonomic changes might play an important role in the mechanisms of tachycardia in patients with this type of accessory pathway with A-V nodallike properties.

In our patient, and also in the ones which we have reported previously, ${ }^{3}$ the weak link in the tachycardia circuit was the accessory pathway. Both during spontaneous termination and termination by induced ventricular premature beats, block always occurred in this pathway.

the investigation of documented or suspected lachycardias: times, staff, problems and costs in. volved. Circulation, 61:1010, 1980.

7. Gallagher, I.J., Pritchett. E.L.C. Benditt, D.C. Tonkin, A.M. Campbell, R.W.F, Dugan, F.A., Bashore "T.M., Tower, A. and Wallace, A.G.: New catheter techniques for analysis of the sequence of retrograde atrial activation in man. Eur. I. Cardiol, 6:1, 1977 .

Q. Akhtar, M., Damato, A.N., Caracta, A.R., Bastford. W.P.. and Lau, S.H.: The gap phenomena daring retrograde conduction in man. Circula. lion, 49:811, 1974.

9. Hofman, B.F., and Cranefield, P.F.: Electrophysiology of the Heart. Futura Publishing Com pany. Mount Kisca. New York, 1976 , p. 132.

10. Lands. A.M. Arnold. A. MacAuliff. I.P. Ludvene, F.P., and Brown, T.L.: Differentiation of recepton systems actwated by sympathominetic amines. Noture, 214:597, 1967.

11. Donald. K.W., Lind, A.R., McNicol, G.W. Humptreyg, P.W., Taylor S.H., and Stauton, H.P.: Cardiovascular responses to sustained (static) contractions. Circ. Aes. 20 \& 21 (Supp) 1): 15,1967 . 


\title{
Observations in Patients Showing A-V Junctional Echoes With
}

a Shorter P-R Than R-P Interval

\section{Distinction Between Intranodal Reentry or Reentry Using an Accessory Pathway With a Long Conduction Time}

\author{
Pedro Brugada, MD; Frits W.H.M. Bär, MD; Eddy J. Vanagt, MD; Peter L. Friedman, MD, \\ PhD; Hein J.J. Wellens, MD, FACC
}

Maasmicht, The Nenerlands

From the Department of Cardiology, University of Limburg. Annadial Hospital, Maastricht, The Netherlands. Maramuscript received Fiebruary 17 . $198 \%_{i}$ revised manuscript receiverd April 1.4, 198:1. accepted April 17,198 .

Address for reprints: Hein $\mathbb{J}$. Wollens, MD, FACC. Department of Cardiology. Uniniwersity of Limburg. Annadal Hospital "Maastricht. The Natherlands.
Single lest stimulation of the ventricle revealed Initiatlom of echoes with a supraventricular ORS complex with a shorter P-R than R-P interval in 28 of 300 pallents consecultvely studied with programmedi lectrlcal stimulatlon of the heart because of difocumented or suspected fachycarclas. In all 28 the Initiation of echoes was related to a disconilnuily in the retrograde conduction curve. In 10 pallents a ditferent atrlal activation sequience in the endocavitary leads was present before and after the discontinuity in the retrograde conduction curve. In flwe of these a susIained thachycardlia with a shorter P-R than R-P Interval could be initiated, and in all tive patlents an accessory pathway with a long conduction time as the retrograde arm of the tachycardla circull could be demonstrated. In these five patients spontaneous Inittation of tachycardlia was observed during simus rhythm or after alrlal premalure beats. Tachycardla accelerated after the administration of atropine " in the remaining 23 patients the initialion of echoes showing a shorter P.R than R-P. Interval was nonsustained. In these patients spontaneous initlation of such echoes during sinus rhythm our iniliation by atrial premature beats was not observed, and echoes with this rellation of the P-R and R-P Intervals systemalically disappeared after administtration of attropine.

It is postulated that in these patients a slow atrloventricular (A-V) nodal pathway is used in the retrograde direction during echoes showing a shorter P-R than R-P interval. Sustained A-W Junctional tachycardia showing this relation between P-FL and R-P inlerva|s favors Incoiponallon of an accessory pathway with slow retrogradie conduction Ir the lachycardia circult.

When single test stimulation of the vertricle results in int tiation of eches with a supraventricular $Q R S$ complex in relation to a critical delay in retrograde conduction to the atria, the presence of dual pathway with wentriculoatrial (V-A) conduction over alowly conducting intranodal pathway is considered the causal mechanism. 1,2 These echoes present electrocardiographically with a retrograde $\mathrm{P}$ wave and a $\mathrm{P}$ - $\mathrm{R}$ interval thet is shorter than the $\mathrm{R}$. $\mathrm{P}^{\mathrm{B}}$ incrwal. A few examples of sustained tachycardin of this lype have been reported. 2 recertlly the existence of accessory pathways whose conduction time in the retrograde direction is Ionger than conduction time over the normal gtrioventricular $(A-V)$ pathway has been documented. "-B Patients with this anomaly present with a supravemtricular tachycardia showing a retroyracte $\mathrm{P}$ wave and a shorter $\mathrm{P}-\mathrm{R}$ than $\mathbf{R}-\mathbf{P}$ interval. because a slowly conducting accesisory pathway in the retrograde direction is being used. "The alectrocardiographic distinction between $V$. A conduction over alowly conducting accessory pathway or a slowly conductinu A.V nodal pathway can be extremely difficult or even impossible. Knowledge of the pathways inwolved in supraventricular tachycardia is of therapeutic interest, per ticularly in those patients whose arrhythmia is poorly controlled by drug 
therapy and who might benelte from surgical procedures. "The present atudy was undertaken to further elucidate the pathways inwolved during reentry in the human beart with retrograde $\mathrm{P}$ wave and a worter P-R than R-P interval.

\section{Methods}

Stady patientst Patients arere included in this investigation if they fulfulled the following eriteria: (1) supraventricular achoes or tachycardia was initiated by ventricular premature beats or ventricular pacing related to a critical delay in V-A conduction. "These echoes showed in the surfase electrocardiogram with a tormal QHS or typical bunde branch block configuration and a thorter $P * R$ than $R \cdot P$ interval. The $\mathrm{H}-\mathrm{V}$ interval of the $\mathrm{H}$ bindle electrogram preceding the echo had to be 35 me or more. (2) A cornplete electrophysiologic inves. tigation was performed because of documented or suspected tachycardien, using a previously described protocol of stimulation, recording and analysis of tracings. In all patients a coronary sinus or left atrial ellectrogram was recorded isimaltaneously with the surface leads $I_{1}$ II, III, $V_{1}$ and $V_{B,}$ and endocavitary tecordings were obtained from the right atrium and His bundle. (3) Anterograde conduction over an accessory pathway was axcluded during the stimulation istudy.

Informed congent was obiäned inom every patient. No patient, was receiving inedication the thme of study, which was performed in the resting, postabsorptive, nonsedated atate. In 12 patient in whom only echoes or nonsustained tachycardias were initiated, the effect of $1 \mathrm{mg}$ of atropine given in travenously was studied. The same amount of atropine was given to four of the five patients in whom sustained tachycardia could be induced.

Electrophygiologic studies: Anterograde and retrograde refractory periads and pathern of $A-V$ and $V-A$ conduction were studied as prewiously described ${ }^{\text {th }}$ using the extrastimulus technique. The atrial activation sequence and the $\mathrm{P}$ waxe configuration in the aurface leads were carefully analyzed both during retrograde conduction to the atria during ventricular pacing and at the time of intiation of echoes or tachycardia. Anterograde conduction curses were analyzed by plotting the atrial premature beat inthervals $\left(A_{1}-A_{2}\right)$ against their $A-Y$ nodal conduction times (as measured by the $\mathrm{A}-\mathrm{H}$ intervals) $\left(\mathrm{A}_{2}-\mathrm{H}_{2}\right)$. Retrograde conduction curves were studied by plotting the ventricular premature beat intervale $\left(\mathrm{V}_{1} . \mathrm{V}_{2}\right)$ against their

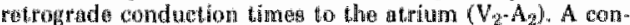
duction corve was considered discontinuous when shortening of the promature beat interwal (atrial or ventrieular) by $10 \mathrm{~ms}$ resulted in an increase in the conduction time of the premaLure beat hy $40 \mathrm{~ms}$ or more. "This sudden unexpected increase in condurtion time of the premature beat on slight whortening of the premature beat interval was constdered suggestive of a shift it conduation from one pathway wo another with a longer conduction time.2,10

In all 28 patients included in this study thit concept of a whith in conduetion from one to another puthway was sup. ported by the intitintion of echoes after the discontimuity in the retrograde condnetion curve, Special car was taken to identify possible tetrograde His bund potentials during retrograd a conduction to the atria during ventricular stimulation. When the retrograde His bundle potential could not bo identified during basic ventricular pacing, presumably because it was hidden in the QRS complex in the His bundle lead, the $\mathrm{S}_{1}-\mathrm{H}_{2}$ interwal was taken as an approximation of the retirograde imput to the His bundle and $A-V$ node. ${ }^{11} S_{1}$ represents the stimulus artifact of the last basic peced ventricular beat, and $\mathrm{H}_{2}$ the retragrade His buatle potential resulting from the ventrictular premature beat. $V_{2}$.

A diagnosis of A.V nodal echoes or tachycardian using in the anterograde direction a slow and in the retrograde direction a fast A.V nodal pathway - the so-called usual type of A.V nodal tachycardia-was made uning previously reported cri. teriat. 10

\section{Results}

In 28 (9.3 percent) of 300 consecutive patients undergoing electrophysiologic investigation because of documented or suspected tachycardias, echoes with a shorter P-R than $\mathbb{R}$-P interval were initiated during ventricular stimulation. Clinical and electrophysiologic. data on these patients are summarized in Table I. Data on 3 of these 28 patients (Patients 1,2 and 3 ) have previousty been reported in detail. 7,8

Mode of initiation of echoes or tachycardia: In 28 patients if was possible to initiate echoes or tachycardia with a shorter $\mathrm{P}$ - $\mathbb{R}$ than $\mathrm{R}$ - $\mathrm{P}$ interval during ventricular stimulation. However, only five patients (Patients 1 to 5) showed initiation of the same type of echoes spor. taneously during sinus rhythm or after induced atrial premature beats.

Initiation of echoes or tachycardia during wentricular stimulation. (Fig. I to 4). Initiation of echoes or tachycardia was related to all patients to delay in retrograde conduction to the atria during ventricular stimulation. In 27 patients retrograde conduction curves were available, and imitiation of echoes in all was related to a discontinuity in the retrograde conduction curve. In Patient 2 the retrograde conduction curve could not. be analyzed because of the presence of almost incessant tachycardia. However, two ranges of $\mathrm{V}-\mathrm{A}$ conduction times with two different atrial activation sequences were identified, and have previously been reported. ${ }^{7}$

Initiation of echoes or tachycardia by atrial premature beats or spontaneously during sinus rhythm. In 5 of the 28 patients (group A) the same type of echoes initiated during ventricular stimulation, with the same pattern of atrial activation in the endocavitary leads, relation of $P-R$ and $R-P$ intervals and supraventtricular QRS complex could be initiated by atriol premature beats or occurred spontaneougly during sinus thythm. In these patients, as previously reported, 7, we conld not identify critical ginus cycle length or a critical A.V conduction time at the time of initiation of tachycardia. The remaining 2 is pationts not showing these phenomena were classilfied in group B.

Anterograde conduction carves: Complete arnterograde conduction curves were available for tho patients in group A. In both patients the conduction curves were comtimuous. In the remaining three patients in group A spontaneous initiation of tachycardia prevented complete study of anterograde conduction curves. Anterograde conduction curves were available for all 23 patients of group B (Table 1 ). In 15 patients a discontinuity in the anterograde conduction curve was present, which was followed in 4 patients by initiation of single echoes and in 2 patients by initiation of $A-V$ nodal tachycardia utilizing in the anterograde direction 
a slow and in the retrograde direction a fast $A$. V nodal patthway.

Observations on the atrial activation sequence in the endocavitary leads and $P$ wave configuration in the surface leads during retrograde conduction to the atria: During retrograde conduction to the atria two different atrial activation sequences were observed in all five patients in group $A$ and in five patients in group $B$ (Table I). The change in the atrial activation sequence was related in wine of these patients to a critical delay in retrograde conduction to the atria during ventricular stimulation and marked by a discontimuity in the retrograde conduction curve. As previously em. phasized, this could not be abserved in Patient 2. In all 10 patients retrograde activation of the atria during fast pathway conduction started in the His bundle lead and was followed by activation in the remaining endocavitary leads (Fig. 1, 3 and 4 ). In the remaining 18 patients in group $B$ the same pattern of atrial activation in the endocavitary leads was recorded before sund aftor the discontimuity in retrogrode conduction (Fig. 2).

We atempted a comparative analysis of the conim figuration of the Plate an the surface leads befory and after the discortinuty in the retrograde conduction curve. This was facilitated by the very long retrograde conduction time at the time of initiation of echoss (Fig. 1 to 4 ). A nesative $P$ wave was recorded in surface lends II, III and $\mathrm{V}_{6}$ during retrograde conduction to the atriat at the time of initiation of echoes or tachycardia. "The $P$ wave was flat with a diphasic negative-positive component in lead I and $V_{1}$.

A completely positive $P$ wabe in lead $V$ during ret. rograde conduction to the atria at the time of initiation. of echoes was recorcled only in those patients not showing a change in the atrial activation sequence before and after the discontinuty in the retrograde conduction curve (Fig. 2). In patients in group A the $\mathrm{P}$ wave was positive in lead $V_{1}$ before the discontimuity in the

TABLE I

Summary of Clinical and Electrophyslologic Dala on 28 Patlents Studled

\begin{tabular}{|c|c|c|c|c|c|c|}
\hline Case & $\begin{array}{c}\text { Age }(y /\}) \\
\& \text { Sex }\end{array}$ & $\begin{array}{l}\text { Indica } \\
\text { tion tor } \\
\text { Situdy }\end{array}$ & $\begin{array}{l}\text { Antenognadio } \\
\text { A-V Nodal } \\
\text { Conduction }\end{array}$ & $\begin{array}{c}\text { Atrian! } \\
\text { Sequance" }\end{array}$ & 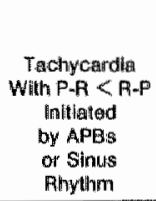 & $\begin{array}{l}\text { Relation } \\
\text { Betwoesy } \\
\text { Sulunodal } \\
\text { Delay of } \\
\text { WPas and } \\
\text { Retrograde } \\
\text { slow Pathway } \\
\text { Conduction }\end{array}$ \\
\hline \multicolumn{7}{|c|}{ Group A } \\
\hline $\begin{array}{l}1 \\
2 \\
3 \\
4 \\
5\end{array}$ & $\begin{array}{c}9 \mathrm{M} \\
6 \mathrm{~F} \\
50 \mathrm{M} \\
54 \mathrm{~F} \\
26 \mathrm{M}\end{array}$ & $\begin{array}{l}\text { SVT } \\
\text { SVT } \\
\text { SVT } \\
\text { SVT } \\
\text { SVT }\end{array}$ & 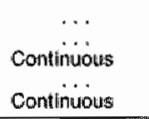 & $\begin{array}{l}\text { Different } \\
\text { Different: } \\
\text { Different } \\
\text { Different } \\
\text { Different }\end{array}$ & $\begin{array}{l}\text { Yes } \\
\text { Yes } \\
\text { Yes } \\
\text { Yes } \\
\text { Yes }\end{array}$ & $\begin{array}{l}\cdots \\
\cdots \\
\cdots\end{array}$ \\
\hline \multicolumn{7}{|c|}{ Group B } \\
\hline $\begin{array}{r}6 \\
7 \\
8 \\
9 \\
10 \\
11 \\
12 \\
13 \\
14 \\
15 \\
16 \\
17 \\
18 \\
19 \\
20 \\
21 \\
22 \\
23 \\
24 \\
25 \\
26 \\
27 \\
28\end{array}$ & $\begin{array}{l}11 \mathrm{~F} \\
5.2 \mathrm{M} \\
30 \mathrm{M} \\
42 \mathrm{M} \\
38 \mathrm{M} \\
35 \mathrm{M} \\
25 \mathrm{~F} \\
46 \mathrm{~F} \\
15 \mathrm{M} \\
33 \mathrm{M} \\
5.4 \mathrm{M} \\
55 \mathrm{~F} \\
55 \mathrm{~F} \\
69 \mathrm{M} \\
45 \mathrm{M} \\
3.2 \mathrm{M} \\
3.5 \mathrm{M} \\
75 \mathrm{~F} \\
41 \mathrm{M} \\
4.1 \mathrm{~F} \\
43 \mathrm{M} \\
40 \mathrm{M} \\
24 \mathrm{~F}\end{array}$ & $\begin{array}{l}\text { SVT } \\
\text { Paip } \\
\text { Palp } \\
\text { Palp } \\
\text { Palp } \\
\text { Palp } \\
V T \\
V T \\
\text { SVT } \\
\text { VT } \\
\text { VT } \\
\text { SVT } \\
\text { SVT } \\
\text { UT } \\
\text { Palp } \\
\text { Palp } \\
\text { Palp } \\
\text { SVT } \\
\text { SVT } \\
\text { Palp } \\
\text { Palp } \\
\text { Palp } \\
\text { WT }\end{array}$ & 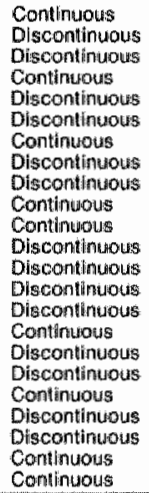 & 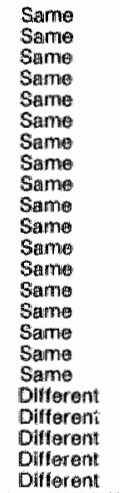 & $\begin{array}{l}\text { No } \\
\text { No } \\
\text { No } \\
\text { No } \\
\text { No } \\
\text { No } \\
\text { No } \\
\text { No } \\
\text { No } \\
\text { No } \\
\text { No } \\
\text { No } \\
\text { No } \\
\text { No } \\
\text { No } \\
\text { No } \\
\text { No } \\
\text { Not } \\
\text { No } \\
\text { No } \\
\text { No } \\
\text { No } \\
\text { No }\end{array}$ & $\begin{array}{c}4 \\
\ldots \\
4 \\
4 \\
4 \\
4 \\
\ldots \\
\ldots \\
\ldots \\
+ \\
+ \\
+ \\
4 \\
4 \\
4 \\
4 \\
4 \\
4\end{array}$ \\
\hline
\end{tabular}

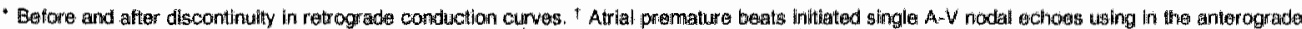

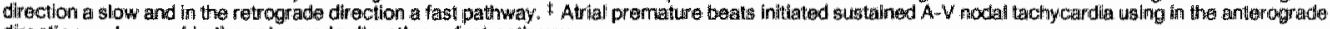
ditiectlon a silow and in the retromade direction a liast patiw

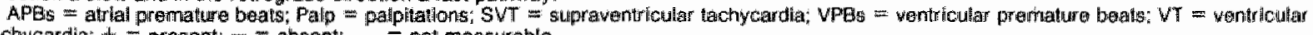
tachycardia +4 present; $-=$ absent; . . . = not measurable. 

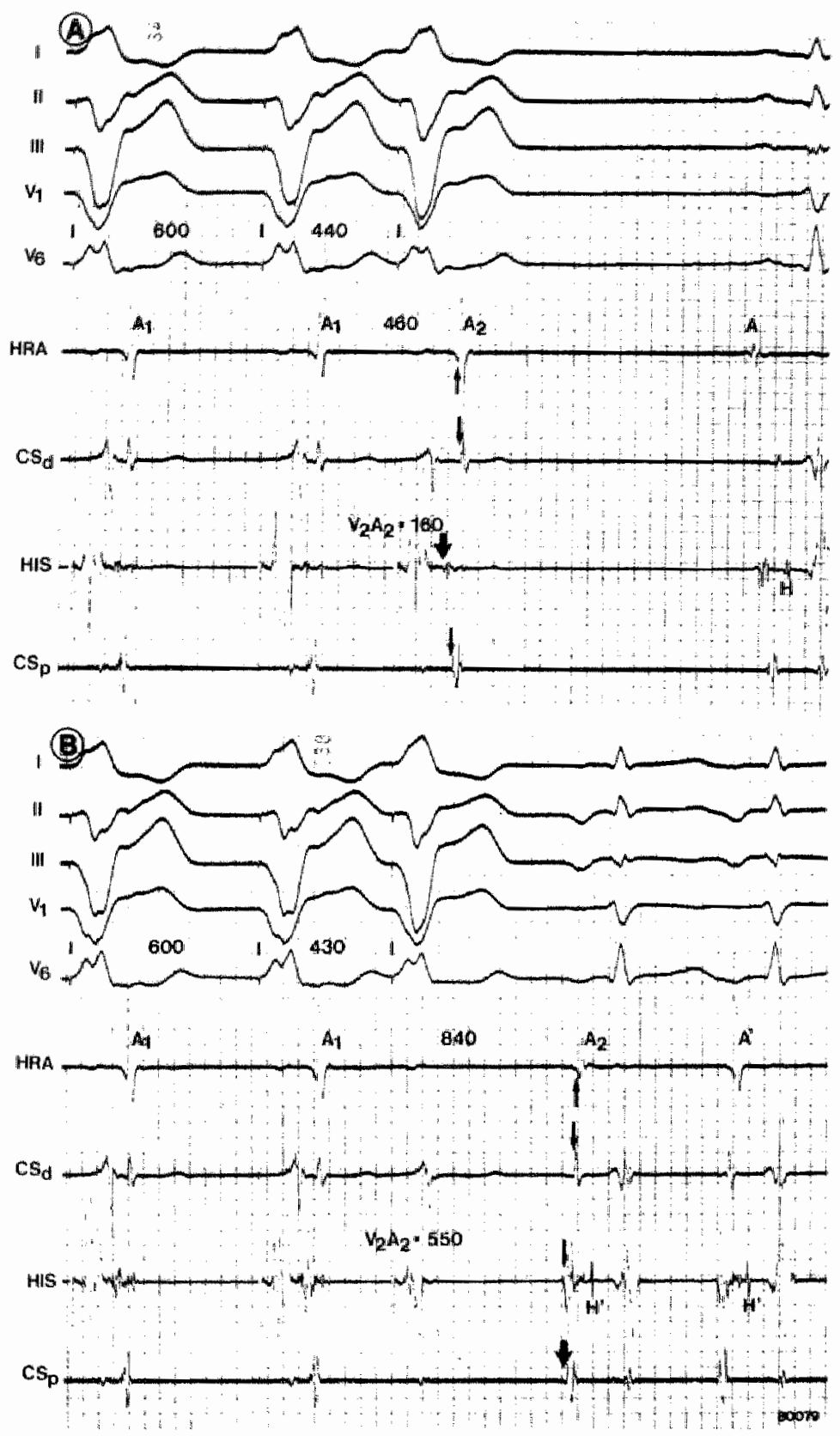

FIGUAR 1 Pattent 3 (group A). Two vertricular premature beat intervals. are: strown during pecing of the right: ventrictlar apex with a basic aycle length of $600 \mathrm{msin}$, 角 $\mathrm{A}$, a wentricular prematur beat given after $440 \mathrm{~ms}$ is followed by retroginade oonducthon to the atrium, the first atrial! activation beting reconded in the $\mathrm{His}$ bundes 斯ed (thick arrow) and thereattos followed by activation in the remalning andocavitary leads (thin arrowsi), Note the megiative $P$ wawe in leads 11 and hll, and a post.

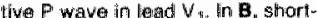
oning of the premature beat interwal by 10 ms results in prolomgation of the wentriculoatral cond Lition tirne of the prentwe best $\left(V_{2}-A_{2}\right.$ inter. wall) by $390 \mathrm{~m} / \mathrm{m}$. and the initialion of echo beats. Note the change in sequence of atralat activation as well as in the P wave configuration in lead $v_{\text {. }}$ at the time of intiation of ochoes. Five surtace leads were simbltaneously recorded with four ondocawitary electrogram inom: the high right atritum (tRA), distal (n) and promitimit (p) coronary sinus (CS) and His buandle area 

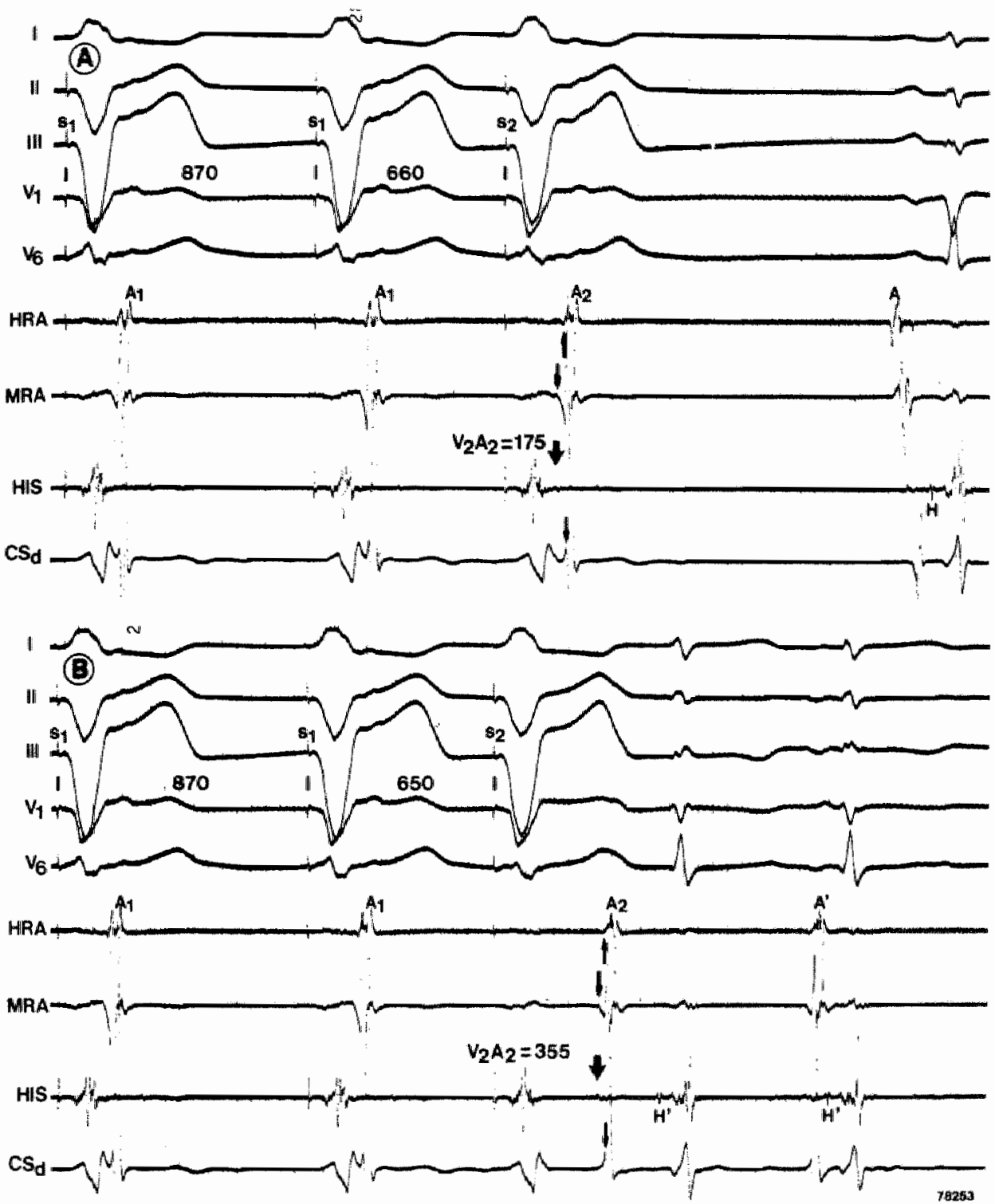

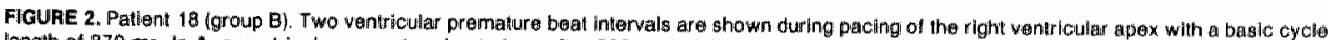

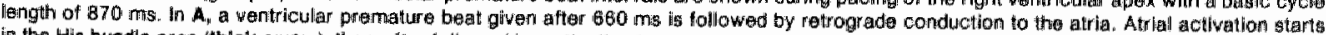

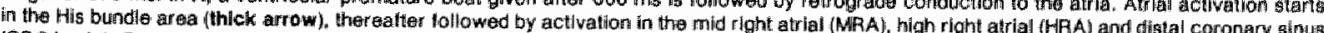

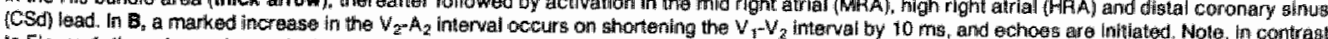
vo Flgure 1 , there is no change in the sequence of atrial activation and $P$ wava configuration in the surface heads at thes time of intitiation of ochoes. The $P$ wawe remains positlve in higad $W$. 
retrograde conduction curve, changing into a lat $\mathrm{P}$ we after the discontimuity (Fig. 1),

Felition between subnodal dolay of wentricular premature bents and conduction over the wlow pat hway during ventricular timulation:" The relaton between retrograde condwction to the atria over the alow pathway and subnodal delay of ventricular premature beats could be studied in 2 patients in group $A$ arid in 14 patients in group $B$ (Table 1). In patients in group A ( Fig. 5 ) retrograde conduction to the atria over the slow pathway was not related o critical $S_{1}-H_{2}$ interval suggesting that retrograde conduction in these patients occurred over a slow pathway that was not related to retrograde input into the His bundle. This observation therefore indicates that the distal end of the glow retrograde pathway did mot communicate with the His bundle.
In 14 patients in group $B$ (Fig. 3 and 4 ), a gap was observed in retrograde conduction over the slow pathway, with resumption of conduction and echoes when wuficient Purlcinje-His delay had occurred to overcome refractoriness of this area. This finding indicates that conduction over the slow pathway was related to retrograde imput into the bundle of His. This observation was rade in all patients in group $\mathrm{B}$ showing a change in the atrial activation sequence after the discontimuity in the retrograde conduction curve, and in nine patients in group B not showing such a change (Table I).

Duration and mode of termination of reentry shouring a shorter P-K than R-P interval: All patients in group A had awstained episodes of tachycardia showing this relation of the $P$ - R and R-P intervals. In patients in group $B$ echoes lasted only one to three cy. cles except in one patient with a maximum of six con

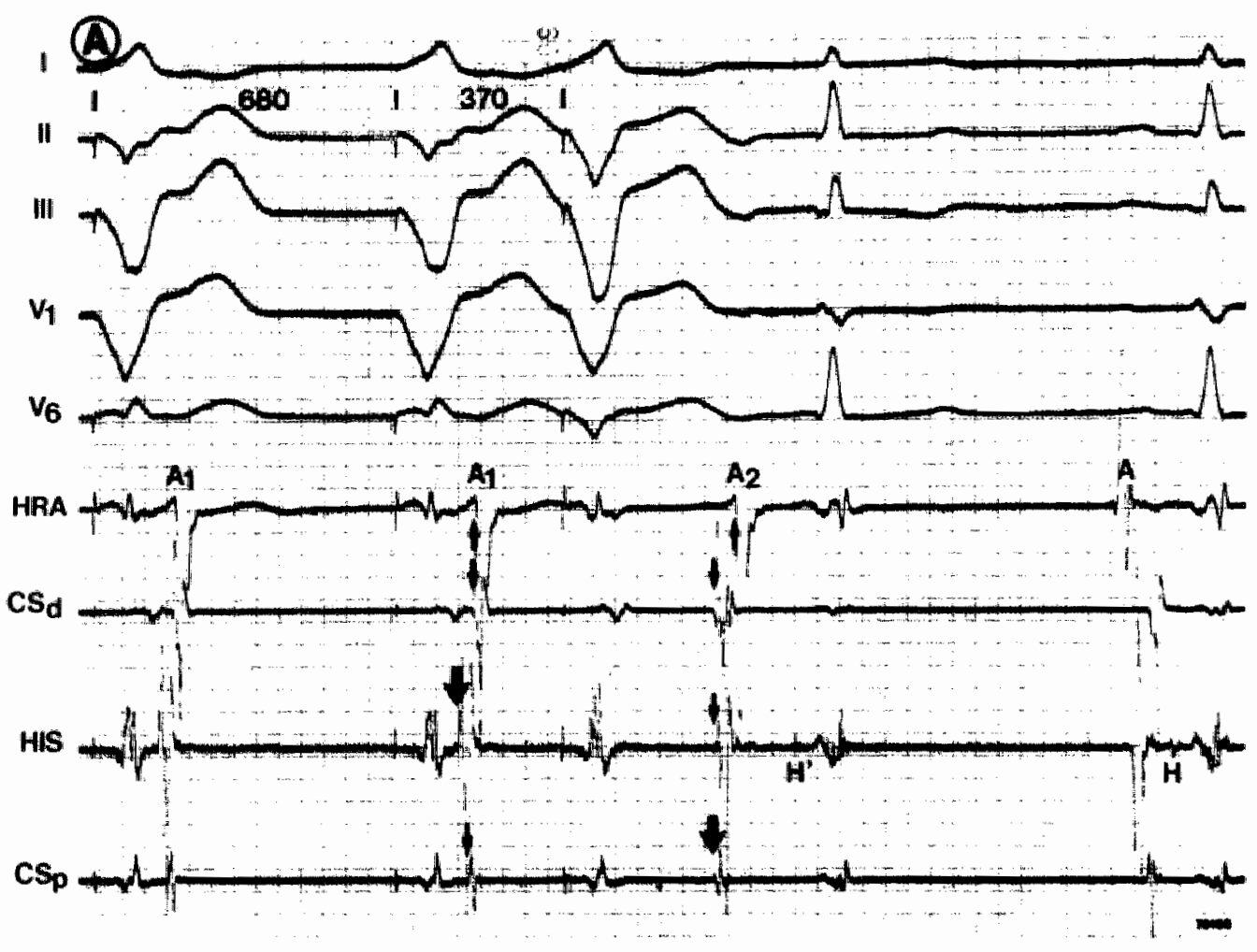

FiaUhas 3. Patlent 24 (group B). A wantricular premature beat given atter 370 ms during basic pecing of the right vantriculas apex with a basic cycle length of $600 \mathrm{~ms}$ is conducted in retrograde manner to the atria showing a change in the sequence of atrial activation as compared with the basic

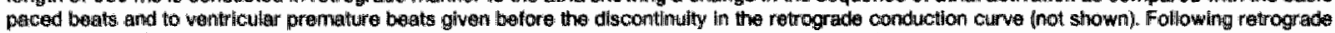

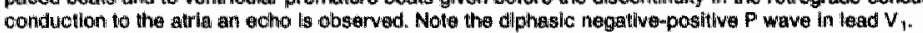



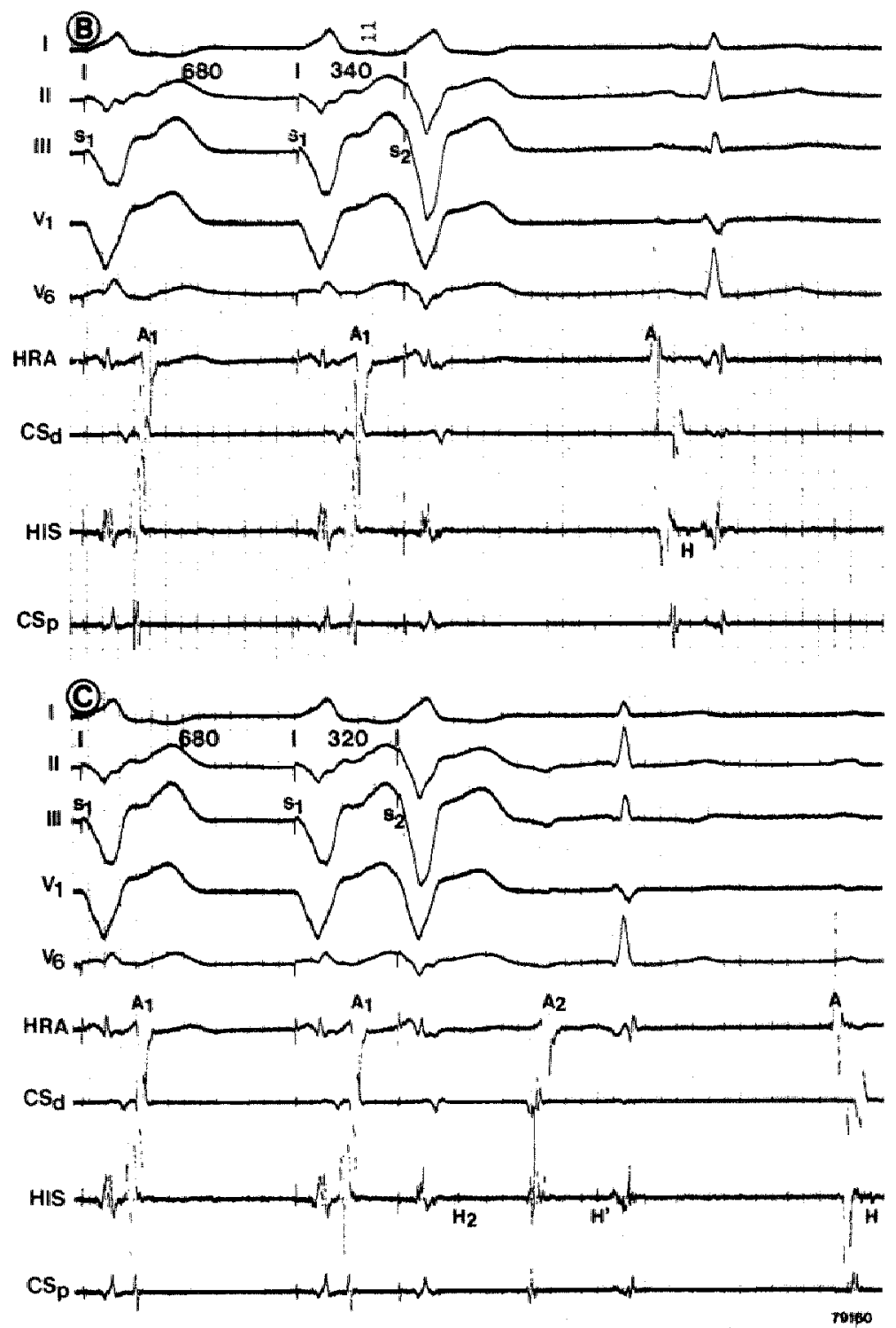

FIGUAE 4. Patient 24 (same patient as in Fig. 3). $\mathrm{B}$, a: ventriculan premature beat given after 340 ma is not followed by retrograde conduction to

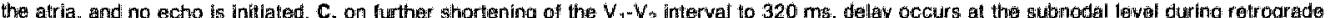
conduction of $W_{2}$. This is shown by the retrograde His bendle potential $\left(H_{2}\right)$ following $V_{2}$. This delay allows resumptor of reatrograde conduction ower the His bundie: followed by retrograde conduction ower the slow A.V nodal patthway, and resumption of anitlation of achoes. 

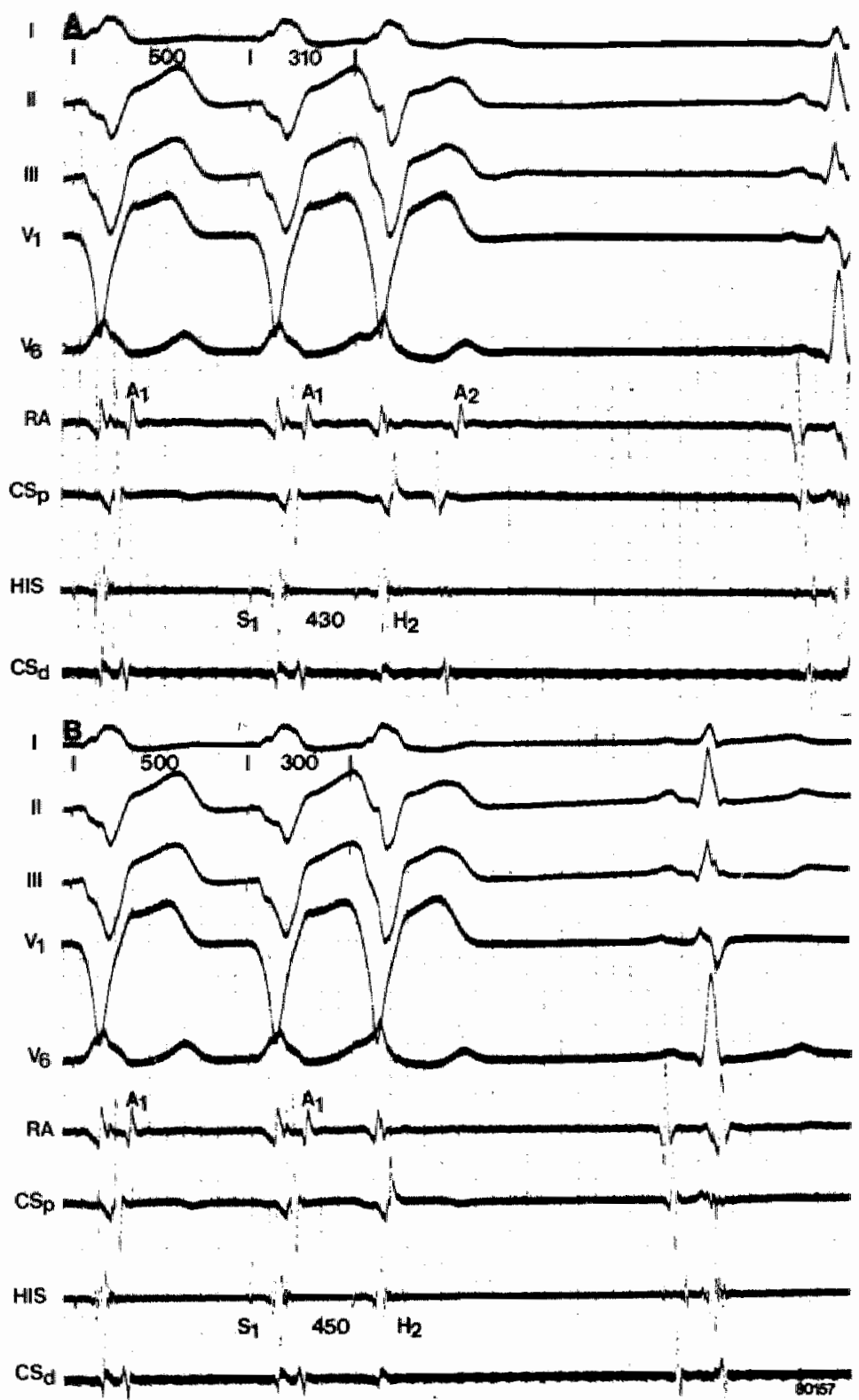

FIQUAE 5. Patlent 5, group A. Two wentrlcular premature beals are shown during pacing of the right ventricular apex with a basic cycle length of $500 \mathrm{~ms}$. In $\mathrm{A}$, a ventricular premmature beal given attar $310 \mathrm{~ms}$ is followed by retrogirade conduction to the atrlum; the first atrial activation is recorded

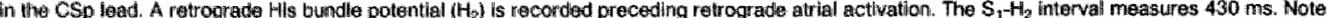
that durfing basic paced beats the earliest atrial actlvation is recorderd in the His bundle leadl, B shortening of the ventricular premature beal interval by $10 \mathrm{~ms}$ results in failure of retrograde condiction to the atria lin spite of prolengation of the $\mathrm{S}_{1} \mathrm{H}_{2}$ inienval indicating that wenticiculoatrial conduction in A occurred over a stowly conducting accessory pathway and that the reltractory pertod of this pathway measured $300 \mathrm{~ms}$ (B). 
secutive echo beats. In no patient in group $B$ was sustained tachycardia of this type observed.

Spontaneaus termination of tachycardia was rarely observed in four patients in group $A$, but frequently occurred in Patient 3 . Termination always occurred by a QRS complex not followed by subsequent atrial activation. Simillarly, in patients in group B with repeated spontaneous termination, block always occurred in the retrograde slow pathway.

Effect of ventricular premature beats during reentry: In three patients in group $A$ (wich rates of tachycardia waryung from 120 to 180 beats/min) atrial activation during tachycardia showing the same atrial activation in the endocavitary leads could be advanced by a single ventricular premature beat delivered at time when the His bundlle was refractory (Fig. 1 of ref. erence 7). In Patient 3 tachycardia was tei minated by a single ventricular premature beat that was not followed by retrograde conduction to the atria and that was delivered at the time of refractoriness of the bundle of His (Fig. 6 of reference 8 ). In Patient 5 in group A, with a rate of tachycardia of 215 beats/min, a ventricular premature beat delivered during tachycardia at the time of refractoriness of the bundle of His did not advance subsequent atrial actiwation. However when the first wentricular premature beat followed by a second one, subsequent atrial activation could be andvanced without modifying the activation of the His bundle. Tachycardis could also be terminuted by this mode of pacing. Because of the short duration of reentry. the effect of ventricular premature beats could not be sys. tematically studied in patients in group $\mathrm{B}$.

Effect of ventricular premature beats during ginus rhythm: In Patient 3 in group A it was observed that chang sinus rhythm, when a ventricular premsture beat was deliwered when the His bundle was expected to be refractory for $V$. e conduction, retrogrado conduction to the atrium was possible (Fig. 6). In six pa. tients in group B wentricular premature beats occurring at the time of refractoriness of the bundle of His were never followed by retrograde conduction to the atria.

Effect of administration of atropine (Table II): Four patients in group $A$ and 12 patients in group $B$ received atropine. As previously described 7,8 this tresulted in acceleration and persistence of tachycardin in patients in group A, with shortening of the A-H and V-A

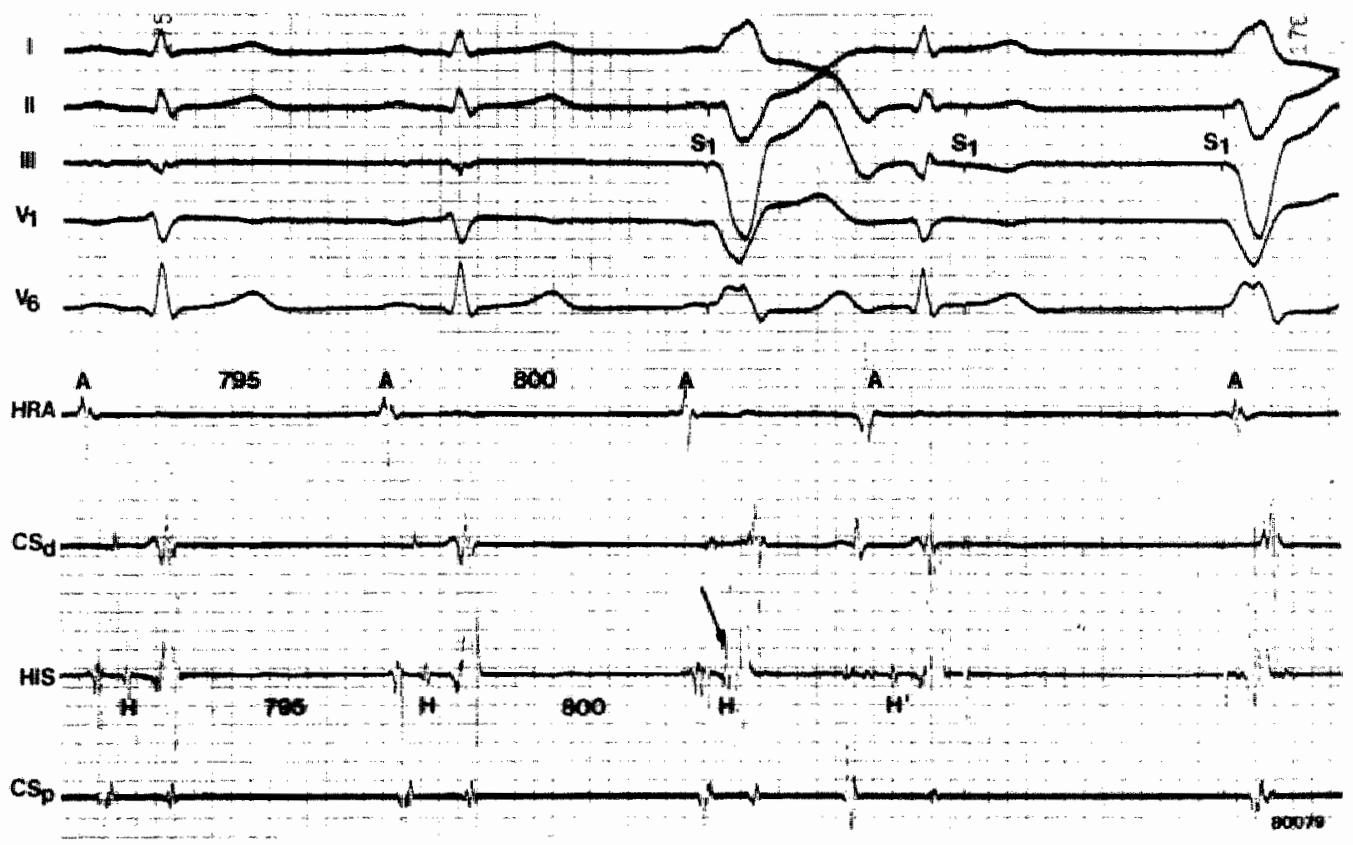

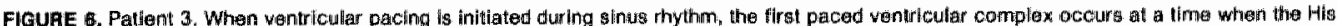
bunde is reltactory firom anterograde canduction of the simus impulse (arrow). Howewer, ventriculoatrial conduction occurs and lia tollowed by an

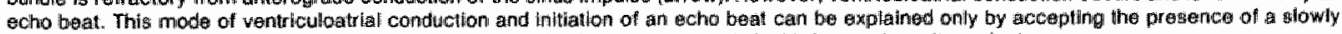

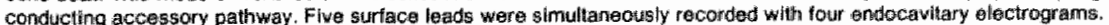


TABLE II

Effect of Atropine Adminlatration on Anterograde and Pretrogrado Conduction and on Iniltation of Tachycardilas

\begin{tabular}{|c|c|c|c|}
\hline \multirow[b]{2}{*}{ Cang } & \multicolumn{2}{|c|}{ Conduthon Curvas } & \multirow{2}{*}{ 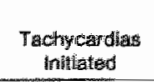 } \\
\hline & Anterogradie & Retrogsado & \\
\hline \multicolumn{4}{|c|}{ Group $A$} \\
\hline $\begin{array}{l}1 \\
3 \\
4 \\
5\end{array}$ & 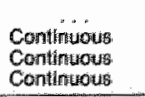 & $\begin{array}{l}\text { Discomitinuous } \\
\text { Discomentinuous }\end{array}$ & 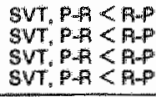 \\
\hline \multicolumn{4}{|c|}{ Groulo $\mathrm{B}$} \\
\hline $\begin{array}{r}6 \\
7 \\
0 \\
10 \\
12 \\
14 \\
17 \\
20 \\
20 \\
24 \\
24 \\
27 \\
\end{array}$ & 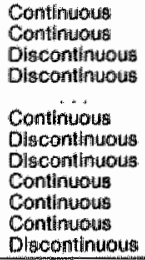 & $\begin{array}{c}\text { Continuous } \\
\text { Continuws } \\
\ldots \\
\text { Continuligus } \\
\ldots \\
\ldots \\
\text { Continious } \\
\text { Continuous } \\
\text { Contlinuous } \\
\text {... }\end{array}$ & $\begin{array}{c}\text { No } \\
\text { No } \\
\text { No } \\
\text { AWN }(s-f) \\
\text { No } \\
\text { No } \\
\text { AWN }(s-1) \\
\text { ANN }(s-1) \\
\text { No } \\
\text { No } \\
\text { No } \\
\text { AVN }(s-1)\end{array}$ \\
\hline
\end{tabular}

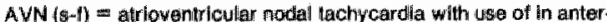

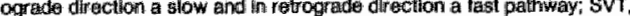

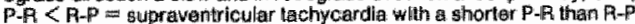
interval.

intervals during tachycardia in all but Patient 5 , who showed only shortening of the A-H interval. In two patients of this group retrograde conduction curves re. mained discontinuous after administration of atropine.

In patients in group $B$ administration of atropine gave completely different results. Echoes or tachycardia with a shorter $P-R$ than $R-P$ interval could not be initiated after the administration of atropine (Table II) in any patient in this group. The retrograde conduction curves became continuous in six patients, including two in whom a change in the atrial activation turence was observed after the discontinuity in the retrograds conduction curve before administration of atropine. In four patients retrogracle conduction was not. vtudied after the administration of atropine because atrial premature beats resulted in initiation of $A-V$ nodal tachycardia uthing a slow pathway in the an. terograde direction arid a fest pathway in the retrograde direction. In the remainimg two petients the retrograde conduction curves were not atudied after administration of atropine.

\section{Discussion}

Characteristices of the dual $A-V$ transmission systom: In 1966. Moe and Mendez ${ }^{12}$ postulated a dual A.V transmission system to explain echoes like those observed in our patients. Characteristically their occurreruce is related to a critical delay in retrograde conduction to the atria during ventricular stimulation. Since then, the site of longitudinal dissociation has been considered to be located in the $A-V$ node $1,2,12-14$ Our results demonstrate that the presence of an accessory A. W pathway with a long conduction time can give rise to an electrocardiographically similar pattern fechoes with atrograde $\mathrm{P}$ wave, a supirventricular QRS complex and a shorter $P-R$ than $R-P$ intervalj. However. our patients were chatacterized by the sustained nature of the arrhythmia, which could also be initiated by atrial premature beats or occur spontaneously during simus rhythm. Furthermore, the methanism persisted with acceleration of tachycardia after administration of atropine. In contrast, in patients showing the "unusual" form of $A-V$ nodal reentry, the arrhythrnia tis not sustained, is not initiated by atrial premature beats, does not occur spontaneotsly during sinus rhythm and camnot be initiated after the administration of atrow pine.

Characteristies of the retrograde accessory $A-V$ pathway: In all patients in group $A$ we found definite evidence of the presence of an accessory A.V pathway, which was concealed in the surface electrocardiogram but was used in retrograde manner during tachycardie. The accessory pathway had a retrograde conduction time that was longer than the retrograde conduction time over the normal A-V pathway. The normal A-V pathway had a retrograde refractory period that was longer than the refractory period of the accessory pathway. These properties resulted in the observation of discontinuous retrograde conduction curves with two different atrial activation sequences depending on the pathway used for retrograde conduction. The diagnosis of an accessory $-V$ pathway used in retrograde manner during tachycardia in patients in group A was based on the following criteria: (1) advancement of subsequent atrial activation during tachycardia with the same atrial activation sequence by a ventricular premature beat delivered during tachycardia at the time of refractoriness of the bundle of $\mathrm{His}^{\mathrm{T}}, 10$; and $(2)$ termination of tachycardia by a ventricular premature beat that was not conducted in retrograde manner to the atria, curring at the time of refractoriness of the bundle of His. ${ }^{8}$ Occasionally, as in Patient 5, these features were demonstrated only by giving two premature ventricular beats consecutively.

New obserwations demonstrating $V-A$ conduction over an accessory pathway with a long conduction time were: (1) the occurrence of V.A conduction after a ventricular premature beat given during sinus rhythm, at a time when the His bundle was refractory for retro. grade conduction (Fig. 6); and (2) the finding that $V$. A conduction over a slow pathway is not related to the timing of retrograde activation of the bundle of $\mathbb{H i s}$, indicating that the slow pathway is functionally dissociated from the His A.V nodal pathway (Fig. 5).

Features of atrial acturation in pressence of accessory pathway: All patients with evidence of the presence of an accessory pathway with a long conduction time manifested two differems atrial activation sequences on careful study with multiple endocavitary recordings. The location of the atrial end of these accessory pathways with a long conduction time, as well 
as the criteria to exclude a nodoventricular accessory pathway, have been discussed previously. We and others ${ }^{* 6}$ have shown that this type of accessory pathway has its atrial end close to the mouth of the coronary sinus. As Sung and Waxman ${ }^{15}$ observed in a preliminary report, in some patients in whom the presence of an accessory pathway can be excluded, a change in the sequence of atrial activation cam be found depending on the use of the fast or the slow A-V nodal pathway. These findings suggest that in some patients there are different atrial entry points for the fast and the slow $A-V$ nodal pathway in the atrium. This observation was made in five of our patients in group B. Janse et al. ${ }^{16}$ previously described the existence of a dual input to the A. W node in the rabbit heart during sinus rhythm and atrial stimulation: a posterior input by way of the crista terminalis entering the node beneath the coronary simus ostium, and an amterior input entering the node as a broad wave front anterior to the ostium of the coronary simus. They also reported the presence of two exits to the atrium during retrograde conduction over the $A-V$ node. A similar situation may exist in our five patients in $g_{\text {group }} \mathrm{B}$ who showed a change in atrial activation pattern after the discontinuity in the retrograde conduction curve.

In retrospect we consider it unfortunate that we did not repeat in our patients the experiments performed by Schuilenburg and Durrer. ${ }^{17}$ They showed that in patients having the type of echo described in our report a part of the reentrant cycle could be preexcited by stimulating the atrium before the expected arrival at the atrium of the retrograde impulse in the course of the echo sequence. A similar study in our patients with comparison of the effect of coronary simus stimulation versus low right atrial stimulation on the time relations during the reentrant cycle would probably have given us more information on the atrial entry sites during reentry and the role of the atrium in the reentrant circuit. Additional work is required to know whether the absence of a change in retrograde atrial activation pattern during reentry after the discontinuity in the retrograde conduction curve indicates an intra $A . V$ nodall reentrant circuit and whether a change in the retrograde atriall activation sequence suggests incorporation of the atrium in the reentrant circut

The five patients in group $B$ showing the change in the sequence of atrial activation after the discontinutity in the retrograde conduction curve could not be distinguished from patients in group A by their pattern of atrial activation in the endocavitary leads or the con. figuration of the $\mathrm{P}$ waves in the surface leads. Patients in group $B$ who manifested the same pattern of atrial activation before and after the discontinuity in the retrograde conduction curve showed (1) first onset of atrial activation in the His bundle electrogram, and (2) a positive $P$ wave in the surface lead $V_{1}$ before and after the discontinuity. That the changes in the atrial activation pattern are real and not a recording artifact is supported by our observation that in patients showing this phenomenon the $\mathrm{P}$ wave changed from positive in lead $V_{1}$ before the discontinuty into lat diphasic $p$ wawe in the same lead after the discontinuty (Fig. 1 ).

Location of the slowly conducting pathway in the A-V node: In 14 patients in grotu $B$, including all five pationts showing the change in retrograde atrigl acti. vation patterr after the discontinuity in the retrograde conduction curve (Patients 24 to 28), we could demon. strate that the slowly conducting pathway was located above the bundle of His. In all 14 the occtirrence of retragrade conduction over the slow pathway was related to critical timing of the retrograde input in to the His bundle-A.V node. This could be beautifully demonstrated by observing the phenomenon of a gap in retrograde conduction over the slow pathway, which was owercome when sufficient subnodal delay permitted resumption of retrograde conduction over the slow pathway (Fig. 3 and 4 ).

In seven of the remaining nine patients in group $B$ our assumption that retrograde longitudinal dissociation. most likely occurred in the $\mathrm{A}-\mathrm{V}$ node was based on the lack of positive criteria for the presence of an accessory pathway, and the finding of anterograde longitudingl dissociation in the A.V node. The latter was shown by (1) presence of a discontanuous anterograde conduction curve, (2) initiation of the "usual" type of A-V nodal echoes (anterograde sllow, retrograde fast) in Patients 8,11 and 14, and (3) initiation of the "usual" type of A.V nodal tachycardia in Patient 17 after administration of atropine. In two patients in group B (Patients 15 and 16) no evidence could be obtained to support the presence of an accessory pathway with a long conduction time. These two patients also showed no signs of longitudinal dissociation of the A.V node in the anterograde direction. We realize that in these nine patients the presence of an accessory pathway in the retrograde direction cannot be totally excluded.

Eighteen patients in group B showed only one se. quence of atrial activation in the endocavitary leads, and this did not change after the discontimuity in the retrograde conduction curve. In 9 of these 18 patients the presence of a retrograde gap in conduction of the type discussed proved that the distal end of the slow pothway was located above the bundle of His. As previously discussed, the similar atrial activation sequence before and after the discontinuity suggests the presence of an upper common pathway in the A.V node in these patients.

Diagnostic considerations: Of diagnostic importance is the observation of initiation of tachycardia or echoes with a shorter $P \cdot R$ than $\mathbf{R}$ - $\mathbb{P}$ interval sponta* meously during sinus rhythm or after atral promature beats in patients in whom an accessory pathway with a long conduction time is used in the retrograde direction. This was never observed in patients in whom a retrograde slow A-V nodal pathway was used. Although it is theoretically possible to observe the initiation of the "unusual" type of echoes during sinus rhythm or atrial stimulation in patients hawing dual $\mathrm{A}-\mathrm{V}$ nodal pathways in the anterograde direction, thils was never observed in our potients. "The presence of a low pathway with a 

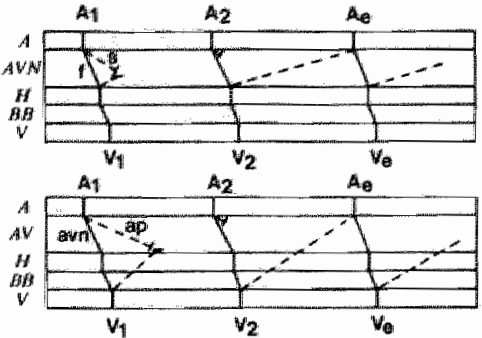

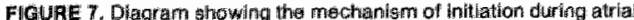
parting of the "unusual" type of intranculal atriowentricular echo (top pandil, and of aupirawentricular tachycardia using in retrograde marner an accessiony pathway with a long conduction tirne (bottom panol). Albough theoretically possible, the mode of intiation deplicked in the

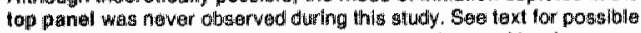

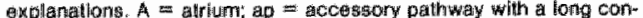

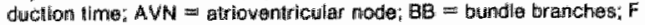

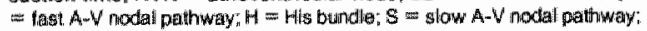
$w=v$ vetriticle.

longer refactory period than the fast pathway is essential for the initivtion of the "unusual" type of intranodal reentry during atrial pacing (Fig. 7). In 15 of our 23 patients in group $B$ we could demonstrate during atrial pacing that the reverse was true, thus explaining why the "unusual" type of intranodel reentry could not be initiated. In the remairing seven patients one can speculate that factors like depth of pentration into the slow pathway or early arrival of the impulse over the fast. pathway at the distal common pathway prewented completion of an intranodal reentrant cycle with an- terograde conduction over the fast and retrograde. conduction over the slow pathway It is uruderstandable that reentry is much more easily initiated during atrial stimulation or even in sinus rbythm in the presence of a slowly conducting accessory pathway, simply by the combination of anterograde block in the accessory pathway and an echo circuit with much larger dimensions than those of the A-V node.

Effect of atropine: The effect of administration of gitropine was very different in patients in group $A$ and group B. Tachycardia persisted and accelerated in those patilents in whom an accessory pathway with a long conduction time was used. However, in no patient in group B could echoes with a shorter P- $\mathbb{R}$ than $R-P$ interval be initiated after the administration of atropine. In all patients in group B in whom this could be tested, atropine resulted in shortening of the retrograde refractory period of the fast pathway, and thus in disappearance of the discontinuity in conduction in the retrograde direction. Wu et all." reported a case of "un(usual" type of $\mathrm{A}-\mathrm{V}$ norlal tachycardia initiated after administration of atropine. In that patient and also in later observations by the same group, the use of an accessory pathway with a long conduction time as the retrograde arm of the tachycardia circuit was not exchuded.

Implications: Our data suggest that in patients with A-V junctional tachycardia whose P-R intervall is shorter than the R-P interwal during the arrhythmia, an intramadal location of the reentrant circuit is ex. tremely rare. For all practical purposes, including medical and surgical treatment, a tachycardia circuit incorporating a slowly conducting accessory pathway should be considered most likely.

\section{Reterences}

1. Mandez C, Moe GK. Demonstration of dual A w nodal conduction system in the isollated rabbit heart. Circ Res 1966;19:37B-93.

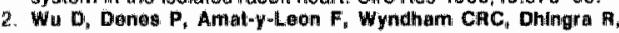

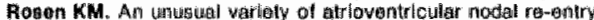

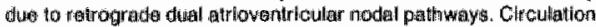
$1977: 50: 50 \mathrm{mo}$

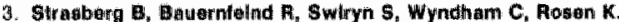
Patrogradg dual $A-V$ nowal paithways (abutr). Circulation 1980;

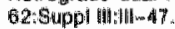

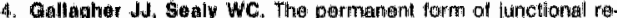
ciprocating tachyoardia: Hurther eluclotation of the underlying mechanisn. Eur J Otarolo: $1970 ; 8: 413-30$.

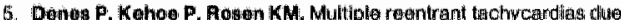
to rekrograde coindwetlon of dual atriowentricular bundies wh

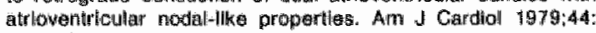
$162-70$.

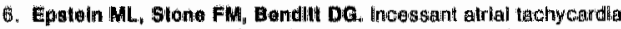
In childthood: association with rate-depaendion conduction fin an accessory atrlowentrioular pathway. Am J Cardiol 1979:44: $496-504$.

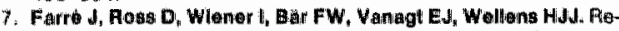
clpirocial lachycardias wising accosisony pathways with long conduction thes. Am J Candlol 1979,44:1099-109.

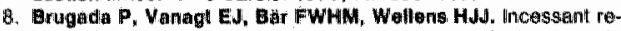

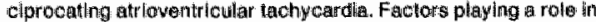
the mechanlsans of the arritythima. Pace 1980;3:670-7.
9. Foss D. Farre Bar FWHA al Comprenensiwe electrophisiological studies in the investigatlon of documented or suspected tachycanties: times, staft, problems and costs involved. Circulation $1980: 61: 1010-6$.

10. Wellens HJ, Durez D. The role of an accessory atrioventhiculrit pathway in ieciprocel tachycardla. Circulation $1975: 52: 58-72$.

11. Josepheon ME, Seldes SF, Clinical cardiac elloctroptrysiology. Philladelphia: La Febiger, 1979:23-59.

12. Moe GK, Nendex $\mathrm{C}$. The phystologic basis of resipracal rhythm Prog Cardiowase Dis 1966;8:461-82.

13. Mhgnane Al, Wallace AC. Evidence for dissoctitlon of conduction and remonty whin the AW node. Circ Res 1966; 19:638-49.

14. Schullenburg PAM Durret in. Ventricular echo beats in the thuman heart ellolted by induced wentrletilar premature beats. Circulathon $1969 ; 40: 337-47$.

15. Sung fo, Waxman HL. Phisiological shitt of rotrograde atrioven tricular nodal outpat mimickling retrograde accessiory pathway conduction (abstr). Circulation 1979;59,60:Suppt H:.11-191.

16. Janse Mu Van Capelle Falh, Anderson RH, Touboul P, Billelte J. Eiractrophysiology and structure of the atriowemirlcular node of the isolated rabbit heart. In: Wollens Hul, Lie K't, Jarus $\mathrm{MJ}_{3}$ edis. The Conducilon System of the Heart. Lelden: Stenfort Kroese, 1976 : $296-315$

17. Schulllanburg $\mathbf{A M}$, Durrer D. Further observallons of the ventricular echo phonomena ollcited in the humen hater. Is the atrim part of the echo pathay ? Circulation 1972;45:629-38. 


\section{Observations in patients with supraventricular tachycardia} having a P-R interval shorter than the R-P interval. The differentiation between atrial tachycardia and reciprocating atrio-ventricular tachycardia using an accessory pathway with long conduction times.

Pedro Brugada, M.D.; jerónimo Farré, M.D.; Bill Heddle, M.B., B.S.; Denis Roy ، M.D.; and Hein J.J. Wellens, M.D., F.A.C.C.

From the Department of Cardiology, University of Limburg, Annadal Hospiral, Maasiricht. The Netherlands.

\section{Summary}

In twenty-five consecutive patients with supraventricular tachycardia (16 incessant and 9 recurrent paroxysmal) having a $P-\mathbb{R}$ interval shorter than the $\mathbb{R}-\mathrm{P}$ interval during the arrluythmia, the mechanism and site of origin of tachycardia was studied by programmed electrical stimulation of the heart. No patient had anterograde conduction over an accessory pathway. Fourteen patients with incessant tachycardia underwent an exercise test during the arrhythmia, and in sixteen patients the effect of $1 \mathrm{mg}$ of atropine given intravenously on the time intervals during tachycardiat was studied. Vagal manoeuvres were performedin all patients. In 7 patients (group A) all with incessant tachycardia, the presence of an accessory pathway with long conduction time used retrogradely during tachycardia was demonstrated. All patients had V-A conduction during ventricular pacing. Tachycardia initiated spontaneously during sinus rhythm, but was also initiated by atrial and ventricular premature beats. Exercise accelerated the rate of tachycardia by shortening both the P-R and the R-P intervals. The same effect was obtained by atropine administration. A continuous 1-to-1 A-V relation was required in these patients to perpetuate the arrhythmia. In 10 patients (group B) V-A conduction during ventricular pacing could not be demonstrated. Seven patients had incessant tachycardia. The arrhythmia initiated spontaneously during sinus rhythm and was also initiated by atrial premature beats. In two patients the mechanism of initiation remained unknown because incessant tachycardia could never be terminated. In no patient tachycardia could be initiated or terminated by ventricular premature beats or ventricular overdrive pacing.

In the remaining 8 patients (group C) V-A conduction was present. Tachycardia initiated spontaneously during sinus rhythm and was also initiated by atrial premature bets. In one patient it could also be initiated by a ventricular premature beat, but in contrast to patients of group $A$. without relation to a critical delay in retrograde conduction.

In group $B$ and $C$ atropine accellerated the rate of tachycardia in 9 of 11 . In seven patients with incessant tachycardia ( 4 of group $B$ and 3 of group C) the rate of tachycardia increased during exercise. Continuation of exercise resulted in the appearance of sinus tachycardia in three of them. In all patients of group $B$ and $C$ a $1-t o-1 A-V$ relation was not required to perpetuate the arrhythmia. Vagal manoeuvres were of help to demonstrate perpetuation of tachycardia when conduction to the ventricles did not occur. An atrial site of origin of tachycardia could be demonstrated in these patients.

All patients of group A had during tachycardia the characteristic configuration of the $P$ wave 
described by Coume. No patient of group $B$ and $C$ had this type of $P$ wave. In them five different P wave configurations were observed.

Our study in paticnts with incessant or recurrent paroxysmal supraventricular tachycardia having a P. $\mathbb{R}$ interval shorter than the R-P interwal during the arrhythmia shows that the differentiation. between an atrial site of origin of tachy-cardia and a circus movement tachycardia using an accessory pathway with long conduction time in retrograde direction can be made by careful analysis of the 12-lead electrocardrogram and use of simple manoeuvres like carotid sinus massage, atropine administration and exercise.

\section{Introduction}

Programmed electrical stimulation of the heart has improved our knowledge of the site of origin, mechanisms and pathways of supraventricular tachycardia in man (1-2). This has resulted in a more rational therapeutical approach to the different types of supraventricular tachycardia, and the development of refined surgical techniques for some of them (3-4). It also increased our abilities of making the correct diagnosis on the 12-lead electrocardiogram in patients with supraventricular tachycardia (5). We have recently reported on patients with sustained $A-V$ junctional tachycardia showing a P-R interval shorter than the R-P interval (6). It was demonstrated that an intranodal location of the re-entry circuit (the so-called "uncommon type" of A-V nodal tachycardia) during this arrhythmia is unlikely. These patients have a circusmovement tachycardia using in atrio-ventricular direction the normal A-V nodal-His-Purkinje pathway and in ventriculoatrial direction an accessory pathway with long conduction times and $\mathrm{A}-\mathrm{V}$ nodal-like properties. Usually these patients present clinically with a tachycardia having an almost incessant or "permanent" character (7).

Atrial tachycardia can present with a similar electrocardiographic and clinical picture. Also in view of the therapeutical implications we would like to discuss how to differentiate between both types of supraventricular tachycardia. Special emphasis will be placed upon the use of the 12-lead ECG and simple non-invasive manoeuvres (like carotid sinus massage, the administration of atropine, and the exercise test) in making this distinction.

\section{Patients and methods}

Twenty-five consecutive patients (table I) fulfilled the following criteria:

a. Permanent or recurrent paroxysmal supraventricular tachycardia continuously or intermittently showing a 1-to-1 A-V relation with a P-R interval shorter than the R-P interval.

b. A complete electrophysiological investigation to delineate the mechanisms, pathways and site of origin of the arrhythmia using our previously described protocol of stimulation, recording, and analysis of tracings (8). The study was performed in the resting, postabsortive nonsedated state, or under light sedation with oral diazepam except in patient 25 who was studied under general anacsthesia. Medication was discontinued at least 48 hours before the study. No patient had received antiarrhythmic drugs with cumulative effects (like Amiodarone) before the investigation. Catheters were placed for both stimulation and recording of intraca rdiac bipolar electrograms in the right atrium, coronary simus and/or left atrium, His bundle area, and the ape $x$ of the right ventricle. With the single test stimulus technique at different basic cycle lengths of pacing (at least two) patterns of $\mathrm{A}-\mathrm{V}$ and $\mathrm{V}-\mathrm{A}$ condnction and refractory periods were measured during atrial and ventricular stimultation. Complete studies could rarely be performed during sinus rhythm in patients having incessant tachycardia. During tachycardia the effect of timed atrial and ventricular premature beats was tested. V-A conduction over a slowly conducting accessory A-V pathway was diagnosed according to previously reported criteria $(6,9-12)$.

c. Patients with anterograde conduction over an accessory pathway and patients with atrial flutter were exchuded.

Fourteen patients having incessant tachycardia underwent a limited exercise test to assess its effects on tachycardia time-intervals. Sixteen patients received $1 \mathrm{mg}$ of atropine intravenousily to 
数品.

55

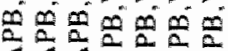

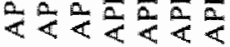

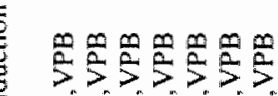

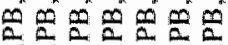

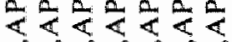

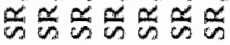

ショシショ

$$
\text { ジシジシシ }
$$

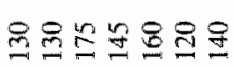

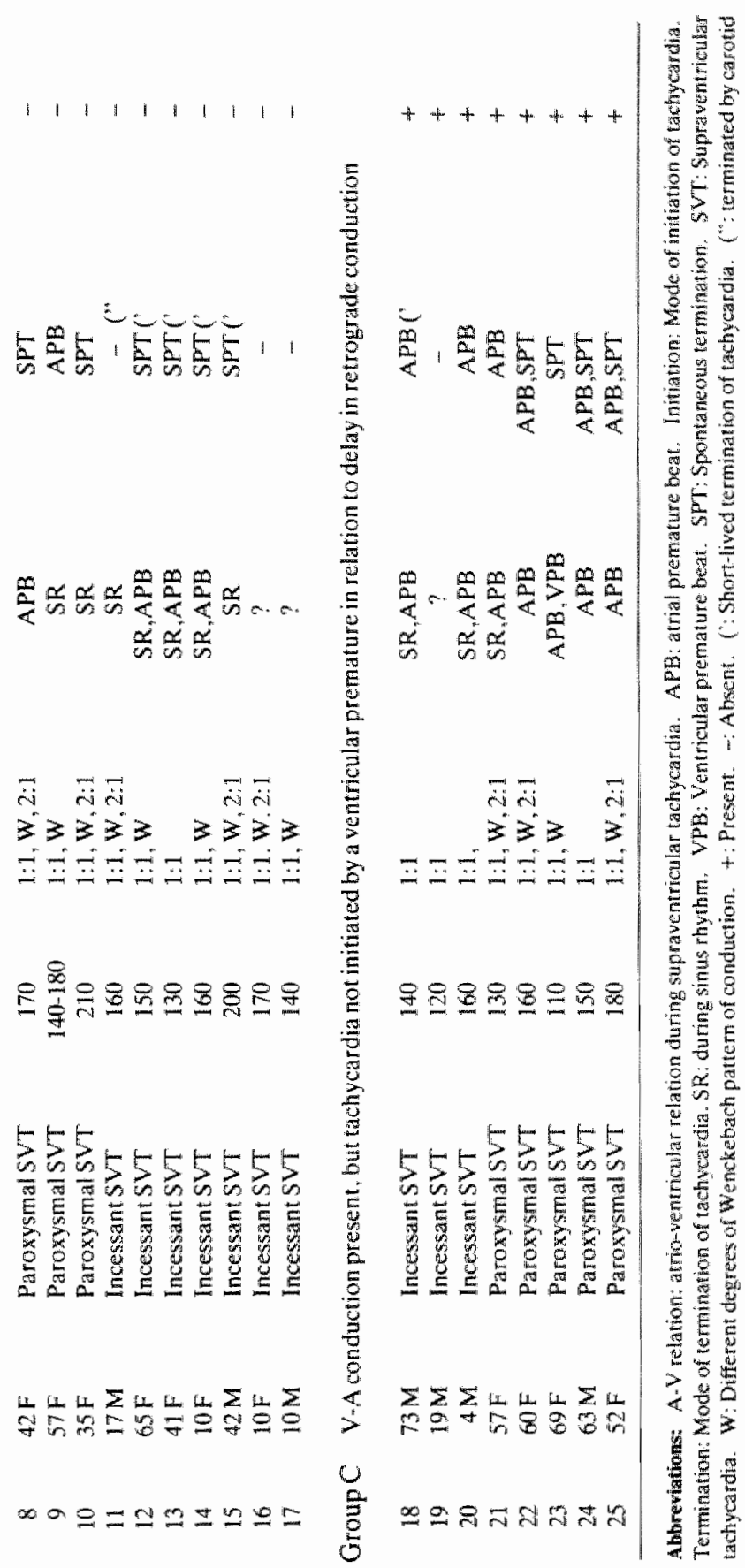




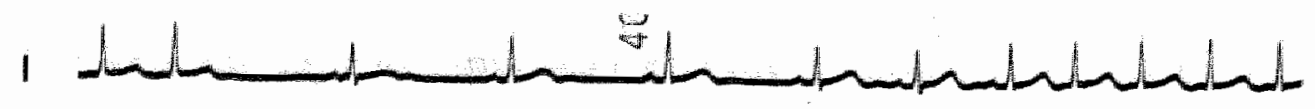

II
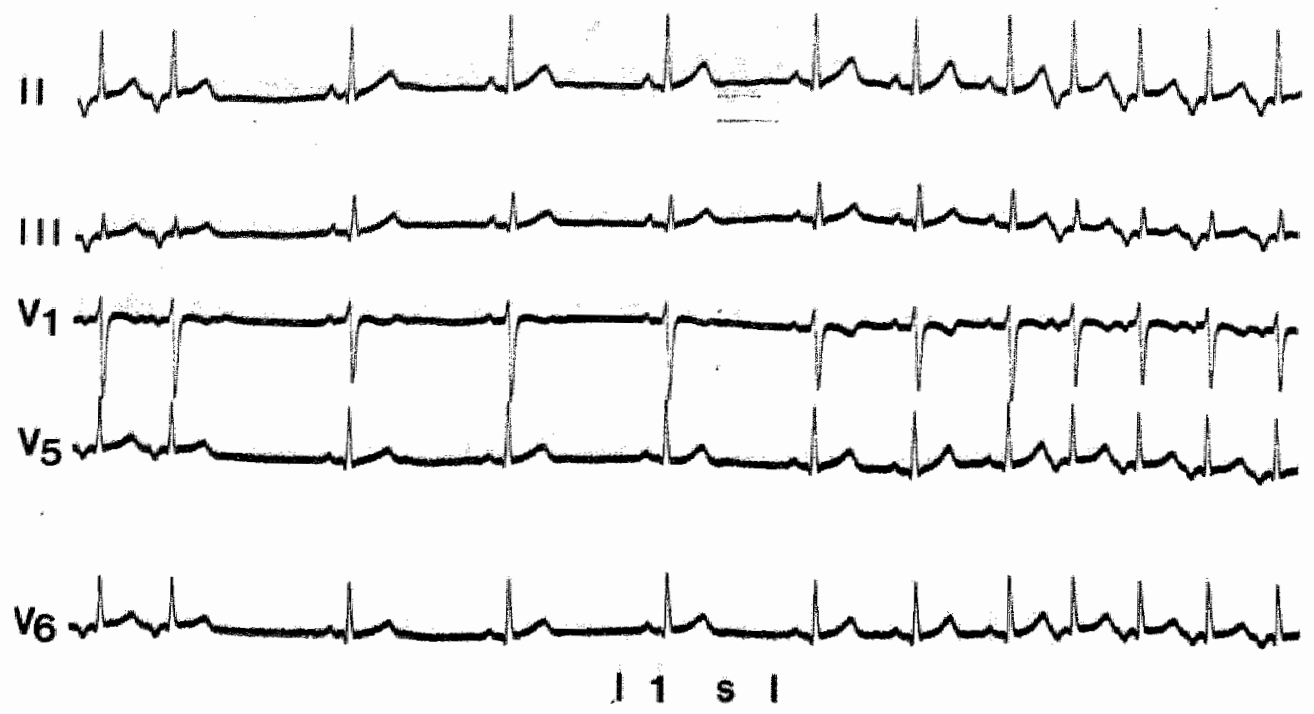

Figure 1

Patient 1. Spontameous termination (left) and re-initiation (right) of a tachycardia using retrogradely an accessory pathway with long conduction times. Tachycardia terminates by a QRS complex not followed by a retrograde $P$ wave. After five sinus cycles showing a progressive increase in rate lachycardia starts. spontaneously. Note the deep negative $P$ wave in leads II, III and in the precordial leads (7). 5 Surface leads were recorded simultaneously.

determine its effects on tachycardia (table II). Apart from 12-lead electrocardiograms recorded before the stimulation study showing simultaneous recordings of three extrenity or precordial leads or six extremity or precordial leads, leads I, II, III, V1 and V6 were simultaneously recorded during tachycardia in the catheterization laboratory in all patients. These tracings were used to analyse the $P$ wave morphology during the arrhythmia.

\section{Results}

Sewentecn of the 25 patients presented clinically with a permanent or almost continuous supraventricular tachycardia (table 1). Eight patients had a recurrent paroxysmal form of supraventricular tachycardia. There were 15 females and 10 malles. Measured at rest during stable basal conditions, rates during tachycardist individually ranged from 110 to 210 beats/min.

\section{Electrophysiological studies:}

a. Initiation of tachycardia:

In twenty-two patients tachycardia initiated spontaneously during sinus rhythm or could be initiated by atrial premature beats. In the remaining three patients with continuous tachycardia in whom the arrhythmia could not be terminated by pacing (patients 16, 17 and 19) the mode of initiation of tachycardia could not be documented. In patients with spontaneous initiation of tachycardia during sinus rhythm no definite relation was found between initiation of tachycardia and simus cycle length although two patients (patient 1 and 12) had a trend towards facilitation of tachycardia by increasing the sinus rate (fig. 1). Ir patients in whom tachycardia could be initiated by an electrically induced atrial premature beat a spontaneously occurring atrial premature beat was sometimes recorded as the mechanism of initiation of tachycardia (fig. 2 ). 


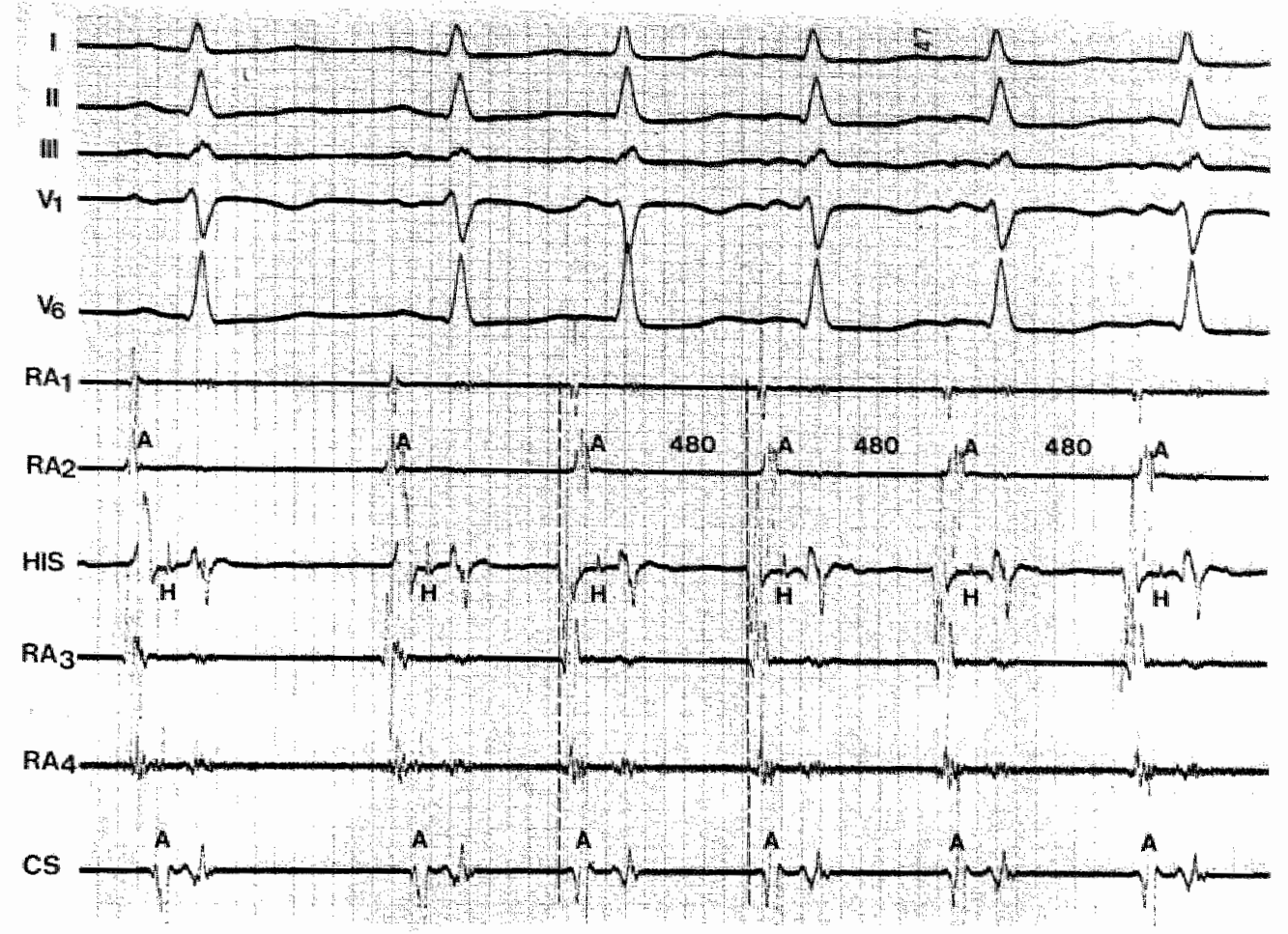

Figure 2

Patient 13. Spontaneous initiation of atrial tachycardia during sinus thythm. 5 Surface leads were recordod simultaneously with four endocavitary bipolar electrograms from the right atrium (RA 1 to RA 4). the lis bundle area and the coronary sinus (CS). The first $P$ wave of the tachycardia shows the same patterin of atrial activation as subsequent tachycardia P waves (broken vertical lines). Compare the P wave morphology in the surface leads during tachycardia in this pationt with the one shown in figure 1 and subsequent figures.

In eight paticnts a tachycardia with the same $P$ wave morphology, pattern of atrial activation in the endocavitary leads, and P . R/R-P relation could be intiated by a ventricular premature beat. In seven of the eight patients initiation of tachycardia by a ventricular premature beat was related to a critical delay in retrograde conduction to the atria. This was not the case in the remaining patient (patient 23).

Based upon their behaviour during ventricular stimulation our patients were divided into threc groups: Group A consisted of the seven patients in whom tachycardia could be initiated by a ventricular premature beat on reaching a critical delay in ventriculomatrial conduction. Group $B$ was composed of patients in whom V-A conduction during ventricular pacing was absent. Group C contained seven patients having ventriculoatrial conduction but no induction of tachycardia during ventricular pacing plus the one patient in whom tachycardia could be initiated by a ventricular premature beat without relation to a critical delay in ventriculo-atrial conduction of the ventricular premature beat.

In patients of group $\mathrm{A}$ initiation of tachycardia by an atrial premature beat was never possibie unless the premature beat was conducted to the ventricle. In patients of group $B$ and $C$ atrial premature beats initiating tachycardia did not require conduction over the $A$-V node (documented by recording a His bundle electrogram following the atrial premature beat). When tachycardia initiated spontaneously during sinus rhythm (table I) a critical delay in A-V conduction could not 
be identified in any paticnt of any group. These observations suggest that in patients of group $A$ structures below the atria (A-V node, His bundle, bundle branches, ventricle) were required to initiate the arrhythmia, whereas this was not the case in patients of group $B$ and $C$.

\section{b. Atrio-ventricular relation during tachycardia}

Patients of group $A$ always had a 1-10-1 A-V relation during tachycardia. The arrhythmia terminated whenever a $Q$ RS complex was not followed by a $P$ wave, or whenever a $P$ wave was not anterogradely conducted to the ventricles. This phenomenon could be observed spontaneously (fig. 3) or could be provoked by carotid sinus massage in all of them and also by other vagal manoeuvres (fig. 4). Characteristically in this group of patients a Wenckebach type of conduction preceded termination of the arrhythmia in $A-V$ or $V$-A direction (fig. 3 and 4 ).

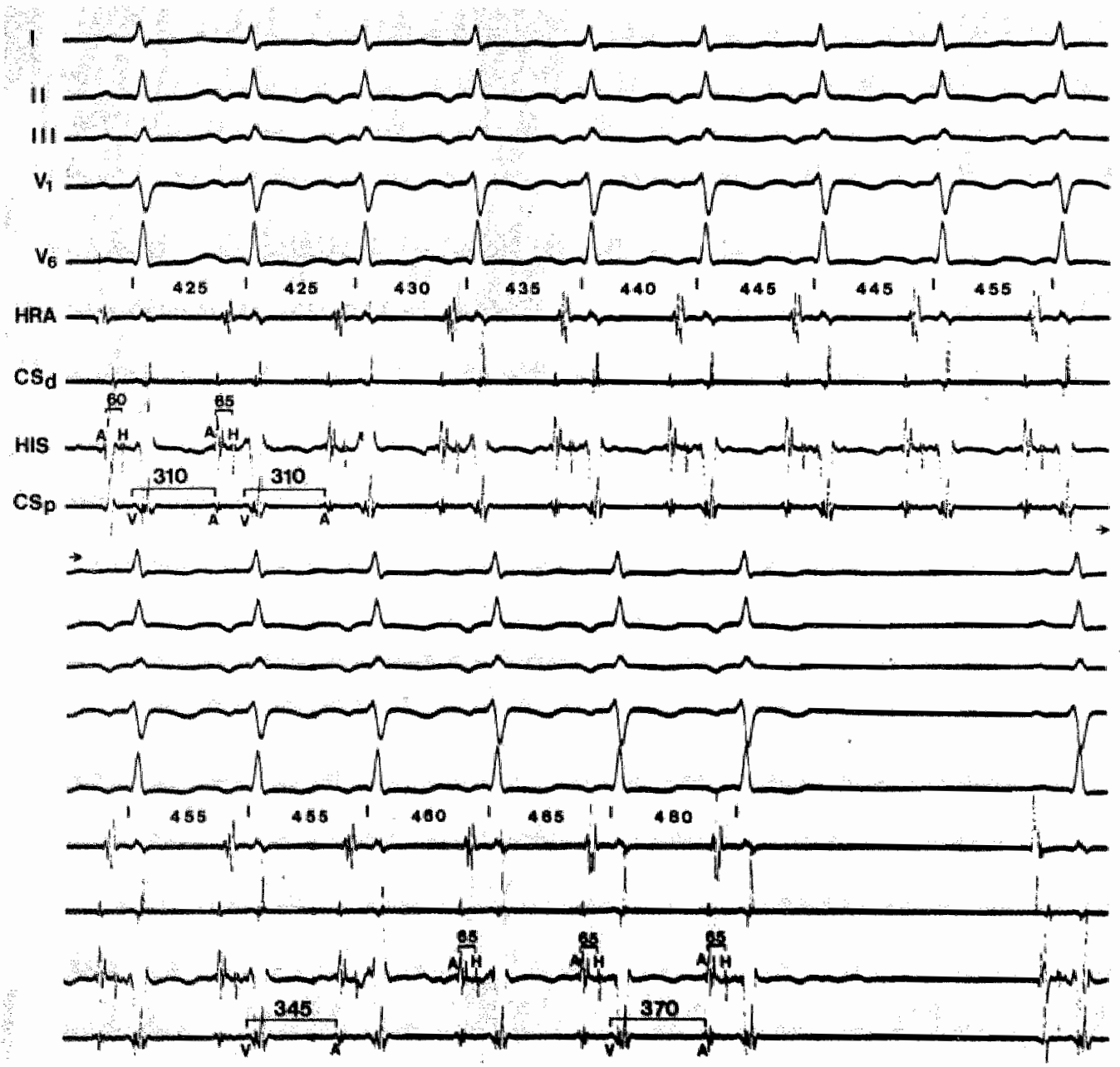

Figure 3

Patient 2. Spontaneous initiation of circusmovement tachycardia using retrogradely an accessory A-V pathway (top panel) and spontancous termination (continuous tracing bottom panel). Termination of tachycardia occurs after progressive prolongation in the V.A conduction time during tachycardia from 310 to $370 \mathrm{~ms}$. There are no changes in the A.H interval. Four endocavitary electrograms were simultaneously recorded with four endocavitary bipotar electrograms. 


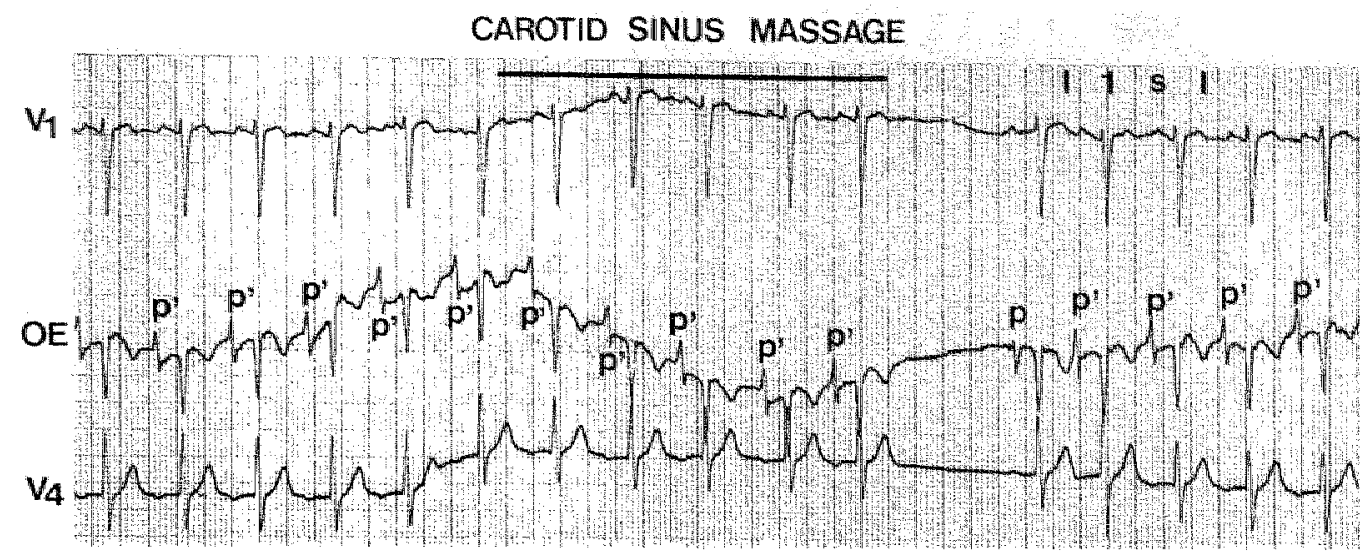

Figure 4

Patient 6 . Termination of circusmovement tachycardia incorporating an accessory pathway with long conduction times retrogradely by carotid sinus massage (CSM). CSM induced cycle length alternation due to alternation in the RP interval. Note that the last $R R$ interval is the shortest and is not followed by a rectroggade Pave. Surface leads $V 1+V_{2}$ were recorded simultaneously with ar oesophageal lead (OF)

In patients of group B and $C$ tachycardia continued in spite of A-V nodal block. When a change in relation between atrial and ventricular events did not occur spontaneously, it could be provoked by carotid sinus massage or other vagal manoeuvres (fig. 5-6), or by inducing ventricular premature beats that changed the atrio-ventricular relation but not the atrial rate during

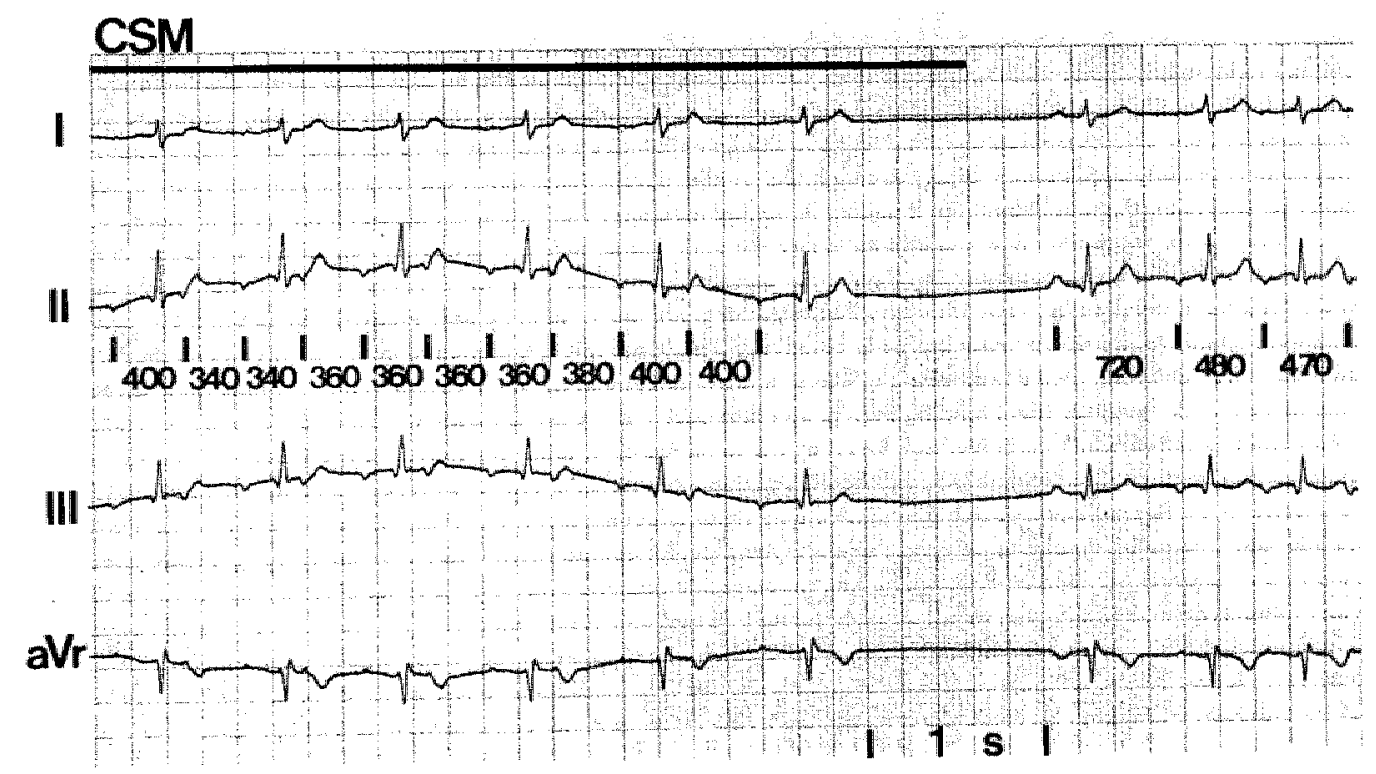

Figure 5

Patient 11. 2-to- $\mathrm{A}-\mathrm{V}$ block and short-lasting termination of atrial tachycardia during catotid sinus massage in a patient with incessant atrial tachycardia. Tachycardia continues in the left part of the figure in spits of the absence of A-V conduction of ewery second $\mathrm{P}$ wave. Following termination of tachycardia and a single sinus beat (right part) tachycardia reinitiates spontaneously. 4 Surface leads were recorded simulltancously. 


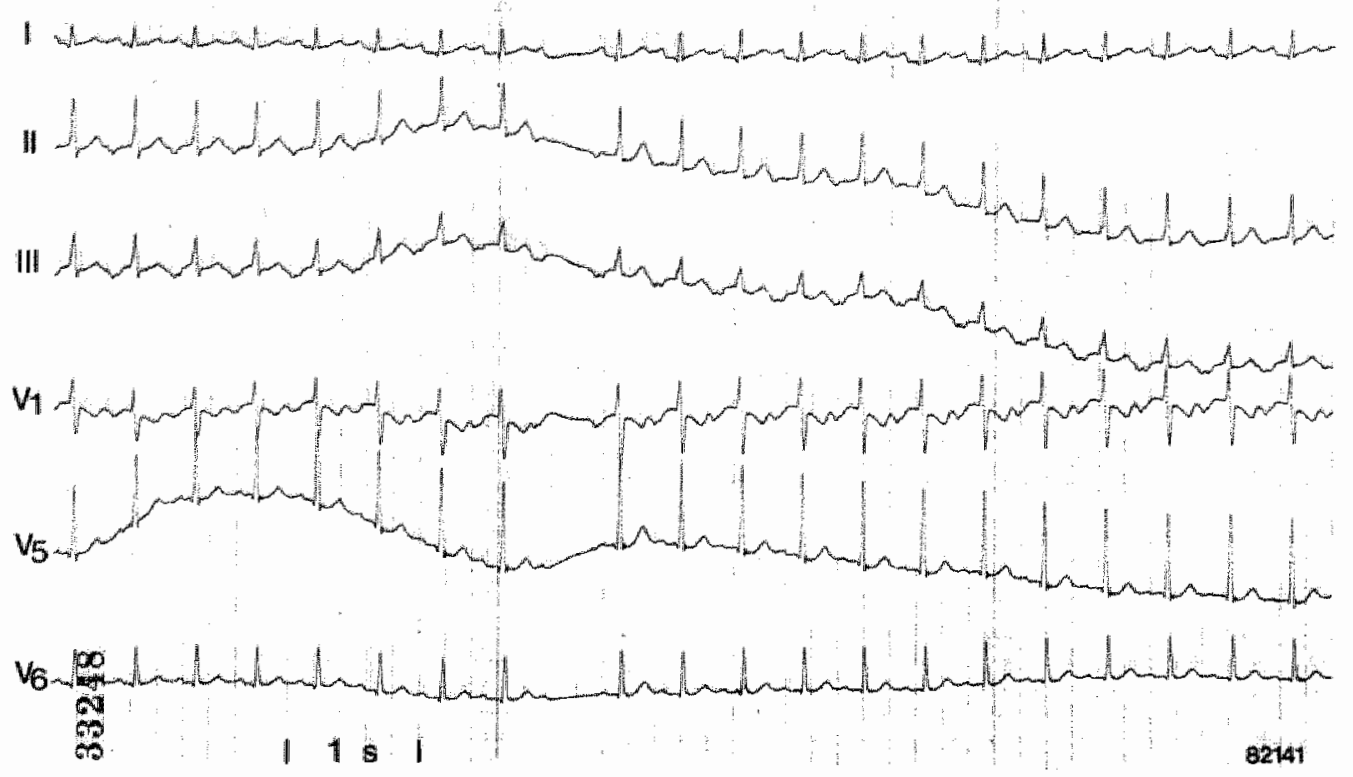

Figure 6

Patient 20. A-V block during atrial tachycardia without termination of the arrhythmia produced by a singie deep inspiration. Six surface leads were recorded simultaneously.

tachycardia. All paticnts of group $B$ and $C$ showed episodes with a $1-10-1 \mathrm{~A}-\mathrm{V}$ relation during tachycardia with a $P-R$ shorter than $\mathbb{R}-P$, but characteristically also changes in the relation between atrial and ventricular complexes (tabic 1 ). This $A-V$ relation could change from $1-t o-1$ with a $P$ - $R$ interval shorter than $R-P$ interval to $1-t o-1$ with $P$ - $R$ interval longer than $R-P$, and thereafter to a Wenckebach type of conduction or higher degrees of $A-V$ block without changes in the atrial rate. This could occur spontaneously, after drug administration (fig. 7), or during exereise or excitement.

It is of interest that paticnts of group $A$ on changing tachycardia rate by atropine, exercise or vagal manocuwres, always mantaned a P-R interval shorter than the R-P interval during tachycardia (fig. 3,4 and 8 ).

c. Termination of tachyeardia

In five patticnts of group A (table l) tachycardia could not be fong-lastingly terminated by programmed stimulation of the heart. In these patients (patients 1,2,4,5 and 7) tachycardia terminated for a few simus cycles but reinitiated immediately thereafter. In the remaining two patients tachycardia could be terminated for longer periods. Spontaneous termination of tachycardia was observed in thee paticnts. This could oceur either by a $P^{\prime}$ wave which was not conducted to the ventricles, or more commonly by a QRS complex. In the latter situation a Wenckebach sequence of conduction in V-A direction was observed (fig. 3). Termination of tachycardia was possible in all patients of group A by atrial premature beats. Termination of tachycardia occurred whenever the atrial premature beat produced block in atriomentricular conduction. In all seven patients termination of tachycardia was possible by a ventricular premature beat which was not conducted to the atria (fig. 9). 

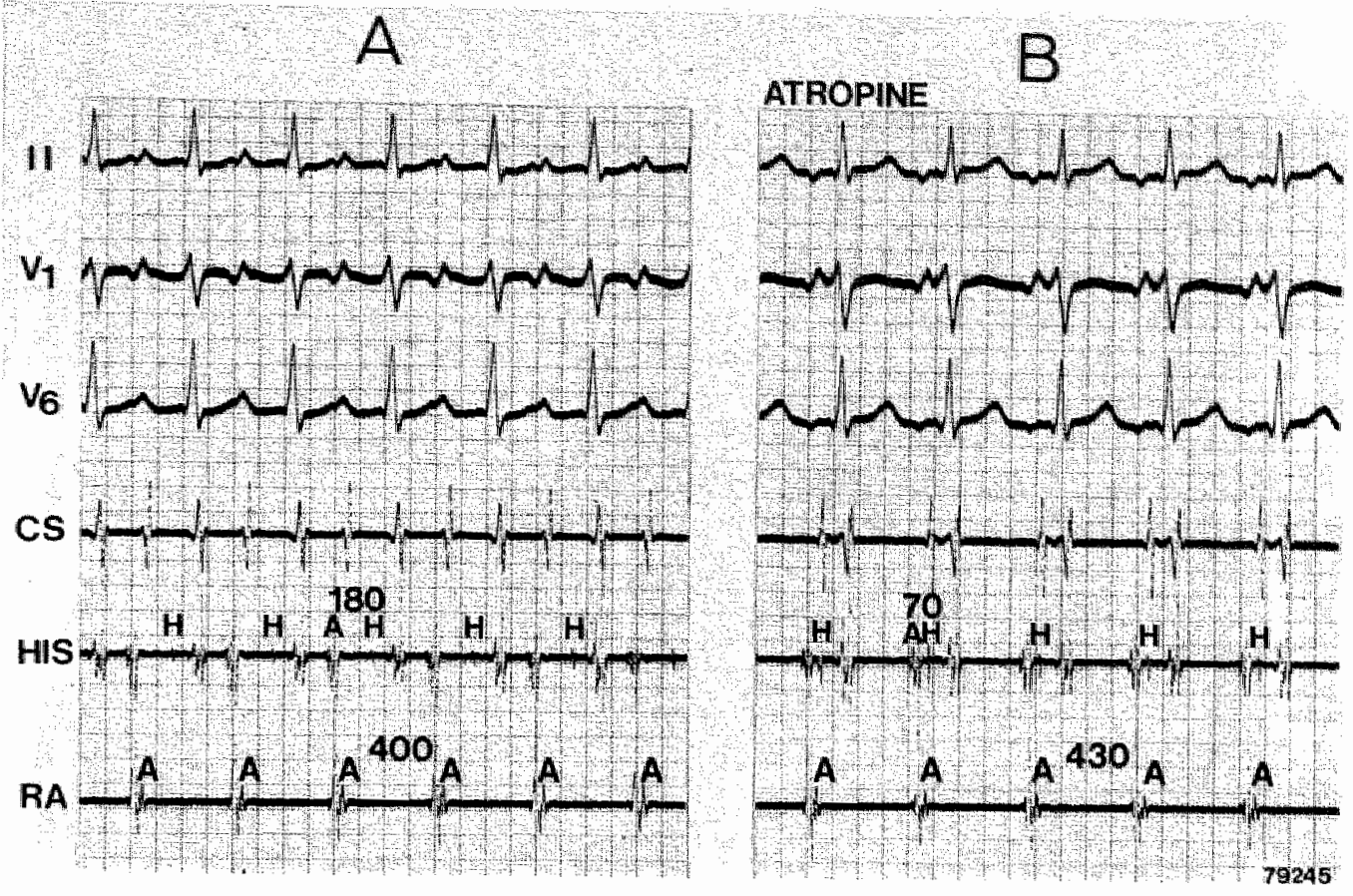

Figure 7

Patient $1 \mathrm{l}$. Effect of $1 \mathrm{mg}$ of atropine given intravenously on time intervals during atrial tachycardia. In panel A (before atropine) the tachycardia cycle longth measures $400 \mathrm{~ms}$ and the P-R interval is only slightly shorter than the R-P interval. The A-H interval is $180 \mathrm{~ms}$. Following atropine (panel B) there is marked shortening of the A-H interval to $70 \mathrm{~ms}$ with no increase in rate of the atrial tachycardia (cycle length $430 \mathrm{~ms}$ ). In the extremity leads marked shortening of $P$ - $R$ interwal and prolongation of the $R$ - $P$ interval can be observed. This was never seen after atropine in parients of group $\mathrm{A}$.

In six group B patients tachycardia terminated spontaneously by a QRS complex which was not followed by a $\mathbb{P}$ wave. In one patient (patient 9) tachycardia could reproducibly be terminated by an induced atrial premature beat. In three patients tachycardia could not be terminated by any mode of stimulation. In this group of patients having no $\mathrm{V}$-A conduction tachycardia could never be terminated by ventricular premature beats or ventricular overdrive pacing.

Group C. In four patients of group C spontaneous termination of tachycardia was observed. In five of them induced atrial premature beats were also able to terminate tachycardia. In one paticnt tachycardia could not be terminated by pacing.

Even when ventriculo-atrialconduction could be demonstrated in this group of paticnts, ventricular premature beats never terminated tachycardia. Following ventriculo-atrial conduction of the ventricular premature beat atrial activation did not occur prematurely enough to terminate the arrhythmia (fig. 10).

\section{Effect of atropine and exercise during tachycardia}

a. Atropine: (table II)

Five patients of group $\mathrm{A}, 6$ of group $\mathrm{B}$, and 5 of group $\mathrm{C}$ received $1 \mathrm{mg}$ of atropine intravenously during tachycardia. The tachycardia rate accelerated in all patients of group $A$, in 4 patients of group $B$, and in 5 of group $C$. It did not change in one patient of group $B$ and slowed slightly in another patient of group B (fig. 7). The A-H interval shortened in all patients following atropine. When tachycardia rate accelerated patients of all three groups showed shortening both of the P-R 
BEFORE PNPNNDNA

II<smiles>CCCCC(C)CC(C)CC(C)CCCC(C)CCCC(C)C</smiles>

III
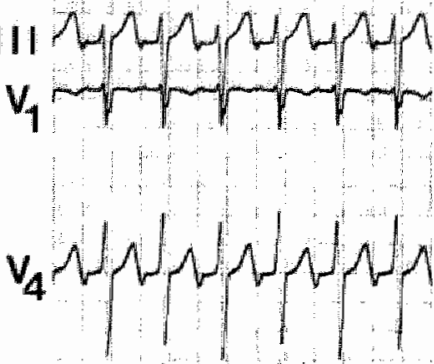

$v_{6} \wedge+w_{p} w_{h}$

\section{$P \cdot R=140 \mathrm{~ms}$ $R \cdot P=260 \mathrm{~ms}$}

AFTER
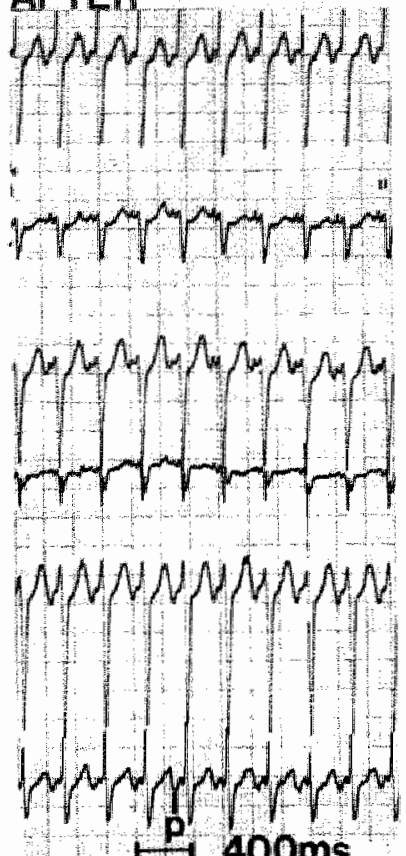

\section{P.R $=80 \mathrm{~ms}$ \\ $R \cdot P=200 \mathrm{~ms}$}

Figure 8

Patient 4. Effech of exercise on the time intervals of a lachycardia using retrogradely an accessory pathway with long conduction times. Before exercise the tachycardia cycle length is $400 \mathrm{~ms}$. The P- $\mathbb{R}$ interval is shorter than the R-P interwal (140 and $260 \mathrm{~ms}$ respectively). Immediately after exercise the tachycardia has accelerated markedly to a cycle length of $280 \mathrm{~ms}$. Both the P.R and the R.P interval have shortened as compared to the racing in the left panel.
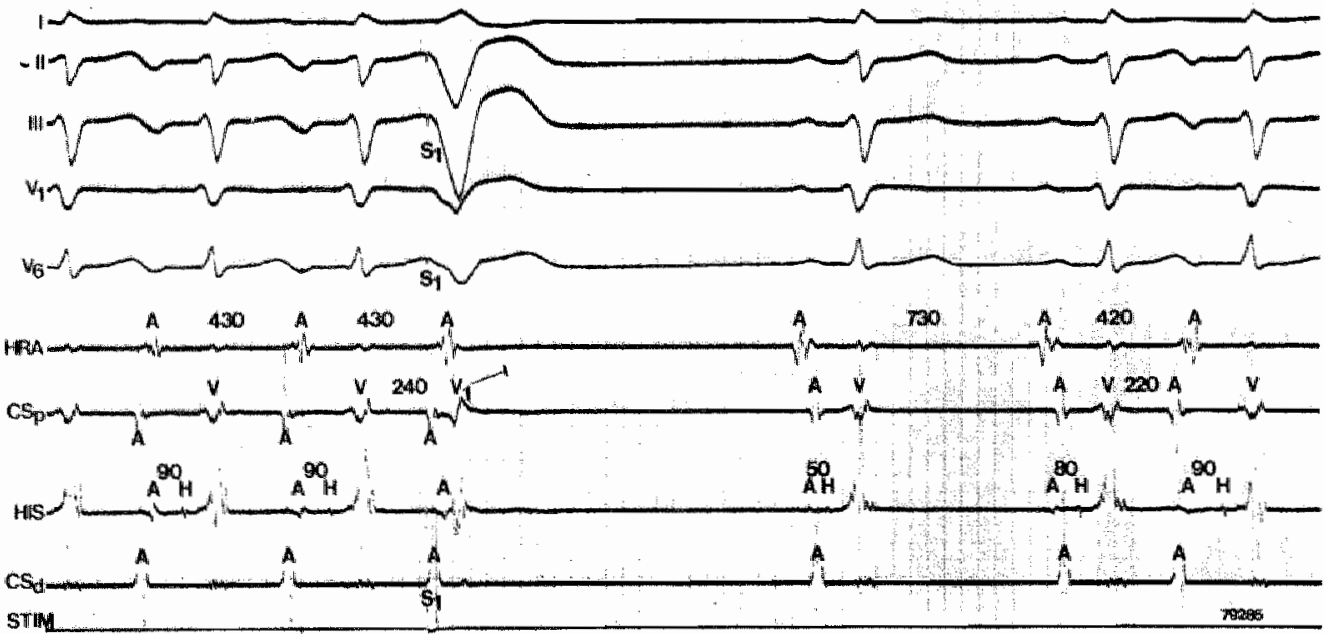

Figure 9

Patient 4 . Termination of circusmovement tachycardia using retrogradelly an accessory pathway with long conduction times by a ventricular premature beat (SI). As shown this ventricular premature beat is not followed by retrograde conduction to the atria. Following termination of tachycardia the arrhythmia reinitiates after two sinus beats (right part). 5 Surface leads were recorded simultaneously with 4 endocavitary electrograms. STIM = stimulation. 


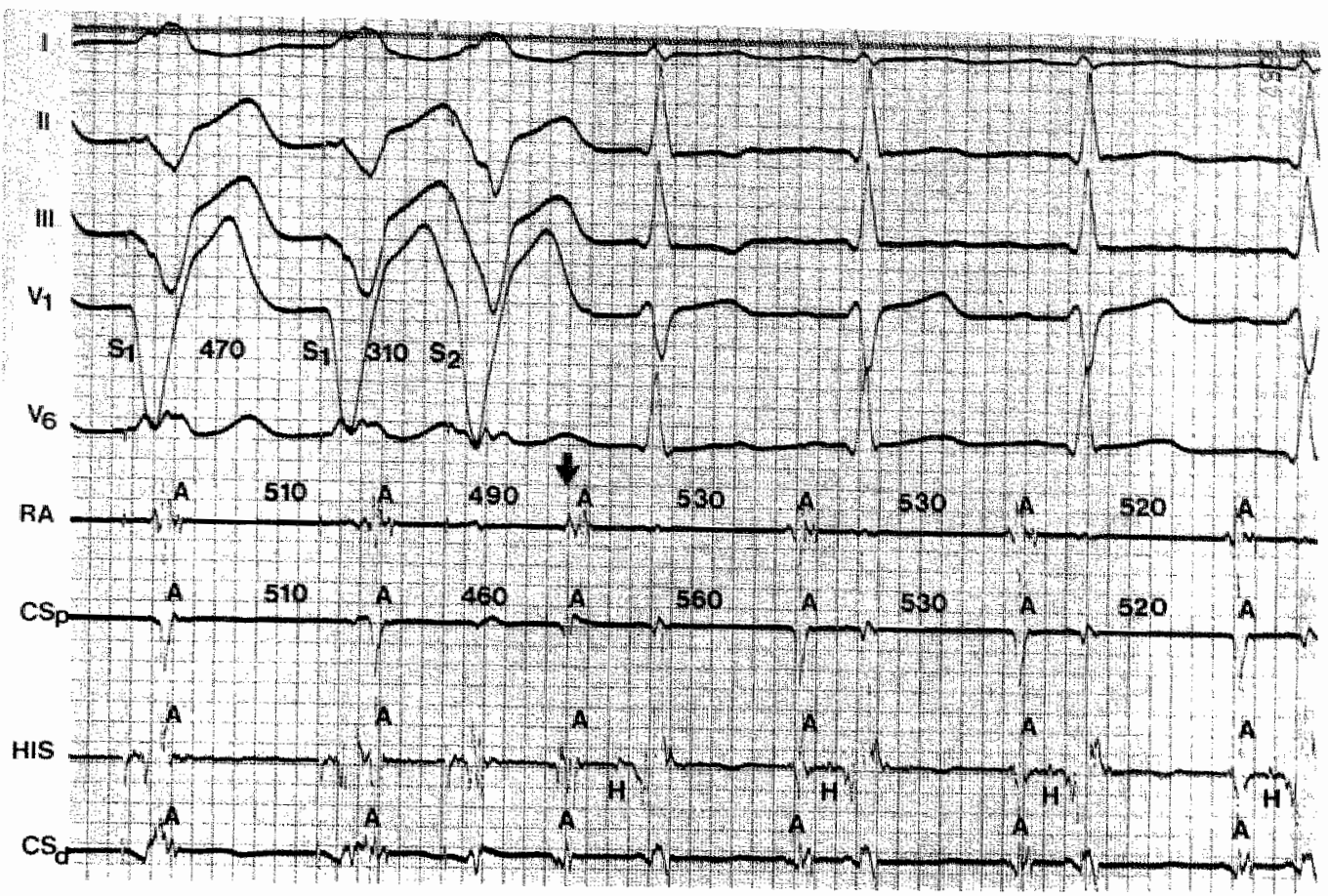

Figure

Patient 19. Demonstration of $\mathrm{V}-\mathrm{A}$ conduction during incessant atrial tachycardia hiving an interval bet ween two successive attrial complexes ranging from 510 to 530 msec. During at rial lachycardia pacing is pertorned in the right wentricular apex. Note that following a ventricular premature beat given after 310 ms oceurs cartier than expected atrial activation (arrow). The pattern of atrial activation of this complex differs from those of the atrial tachycardia (particularly at the RA and CSp electrograms) indicating that retrograde conduction following the ventricular premature beat results in a different atrial activation pattern as during atrial tachycardia. Such an observation indicates an atrial origin of the tachycardia. 5 Surface leads were recorded simultaneously with 4 endocavitary bipolar electrograms.

and R-P intervals. Therefore the response to atropine administration did not distinguish between them. In the two patients of group $B$ with no or minimal change in tachycardia rate a marked change was observed in the P-R/R-P relation following atropine (fig. 7). This response was not observed in any patient of group $A$.

\section{b. Exercise: (table II)}

Exercise accelerated the rate of tachycardia in all 7 patients of group $A$ and in 6 paticnts of group $B$ and $C$ having incessant tachycardia (table II). In all patients the $P-R$ and $R-P$ intervals shortened during tachycardia (figs. 8 and 11). Therefore patients of group A, B and C could not be distinguished on the basis of their behaviour during exercise. It is of interest however to observe that in three patients (patients 11, 16 and 19) maximal exercise resulted in sinus $P$ waves replacing the tachycardia $P$ wave. When exercise was terminated progressive slowing in simus rate was followed by a transition from a sinus $P$ wave back to the atrial tachycardia $P$ wave. During this period fusion $P$ waves were observed in these patients (fig. 12). This phenomenon was not observed during exercise in any patient of group $\mathrm{A}$.

\section{Carotid sinus massage and other vagal manoeuvres}

Carotid sinus massage, deep inspiration or the valsalva manoeuvre produced short-lived rermination of tachycardia in all patients of group. A. Perpetuation of the arrhythmia when A-V or V-A block occurred was never observed (fig. 4) in this group of paticnts. 
Effect of atropine and exercise on tachycardia time-intervals

\begin{tabular}{|c|c|c|c|c|c|c|c|c|c|c|}
\hline \multirow{4}{*}{ Patient } & \multicolumn{5}{|c|}{ Atropine } & \multicolumn{5}{|c|}{ Exercise } \\
\hline & \multirow{2}{*}{\multicolumn{3}{|c|}{$\begin{array}{r}P-P \\
(m s)\end{array}$}} & \multirow{3}{*}{\multicolumn{2}{|c|}{$P-R$}} & \multirow{2}{*}{\multicolumn{3}{|c|}{$\begin{array}{l}P-P \\
(m s)\end{array}$}} & \multirow{3}{*}{\multicolumn{2}{|c|}{$\begin{array}{l}P-R \quad R-P \\
\text { during }\end{array}$}} \\
\hline & & & & & & & & & & \\
\hline & before & & after & & & before & - & during & & \\
\hline \multicolumn{11}{|c|}{ Group A } \\
\hline 1 & 460 & & 380 & $S$ & $\mathrm{~S}$ & 430 & & 315 & 5 & $\mathrm{~S}$ \\
\hline 2 & & N.G. & & $\mathrm{N} . \mathrm{G}$. & N.G. & 460 & & 350 & $\mathrm{~S}$ & $S$ \\
\hline 3 & 520 & & 400 & $\mathrm{~S}$ & $\mathrm{~S}$ & 500 & & 440 & $S$ & $S$ \\
\hline 4 & 430 & & 330 & $\mathrm{~S}$ & $\mathrm{~S}$ & 400 & & 280 & $\mathrm{~S}$ & $\mathrm{~s}$ \\
\hline 5 & & N.G. & & $N \cdot G$ & N.G. & 375 & & 310 & $S$ & $\mathrm{~S}$ \\
\hline 6 & 500 & & 380 & $\mathrm{~S}$ & $\mathrm{~S}$ & 500 & & 390 & $\mathrm{~S}$ & $\mathrm{~S}$ \\
\hline 7 & 450 & & 360 & $\mathrm{~S}$ & $\mathrm{~S}$ & 450 & & 350 & $S$ & $S$ \\
\hline \multicolumn{11}{|c|}{ Group B } \\
\hline 8 & & N. $\mathbf{G}_{*}$ & & N.G. & N.G. & & N.P. & & N.P. & N.P. \\
\hline 9 & & N.G. & & N.G. & N.G. & & N.P. & & N.P. & N.P. \\
\hline 10 & 310 & & 240 & $\mathrm{~S}$ & $\mathrm{~S}$ & & N.P. & & N.P. & N.P. \\
\hline 11 & 400 & & 430 & $S$ & 1 & 450 & & $\left.400^{\prime}\right)$ & $\mathrm{S}$ & $\mathrm{S}$ \\
\hline 12 & 360 & & 350 & $S$ & I & & N.P. & & N.P. & N.P. \\
\hline 13 & 480 & & 400 & $\mathrm{~S}$ & $\mathrm{~S}$ & 500 & & 320 & $S$ & $S$ \\
\hline 14 & & N.G. & & N.G. & N.G. & 400 & & 380 & $\mathbf{S}$ & $\mathrm{S}$ \\
\hline 15 & & N.G. & & $N_{n} G$ & N.G. & & N.P. & & N.P. & N.P. \\
\hline 16 & 350 & & 300 & $\mathrm{~S}$ & $\mathrm{~S}$ & 350 & & 300') & $S$ & $S$ \\
\hline 17 & 440 & & 400 & $\mathrm{~S}$ & $\mathrm{~S}$ & & N.P. & & N.P. & N.P. \\
\hline \multicolumn{11}{|c|}{ Group C } \\
\hline 18 & 460 & & 430 & $S$ & $S$ & 460 & & 400 & $\mathrm{~S}$ & $\mathrm{~s}$ \\
\hline 19 & 500 & & 400 & $\mathrm{~S}$ & S & 500 & & $\left.380^{\circ}\right)$ & $\mathrm{S}$ & $\mathrm{S}$ \\
\hline 20 & & N.G. & & N.G. & N.G. & 380 & & $240^{\prime}$ & N.P. & N.P. \\
\hline 21 & & N.G. & & N.G. & N.G. & & N.P. & & N.P. & N.P. \\
\hline 22 & 470 & & 430 & $S$ & I & & N.P. & & N.P. & N.P. \\
\hline 23 & & N.G. & & $\mathrm{N}, \mathrm{G}$ & N.G. & & N.P. & & N.P. & N.P. \\
\hline 24 & 480 & & 340 & $\mathrm{~S}$ & $\mathrm{~S}$ & & N.P. & & N.P. & N.P. \\
\hline 25 & 380 & & 335 & $\mathrm{~S}$ & $\mathrm{~S}$ & & N.P. & & N.P. & N.P. \\
\hline
\end{tabular}

Abbreviations: P-P: interval between subsequent $P$ waves during tachycardia. $P-R: P-R$ interval during tachycardia. R-P: R-P interval during tachycardia. N.G.: Not given. N.P.: Not performed. S: shortening. I: increase or prolongation. ): Sinus tachycardia at this cycle length appeared during exercise.

Vagal manoeuvres produced $A=V$ block during tachycardia in all patients of group $B$ and $C$ (fig. 56) with perpetuation of tachycardia. In patient 11 (fig. 5) tachycardia was also terminated by carotid sinus massage after a short period of perpetuation in spite of A-V block. Vagal manoeuvres were of help to identify those patients in whom the arrhythmia perpetuated when a 1-to-1 A-V relation was not present, excluding participation of an accessory $A-V$ pathway in the mechanism of tachycardia. 


\section{before exercise}

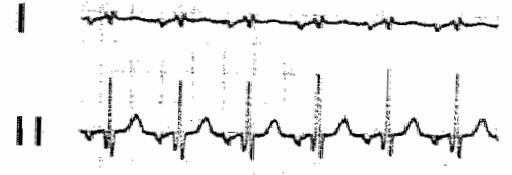

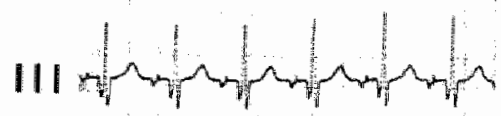

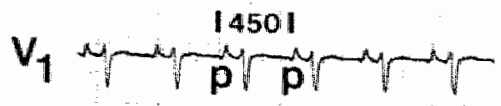

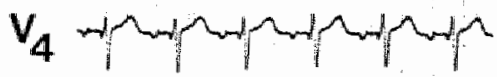

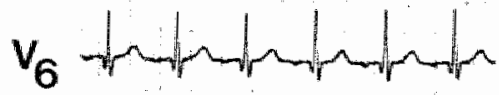

\section{during exercise}

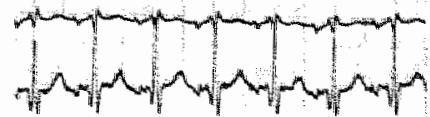

$\lim _{1}$
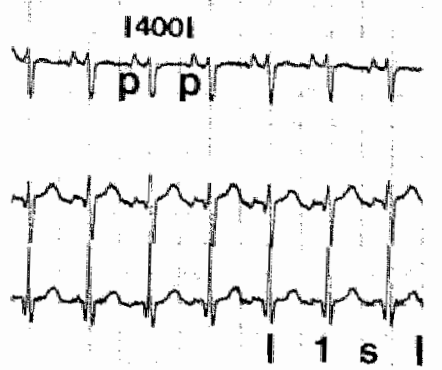

Figure 11

Patient 11. Effect of exercise in atrial tachycardia. Before exercise the tachycardia cycle length is $450 \mathrm{~ms}$ (right panel) and shortens to $400 \mathrm{~ms}$ during exercise (left panel) with shortening of both the P-R and R-P intervals. 6 Surface leads were simultaneously recorded.

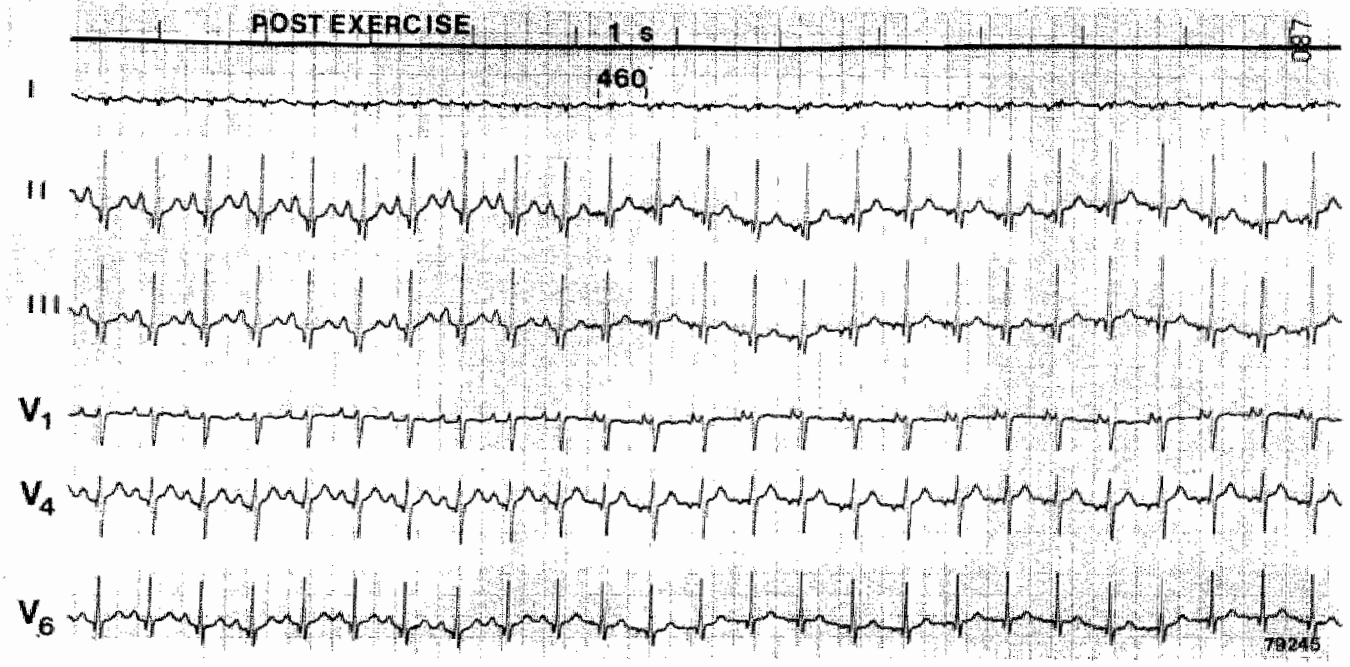

Figure 12

Same patient as in figure 11 . Immediately after termination of exercise there is a change from simus tachycardia back to atrial tachycardia. During maximal exercise the rate of the sinus node exceded the ratc of the atrial tachycardia, During the change from sinus rhythm to atrial tachycardia fusion $P$ waves are observed. 6 Surface leads were simultaneously recorded. 


\section{P wave morphology in the surface leads and pattern of endocavitary activation during tachycardia}

Patients of group $A$ showed a characteristic $P$ wave configuration in the 12-lead electrocardiogram. As observed in figures 1.3 and 9 , the $P$ wave was deeply negative in leads $I I$, III and in leads V3 to V6. The Pave was diphasic or flat in leads II and Vil.

In patients of group $B$ and $C$ five morphologically different types of $P$ waves were recorded (fig. 6 and fig. 13). Ten patients had a cranio-caudal $P$ wave during tachycardia which was not always ellearly different on the 12-lead electrocardiogram from the P wave during sinus rhythm (panel B of fig. 13). A different pattern of atrial activation was observed, howewer, in the cndocavitary leads when compared to the sinus $P$ wave in all 10 patients. One patient (patient 17) had all negative $P$ wave in lead I (panel $C$ of fig. 13). In this patient endocardial atrial mapping demonstrated a site of origin of tachycardia in the left atrium. Three patients showed during taclyycardia a caudo-cranial $P$ wave (pane $D$ of fig. 13) which was negative in the left precordial leads. A comparison between these three patients and patients of group A revealed that patients of group $A$ had a much deeper and wider $P$ wave in the inferior leads (compare fig. 13 panel D with the tachycardia shown in figs. 1 and 3). The remaining patient (patient 20) showed a right-toleft $P$ wave which was diphasic and deeply negative in lead V1. Atrial mapping demonstrated a site of origin of tachycardia in the low anterior right atrium in this patient.
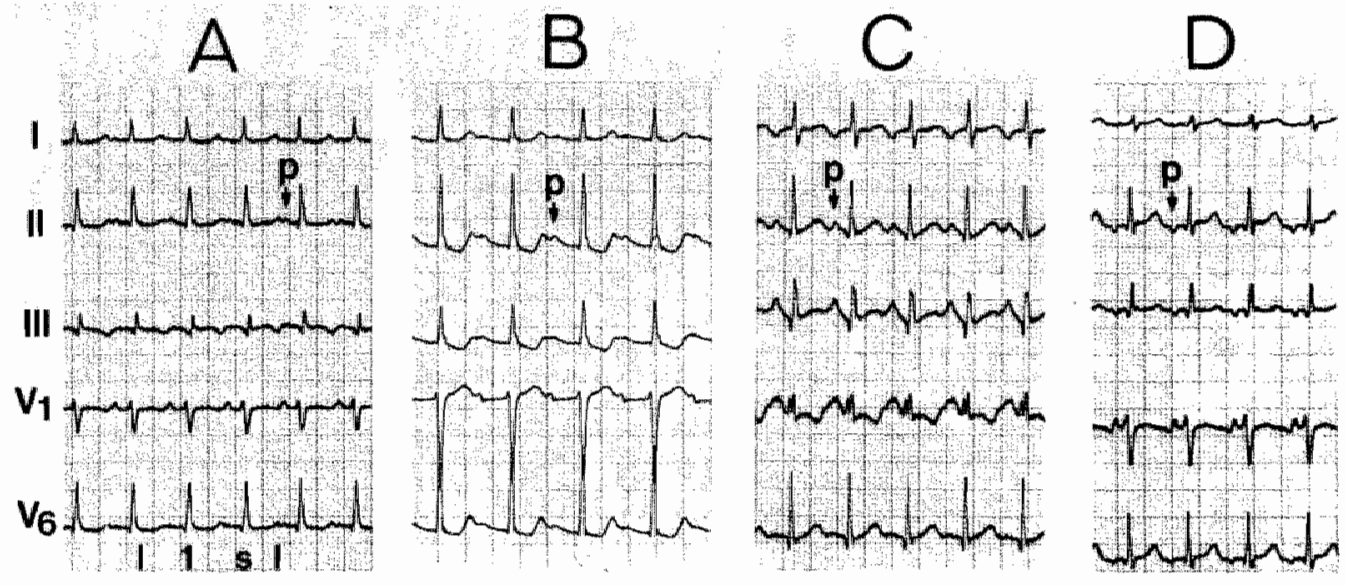

Figure 13

Four panels showiag 5 surface leads in four different patients of group $B$ and $C$ to illustrate five different types of $\mathbb{P}$ waves observed during atrial tachycardia. Panel $A$ and $B$ show two different sorts of cranio-caudal $P$ waves. Patients having $P$ waves like the ones shown in panel $B$ required endocawitary electrograms to differentiate them from sinus $P$ waves. Panel $C$ shows our only patient with $P$ wave indicating activation from left to right. Panel D illustrates the caudo-craneal $P$ wave observed in three patients of group B. A right-to-left $P$ wave observed in patient 20 is illustrated in fig. 6.

\section{Discussion}

\section{Site of origin and mechanisms of supraventricular tachycardia in patients of group $A, B$ and $C$}

Twenty-five consecutive patients with paroxysmal or incessant supraventricular tachycardia showing intermittently or continuously a $1-t 0-1$ A-V relation with a $P-\mathbb{R}$ interval shorter than the R-P interval were included in the present study.

In the seven patients of group A a continuous 1-to- -1 -V relation was required to perpetuate tachycardia. In all seven patients we were able to terminate reproducibly the tachycardia for shorter or longer periods whenever this 1-to-1 A-V relation was interrupted. This could be accomplished by giving an atrial premature beat which was not conducted to the ventricles, or by a 
ventricular premature beat which was not followed by retrograde activation of the atria. This last mode of termination of tachycardia excludes an atrial site of origin of the arrhythmia and indicates the incorporation of $\mathrm{A}-\mathrm{V}$ junctional structures in the tachycardia circuit. In all 7 patients of group $A$, using previously reported criteria $(6,9-12)$, a slowly conducting accessory A-V pathway was demonstrated to be the retrograde pathway of a circusmovement using anterogradely the normal A-V nodal-His-Purkinje pathway. The use of this slowly conducting accessory $A-V$ pathway in retrograde direction resulted in the electrocardiographic pattern observed (a P- $R$ interval shorter than the R-P interval). As expected all group $A$ patients had ventriculo-atrial conduction during ventricular pacing.

Ten patients of group B had no ventriculo-atrial conduction during stimulation of the ventricles. This observation excludes the possibility of a tachycardia using retrogradely an accessory A-V pathway. Six of the ten patients had a configuration of their $P$ waves during tachycardia indicating cranio-caudal atrial activation suggesting that neither an accessory A-V pathway with an atrial end in the A-V groove, nor an intranodal re-entry circuit was responsible for the arrhythmia (13-15). One patient (patient 17) had a left-to right $P$ wave, and the remaining three patients (patients 11 , 15 and 16) had a caudo-cranial $P$ wave. Definitive proof in these patients, as well as in the six patients with craniocaudal $P$ wave, that an accessory $A-V$ pathway was not playing a role in the mechanism of their arrhythmia was obtained by observing changes in the pattern of $A-V$ conduction from 1-to-1 to different degrees of A-V block without termination of the arrhythmia. This observation demonstrates that activation of the ventricles is not necessary to sustain the tachycardia. When A-V block did not occur spontaneously, it could be provoked by carotid massage or other vagal manoeuvres. With the aid of endocavitary recordings it could be shown that A-V nodal conduction (as assessed from recording a His bundle electrogram following the atrial

complex) was not necessary to perpetuate tachycardia. This observation is of importance in the three patients having a caudo-cranial $P$ wave during tachycardia, because it suggest that the arrhythmia is not originating in the A-V node. Theoretically a "reversed" type of A-V nodal tachycardia with a distal common A-V nodal pathway located above the bundle of His cannot be completely excluded (16).

Patients of group C also showed variations in A-V relation without termination of tachycardia either spontaneously or following vagal manoeuvres. In contrast to patients of group B however, $\mathrm{V}$-A conduction was possible in all eight patients of group $\mathrm{C}$. An A-V nodal origin of the tachycardia could be excluded however by observing:

a. A cranio-caudal or eccentrical $P$ wave during the arrhythmia and

b. A pattern of endocardial atriall activation during tachycardia which was different from the pattern observed in the endocavitary leads following retrograde conduction during ventricular pacing.

In some patients fusion between atrial tachycardia $P$ wave and retrograde conduction could be recorded. In one patient of this group (patient 23) tachycardia could be initiated by a ventricular premature beat not showing a critical delay in retrograde conduction to the atria. In this patient tachycardia could also easily be initiated by a single atrial premature beat. Apparently retrograde conduction following the ventricular premature beat resulted in atrial activation early enough to initiate the arrhythmia.

\section{Effect of atropine and exercise on time intervals during tachycardia}

In patients of group A, B and C atropine administration could increase the rate of the tachycardia. Both the P-R, R-P and P-P intervals shortened during tachycardia in these patients. It was not possible to distinguish between those patients having an atrial site of origin of their arrhythmia and those using retrogradelly an accessory A-V pathway with long conduction time (group A). It is of interest however, that while tachycardia rate increased in all patients of group A, two patients of group B showed no change or even slight slowing in rate of tachycardia (fig. 7). In these patients the R-P interval prolonged because of shortening of the P-R interval after atropine. 
In all patients with incessant tachycardia exercise accelerated the rate of tachycardia whatever the mechanism. This observation therefore was of no help to differentiate the mechanism of tachycardia because all patients showed 1-to-1. A-V relation during exercise. In three patients however exereise accelerated sinus rate to such an extent that sinus tachycardia replaced atrial tachycardia (fig. 12). Afrial tachycardia reganed control of the heart immediately after a decrease in simus rate in the postexercise period. There was a trend for patients with incessant reciprocating atrio-ventricular tachycardia to show a more marked increase in tachycardia rate during exercise as compared to patients with incessant atrial tachycardia (table II). Accurate analysis of this aspect was however not possible because of the sinus tachycardia appearing during exercise in three patients with incessant atrial tachycardia. In patients having reciprocating atro-ventricular tachycardia using retrogradely an accessory pathway with long conduction times acceleration of the simus rate and overdriving of the tachyeardia can theoretically occur in the presence of sinus node entrance block. This phenomenon was not observed however in any patient of group A.

\section{Differential diagnosis of a supraventricular tachycardia with a P-R interval shorter than the R-P interval}

In patients presenting with at sustained supraventricular tachycardia having a 1-to-1 A-V relation and a Por interval shorter than the R-P interval four different mechanisms for the arrhythmia have to be considered:

a. atrial tachycardia,

b. a "reversed typc" of $A-V$ nodal tachycardia,

c. reciprocating $A \times V$ tachycardia using an accessory pathway with long conduction times,

d. reciprocating A-V tachycardia retrogradely using an accessory pathway with fast conduction velocity in the presence of enhanced anterograde A-V nodal conduction, or, as recently pointed out by Gallagher et al. (17) in the presence of delay in retrograde conduction in the atrialized portion of the right ventricle in patients with Ebstein's anomaly of the tricuspid valve, and

e. A-V nodal tachycardia with 2-to-1. A-V block (16)

Recently we have shown that a sustained supraventricular tachycardia having a $P$ - $R$ interval shorter than the R-P interval is unlikely to be the result of a "reversed" (fastslow) re-entry loop in the A-V node (6). In this study of twenty-five consecutive patients no one was included having a retrogradely conducting accessory pathway of the fast type in the presence of enhanced anterograde A-V nodal conduction nor was any patient with "common" type of A-V nodal tachycardia having. 2-10- $\|$ A-V block included. The former paticnits usually present with a fast tachycardia because the R-P interval is in the order of 90 to $160 \mathrm{msec}$ and the P-R interval of similar magnitude. In childhood enhanced anterograde atriowent ricular conduction is more common and probably accounts for the rather poor discriminating value of the P-R/R-P relation during supraventricular Inchycardia in localizing the site of origin of the arrhythmia in that age group (18). The majority of adult patients using an accessory pathway of the fast type have a tachycardia with a P-R interval longer than the R-P interval $(1-2,5)$. Therefore, in the adult patient when confronted with a supraventricular tachycardia showing a P-R interval shorter than the R-P interval two major possibilities have to be considered:

a. atrial tachycardia, and

b. reciprocating atrio-ventricular tachycardia using an accessory pathway with long conduction time in retrograde direction.

The correct diagnosis can be made by using the following approach (fig. 14):

a. Perpetuation of tachycardia during $A-V$ block of the $P$ waves. "This definitely excludes the possibility of a tachycardia incorporating an accessory A-V pathway. As shown in figs. 5-6 if A-V block does not occur spontaneously vagal manoeuvres is of great help to demonstrate this phenomenon. 


\section{Diagnostic approach to supraventricular tachycardia with $\mathbf{P R}<\mathbf{R P}$}
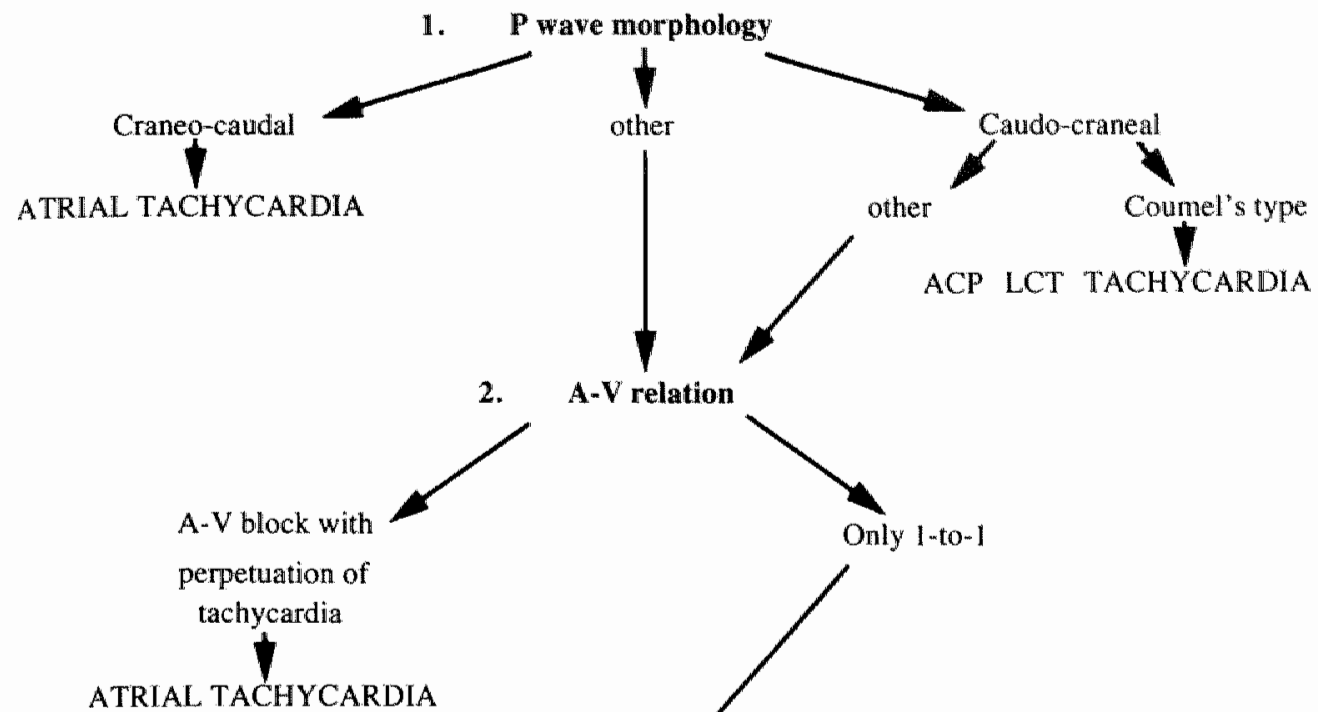

A-V relation

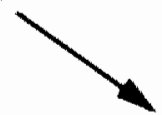

Only [-to-]

3. Vagal manoevres

A-V block with

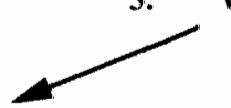

perpetuation of tachycardia
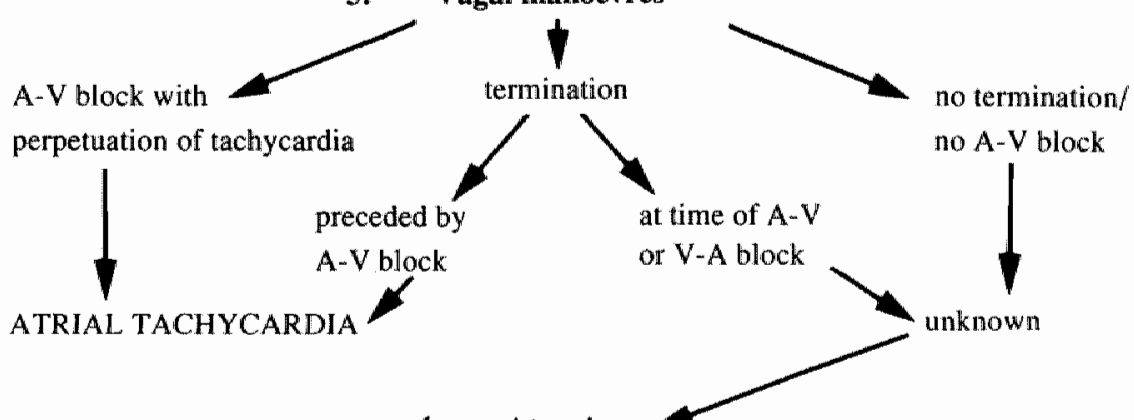

Shortening of PR without change in tachycardia rate $\downarrow_{\text {ATRIAL TACHYCARDIA }}^{\perp}$

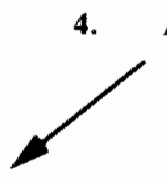

5. Electrophysiologic study

Shortening of PR and RP with acceleration of tachycardia

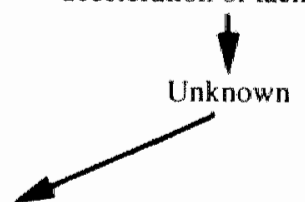
and a 1-to-1 A-V relation. Abbreviations: AccP LCT: accessory pathway with long conduction time. 
b. A P wave configuration indicating cranio-caudal activation of the atria during tachycardia. This makes retrograde activation of the atria from the $A-V$ node or over an accessory pathway with its atrial end located in the $A \cdot V$ groove extremely unlikely. Such a configuration of the $P$ wave argues in fawour of atrial tachycardia.

c. Termination of tachycardia by a ventricular premature beat (spontaneous or induced) which is not retrogradely conducted to the atria. This observation indicates that structures other than the atria are required to perpetuate the arrhythmia. When in addition the ventricular premature beat occurs at the time when the His bundle is refractory for retrograde conduction and the tachycardia is terminated without $\mathrm{V}$-A conduction of the ventricular premature beat, participation of an accessory pathway in retrograde direction is certain (6).

d. Initiation of the tachycardia by a ventricular premature beat on reaching a critical delay in retrograde conduction to the atria. As previously reported (6), in patients using retrogradely an accessory pathway with long conduction time tachycardia is initiated when retrograde conduction to the atria is blocked over the A-V node and exclusively occurs over the accessory pathway.

e. Disappearance of the abnormal $P$ waves during tachycardia and the appearance of sinus $P$ waves during exercise. This argues for atrial tachycardia.

P. Marked shortening in the P-R interval during tachycardia without change in the P-P interwal during atropine administration indicates an atrial origin of the arrhythmia. In patients with an accessory pathway with long conduction time the R-P interval shortens following atropine because of the A-V nodal-like properties of the accessory pathway.

g. As described by Coumel (7) the $P$ wave observed in patients of group $A$ has a characteristic configuration due to the location of the atrial end of the accessory pathway close to the mouth of the coronary sinus. Theoretically an atrial tachycardia arising in this area can show the same $P$ wave morphology.

\section{Conclusions}

Our study demonstrates that differentiation between atrial tachycardia and a tachycardia using an accessory pathway with long conduction time in retrograde direction can be made on the 12-lead ECG alone or by using simple manocuvres like carotid sinus massage. Observations on the mode of initiation and termination of the arrhythmia (particularly by ventricular premature beats) facilitates making the correct diagnosis.

\section{References}

1. Wellens, H.J.J.; Durrer, D.: The rolle of an accessory atrioventricular pathway in reciprocal tachycardia: observations in patients with and without the Wolff-Parkinson-White syndrome. Circulation $52: 58,1975$.

2. Akhtar, M. Damato, A.N.; Ruskin, I.N.; et all.: Antegrade andretrograde conduction chatracteristics in three pattens of paroxysmal atrio-ventricular junctional re-entrant tachycardia. A.m. Heart J, 95:22, 1978.

3. Gallagher, J.J.; Gilbert M., Svenson, R.H.; Sealy, W.C.; Kasell, J.; Vallau, A.G.: Wolff-Parkinson* White syndrome. The problem, evaluation and surgicad correction. Circulation 51:767, 1975.

4. Harrison, L.; Gallager, J.J.; Kasell, J., et al, : Cryosurgical ablation of the attrio-ventricular node-His bundle: an new method for producing atrio-vent ricular block. Circulation 55:463, 1977.

5. Farre, J. and Wellens, H.J.J.: The value of the electrocardiogram in diagnosing site of origin and mechanism of suprawentricular tachycardia. In: Wellens H.J.J. and Kubertus H.E., eds.: "What's new in electrocardiography". Martinus Nijhof Publishers, The Hague 1981; p. 131.

6. Brugada, P.; Bär, F.W.H.M." Vanagt, E.J.; Friedman, P.L.; Wellens, H.J.J.: Observations in patients showing A-V junctional echoes with a shorter P.R than R-P interval. Am. J. Cardiol. 48:611, 1981.

7. Counel, P.; Attuel, P.; Leclercq, J.F.: Permanent form of junctional reciprocating tachycardia: mechanism, clinical and therapeutical implications. In: Naruia O.S. (Ed).: Cardiac arrhythmias, electrophysiology. diagnosis and managernent. Williams and Wilkins, Baltimore 1979, p. 347. 
8. Ress, D.; Farré, J.; Bär, F.W.H.M. et al.: Comprehensive electrophysiotogical studices in the in westigatron of documented or suspected tachycardias: hines, staff problams and costs involved. Circulation 61 : 1010 , 1900.

9. Gallagher, J.I.; Sealy, W.C.: The permanent form of reciprocating tachycurdia: further elucidation of the underlying mechanism. Eur. J. Cardiol. 8:413, 1978.

10. Denes, P.: Kehoe, P.; Rosen, K.M." Multiple rewentrant tachycardias due to retrograde nonduction of dual atrio-ventricular bundles with atro-ventricular nodalike properties. Am, J. Cardiol. 44:162, 1979.

11. Epstein, M.L.; Stone, F.M.; Bendit, D.G.: Incessant atrial tachycardia in childhood: association will rate deperndent conduction in an accessory arrio-ventricular pathway. Am. J. Cardiol.: 44:498. 1979.

12. Farré, J.; Ross, D.; Wiener, 1.; Bär, F.W.H.M.; Vanagt, E. I.; Wellens, H. J.J.: Reciprocal tachycardias using accessory pathways with long conduction times. Am. J. Cardiol. 44:1099. 1979.

13. Amat-y-Leon, $F_{*}$; Dhingra, R.C.; Ww, D.; Denes, P.; Wyndham, C.; Rosen, K. M.: Catheter mapping of retrograde atrial activation. Observations during ventricular pacing and A-V nodal re-entrant paroxysmal Aachycardia. British Heart J. 38:365, 1976.

14. Maclean, W.A.H.; Karp, R.; Kouchoukos, N.T, James, T.N.; Waldo, A. Li* "P-waves during ectopic atrial rhythms in man. A study utilizing atrial pacing with fixed clectrodes. Circulation 52:426. 1975.

15. Garcia-Civera, R.; Ferrero, J.A." Sanjuan, R. et al.: Retnograde P-wave polarity in reciprocating: tachycardias utilizing Hateral bypass tracts. Eur. Heant J. $1: 137,1980$.

16. Wellens $H_{*}$ J.J.; Wesdorp, H.; Düren, D.R.; Lie, K.l.: Second degree block during reciprocal attrion ventricular nodal tachycardia. Circulation, 53:595, 1976.

17. Gallagher, J.J.; Smith, W.M.; Kerr, C.R.; German, L.D.; Sterba, R.; Sealy, W.C.: Etiology of long R-P" tachycardia in 33 cases of supraventricular tachycardia. Circulation 64 (IV), $145,1981$.

18. Garson Jr., J. and Gillete, P.C.: Electrophysiologic studies of supraventriculat tachycardia in children. 11. Prediction of specific mechantsms by noninvasive features. Am. Heart J. 102:383, 1981 . 


\section{Summary}

In this study new observations are described on the role of the $A-V$ junction in tachycardias in man using the method of programmed electrical stimulation of the heart. In chapler III the complexity of the human A-V node during stimulation is illustrated by some unusual modes of initiation of $\mathrm{A}-\mathrm{V}$ nodal tachycardia. As shown in chapter IV different re-entry circuits can interact in the human heart and result in termination of arrhythmias. The observation of a discontinuous A-V nodal conduction curve in anterograde direction has not the same significance in patients with and without documented tachycardia. Chapter $V$ showed that in the last group of paticnts a long retrograde refractory period of the fast pathway prevents initiation of re-entry in the A-V node. In some of these patients, however, a sustained tachycardia can be initiated after atropinc administration. Atropine results in shortening of the refractory period of the retrograde fast pathway. Chapter VI describes that during atrial fibrillation the pattern of atrio-ventricular conduction in the presence of dual A-V nodal pathways does not differ from the pattern observed during $A-V$ conduction over an $A-V$ node without discontinuous curves. Complex electrocardiographic patterns can occur during ventricular tachycardia in patients having dual A-V nodal pathways as shown in chapter VII. Chapter VIII reports that in the incessant form of reciprocating atrio-ventricular tachycardia autonomic tone plays an important role. As pointed out in chapter IX and $X$ the electrocardiogram, effect of drug administration, cxercise test, vagal manoeuvres and observations during electrophysiologic studies help us to differentiate between the different mechanisms of incessant supraventricular tachycardia.

\section{Samenvatting}

In deze studie worden nieuwe waarnemingen beschreven over de rol van de AV knoop bij tachycardieën. Deze waarnemingen zijn gedaan tijdens geprogrammeerde ellektrische stimulatic van het hart bij de mens.

In hoofdstuk III wordt de complexiteit van A-V nodale geleiding gedemonstrecrd aan de hand van enkele voorbeelden, die de verschillende manieren laten zien warop $A$-V nodale tachycandicen opgewekt kumnen worden. In hoofdstuk IV wordt aangegeven hoe verschillende re-entry circuits in het hart elkaar kunnen beinvloeden en dat deze wisselwerking kan leiden tot het beeindigen van de tachycardie. Wanneer mer cen of twee wegen in de anterograde $A$ - $V$ nodale geleidingscurve is de betekenis verschillend bij patiënten met en patienten zonder gedokumentecrde tachycardieèn.

Hoofdstuk $V$ latat zien, dat in deze laatste groep patienten cen lange retrograde refactaire periode van het snel geleidende. AV knoop pad het ontstaan van re-entry tachycardicën voorkont. Bij sommigen van deze patienten kan een stabicle tachycardie wel worden gestart ha atropine toediening. Atropine veroorzakt dan cen verkorting van de refractaire periode van het in retrograde richting snel geleidende pad in de $\mathrm{A}-\mathrm{V}$ knoop.

In hoofdstuk Vl wordt beschreven dat de a an- of afwezigheid van twee intra $A-V$ nodale paden het A-V geleidingspatroon bij boezemfibrilleren niet beinvloedt. Dat de atwwezigheid wan twec A-V nodale paden kan leiden tot complexe electrocardiografische beelden bij een kamertachycardic wordt gedemonstreerd in hoofdstuk VIII.

In hooldstuk VIII wordt geillustreerd dat het autonome zenuwstelsel een belangrijke rol speelt bij A- $V$ nodale re-entry tachycardieen.

In de hoofdstukken IX en $X$ wordt beschreven hoe men moet differentiëren tussen de verschillende soorten van supraventriculaire tachycardieèn door op cen juiste wijze gebruik te maken van het electrocardiogram, resultaten van geneesmiddelentoediening, insparningselcetrocardiografic, vagale manoeuvres en geprogrammeerde prikkeling van het hart. 


\section{Resumen}

Usando la técnica de estimulación eléctrica programada del corazón se han descrito en este estudio nuevas observaciones sobre el papel que la unión $\mathrm{A}-\mathrm{V}$ tiene en las taquicardias humanas. En el capítulo III se ha ilustrado la complexidad del nodo $A-V$ analizando modos poco comunes de inicio de la taquicardia intranodal. Tal como se ha ilustrado en el capítulo IV cuando mas de un posible circuito de reentrada se halla presente en el corazón, pueden interferir entre sí y resultar en terminación de una taquicardia en uno de los circuitos. Una curva de doble paso intranodall observada durante la estimulación auricular no tiene el mismo significado en pacientes con taquicardia supraventricular documentada que en pacientes sin documentación electrocardiográfica de taquicardia supraventricular. En cl capitulo $V$ se describió que en el último grupo de pacientes el periodo refractario de la vía rápida intranodal es largo en dirección retrógrada e impide iniciar la taquicardia nodal. En alguno de estos paciented sin embargo, la taquicardia puede iniciarse despues de atropina, debido al acortamiento del período refractario retrógrado de la vía rápida. El signilicado de esta arritmia en estos pacientes es hasta ahora desconocido. En el capítulo VI se ha mostrado que el patrón de conducción atrio-ventricular durante la fibrilación auricular no difiere entre pacientes con o sin curvas de doble paso intranodal. El capitulo VII ha ilustrado como patrones electrocardiográficos complejos pueden aparecer durante una taquicardia ventricular cuanclo existe un doble paso in tranodal. El capítulo VIII demuestra que el tono autonómico tiene un papelimportante en el síndrome de la taquicardia incesante supraventricular debida a una via accesoria oculta con conducción lenta. En los capítulos $\mathbb{X}$ y $X$ se ha descrito como usando el electrocardiograma, efectos de administración de drogas, prueba de esfuerzo, maniobras vagales y las observaciones hechas durante el estudio electrofisiológico, podemos llegar al diagnóstico del mecanismo de las taquicardias incesantes supraventriculares.

\section{Resum}

En aquest estudi es presenten noves observacions sobre el paper de l'unió A-V en els mecanismes de les taquicardies en el home. Aquestes observacions s'han fet util. litzant la tècnica de estimulació programada del cor. En el capitol III s'il lustra la complexitat del nodo A-V humá per mitjá de modos poc comuns d'inici de la taquicardia. El capítol IV demostra la possibilitat d'interacció entre dos circuits per re-entrada. Una corva discontinua del nodo A-V no té el mateix significat en pacients que s'estudien degut a taquicardia supraventricular documentada que en pacients sense taquicardia documentada. El capítol Vensenya que en l'ultim grup de pacients al període refractari de la via nodal rápida es llarg en direcció retrògrada i impedeix iniciar la taquicardia. En algun daquests pacients es pot iniciar una taquicardia despres de donar atropina; que disminuicix la duració del periode refractari de la via rápida retrògrada. El capítol VI descriu que el patró de conducció A-V durant la fibril. lació auricular no varia degut a la presència de dos pasos intranodals. El capitol VII demostra un patró electrocardiografic complex degut a una taquicardia ventricular en un pacient amb doble pas intranodal. Al capitol VIII s'explica com el tó autonòmic té un paper important en els mecanismes de la taquicandia incessant $A-V$ per re-entrada. Als capitols IX i X s"ensenya com es pot arribat al diagnostic correcte del mecanisme de les taquicardies incessants supraventriculars fent servir l'electrocardiograma, els resultats d'administració de drogues, la prová d'esfors, maniobres vagals i l'estudi electrofisiologic. 